\title{
A virtual thermostat for local temperature control
}

\author{
By
}

Mohamed Abd Albasth Alhashme

A thesis submitted in conformity with the requirements for the degree of $\mathrm{PhD}$

Mechanical and Industrial Engineering

University of Toronto

(C) Copyright 2017 by Mohamed Alhashme 


\title{
A virtual thermostat for local temperature control
}

\author{
Mohamed Alhashme \\ Doctor of Philosophy \\ Mechanical and Industrial Engineering \\ University of Toronto
}

2017

\section{Abstract}

This thesis presents design and operation of a newly developed virtual thermostat to control any desired local temperature in an HVAC controlled space. Conventional HVAC thermostats use a single point temperature sensor at one fixed location in a controlled space to control the temperature of the whole space. The single point temperature sensor does not represent the entire controlled domain. In addition, in most applications only a small zone in the controlled space needs to be controlled (for example where the people are located). Heating and cooling of the unnecessary zones lead to extra energy consumption that can be saved if only the required zones are controlled. Such a control system requires knowledge of the temperature distribution in the whole zone at all times. In this work, we have used computational fluid dynamics (CFD) to determine the distributive temperature inside the controlled space at all times and turn the HVAC system $\mathrm{ON}$ and OFF based on the temperature of the desired zone in the space. In this study, we have determined the energy savings by comparing the energy consumption of a conventional thermostat controlled system with a locally controlled one. Several cases with different heat losses, and different inlet air velocities and directions are studied. Energy savings of up to $22 \%$ is realized for the cases studied here. In addition, the study showed the effect of person's location on the energy saving using the local control. One of the main problems with such a control system is that the CFD calculations may take a long time (10- 24 hours depending on the complexity of the 
problem), which is not practical for real-time temperature control. In order to reduce the computational times and simulate various operating conditions quickly, an artificial neural network (ANN) model is used to train the temperature control system. This resulted in reduction of the computational times to few seconds, making this system practical. This thesis, presents various elements of the newly developed virtual thermostat and its operating principals. 


\section{Acknowledgments}

I owe my deepest appreciation to my parents for their infinite love and encouragement. The support that they provided is the greatest gift which anyone dreams to get. They allowed me to realize my own potential and passion. I wish to express my warm and sincere thanks to my wife, Rihab, for her unconditional care and support. Her patience and love made the hard times easy and the good times magnificent. I do not want to forget my little man, my son Eyas, for his amazing job on bring new life to our family and making us happier. Moreover, I wish to thank my entire family for their support and encouragement. Thank you all for everything.

It's difficult to overemphasize my gratitude to my supervisor, Professor Nasser Ashgriz, for his encouragement, strong support at each stage of my Ph.D. studies during the last four years. He is an incredible reservoir of knowledge and I have learned so much from him. The way he deals with his students makes us feel as we are his best friends or even more like part of his family. His enthusiasm and inspiration toward invention and creativity created entrepreneurial spirit inside me. This entrepreneurial thinking allowed me to see the world from different angle and perspective. Thank you for everything.

I would like to thank my thesis committee: Professor Ridha Ben Mrad and Professor Pierre Sullivan, for their insightful comments to improve the coherence of the thesis.

Finally, I want to thank all my lab mates for the great experience and good time.

\section{Mohamed Alhashme}

Toronto, Canada 


\section{Table of Contents}

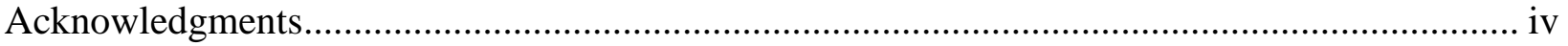

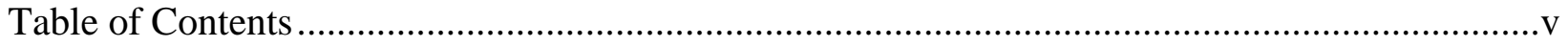

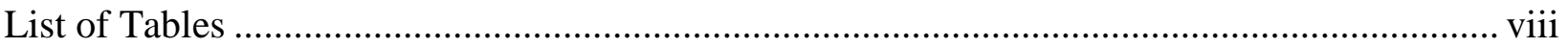

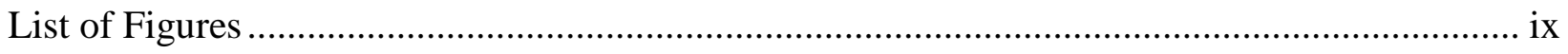



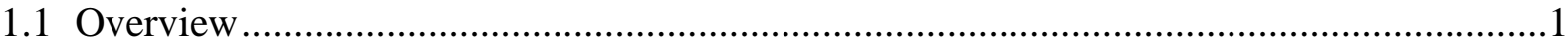

1.2 Other Applications of CFD base control …………....................................................6

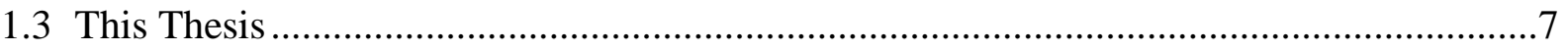

Chapter 2 The advantages of local temperature control ..........................................................

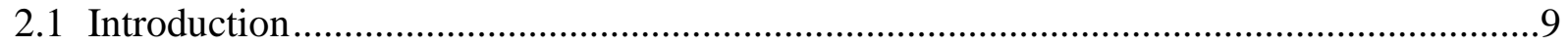

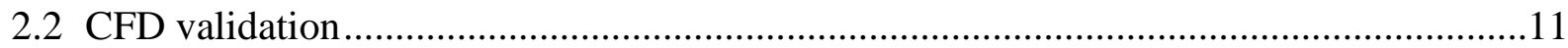



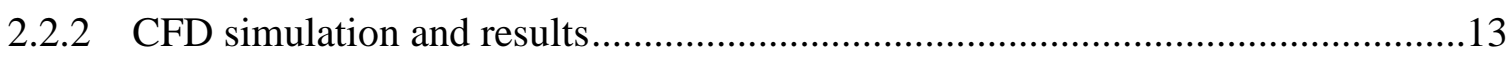

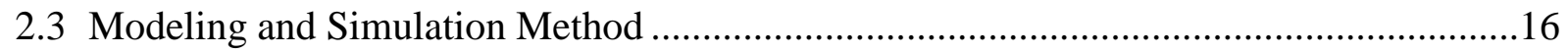

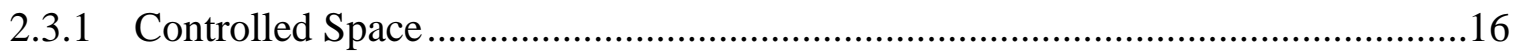

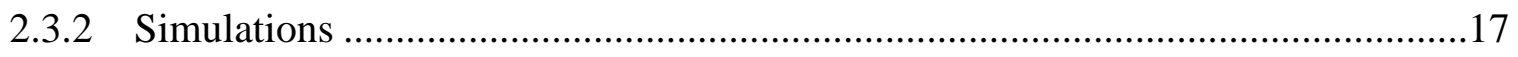

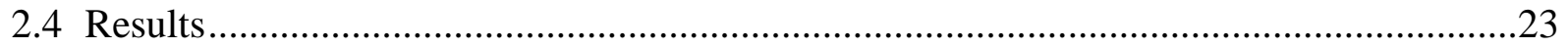

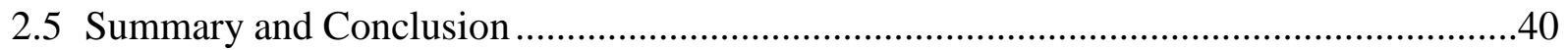

Chapter 3 A Coupled CFD-ANN Method to Control a Special Temperature Distribution............42

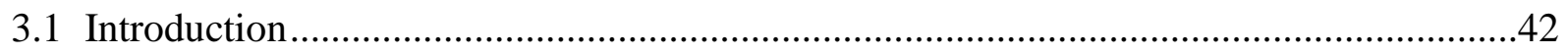

3.2 Modeling approach to reduce the computational time ........................................................4

3.3 Controlled space

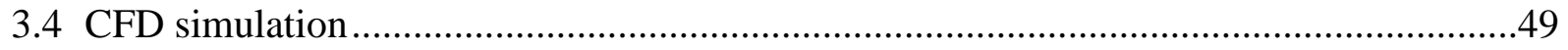




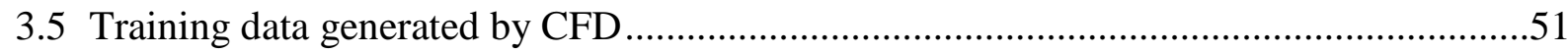



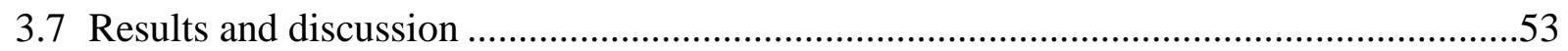



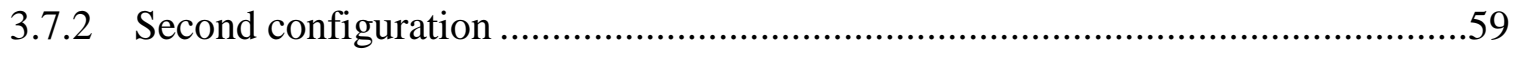

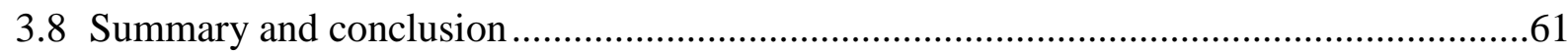

Chapter 4 The effect of person location inside the controlled space on energy consumption

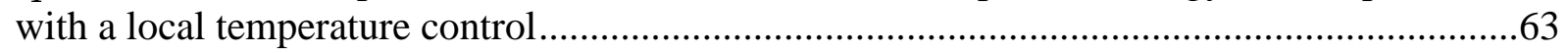

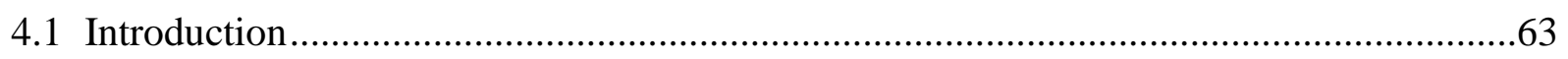

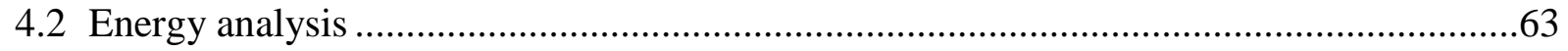

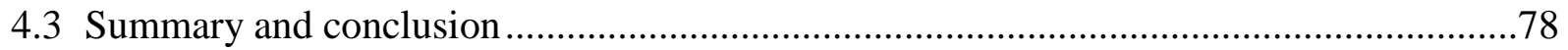

Chapter 5 Device components and its working methodology ..............................................79

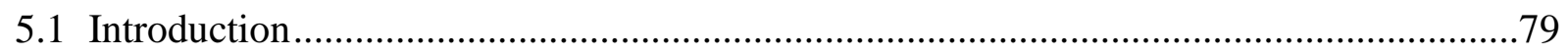

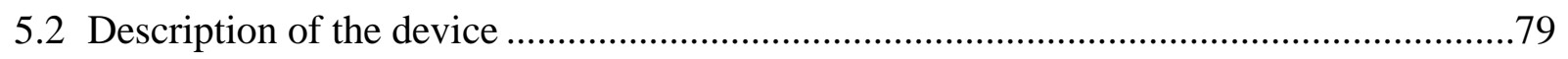

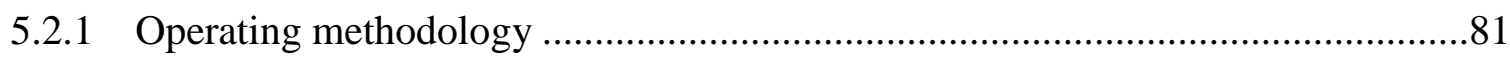

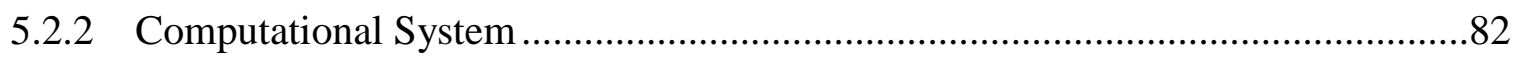

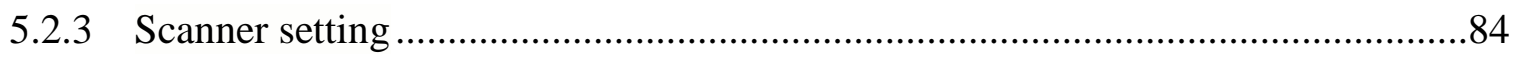

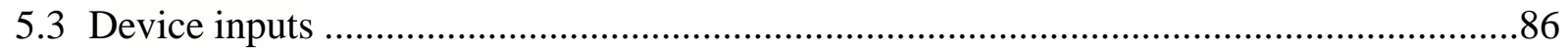

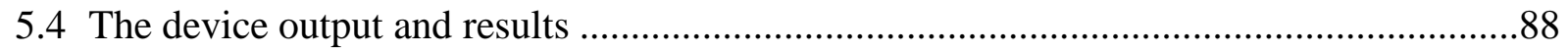

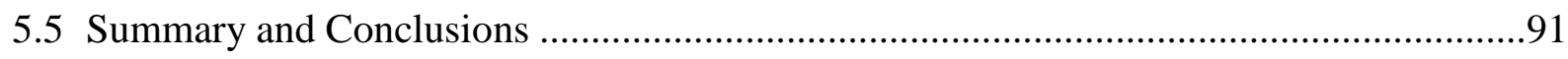



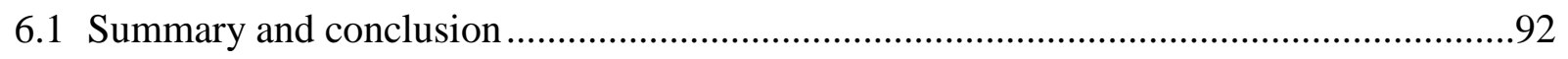

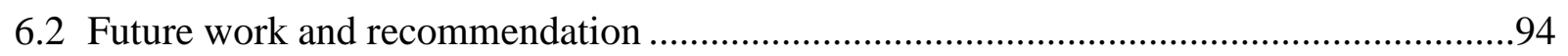

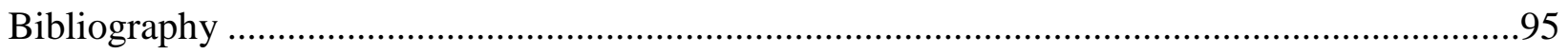

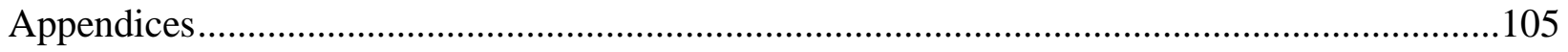

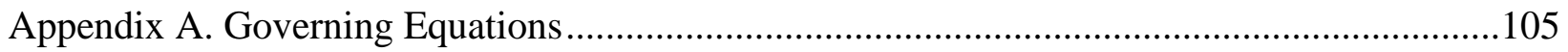


Appendix B. Standard wall functions .

Appendix C. Operation conditions of the HVAC system for the controlled space. ....................110

Appendix D. Energy difference percentage based on person location ....................................128

Appendix E. The UDF for controlling the temperature locally in ANSYS FLUENT

Appendix F. Python source code of the device.. 


\section{List of Tables}

Table 2.1 Results of the mesh refinement study ............................................................ 19

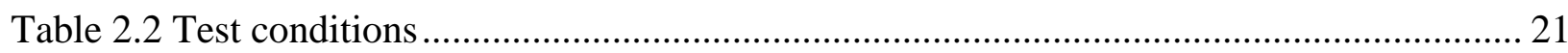

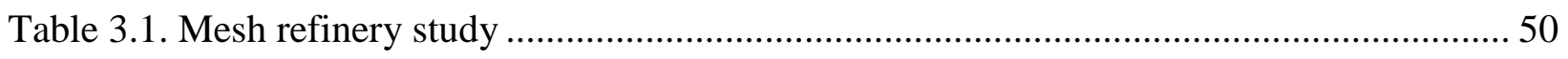

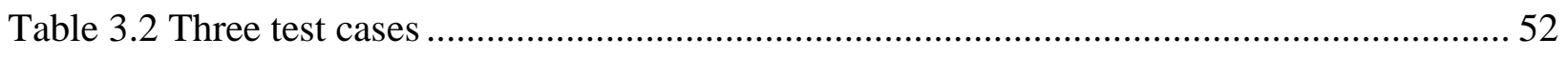

Table 3.3. Comparison between the ANN and CFD for the three test cases ........................... 58

Table 4.1 The effect of person location on energy with respect to the person location at the center

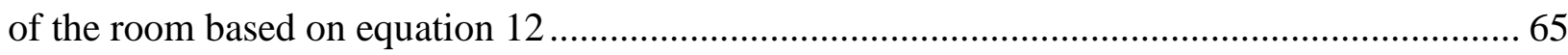

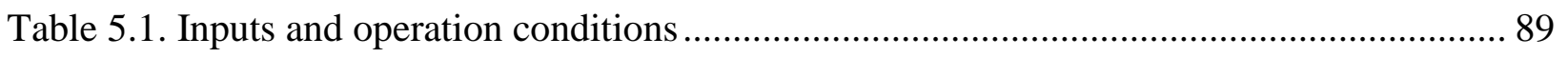




\section{List of Figures}

Figure 2.1 CFD benchmarking - Nielson et al.'s tests [57] .............................................. 12

Figure 2.2 Locations of the temperature and velocity measurements [19].............................. 12

Figure 2.3 Temperature comparison between CFD results and experimental data at 4 different

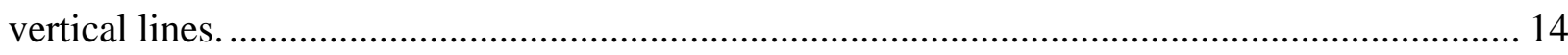

Figure 2.4 Velocity comparison between CFD results and experimental data at 4 different

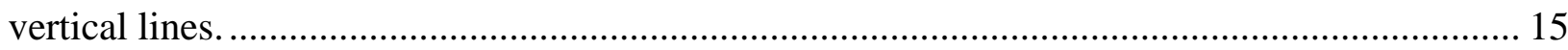

Figure 2.5 Configuration of the HVAC system for (a) the heating and (b) the cooling conditions.

Figure 2.6 Isosurfaces of velocity for direct and indirect heating systems.

Figure 2.7 Case 9 displacement heating system for both local and conventional control with inlet air velocity of $0.2 \mathrm{~m} / \mathrm{s}$ and a wall thickness of $63 \mathrm{~cm}$.

Figure 2.8 Temperature variation around the person for the last 10 minutes of the operation hour using local and sensor controls for different cases.

Figure 2.9 Energy saving when local control is used instead of sensor control. ...................... 28

Figure 2.10 Average temperature rate around the person with different inlet velocities 29

Figure 2.11 Different temperature contour plots and streamlines at different time frames for direct and indirect heating. 30

Figure 2.12 Average temperature around the person and percentage of time in the comfort range for different inlet velocity within an hour.

Figure 2.13 System instability for an hour and temperature drop for different air inlet velocities and conditions.

Figure 2.14 Temperature variation in direct heating for the local control with an inlet air velocity of $3 \mathrm{~m} / \mathrm{s}$. 34 
Figure 2.15 Vertical and horizontal slices in the middle of the controlled space and temperature variation along the controlled space (for direct heating with inlet velocity of $3 \mathrm{~m} / \mathrm{s}$ ). 35

Figure 2.16 Contour plot of temperature distribution and velocity vector for a directed $1 \mathrm{~m} / \mathrm{s}$ of air and directed $3 \mathrm{~m} / \mathrm{s}$ of air. 36

Figure 2.17 Location of the vertical slice in the middle of the controlled space and vertical line where the temperature variation is plotted.

Figure 2.18 Temperature variation along the line shown in figure 13 for different cases 39

Figure3.1 temperature distribution and velocity vectors around a person standing at the center of a room, with $\mathrm{HVAC}$ air inlet velocity of $0.4 \mathrm{~m} / \mathrm{s}$, inlet temperature $30^{\circ} \mathrm{C}$, outside temperature 10 ${ }^{\circ} \mathrm{C}$ 45

Figure 3.2. The average temperature variation around a person standing at the center of a room, with $\mathrm{HVAC}$ air inlet velocity of $0.4 \mathrm{~m} / \mathrm{s}$, inlet temperature $30^{\circ} \mathrm{C}$, outside temperature $10^{\circ} \mathrm{C}$.... 46

Figure 3.3. Inputs and outputs parameters for ANN 47

Figure 3.4. Flow chart shows the process steps for training the ANN.

Figure 3.5. Configuration of heating HVAC system with person at different locations 49

Figure 3.6. ANN model with 3 hidden layers and one output layer. 53

Figure 3.7 Temperature variation inside controlled space when outside temperature is $20^{\circ} \mathrm{C}$ and inlet velocity $0.2 \mathrm{~m} / \mathrm{s}$ and inlet temperature is $30^{\circ} \mathrm{C}$. 54

Figure 3.8. Regression of the training and testing 55

Figure 3.9. Training performance and status 56

Figure 3.10 ANN prediction error of the first input configuration for the 3 test cases 57

Figure 3.11. ANN model for the second configuration 59

Figure 3.12. Regression results of second ANN configuration 60 
Figure 3.13. Training and test performance.

Figure 4.1 room configuration and person locations 64

Figure 4.2 Energy difference percentage of different location compared with middle location with inlet velocity $=1 \mathrm{~m} / \mathrm{s}$, inlet temperature $=35^{\circ} \mathrm{C}$, and outside temperature $=10^{\circ} \mathrm{C}$

Figure 4.3 Energy difference percentage of different location compared with middle location with inlet velocity $=0.2 \mathrm{~m} / \mathrm{s}$, inlet temperature $=25^{\circ} \mathrm{C}$, and outside temperature $=5^{\circ} \mathrm{C}$

Figure 4.4 iso-surface of two temperature value $24{ }^{\circ} \mathrm{C}$ and $25^{\circ} \mathrm{C}$ for a room with person standing in the middle, inlet velocity $0.2 \mathrm{~m} / \mathrm{s}$, inlet temperature $27^{\circ} \mathrm{C}$, and outside temperature zero degree Celsius

Figure 4.5 Energy difference percentage of different location compared with middle location with inlet velocity $=1 \mathrm{~m} / \mathrm{s}$, inlet temperature $=25^{\circ} \mathrm{C}$, and outside temperature $=15^{\circ} \mathrm{C}$

Figure 4.6 average temperature variation around the person at different locations with inlet velocity $=1 \mathrm{~m} / \mathrm{s}$, inlet temperature $=25^{\circ} \mathrm{C}$, and outside temperature $=15^{\circ} \mathrm{C}$.

Figure 4.7 iso-surfaces of temperature values of $24{ }^{\circ} \mathrm{C}$ and $25^{\circ} \mathrm{C}$ for the person at different locations. The inlet velocity is $1 \mathrm{~m} / \mathrm{s}$, inlet temperature is $25^{\circ} \mathrm{C}$, and outside temperature is $15^{\circ} \mathrm{C}$

Figure 4.8 Energy difference percentage of different location compared with middle location with inlet velocity $=0.2 \mathrm{~m} / \mathrm{s}$, inlet temperature $=35^{\circ} \mathrm{C}$, and outside temperature $=15^{\circ} \mathrm{C}$ 72

Figure 4.9 average temperature variation around the person at different locations with inlet velocity $=0.2 \mathrm{~m} / \mathrm{s}$, inlet temperature $=35^{\circ} \mathrm{C}$, and outside temperature $=15^{\circ} \mathrm{C}$

Figure 4.10 temperature distribution inside a room with inlet velocity $=0.2 \mathrm{~m} / \mathrm{s}$, inlet temperature $=35^{\circ} \mathrm{C}$, and outside temperature $=15^{\circ} \mathrm{C}$. The controlling is based on two locations: middle (location a) and next to the inlet (location b) 73

Figure 4.11 Energy difference percentage of different locations compared with middle location when inlet velocity $=2 \mathrm{~m} / \mathrm{s}$, inlet temperature $=30$ and $25^{\circ} \mathrm{C}$, and outside temperature $=15^{\circ} \mathrm{C} \ldots .74$ 
Figure 4.12 Energy difference percentage of different location compared with middle location with inlet velocity $=0.2 \mathrm{~m} / \mathrm{s}$, inlet temperature $=35^{\circ} \mathrm{C}$, and outside temperature $=5^{\circ} \mathrm{C}$

Figure 4.13 Energy difference percentage of different location compared with middle location with inlet velocity $=1 \mathrm{~m} / \mathrm{s}$, inlet temperature $=30$ and $35^{\circ} \mathrm{C}$, and outside temperature $=15$ and 20 ${ }^{\circ} \mathrm{C}$

Figure 4.14 average temperature variation around the person at different locations with inlet velocity $=1 \mathrm{~m} / \mathrm{s}$, inlet temperature $=35^{\circ} \mathrm{C}$, and outside temperature $=15^{\circ} \mathrm{C}$

Figure 4.15 4.16 iso-surfaces of temperature values of $24{ }^{\circ} \mathrm{C}$ and $25^{\circ} \mathrm{C}$ for the person at the different location. The inlet velocity is $1 \mathrm{~m} / \mathrm{s}$, inlet temperature is $35^{\circ} \mathrm{C}$, and outside temperature is $15^{\circ} \mathrm{C}$

Figure 5.1 Components of the virtual thermostat device.... 80

Figure 5.2. Simplified flow chart to show the main steps in the virtual thermostat device..... 81

Figure 5.3. Flow chart of control unit 83

Figure 5.4. Temperature variation around the person to explain operation time 84

Figure 5.5 three dimension model of MUSSL Lab at University of Toronto reconstructed using Microsoft Kinect 85

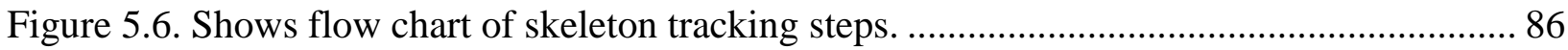

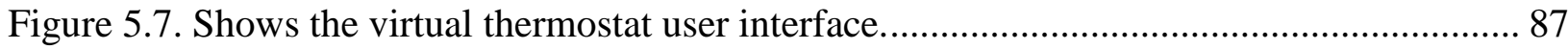

Figure 5.8. Test cases for the person standing at different locations.................................... 88

Figure 5.9. Average temperature variation around the person with inlet velocity of $0.4 \mathrm{~m} / \mathrm{s}$, inlet temperature $30^{\circ} \mathrm{C}$, outside temperature $10^{\circ} \mathrm{C}$, and the person location is at the center.

Figure 5.10. The average temperature plots around the person for different operation condition. 


\section{Chapter 1 Introduction}

\subsection{Overview}

A substantial amount of global energy consumption relates to the heating, ventilating, and air conditioning (HVAC) systems for the residential buildings. Indoor environment, where most people spend $80-90 \%$ of their time, has a significant effect on human health and work quality. The most recent estimates from Residential Energy Consumption Survey (RECS) [1], collected in 2010 and 2011 and released in 2011 and 2012, show that in 2009 heating and cooling energy consumption represent $48 \%$ of the energy consumption of U.S. homes. In a colder climate, such as Canada, the energy consumption percentage, for heating and cooling, increases to 64\% [2]. Therefore, a small improvement in the indoor thermal control may result in significant global energy savings. A survey conducted by the international facility management association (IFMA) shows that the top complains in offices are that "it is too hot and too cold" [3]. Many smart thermostats and methods have been introduced to overcome the problem of balancing between energy consumption and human thermal comfort. However, the more intelligent the system is the more complex it gets [4]. A survey by Rau et al. [5] shows the main issues with smart thermostats and people reaction about them. Various methodologies and devices have been developed and introduced during the last two decades to reduce energy consumption for residential and commercial buildings. By a small change in the thermostat setting during the night times, significant energy savings can be obtained [6]. The development of advanced techniques, such as artificial intelligent (AI) and motion detection reveal great opportunities for the smart thermostat, but it can create negative experiences when integrated with the old user interface. Programmable thermostat, which allows householders to set up an HVAC system to operate at certain times, has becomes a common tool to reduce HVAC energy consumption. Smart thermostats (such as one by Nest [7] and Scott et al. [8]) learn people's habits and adjust the HVAC system accordingly. Such systems can save up to $15 \%$ of energy [7], [8]. However, new kind of problems arise with smart thermostats such as that people are losing a sense of control. The heating was occasionally turned on without a reason, because of old habits which were recognized and learned permanently. The 
temperature remains unrelaxed because of pets movement was detected inside the space. As a result, users turn OFF all smart thermostat features [9]. The interaction design of smart thermostats has become another major issue. A system by Gupta et al [10] predicts the occupancy of the house by utilizing householders cell phone GPS. By using the GPS, they have shown that they can save up to $7 \%$ of energy. Lee et al [11] developed occupancy prediction algorithms using cell tower information and Wi-Fi. They claimed 25\% energy saving can be achieved. Erickson et al [12] developed POEM controlling device that uses a camera and passive infrared for occupancy prediction. They claimed around $30 \%$ of energy saving can be achieved. $\mathrm{CO}_{2}$ sensors are another alternative for occupancy prediction. However, this method suffers from slow respond time and calibration problems [13]. Pisharoty et al. [14] have developed a device that sends emails to a user notifying them on the occupancy of the house and its temperature conditions. They showed that this system could save more than $4.7 \%$ energy compared with a manually programmed thermostat and more than $12.4 \%$ compared with Nest. Zhang et al. [15] showed that up to $40 \%$ of energy reduction with acceptable thermal comfort can be achieved if a personal ventilation system is used to directly aim at an individual. Gao and Keshav [16] developed a thermostat which utilizes personal thermal comfort model to control HVAC system. The device considers different parameters such as air temperature, humidity, person activity level, and thickness of clothing insulation.

All of the mentioned methods work with the assumption of well-mixed temperature, which means for a control system it does not matter if a person is next to an air inlet or far away from an air inlet both of them feel the same. This assumption of well-mixed temperature leads to extra unnecessary energy and reduces human thermal comfort. Another methodology to reduce energy consumption is by using a local temperature control "focusing on condition around the person". This can improve energy consumption by reducing the amount of energy required to control the entire space and improve human thermal comfort. A report from U.S. department of energy [17] showed that between 17-23\% of energy saving can be achieved by using occupancy-based control. Zhou and Huang [18] conduct an experimental study to show the advantages of using wireless temperature sensors in occupied zone compared with a temperature sensor in return duct. The results showed up to $32 \%$ of energy saving for mixing ventilation system and $15 \%$ for displacement ventilation. In addition, other papers have been conducted to study the effect of 
occupancy measurements in energy saving [19]-[23]. Weber [24] has invented a portable sensor, which users can carry and place anywhere in the space close to the person. This sensor provides a more accurate temperature feedback in the zone close to the person. The main issue with such a device is that you need to carry the sensor where ever you want to go; in addition, it just measures single point near the person.

Almost all thermostats use a single point temperature sensor located at a certain location in the control space to control the temperature of the whole space, which means the control is based on the assumption of well-mixed indoor air. Generally, there is no control on the air temperature at locations far away from the temperature sensor. This lack of temperature control affects the energy efficiency of an HVAC system by unnecessarily heating/cooling of a zone. In addition, the location of the thermostat sensor influences not only the energy consumption of the system but also the thermal comfort of the occupants of the space. Another drawback of a single point sensor is its disability of keeping the desired level of thermal comfort with low energy consumption.

There is not any device which can measure air temperature around people from a far distance. Infrared sensors can only measure the surface temperature of an object, which do not represent the air temperature around that object. Another important factor in HVAC system control is a human thermal comfort. Human thermal comfort depends on several criteria which can be divided into two categories. The first category includes the parameters which influence heat losses and gains from individuals such as relative air temperatures, air velocity around people, humidity, clothing insulation, mean radiant temperature, and metabolic rate. The second category includes psychological parameters such as emotion and individual expectation. All the first category factors can be lumped into one factor called Predicted Mean Vote (PMV) which has been developed by Ole Fanger (1970). PMV factor can be calculated as following [25]:

$$
\begin{aligned}
P M V=(0.303 & \left.e^{-0.036 M}+0.028\right)[(M-W)-3.05 \\
& \times 10^{-3}\left(5733-6.99(M-W)-P_{a}\right)-0.42((M-W)-58.15) \\
& -1.7 \times 10^{-5} M\left(5867-P_{a}\right)-0.0014 M\left(34-t_{a}\right)-3.96 \\
& \left.\times 10^{-8} f_{c l}\left(\left(t_{c l}+273\right)^{4}-\left(\overline{t_{r}}+273\right)^{4}\right)-f_{c l} h_{c}\left(t_{c l}-t_{a}\right)\right]
\end{aligned}
$$

Where 


$$
\begin{aligned}
& t_{c l}= 35.7-0.028(M-W) \\
&-I_{c l}\left\{3.96 \times 10^{-8} f_{c l}\left[\left(t_{c l}+273\right)^{4}-\left(\overline{t_{r}}+273\right)^{4}\right]+f_{c l} h_{c}\left(t_{c l}-t_{a}\right)\right\} \\
& h_{c}= \begin{cases}2.38\left(t_{c l}-t_{a}\right)^{0.25} & 2.38\left(t_{c l}-t_{a}\right)^{0.25}>12.1 \sqrt{V} \\
12.1 \sqrt{V} & 2.38\left(t_{c l}-t_{a}\right)^{0.25}<12.1 \sqrt{V}\end{cases} \\
& f_{c l}= \begin{cases}1+1.29 I_{c l} & I_{c l} \leq 0.078 m^{2}{ }^{\circ} \mathrm{C} / W \\
1.05+0.645 I_{c l} & I_{c l}>0.078 m^{2}{ }^{\circ} \mathrm{C} / W\end{cases}
\end{aligned}
$$

Where $M$ is the metabolic heat production $\left(\frac{W}{m^{2}}\right) ; W$ is the external work accomplished $(W) ; P_{a}$ is water vapor pressure of the ambient air $(k P a) ; t_{a}$ is the temperature of the ambient air $\left({ }^{\circ} \mathrm{C}\right) ; f_{c l}$ is the clothing area factor; $\overline{t_{r}}$ is the mean radiation temperature; $h_{c}$ is the convection heat transfer coefficient $\left(\frac{W}{m^{2} K}\right) ; V$ is the air velocity $\left(\frac{m}{s}\right) ; I_{c l}$ is the thermal resistance of clothing (clo).

PMV factor range from -3 which is cold to +3 which is hot. The recommended PMV range for human thermal comforted based on ASHRAE 55 is between -0.5 and +0.5 . People do not prefer same PMV value for comfort for example if somebody feels comfort with 0.5 other may do not feel the same but they rather have -0.1 to feel comfort. Since there are large variations in people in terms of physiological and psychological thermal satisfaction. There is another factor to consider the percentage of people who are dissatisfied with thermal conditions and this factor called Predicted Percentage of Dissatisfied (PPD) which is a function of PMV. ASHRAE 55 recommends less than $10 \%$ of people dissatisfied for an interior space. The PPD factor can be calculated as following [26]:

$$
P P D=100-95 e^{\left(-0.03353 P M V^{4}-0.2179 P M V^{2}\right)}
$$

The PMV and PPD factors are measured at different locations inside the controlled space. PMV requires the measurements of several local factors around the person such as the average temperature around the person, air velocity, vapor pressure of air, convective heat transfer coefficient, and mean radiant temperature. Most of those parameters cannot be measured from a far distance and require a physical device to be near a targeted person or location. A portable device that can measure all of those parameters can be very expensive and not practical for home use. 
However, the alternative solution is to estimate those parameters using either mathematical model or numerical methods. Because of the problem complexity, there is not any general mathematical model that can predicate temperature or PMV/PPD parameters around person inside controlled space at different operation conditions and locations. Numerical methods are another way to estimate those parameters. Atam and Helsen [27] provided a summary of different energy building modeling approaches. The more accurate the numerical solver is the better it is in predicting local parameters far away from the sensor which leads to more energy saving and better human thermal comfort. Computational fluid dynamic (CFD) [28] is one of those methods. CFD is a very accurate numerical solver, which is will be our solver in this study. The fundamental concept of CFD is solving Navier-Stokes (N-S) equations numerically, by dividing a domain to finite volume, to provide air velocity distribution of the domain. In addition, energy equations, or species transport equations can be coupled with N-S to provide temperature or species distribution inside the domain. CFD can provide a distributed information about all the human thermal parameters, such as air temperature, velocity, and humidity, inside a controlled space. From the distributed information specific local information can be extracted and used as feedback to the control system. This approach is a prediction based approach. The control system can estimate operation time (ON/OFF time) of a ventilation system based on a future prediction of the human comfort parameters. One of the CFD disadvantages is that it can be time-consuming. Therefore, another numerical method can be considered such as Fast fluid dynamic (FFD) [29]-[32]. FFD is less accurate than CFD but more stable and faster than CFD. Fast fluid dynamic will not be touched upon in this study but will be in our consideration for future work. A review paper on optimized control systems, conducted by Shailkh et al [33], showed an increase in trend of automated control systems and computational optimization schemes.

The main problem that prevents such system to be practical for real-time control is the computational time. CFD need hours or days, depend on the complexity of the controlled space, just to provide one-hour temperature estimation. In addition, any change in the operation conditions, people location, or/and boundary conditions requires running CFD simulation to predict the new operation time. The best way to solve those two problems is by creating a database from old CFD simulation results to train regression fitting model to estimate the operation time of new conditions. Because of the fuzziness and nonlinearity of the problem, the best regression 
fitting model is artificial neural network (ANN) model. After training the ANN model using the old CFD results, the model will be able to control the temperature in few seconds. Training period depends on the complexity of the controlled space and the computational time of the numerical solver. Increasing the computational speed of the numerical solver can reduce learning period of the device such as using FFD on graphics processing unit (GPU) [30], [31], [34] which can boost the speed 1500 times. In this thesis, FFD on GPU will not be considered and it will be in our future work.

\subsection{Other Applications of CFD base control}

CFD based control (predictive control) can be used in a variety of other applications. Local temperature control can be used in many food sectors. One example of food sector is a meat air blast chilling process [35], [36]. After slaughtering, meat carcasses are cooled down with a specific rate. The heat is lost through conduction within the meat toward the carcass surface and through evaporation, convection, and radiation at the carcass interface with air. The heat losses rate and surface water activity affect food safety (microbial growth), meat quality, and weight losses. Meat carcasses are usually hanged in a number of rows inside refrigerator and blast chilling air is applied from one side. The first rows have different cooling and evaporating rates compared with last rows. To have a temperature sensor in every one can be very hard because of the high numbers of meat carcasses. Therefore, CFD based control can be used to predict the rate of change heat and evaporation and control the air inlet based on from just one location. Other food industry applications where CFD control can be used are food drying, sterilization, cooking, and mixing [37]-[39]. Another application of CFD based control is real time smoke distribution prediction inside building in case of a fire. The control method can be used as feedback for evacuating plan or even utilizing air condition systems to guide the smoke path inside a building away from people. In greenhouse CFD based control can also be very helpful to ensure proper conditions are applied at different spots inside the control space. CFD based predictive control can be used for controlling the melt temperature in plastic injection molding by controlling the feeding rate based on CFD feedback. Gerber et al [40] showed the advantage of coupled CFD with model predictive control. 


\subsection{This Thesis}

In this thesis, our main focus is on local temperature control. The other human thermal comfort parameters will not be considered at the time. The reason for that is to show clearly the ability of our system compared with a conventional thermostat which just controls temperature. The main idea of our invention is to estimate average temperature of a target location inside a controlled space using CFD. The estimated average temperature will be used as feedback for HVAC system control to turn system ON/OFF. In order to estimate the average temperature using CFD solver, a geometry of the controlled space, people location, and boundary condition must be imported in automatic manners. Three dimension scanner device is used to construct a 3D geometry of a controlled space. A number of sensors and software applications are used to estimate the boundary conditions. In addition, there are some parameters which will be imported by the user. Our device is called a virtual thermostat. One of the main issue with using CFD solver is a computational time. In addition, CFD calculation needs to be conducted each time a boundary condition of a controlled space is changed or a person moved to different location. Therefore, CFD is coupled with artificial neural networks (ANN) by training ANN model using old CFD results. After training ANN model, the model is used to predict the operation time of the new condition of HVAC system in few of seconds. The structure of this thesis is organized as follows:

The second chapter of the thesis is conducted to show the advantages of local temperature control over single point temperature control, which is far away from a target location. The study is done using CFD simulation of a controlled space with standing person in the middle of a room subject to HVAC system. The air inlet and outside conditions are changed for a several of cases. The HVAC system is controlled using two different control methods. One method is using a conventional thermostat (at the wall or close to the air return duct). The other method is using local control method (virtual thermostat). The two methods required to keep the person at comfort temperature between $24^{\circ} \mathrm{C}$ and $25^{\circ} \mathrm{C}$. The air inlet of the HVAC system with the conventional thermostat is turned $\mathrm{ON}$ or $\mathrm{OFF}$ when the average temperature around the device reaches maximum or minimum preferred temperature. For the local control method, the system is turned $\mathrm{ON}$ or $\mathrm{OFF}$ if the average temperature around the person reaches maximum or minimum preferred temperature. The two methods are compared to the same conditions in term of energy saving, human thermal comfort, and system stability (number of times the system turns ON and OFF). 
The third chapter is conducted to make the virtual thermostat device practical for real-time control. The issue with using CFD for local temperature control is computational time and calculation necessity for any new conditions. The problem is solved by training ANN model using old CFD results as training database. The trained model is used to control the HVAC system. The study is conducted using CFD simulation of a person standing at a different location inside a controlled space and subject to HVAC system. The HVAC conditions are changed. The operation time of the HVAC system is estimated at those different conditions, and person locations. The operation conditions are used to train two ANN input configuration models. The study shows ANN prediction accuracy compared with $\mathrm{CFD}$, the required size of the training database, the required training period, and best ANN training algorithm.

The fourth chapter conducted to analyze the effect of person location inside the controlled space on local temperature control. The analysis is in terms of the energy (usage/ demand) difference between a person standing in some location inside the controlled space and with the person standing in the middle of the controlled space. In addition, the study includes the behavior of warm air inside the controlled space by looking at iso-surface plot of two values of temperature $24^{\circ} \mathrm{C}$ and $25^{\circ} \mathrm{C}$ and temperature variation around the person.

The fifth chapter conducted to show the device components, working methodology, information flow chart, input parameters, and device limitations. This chapter shows the main components of the virtual thermostat and how they are working. One of the main components of the device is the 3D scanner, Microsoft Kinect. The Kinect provide the user with depth and RGB data. The depth information is provided as point cloud data. This chapter shows how 3D model of the space is reconstructed including the scanning mechanism. The other main part of the virtual thermostat device is the CFD solver. In this chapter information about how the solver is set up and how information is imported is shown. In addition to those parties, this chapter shows how other information are imported including boundary conditions, user input through the device user interface. The information flow between the components is shown too.

The sixth chapter provides a summary and conclusion of this work. In addition to recommendations and future work. 


\section{Chapter 2 The advantages of local temperature control ${ }^{1}$}

\subsection{Introduction}

The objective of the present chapter is to determine the potential energy savings by using the temperature around a person to control an HVAC system as compared to that of a conventional thermostat located at a fixed location on a wall in the controlled space. The energy saving in this study represents the energy which can be saved by switching from a conventional control to a local control. This energy saving does not represent the entire energy saving of HVAC system.

To conduct this study a computational fluid dynamics (CFD) method is used to simulate the transient flow and temperature field of an indoor space, which has an HVAC system and a person standing in the middle of the space. CFD has been used by several investigators to study the performance of HVAC systems. For example, Murakami et al. [41] developed a 3D-CFD simulation model of a human (just rectangular box) in the middle of a semi-enclose space to choose between two different HVAC systems. CFD has also been integrated with building simulation to provide specialists with information related to poor indoor environments and potential consequences during building design stages. For instance, Bartak et al. [42] studied and validated the possible outcomes of a room with several surface temperatures, and inlet/outlet air position configuration. CFD has also been integrated with other energy software packages to provide complementary information about the energy performance of buildings. For instance, Zhai et al. [43]-[45] used CFD to study the cooling load of a large indoor auto racing complex for two different cooling methods. Beausoleil-Morrison [46] introduced adaptive conflation controller with two possible control schemes to support coupling of CFD with ESP-r programs. He examined the controller with HVAC system case and showed how the adaptive conflation controller can simulate realistic operation condition. Kim et al. [47] introduced a technique for coupling a building envelope model to a CFD to improve energy efficient and thermal human comfort. Chen et al. [48] studied temperature and velocity distribution of UFAD and conventional air distribution

\footnotetext{
1 The content in this chapter has been published in the Energy and Buildings journal, "A virtual thermostat for local temperature control”, M.Alhashme and N.Ashgriz, 2016, 126, 323-339, DOI: 10.1016/j.enbuild.2016.05.045
} 
(CAD) with variable air volume (VAV) by comparing CFD results with experimental data. The results show a reasonable agreement between numerical and experimental data. The maximum temperature error was about $10 \%$ and $25 \%$ for velocity. Lin et al. [26] study the effect of air supply location on the performance of displacement ventilation (DV) system based on indoor air quality and thermal comfort. The study has been conducted using CFD and the results show that the air supplier should be closer to the space center to provide a more uniform thermal condition. Stavrakakis et al. [49], [50] presented a computational method to optimize the thermal comfort of the naturally ventilated building by improving the design of the windows. The method is based on utilizing CFD results to train Radial Basis Function Artificial Neural Network (RBF-ANN), which is used to optimize the design of the windows. The optimized design has been verified with CFD results, which showed good agreement. Zhou and Haghighat [51], [52] developed and implemented an optimization scheme for a ventilation system to improve comfort, indoor air quality, and energy consumption of office buildings. The scheme utilizes CFD in combination with genetic algorithm and artificial neural network. The improved ventilation system showed better comfort level, higher ventilating efficiency, and lower energy consumption in comparison with the tested conditions. References [53]-[57] show other applications of using CFD on ventilation system design.

One of the thermal comfort parameters is a zone temperature, which requires an HVAC system to operate in a specific range of temperatures. ASHRAE Standard 55-2010 provides standards for the thermal comfort range. This chapter mainly focuses on the air temperature control and its objective is to develop a methodology to control the air temperature around people in a closed space. This is different than controlling the temperature based on a thermostat set on a wall in a controlled space, which can be away from the people occupying the controlled space. Since it is not possible to have thermostats everywhere in a space, here we are introducing a virtual temperature measurement method using computational fluid dynamics (CFD). In this method an average temperature around the person is estimated and based on this estimation, the HVAC system is controlled by turning the air inlet ON and OFF. A tested model is a person inside a room with a ventilation system. To show the advantage of using local temperature control over the conventional thermostat, the two control systems are compared by controlling the air inlet velocity based on the average temperature at specified locations in the room. One of the specified locations 
is a zone around the person and the other one is a small zone around the conventional thermostat. The results are compared based on energy saving and how good the control system keeps the average temperature around the person in a preferred temperature range. All the systems have been tested for an hour of operation. In this study, thirteen parametric cases have been considered to cover important aspects of HVAC control system. For example, different inlet velocities to cover two ventilation mixing mechanism (displacement and mixing ventilation); different inlet air directions to demonstrate the effect of the position of a person in the controlled space with respect to the inlet; and different wall thicknesses to show the effect of heating/cooling loads.

\subsection{CFD validation}

\subsubsection{Benchmark test}

Nielsen et al. [58] have provided a set of experimental data for benchmarking CFD codes for HVAC system. They have performed temperature and velocity measurements in a full scale insulated test chamber with a manikin standing in the middle of the chamber. Figure 2.1 shows the test chamber $(3 \mathrm{~m} \times 3.5 \mathrm{~m} \times 2.5 \mathrm{~m})$ and the thermal manikin. The dimensions of the inlet and the outlet ducts are $0.2 \mathrm{~m} \times 0.4 \mathrm{~m}^{2}$. The inlet air velocity is $0.182 \mathrm{~m} / \mathrm{s}$ with $30 \%$ turbulence intensity and temperature of $22.8^{\circ} \mathrm{C}^{3}$. The manikin generates a total heat flux of $76 \mathrm{~W}$. The location of the vertical line where the temperature and velocity are measured are shown in Figure 2.2. Temperatures are measured ${ }^{4}$ at 7 different points along each vertical line. Velocities are measured ${ }^{5}$ at 6 different points along each vertical lines.

\footnotetext{
2 The outlet duct size has wrong size of $0.3 \mathrm{~m} \times 0.3 \mathrm{~m}$ in the excel sheet (personal communication with Nielson [58]).

${ }^{3}$ Personal communication with Nielson [58]

${ }^{4}$ T-type thermocouple with accuracy of $\pm 1^{\circ} \mathrm{C}$.

${ }^{5}$ Inlet velocity is measured using thermistor anemometer, room air velocity using ultrasonic anemometer \pm 0.036 $\mathrm{m} / \mathrm{s}$.
} 
Chapter 2. The advantages of local temperature control

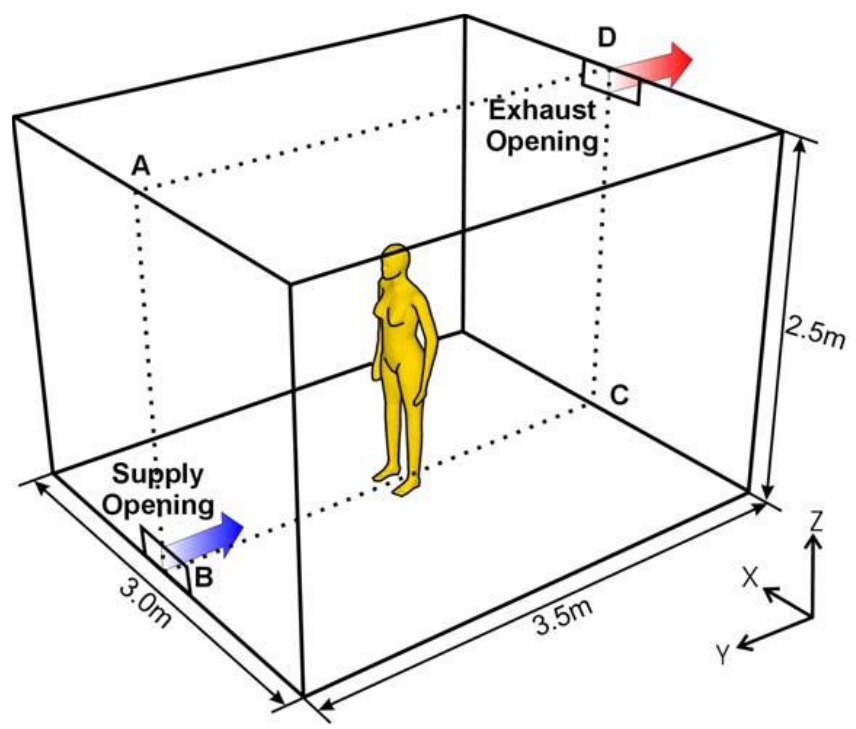

Figure 2.1 CFD benchmarking - Nielson et al.'s tests [58].



Figure 2.2 Locations of the temperature and velocity measurements $[19]^{6}$.

\footnotetext{
6 The figure is not for scale.
} 


\subsubsection{CFD simulation and results}

The 3D geometry of the test chamber is built using ANSYS DesignModeler 15.0. Advance Proximity and Curvature sizing algorithm are used to generate a fine grid with approximately 1,229,683 tetrahedral elements. ANSYS FLUENT 15.0.7 is used as CFD simulation platform. Simulations were performed on a DELL-XPS with eight $3.4 \mathrm{GHz}$ CPU and $32 \mathrm{~GB}$ of RAM. No slip and penetration conditions are imposed on the walls and the manikin. The outside wall temperature is assumed to remain constant at $25^{\circ} \mathrm{C}$ during the simulation. The floor, the ceiling, and the walls of the test chamber are assumed to be insulated using a $1 \mathrm{~m}$ thick wood with a thermal conductivity of $0.173 \mathrm{~W} /(\mathrm{m} \mathrm{K})$. The total uniform heat flux from manikin surface is $76 \mathrm{~W}$. The inlet air velocity is $0.182 \mathrm{~m} / \mathrm{s}$. The turbulent intensity is $30 \%$ in the inlet with a turbulent length scale of 0.1. The inlet flow temperature is set to $22.8{ }^{\circ} \mathrm{C}$. Renormalization group (RNG) ${ }^{7} \kappa-\varepsilon$ model with standard wall functions ${ }^{8}$ for near wall treatment is used. Boussinesq approximation is used to model the buoyancy effects of the air with a constant density coefficient of $1.225 \mathrm{~kg} / \mathrm{m}^{3}$ and a constant thermal expansion coefficient of $0.0032 \mathrm{l} / \mathrm{k}$. In addition, under relaxation factors of 0.7 for pressure and 0.3 for momentum are used. The convergence residual magnitude for continuity and momentum are set to $10^{-4}$, while residual of energy is $10^{-6}$. First the problem is treated as a steady state case. Once the steady state solution is found, it is used as initial condition for a transient simulation. The transient simulations are performed for 120 seconds. The time step has been chosen based on the error convergence. A time step of 1 second and 100 iterations per time step are found to be sufficient to provide the above desirable residual error for the whole 120 second.

Measured and calculated temperatures and velocities are plotted in Figure 2.3 and Figure 2.4, respectively. The difference between the calculated and measured temperatures are less than 0.5 ${ }^{\circ} \mathrm{C}$. Similarly, the calculated velocities match the measured values at a location far from the manikin. However, the calculated velocities over predict the measured values in locations close to

\footnotetext{
7 The RNG $k-\varepsilon$ model is derived using renormalization group theory which is rigorous statistical technique. The model is similar to standard $k-\varepsilon$ but with additional terms in $\varepsilon$ equation to enhances the accuracy.

8 The standard wall functions is based on the work of launder and Spalding [83] see Appendix B. Standard wall functions.
} 
Chapter 2. The advantages of local temperature control

the manikin at height of $1 \mathrm{~m}$ and higher. The reason for this difference may be related to the shape of the manikin: A female manikin was used in the experiments, whereas we used a simpler male manikin.
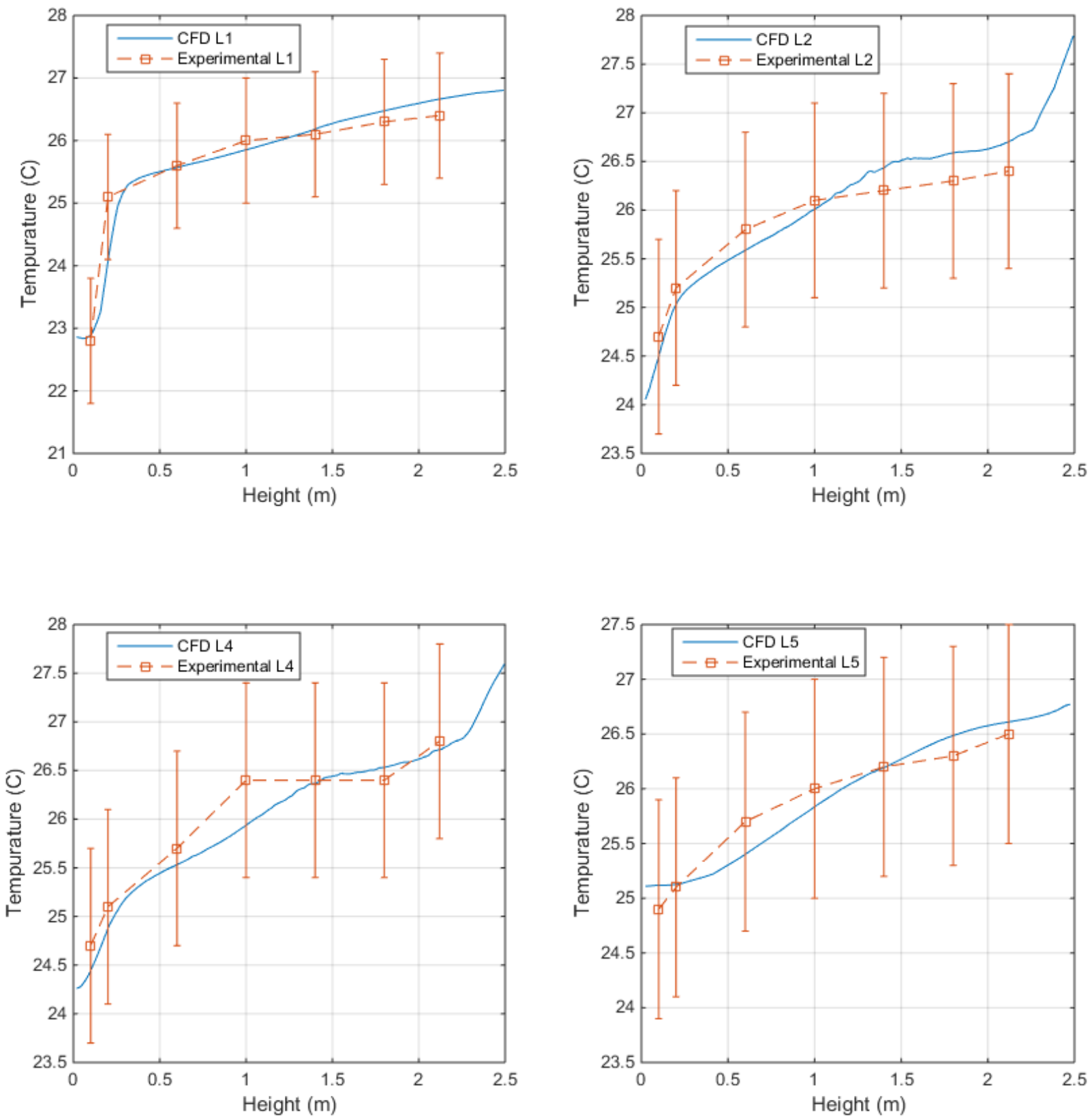

Figure 2.3 Temperature comparison between CFD results and experimental data at 4 different vertical lines. 
Chapter 2. The advantages of local temperature control

(a)

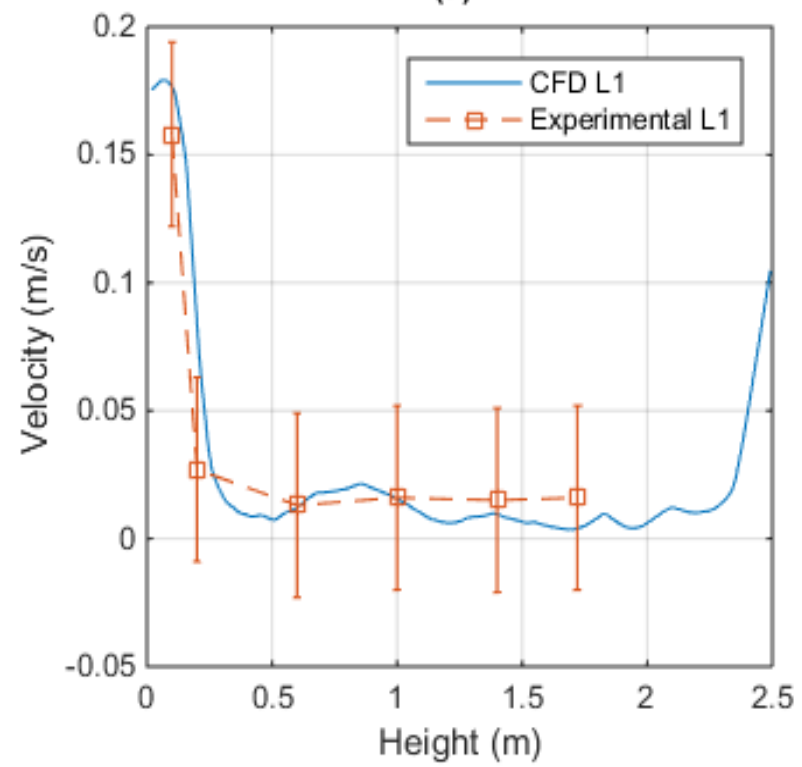

(c)

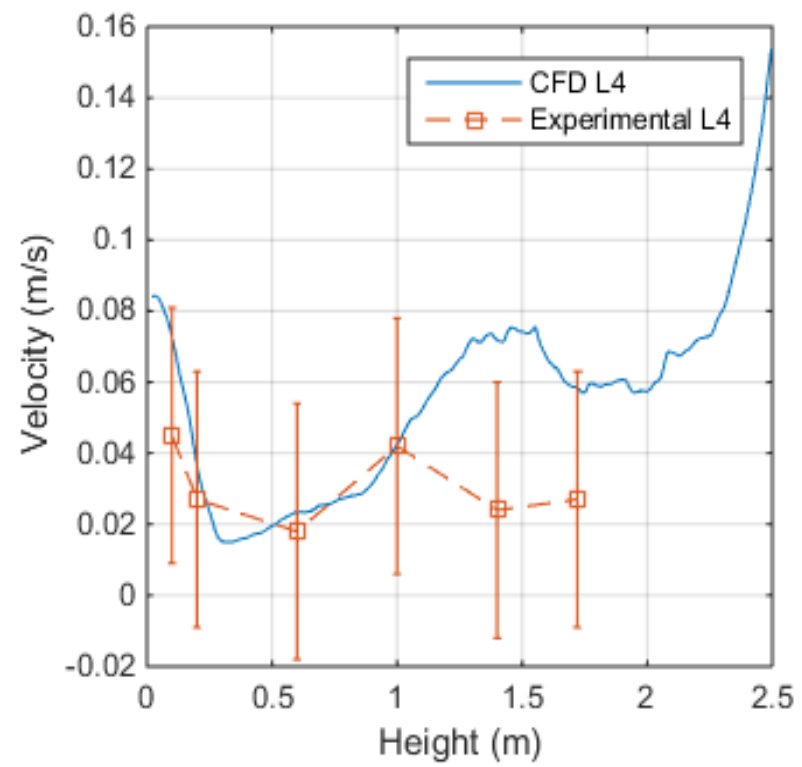

(b)

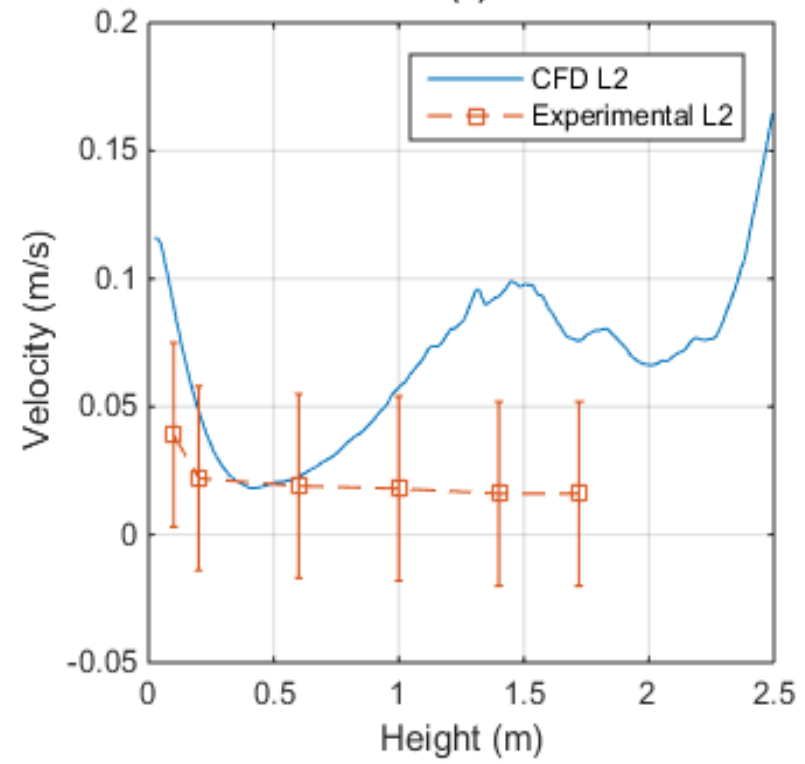

(d)

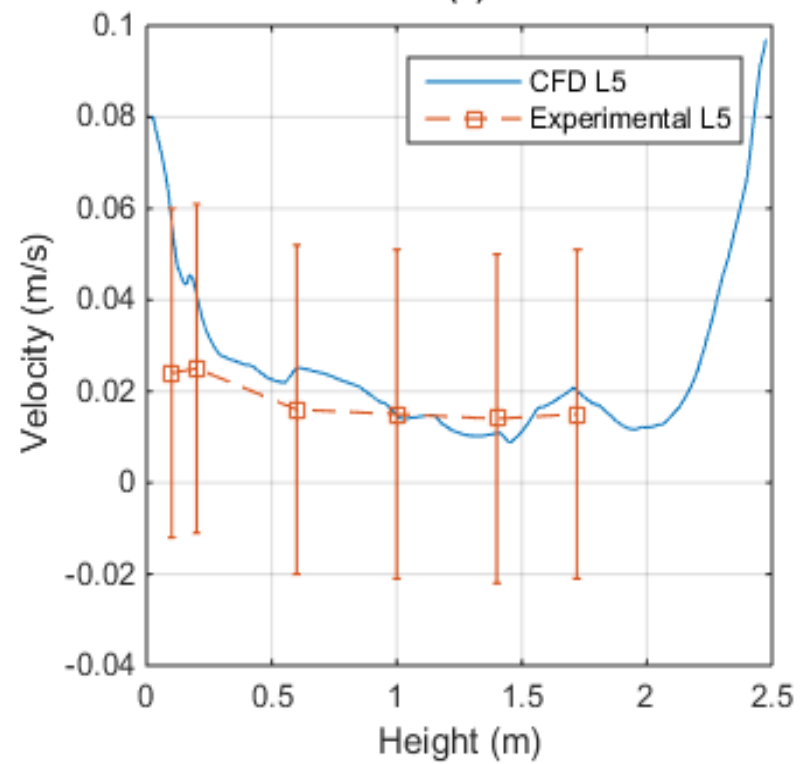

Figure 2.4 Velocity comparison between CFD results and experimental data at 4 different vertical lines. 


\subsection{Modeling and Simulation Method}

\subsubsection{Controlled Space}

To show the effectiveness of a local feedback, a room with a person inside it is considered for both heating and cooling conditions. A $4 m \times 4 m \times 2.5 m$ model of the room is constructed using ANSYS DesignModeler 15.0. Figure 2.5 shows the 3D model of the room with a person standing in the middle. The stars in the figures indicate the center of the coordinate system. For the heating conditions, the inlet and the outlet ducts are located on the upper and lower corners of the east wall, respectively, as shown in Figure 2.5a. In the present study, "inlet" refers to the air inlet duct, which HVAC system uses to deliver air into the controlled space; and "outlet" refers to the air outlet duct, where air leaves the controlled space. The center of the outlet is at $(3.5 \mathrm{~m}, 4 \mathrm{~m}, 0.2 \mathrm{~m})$ of $x, y, z$, and the center of the inlet is at $(3.5 m, 4 m, 2.3 m)$ of $x, y, z$, respectively. For the cooling conditions, the inlet duct is located on the east wall and the outlet duct is located on the north wall, as shown in Figure $2.5 \mathrm{~b}$. The outlet is at $(0,0.5 \mathrm{~m}, 0.2 \mathrm{~m})$ of $\mathrm{x}, \mathrm{y}, \mathrm{z}$ and the inlet is at $(0,0.5 \mathrm{~m}, 2.3 \mathrm{~m})$ of $\mathrm{x}, \mathrm{y}, \mathrm{z}$, respectively. This arrangement is chosen to prevent flow going directly from the inlet to the outlet without circulating in the room and that the outlet is near the stagnate zone to remove unwanted warm or cold air from the room. However, the inlet and the outlet layouts are not designed to optimize the HVAC system performance. The cross-sectional area of both the inlet and the outlet is $0.2 \times 0.8 \mathrm{~m}^{2}$.

HVAC temperature sensors are usually located near the air return outlets or in the "dead zones," which are locations on a wall where there are very low flow fluctuations. The temperature sensor is then used to turn the HVAC system ON and OFF (This type of control is known as bangbang). Figure 2.5 shows the locations of the temperature sensors for both the heating and the cooling conditions. In the heating condition, the sensor is located on the wall and either in between the inlet and the outlet ducts or near the outlet $(10 \mathrm{~cm}$ above the outlet). In the cooling condition, the sensor is located near the outlet $(10 \mathrm{~cm}$ below the outlet). The sensor is not located exactly at the outlet to avoid the effect of a backflow that may occur in the simulation. In addition, an average temperature of a small zone, $10 \mathrm{~cm}$ radius, around the sensor is used to represent the temperature at the sensor location. This zonal average temperature reduces temperature fluctuations, as compared to the temperature at the exact location of the sensor. 
A locally controlled HVAC system uses the temperature in the desired location to control the HVAC. In the present study, the average temperature around the person in the room is used to control the HVAC. The average temperature is obtained based on a cell volume average of a spherical zone with a radius of $90 \mathrm{~cm}$ around the person (this radius covers an $180 \mathrm{~cm}$ tall person) ${ }^{9}$. The human body is set to be at a constant temperature of $37^{\circ} \mathrm{C}$. The outside temperature of the room is set to $30^{\circ} \mathrm{C}$ during the cooling cases, and to $10^{\circ} \mathrm{C}$ during the heating cases. The walls of the room are assumed to be made of wood with a thermal conductivity of $0.173 \mathrm{~W} /(\mathrm{m} \mathrm{K})$. Two different wall thicknesses of $20 \mathrm{~cm}$ and $63 \mathrm{~cm}$ are considered. The top and the bottom walls of the room are assumed to be insulated.

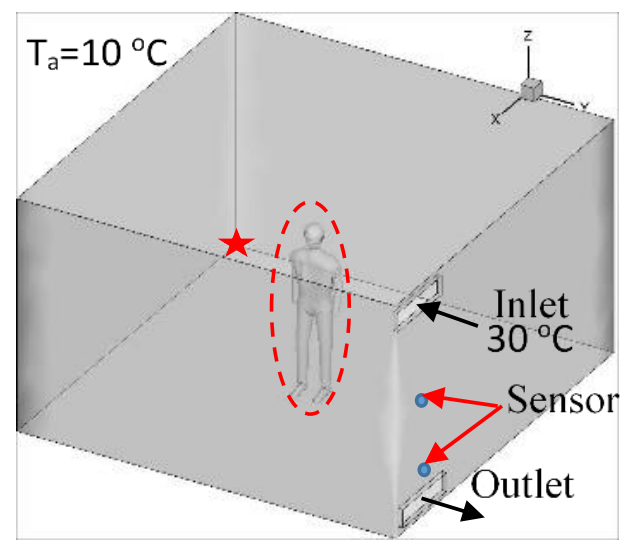

(a) Heating



(b) Cooling

Figure 2.5 Configuration of the HVAC system for (a) the heating and (b) the cooling conditions.

\subsubsection{Simulations}

Advance Proximity and Curvature sizing algorithm are used to generate a grid with approximately 785,242 tetrahedral elements. Grid convergence index (GCI) is used to show grid refinement effect on the average temperatures around the person and around the conventional thermostat. Three different grid sizes are used $(1,585,410,1,155,762$, and 785,242$)$ to estimate the

\footnotetext{
${ }^{9}$ Appendix E. The UDF for controlling the temperature locally in ANSYS FLUENT
} 
Chapter 2. The advantages of local temperature control

GCI index. GCI is calculated as follows (sub/superscripts refer to the grid size starting from 1 as fine, 2 as a medium, and 3 as coarse) and all the equations used are from Celik et al. [59]:

1- The grid refinement factor $r$ is measured using:

$$
\begin{aligned}
& r_{21}=\left(\frac{N_{1}}{N_{2}}\right)^{\frac{1}{3}} \\
& r_{32}=\left(\frac{N_{2}}{N_{3}}\right)^{\frac{1}{3}}
\end{aligned}
$$

2- The order of convergence $p$ is obtained by solving the following implicit function:

$$
p=\frac{1}{\ln \left(r_{21}\right)}\left|\ln \left(\left|\frac{\varepsilon_{32}}{\varepsilon_{21}}\right|\right)+\ln \left(\frac{r_{21}^{p}-s}{r_{32}^{p}-s}\right)\right|
$$

Where $s=\operatorname{sgn}\left(\frac{\varepsilon_{32}}{\varepsilon_{21}}\right), \varepsilon_{21}=T_{2}-T_{1}$, and $\varepsilon_{32}=T_{3}-T_{2} . T$ refers to the average temperature around the person or around the conventional thermostat.

3- The reported results are:

a. Approximate relative error:

$$
e_{a}^{21}=\left|\frac{T_{1}-T_{2}}{T_{1}}\right|
$$

(And a similar relation for $e_{a}^{32}$ )

b. Extrapolated relative error:

$$
e_{\text {ext }}^{21}=\left|\frac{T_{\text {ext }}^{21}-T_{1}}{T_{\text {ext }}^{21}}\right|
$$

Where $T_{\text {ext }}^{21}=\frac{r_{21}^{p} T_{1}-T_{2}}{r_{21}^{p}-1}$ (and similar relations for $e_{\text {ext }}^{32}$ and $T_{\text {ext }}^{32}$ )

c. The grid convergence index:

$$
G C I_{\text {fine }}^{21}=\frac{1.25 e_{a}^{21}}{r_{21}^{p}-1}
$$

And similarly for $G C I_{\text {coarse }}^{32}$.

The average temperature around the person and around the conventional thermostat is calculated for the three different meshes and for 60 seconds. Case 9 is used as the test case (see 
Table 2.2). The approximate relative error, extrapolated relative error, and the grid convergence are calculated and averaged over time as shown in Table 2.1. Based on the results, the coarse mesh is chosen because of its low GCI and to reduce time cost.

Table 2.1 Results of the mesh refinement study

\begin{tabular}{|c|c|c|c|c|c|c|}
\hline \multirow{2}{*}{$\begin{array}{l}\text { Location of the } \\
\text { verage temperature }\end{array}$} & \multicolumn{2}{|c|}{$\begin{array}{l}\text { Approximate } \\
\text { relative error }\end{array}$} & \multicolumn{2}{|c|}{$\begin{array}{l}\text { Extrapolated } \\
\text { relative error }\end{array}$} & \multicolumn{2}{|c|}{$\begin{array}{l}\text { The grid convergence } \\
\text { index }\end{array}$} \\
\hline & $e_{a}^{21} \%$ & $e_{a}^{32} \%$ & $e_{e x t}^{21} \%$ & $e_{e x t}^{32} \%$ & $G C I_{\text {fine }}^{21} \%$ & $G C I_{\text {coarse }}^{32} \%$ \\
\hline Person & 0.0611 & 0.2075 & 0.0509 & 0.0954 & 0.0637 & 0.1189 \\
\hline Thermostat & 0.0893 & 0.116 & 0.3557 & 0.3239 & 0.4457 & 0.4035 \\
\hline
\end{tabular}

ANSYS FLUENT 15.0.7 is used as the CFD simulation platform ${ }^{10}$. The simulations are performed on a DELL-XPS with eight 3.4GHz CPU and 32 GB of RAM. No slip and penetration conditions are imposed on the walls and the person's body. The outside wall temperature is assumed to remain constant at $30^{\circ} \mathrm{C}$ during the cooling and $10{ }^{\circ} \mathrm{C}$ during the heating cases. The floor and the ceiling of the room are insulated. The surface temperature of the human body is taken as $37^{\circ} \mathrm{C}$. The hydraulic diameters of the inlet and outlet are both $0.32 \mathrm{~m}$. Different HVAC fan settings are used to provide inlet air velocities of $0.4 \mathrm{~m} / \mathrm{s}, 1 \mathrm{~m} / \mathrm{s}$, and $3 \mathrm{~m} / \mathrm{s}$ during the heating and cooling - except for one case where a velocity of $0.2 \mathrm{~m} / \mathrm{s}$ is used for a wall thickness of $63 \mathrm{~cm}^{11}$. The turbulent intensity is assumed to be $5 \%$ at the inlet. The inlet flow temperature is set to $30{ }^{\circ} \mathrm{C}$

\footnotetext{
10 Appendix A. Governing Equations

${ }^{11}$ It is recommend by ASHREA55 to have a velocity of $0.2 \mathrm{~m} / \mathrm{s}$ for a displacement ventilation but because in the case of wall thickness of $20 \mathrm{~cm}$ the system could not reach the preferred temperature range, a slightly higher speed $(0.4 \mathrm{~m} / \mathrm{s})$ is used.
} 
in the heating and to $16^{\circ} \mathrm{C}$ in the cooling cases. The inlet temperature for both systems has been chosen based on a typical air conditioner temperature range between $16^{\circ} \mathrm{C}$ and $30^{\circ} \mathrm{C}$.

Chen [60] tested five different turbulent models in a ventilated space and found RNG $\kappa-\varepsilon$ model to be the best model since it counts for both high and low Reynolds numbers. Therefore, RNG $\kappa-\varepsilon$ model with standard wall functions for near wall treatment is used. Boussinesq approximation is used to simulate the buoyancy effect of the air with constant density coefficient of $1.225 \mathrm{~kg} / \mathrm{m}^{3}$ and a constant thermal expansion coefficient $0.00321 / \mathrm{k}$. In addition, under relaxation factors of 0.7 for pressure and 0.3 for momentum are used. The convergence residual magnitude for the continuity and the momentum are set to be $10^{-4}$, while residual of energy is $10^{-6}$. The time step is chosen based on the error convergence. Time step of 1 second and $100 \max$ iteration per time step is found sufficient to reach the above desirable residual error for the whole 1 hour.

Two different heating/cooling methods are considered: Direct and indirect heating/cooling methods. In the direct heating/cooling method, the air is directed towards the person. This is achieved by specifying the direction of the inlet velocity vectors. In the indirect heating/cooling method, the inlet flow is normal to the inlet plane (see Figure 2.6). Figure 2.6a shows the isosurfaces of air directed towards the person while Figure 2.6b shows isosurfaces of the air directed away from the person. To change the heat loss load of the controlled space, two wall thicknesses are considered: $20 \mathrm{~cm}\left(1.156 \mathrm{~m}^{2} \mathrm{k} / \mathrm{W}\right)$ and $63 \mathrm{~cm}\left(3.468 \mathrm{~m}^{2} \mathrm{k} / \mathrm{W}\right)$.

Table 2.2 shows different setup cases for the controlled space. The energy consumption and the human comfort using a locally controlled system (temperature around the person) and a conventionally controlled system (temperature sensor being in a fixed location on the wall) are determined and compared with each other. Human comfort, in this case, refers to how long the control system is able to keep the person in the preferred temperature range. 
Chapter 2. The advantages of local temperature control

Table 2.2 Test conditions

\begin{tabular}{|c|c|c|c|c|c|c|}
\hline \multirow{3}{*}{ CASES } & \multirow{3}{*}{$\begin{array}{c}\text { HVAC } \\
\text { Objective }\end{array}$} & \multicolumn{3}{|c|}{ Air inlet properties } & \multicolumn{2}{|c|}{ Parameters } \\
\hline & & Velocity & Temperature & Direction & Sensor location & $\begin{array}{l}\text { Wall thermal resistance } \\
\qquad\left(\mathbf{m}^{2} \mathbf{K} / \mathbf{W}\right)\end{array}$ \\
\hline & & $\mathbf{m} / \mathbf{s}$ & ${ }^{\circ} \mathrm{C}$ & & & \\
\hline 1 & Heating & 0.4 & 30 & Indirect & Between inlet and outlet & 1.156 \\
\hline 2 & Heating & 1 & 30 & Indirect & Between inlet and outlet & 1.156 \\
\hline 3 & Heating & 3 & 30 & Indirect & Between inlet and outlet & 1.156 \\
\hline 4 & Heating & 1 & 30 & Direct & Between inlet and outlet & 1.156 \\
\hline 5 & Heating & 3 & 30 & Direct & Between inlet and outlet & 1.156 \\
\hline 6 & Heating & 0.4 & 30 & Indirect & Near outlet & 1.156 \\
\hline 7 & Heating & 1 & 30 & Indirect & Near the outlet & 1.156 \\
\hline 8 & Heating & 3 & 30 & Indirect & Near the outlet & 1.156 \\
\hline 9 & Heating & 0.2 & 30 & Indirect & $\begin{array}{c}\text { Between the inlet and } \\
\text { the outlet }\end{array}$ & 3.468 \\
\hline 10 & Heating & 1 & 30 & Indirect & $\begin{array}{c}\text { Between the inlet and } \\
\text { the outlet }\end{array}$ & 3.468 \\
\hline 11 & Cooling & 0.4 & 16 & Indirect & Near the outlet & 1.156 \\
\hline 12 & Cooling & 1 & 16 & Indirect & Near the outlet & 1.156 \\
\hline 13 & Cooling & 3 & 16 & Indirect & Near the outlet & 1.156 \\
\hline
\end{tabular}


Cases 1, 6, 9, and 11 show the setup of the displacement ventilation system for the inlet velocity of $0.4 \mathrm{~m} / \mathrm{s}$ in which case the wall thermal resistance is taken as $1.156 \mathrm{~m}^{2} \mathrm{k} / \mathrm{W}$ and for the inlet velocity of $0.2 \mathrm{~m} / \mathrm{s}$ in which case the wall thermal resistance is taken as $3.468 \mathrm{~m}^{2} \mathrm{k} / \mathrm{W}$.



a. Direct heating system

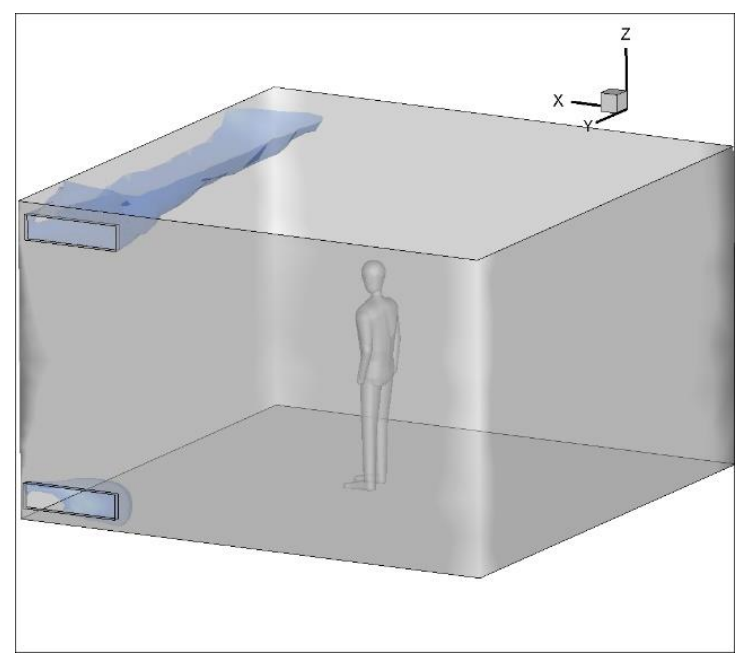

b. Indirect heating system

Figure 2.6 Isosurfaces of velocity for direct and indirect heating systems.

Case 1 is a heating case with the sensor located in between the inlet and outlet. Case 6 is also a heating case with the sensor located near the outlet. Case 11 is a cooling case with the sensor located near the outlet. Cases 2 and 3 are heating cases with a wall thermal resistance of 1.156 $\mathrm{m}^{2} \mathrm{k} / \mathrm{W}$, inlet air velocity of 1 and 3, respectively, indirect air inlet, and the sensor located between the inlet and outlet. Cases 4 and 5 are similar to cases 2 and 3, except for having direct heating instead of indirect heating. Cases 2 to 5 together show the effect of the location of the person with respect to the inlet. Cases 7 and 8 show the effect of moving the sensor location from between the inlet and the outlet to near the outlet for an indirect heating system with inlet velocity of 1 and 3 $\mathrm{m} / \mathrm{s}$, respectively. In cases 9 and 10, the heat losses are reduced by increasing the wall thickness for the indirect heating system and the sensor is in between the inlet and outlet. In cases 11, 12, and 13 , the system is switched to a cooling system with different inlet velocities of $0.4,1$, and 3 $\mathrm{m} / \mathrm{s}$ and wall thermal resistance of $1.156 \mathrm{~m}^{2} \mathrm{k} / \mathrm{W}$. 


\subsection{Results}

Figure 2.7 shows time variation of the temperature at two locations, around the person $(\mathbf{P})$ and at the sensor location (S) (on the wall), and for two different control systems: the local controlled (LC) and the sensor controlled (SC), and for the heating (H) and for the cooling $(\mathbf{C})$ conditions. The temperatures for the heating conditions are referred to as $T_{P L C}^{H}, T_{S L C}^{H}, T_{P S C}^{H}, T_{S S C}^{H}$ (similar temperatures are defined for the cooling conditions). The sold lines in Figure 2.7 Case 9 displacement heating system for both local and conventional control with inlet air velocity of $0.2 \mathrm{~m} / \mathrm{s}$ and a wall thickness of $63 \mathrm{~cm}$. refer to the average temperature around the person, while the discontinuous lines refer to the average temperature around the temperature sensor. In addition, the thick double sided arrow refers to the operation time of the conventional control system and the thin double side arrow refers to the local control system. In the case shown in Figure 2.7, the wall thickness is $63 \mathrm{~cm}\left(3.468 \mathrm{~m}^{2} \mathrm{~K} / \mathrm{W}\right)$ and the inlet air velocity is $0.2 \mathrm{~m} / \mathrm{s}$ and its temperature is $30^{\circ} \mathrm{C}$.

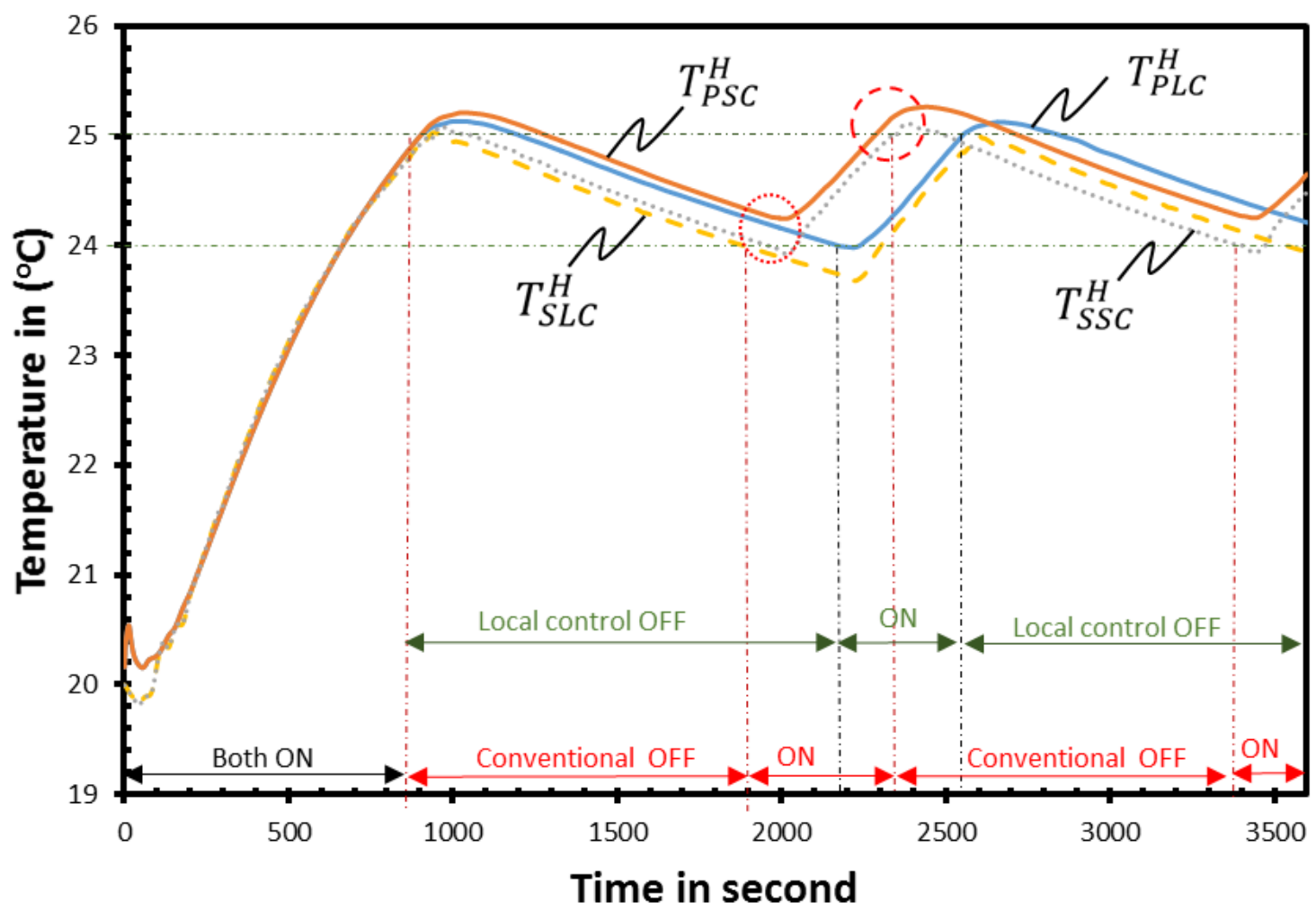

Figure 2.7 Case 9 displacement heating system for both local and conventional control with inlet air velocity of $0.2 \mathrm{~m} / \mathrm{s}$ and a wall thickness of $63 \mathrm{~cm}$. 
Sensor controlled (SC): A conventional HVAC system turns ON and OFF based on the temperature reading of thermostat sensor set on the wall. This temperature is shown by the dotted gray line in Figure $2.7\left(T_{S S C}^{H}\right)$. For such a sensor controlled HVAC system, the temperature around the person is calculated and shown as a solid thick line in Figure $7\left(T_{P S C}^{H}\right)$. The results show that the temperature around the person $T_{P S C}^{H}$ overshoots the high temperature limit of $25^{\circ} \mathrm{C}$.

Local controlled (LC): In a locally controlled HVAC system, the HVAC system turns ON and OFF based on a temperature determined by the CFD modeling for the exact location of the person, $T_{P L C}^{H}$. For such a virtual thermostat the temperature around the sensor is also determined and plotted for comparison $T_{S L C}^{H}$. In this case, the temperature around the sensor overshoots the low temperature limit of $24^{\circ} \mathrm{C}$.

On Figure 2.7, the thin solid line shows the average temperature around the person while the dashed line shows the temperature around the sensor, both for the locally controlled system. In this case, the average temperature around the person increases from $20^{\circ} \mathrm{C}$ to $25^{\circ} \mathrm{C}$ within 900 seconds (15 minutes), at which time the heating is turned OFF. After this time ( $\mathrm{t}=900 \mathrm{~s})$, the temperature around the person remains in the comfort range $\left(24^{\circ} \mathrm{C}-25^{\circ} \mathrm{C}\right)$, and slowly drops within 21.25 minutes $(t=2175 \mathrm{~s})$. At this time $(t=2175 \mathrm{~s})$ the heating is turned $\mathrm{ON}$ again for 6.233 minutes and is turned OFF again at $(\mathrm{t}=2549 \mathrm{~s})$. After this time $(\mathrm{t}=2549 \mathrm{~s})$, the system stays OFF for the rest of the hour. However, in the beginning, the temperature around the sensor (dash line) drops below the $20^{\circ} \mathrm{C}$ before it starts to increase to reach and overlap with the average temperature around the person. When the system is turned OFF at the time $(\mathrm{t}=900 \mathrm{~s})$, the average temperature around the sensor starts to drop at a faster rate than the average temperature around the person. As a result, the temperature around the sensor reaches a minimum temperature $(\mathrm{t}=1888 \mathrm{~s})$ before the average temperature around the person reaches a minimum temperature (with a difference of 4.7 minutes). By the time the system is turned $\mathrm{ON}$ again $(\mathrm{t}=2175 \mathrm{~s})$, the average temperature around the sensor reaches below $23.7^{\circ} \mathrm{C}$. After this time, the temperature around the sensor starts to increase faster than the temperature around the person. By the time the temperature around the person reaches $25^{\circ} \mathrm{C}$, the temperature around the sensor is $24.85^{\circ} \mathrm{C}$. After this time $(\mathrm{t}=2549 \mathrm{~s})$, the temperature drops again faster than the average temperature around the person to reach $24^{\circ} \mathrm{C}$ in $\mathrm{t}=3538 \mathrm{~s}$. 
On Figure 2.7, the thick solid line shows the temperature around the person and the dotted line refers to the temperature measured by the sensor, both for the conventional thermostat controlled system. The temperature around the temperature sensor and the person are slightly different at the beginning when the temperature starts to rise from $20^{\circ} \mathrm{C}$ towards $25^{\circ} \mathrm{C}$, but after a couple of minutes they reach each other. The temperature around the sensor reaches $25^{\circ} \mathrm{C}$ in 15.42 minutes $(\mathrm{t}=925 \mathrm{~s})$ when the HVAC system is turned OFF. After this time $(\mathrm{t}=925 \mathrm{~s})$, the system stays OFF for 17.33 minutes while the temperature around the sensor drops to $24^{\circ} \mathrm{C}$ and the system is turned $\mathrm{ON}$ again $(\mathrm{t}=1965 \mathrm{~s})$. After this time, the temperature around the sensor starts to increase, reaching to $25^{\circ} \mathrm{C}$ at the time of 2332 second, at which time the system is turned OFF. When the system is turned OFF, the temperature around the sensor drops to $24^{\circ} \mathrm{C}$ at the time of 3392 seconds and is turned ON again, and stays ON for the rest of the hour. On the other hand, temperature around the person seems to have good overlap with the temperature around the sensor at the beginning when the temperature is raised from $20^{\circ} \mathrm{C}$ to $25^{\circ} \mathrm{C}$. However, when the system is turned OFF for the first time, the two average temperatures start to separate because of the two different temperature dropping rate. By 1965 second, when the temperature around the sensor reached $24^{\circ} \mathrm{C}$, the average temperature around the person is $24.3^{\circ} \mathrm{C}$. After this time $(\mathrm{t}=1965 \mathrm{~s})$, the temperature around the person starts to increase again and even goes over $25^{\circ} \mathrm{C}$ when the system is turned $\mathrm{OFF}$ at 2332 second. The average temperature around the person follows the same path for the following cycles.

Comparison of the local temperature control and the sensor temperature control shows that the local control provides a better comfort by keeping the average temperature around the person in the comfort zone for a longer time. It is found that the person spends around $63 \%$ of the time in the comfort temperature range when the local controlled is used and 58.4\% when the conventional control is used. In addition, local control is a more energy saving system by turning OFF the air flow when it is not necessary, at least for the cases studied herein. The operation time of HVAC system based on the local control requires the system to turn ON just 2 times during the hour; however, the conventional thermostat turns the system ON 3 times during this hour. The local control utilizes the whole comfort range and does not turn the system ON until the average temperature around the person drops below $24^{\circ} \mathrm{C}$ while the conventional thermostat cannot control the exact temperature around the person. The dotted circle shows the difference between the sensor 
reading and average temperature around the person during the conventional control system and the dashed circle shows the overheating which occurs when the conventional control is used. The comparison of operation time (energy saving) of both systems, shows that the local control saves more than $15 \%$ of the operation time than the conventional control. The operation time percentage is calculated with respect to the operation time of the conventional control system according to $\frac{\left(t_{\text {conv }}-t_{\text {local }}\right)}{t_{\text {conv }}} \times 100$.

Figure 2.8 shows the average temperature variation around the person for the last 10 minutes of the operation for different cases with different inlet air velocities. The solid lines refer to the average temperature around the person using the local control and discontinues lines refer to the average temperature around the person using sensor control. The graphs on the first column from the left have an inlet velocity of $0.4 \mathrm{~m} / \mathrm{s}$-except for the fourth one, which has a velocity of $0.2 \mathrm{~m} / \mathrm{s}$. The graphs on the second column have an inlet velocity of $1 \mathrm{~m} / \mathrm{s}$, and the ones in the last column have an inlet velocity of $3 \mathrm{~m} / \mathrm{s}$. Figure 2.8 compares effects of various parameters on the energy saving, a number of cycles, average temperature, the rate of change of temperature, and rate of temperature drop, using the locally controlled and thermostat controlled systems.

Figure 2.9 shows the percentage of energy saving by using a locally controlled HVAC system over a conventional sensor controlled system. The energy usage is directly related to the ON time of the HVAC system. The energy saving percentage is equal to the operation time percentage, which is calculated using $\frac{\left(t_{c o n v}-t_{\text {local }}\right)}{t_{c o n v}} \times 100$. The percentage of energy saving is plotted for 3 different fan settings, i.e., inlet air velocities of $0.4 \mathrm{~m} / \mathrm{s}, 1 \mathrm{~m} / \mathrm{s}$, and $3 \mathrm{~m} / \mathrm{s}$. There is also one case with $0.2 \mathrm{~m} / \mathrm{s}$ inlet velocity.

Generally, in all cases (but one) there is a significant energy saving by using a locally controlled temperature. The energy saving is more than $20 \%$ at low fan setting (inlet velocity of $0.4 \mathrm{~m} / \mathrm{s}$ ) and reduced to about $5-10 \%$ at high fan setting (inlet velocity of $3 \mathrm{~m} / \mathrm{s}$ ).

The energy saving reduces at higher inlet velocity because of the enhanced mixing. The temperature difference between the wall (sensor) and the person reduces at high mixing conditions. Also, the local control has overheating as the velocity increases. 
Chapter 2. The advantages of local temperature control

Energy saving is almost the same (about $8 \%$ ) for all three inlet velocities when local control is compared with a sensor-controlled system with the sensor located in between the inlet and the outlet. Energy saving is more (about 15\%) at higher velocities when the local control is compared with a sensor-controlled system with the sensor located close to the outlet.

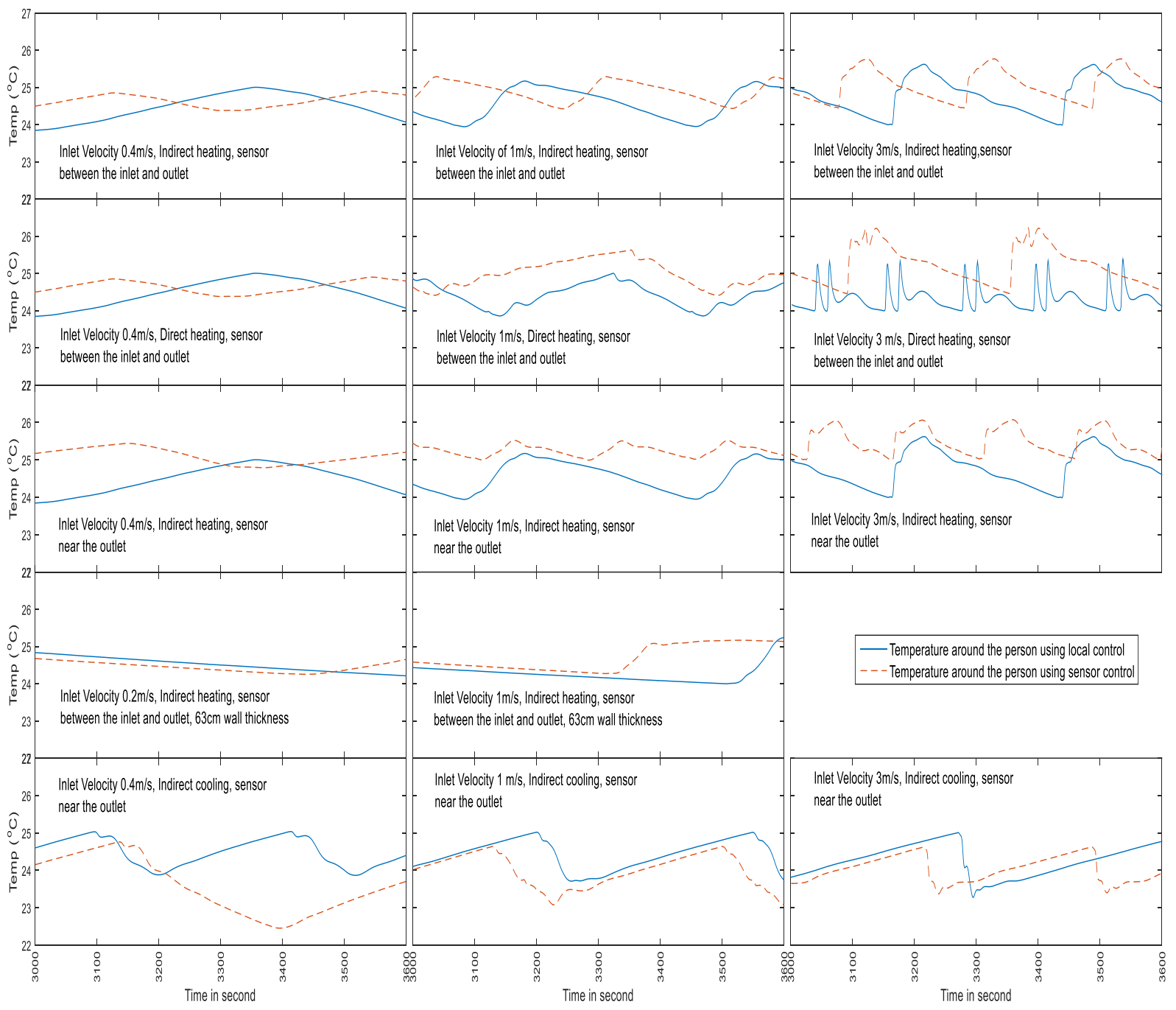

Figure 2.8 Temperature variation around the person for the last 10 minutes of the operation hour using local and sensor controls for different cases.

In the HVAC system that directs the heat toward the person, the energy saving increases with increase in the inlet velocity. In the direct heating system and using a locally controlled thermostat, the change in the local temperature is faster (rapid respond time), therefore, the energy efficiency 
improves with increasing velocity. For the cooling case, the energy saving decreases with increase in velocity due to the enhanced mixing.

In all the cases shown in Figure 2.9, the wall thickness is $20 \mathrm{~cm}$ except for one case, in which the wall thickness is $63 \mathrm{~cm}$. In this case, the efficiency of the local control drops below that of a sensor control. The reason is due to overheating in the local system because of high insulation and high speed. To overcome such a problem the amount of heat losses through the walls have to be considered in controlling HVAC system, to be able to turn the system ON or OFF before the target average temperature reaches the comfort temperature. In general, the energy saving decreases when inlet velocity increases because the high speed enhances mixing mechanism which reduces the temperature difference between the sensor and the person. However, in the case of direct heating, the energy saving increases with the inlet velocity because the person acts as an obstacle which prevents the mixing.



Figure 2.9 Energy saving when local control is used instead of sensor control. 
To further investigate the effect of direct and indirect heating, the rate of change of temperature around the person (i.e. heating or cooling rate) for three different inlet air velocities are determined and shown in Figure 2.10.

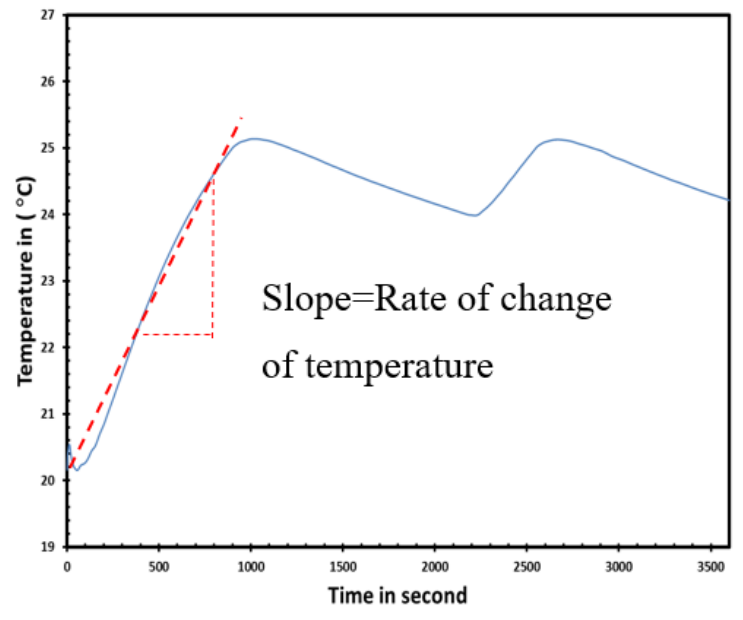

(a)

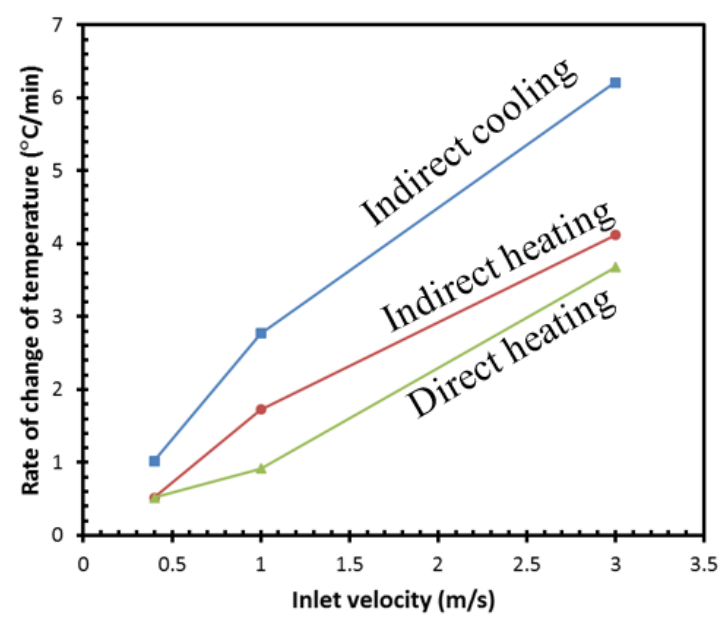

(b)

\section{Figure 2.10 Average temperature rate around the person with different inlet velocities}

The results show that the rate of heating and cooling (temperature slope around the person from the initial condition to the maximum preferred condition) is higher for the indirect heating and cooling systems than that for the direct heating cases. This is not intuitive since it was expected to have a higher slope for the direct heating than the indirect heating. In order to investigate those results, different temperature contour plots for the heating case at different time frames $(20,40$, and 80 seconds) and for both direct and indirect heating cases are extracted. The contour plots show that indirect heating generates a better mixing than the direct heating (the color is uniform after $80 \mathrm{sec}$ in case of indirect heating). In the case of the direct heating, the person's body works as an obstacle, which absorbs the air inlet momentum and, consequently, it lowers the mixing (Figure 2.11). However, after a period of time when the system becomes more stable (more uniform temperature distribution in the controlled space), direct heating starts to give a higher heating rate, which reaches up to $24^{\circ} \mathrm{C} / \mathrm{min}$ when the inlet velocity is $3 \mathrm{~m} / \mathrm{s}$ compared to $9^{\circ} \mathrm{C} / \mathrm{min}$ for the indirect heating with the same inlet velocity. 
In order to compare different cases based on thermal comfort, the average temperature around the person for a period of one hour is determined. Since the thermal comfort is set to be between $24^{\circ} \mathrm{C}$ and $25^{\circ} \mathrm{C}$, the closer the average temperature to $24.5^{\circ} \mathrm{C}$ the better the thermal comfort of that system. Figure 2.12 (a) shows the average temperature around the person in an hour using the local and the sensor control with different conditions and different inlet velocities.

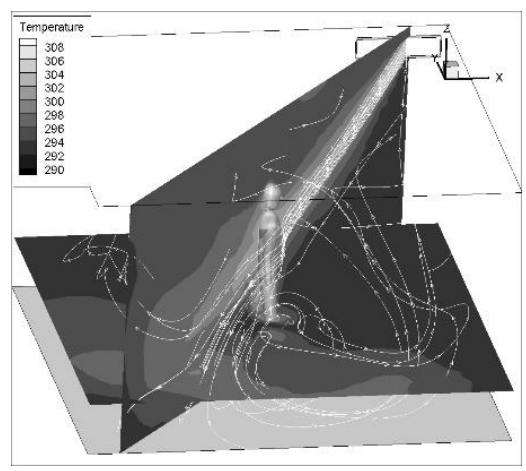

a) Direct $3 \mathrm{~m} / \mathrm{s}$ at $20 \mathrm{sec}$.

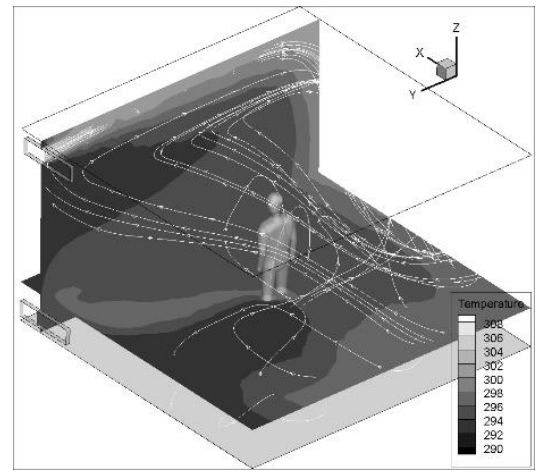

d) Indirect $3 \mathrm{~m} / \mathrm{s}$ at $20 \mathrm{sec}$.

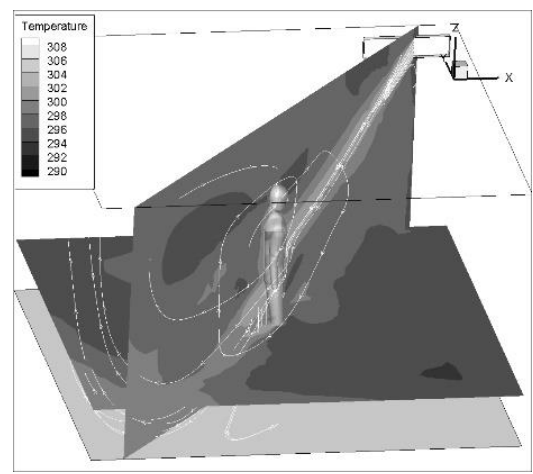

b) Direct $3 \mathrm{~m} / \mathrm{s}$ at $40 \mathrm{sec}$.

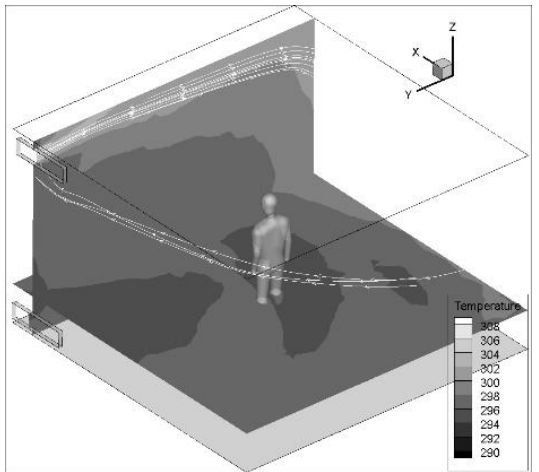

e) Indirect $3 \mathrm{~m} / \mathrm{s}$ at $40 \mathrm{sec}$.

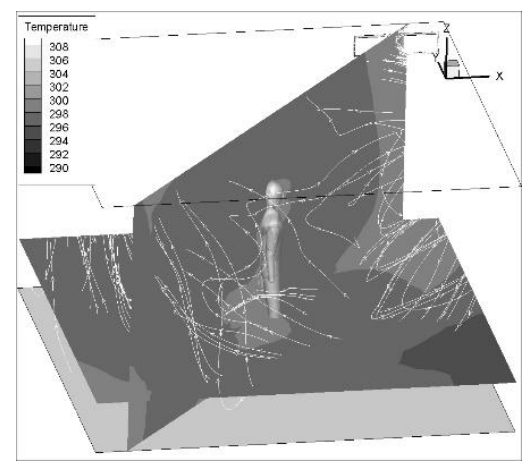

c) Direct $3 \mathrm{~m} / \mathrm{s}$ at $80 \mathrm{sec}$.

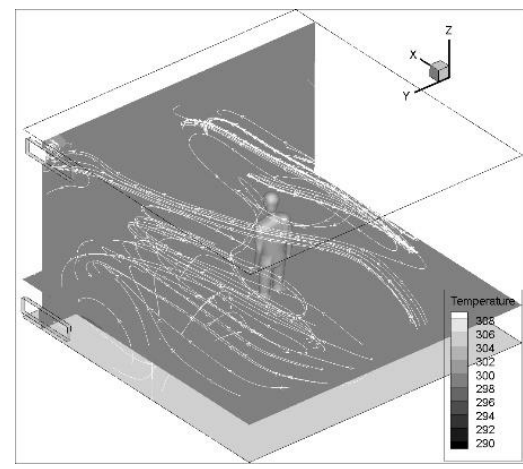

f) Indirect $3 \mathrm{~m} / \mathrm{s}$ at $80 \mathrm{sec}$.

Figure 2.11 Different temperature contour plots and streamlines at different time frames for direct and indirect heating.

The results show that the locally controlled HVAC system provides the best thermal comfort at low air setting, i.e. $\mathrm{V}_{\text {air }}=0.4 \mathrm{~m} / \mathrm{s}$. The average temperature deviates from $24.5^{\circ} \mathrm{C}$ as the inlet velocity increases. The deviation from $24.5^{\circ} \mathrm{C}$ increases from local control with direct heating to local control with indirect heating, to sensor control with indirect heating and sensor in between the inlet and outlet to sensor control with direct heating with the sensor in between the inlet and 
outlet to sensor control with indirect heating and sensor near the outlet. Highly insulated system (with wall thickness $63 \mathrm{~cm}$ ) do not show a significant difference between the two control systems.

Figure 2.12 (b), shows the percentage of time at which the person stays in the thermal comfort range during one hour. Higher comfort time percentage means better comfort. Generally, the comfort time percentage decreases as the inlet velocity increases when sensor control is in use; however in the case of cooling, sensor control provides a better comfort as the velocity increases because of the high mixing. The maximum comfort time percentage is around $60 \%$ when sensor control is used and the comfort time goes to zero when sensor is located at the outlet of the heating system. On the other hand, the minimum comfort time percentage by local control is around $60 \%$ and the maximum percentage goes up to $90 \%$. Direct heating shows longer comfort when local control is used and it increases as the velocity increases because of faster respond by the local control compared to the sensor control.

Another advantage of controlling a local internal temperature in a space than a temperature on a wall is that the internal temperature is usually more stable in time. This stability is tested by determining the number of times the HVAC system comes ON and OFF for both the local controlled and the sensor controlled systems. Figure 13(a) shows the number of times the HVAC system turns ON during one hour of operation. The number of times the system turns ON using indirect heating with local control increases from 5 to 10 to 13, whereas for indirect heating with sensor control with sensor in between the inlet and outlet the number increase from 8 to 14 to 18 when inlet air velocity is increased from 0.4 to 1 to $3 \mathrm{~m} / \mathrm{s}$. The lowest number of heating cycles corresponds to a better insulation space (see indirect heating local and sensor control lines for the wall thickness of $63 \mathrm{~cm}$ ). The system is more stable for sensor control when direct heating is used, and it is much more for indirect heating with sensor control near the outlet. Also, the number of cycles significantly increases with inlet velocity if direct heating and local control is used (at $\mathrm{V}_{\text {air }}=3 \mathrm{~m} / \mathrm{s}$ number of cycles $=60$ ).

Figure 2.13 (b), shows a temperature drop around the person when the system is OFF. For the heating the temperature drop slope is negative and for the cooling it is positive, but in this figure, just absolute values are used. The figure clearly shows a fast drop in direct heating as velocity increases when local control is used. This is related to uneven temperature distribution, 
Chapter 2. The advantages of local temperature control

which local control produces when the inlet velocity is very high and directed to the person. The drop rate temperature for almost all the cases except for directed heating with high speed is between 0.1 to $0.6{ }^{\circ} \mathrm{C} / \mathrm{min}$.

a)

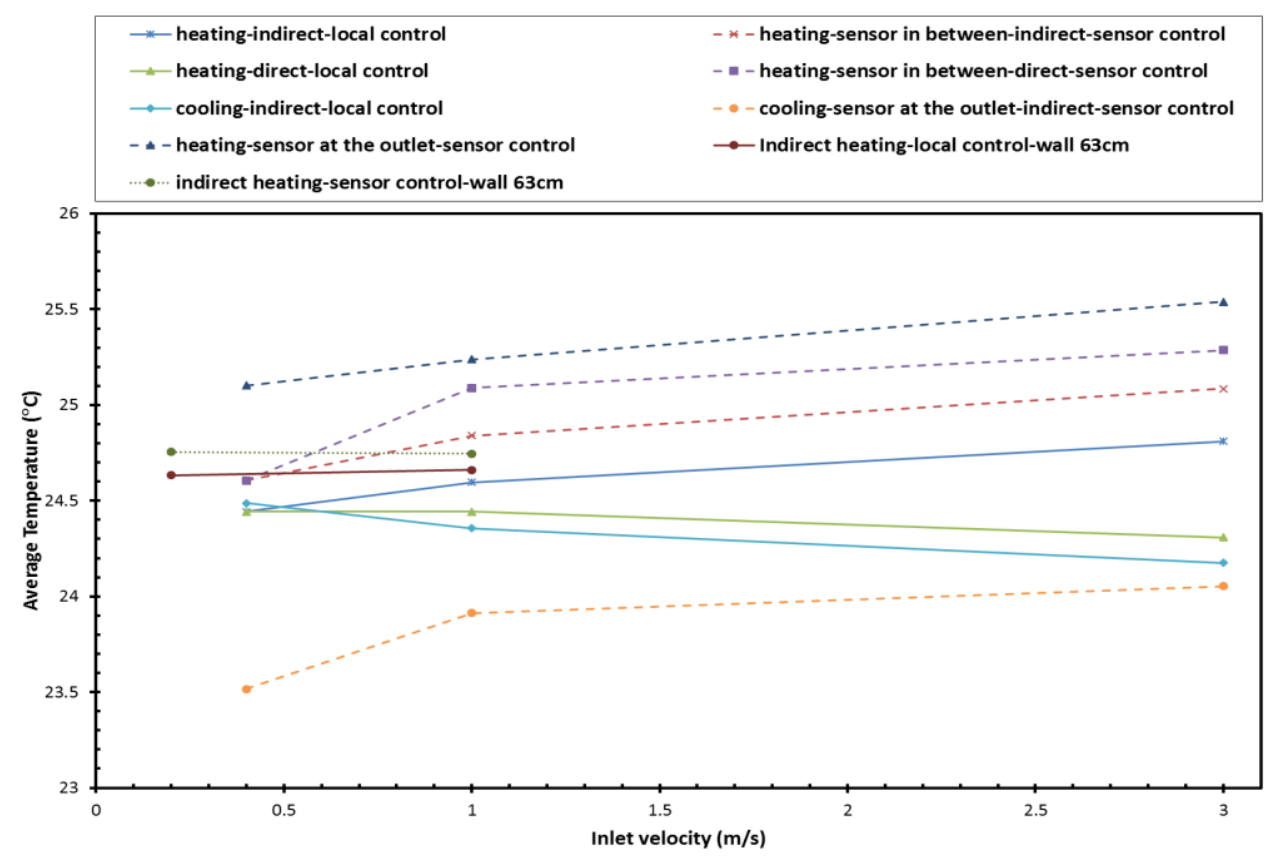

b)

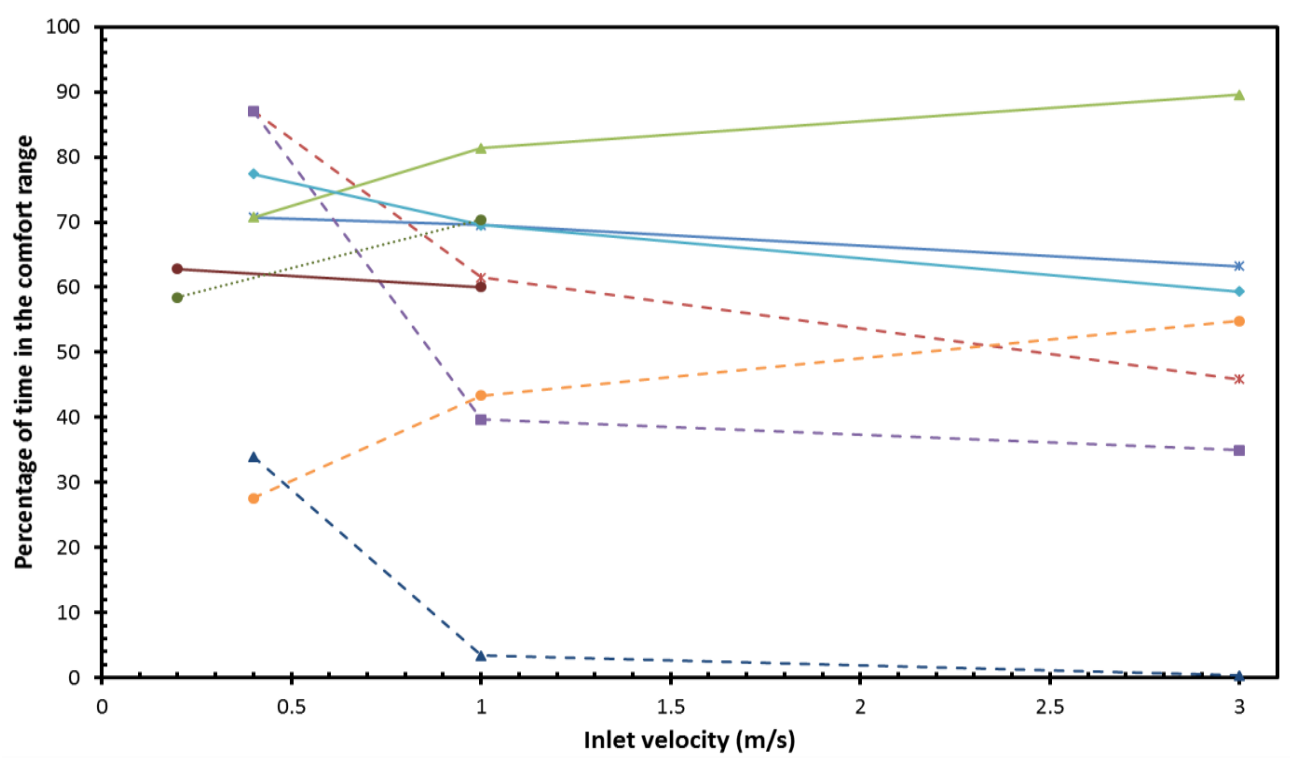

Figure 2.12 Average temperature around the person and percentage of time in the comfort range for different inlet velocity within an hour. 
Chapter 2. The advantages of local temperature control

a)
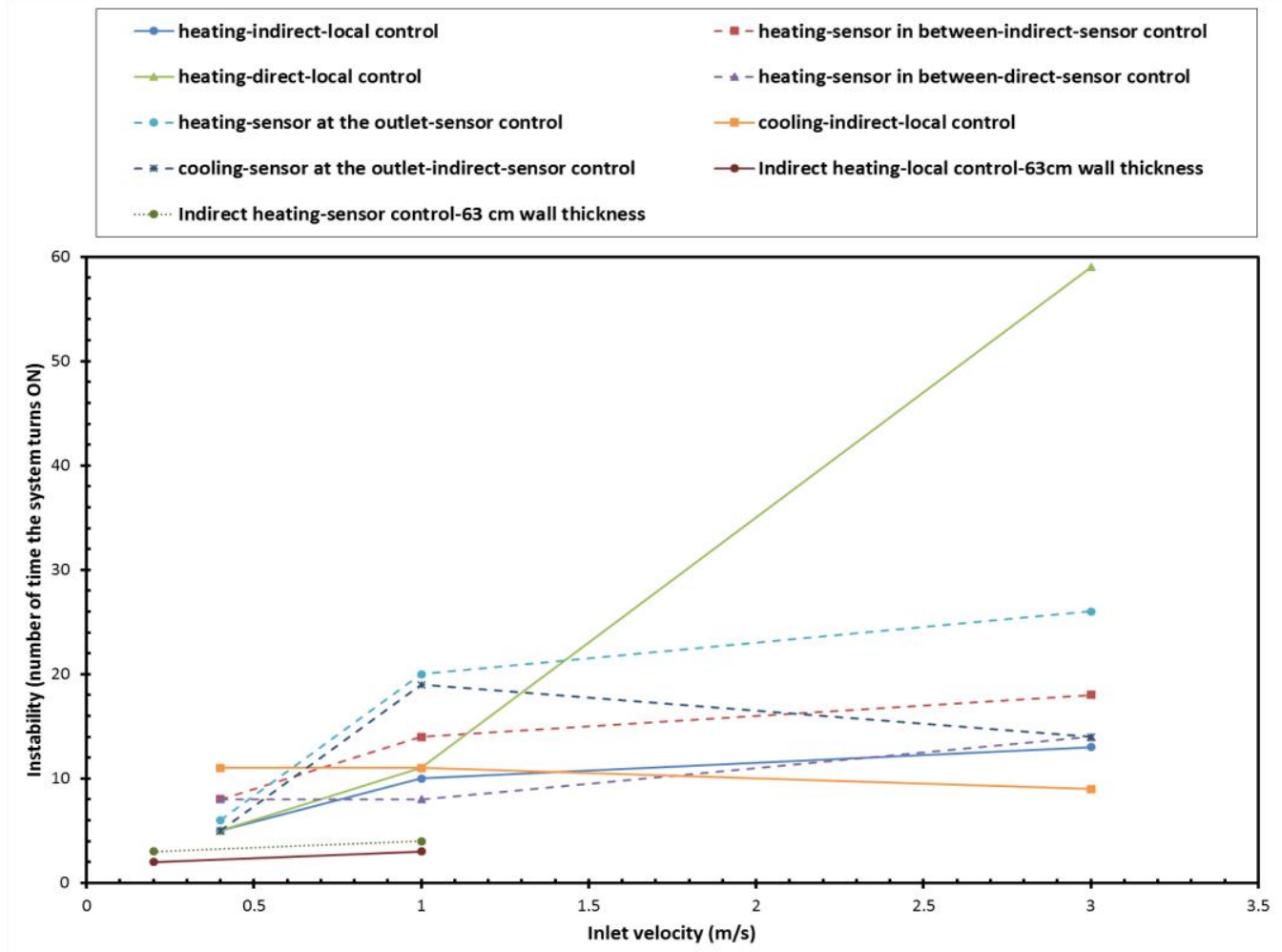

b)

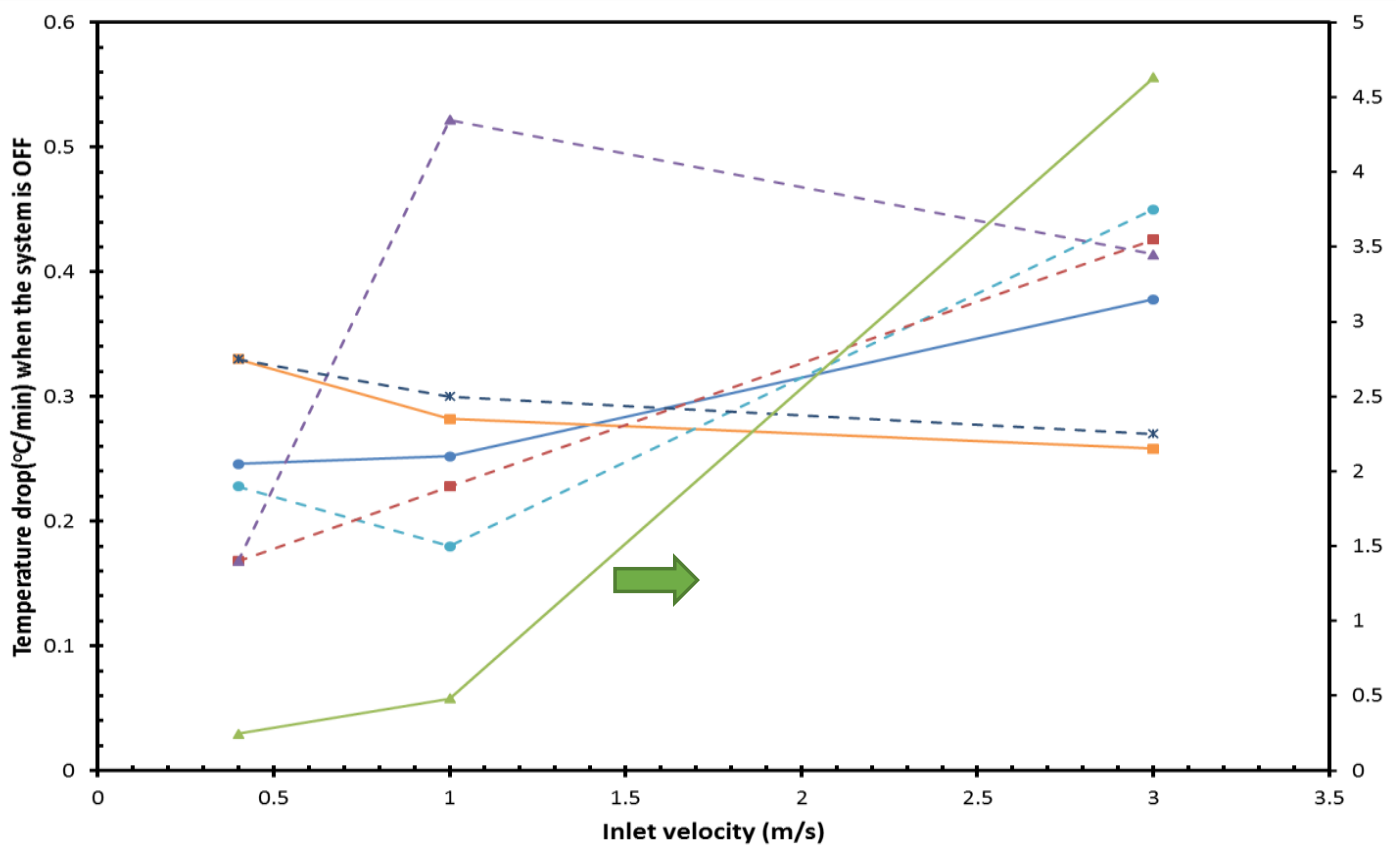

Figure 2.13 System instability for an hour and temperature drop for different air inlet velocities and conditions. 
To investigate the reason for a high instability in the case with a directed high-speed air with local control, the average temperature around the person with time is determined. Figure 2.14 shows, the average temperature around the person, when the local control with $3 \mathrm{~m} / \mathrm{s}$ directed air is used, shows two different temperature drop rates. The first temperature drop rate is higher than the second one. The first temperature drop rate is $4.6^{\circ} \mathrm{C} / \mathrm{min}$ and the second one is $0.4^{\circ} \mathrm{C} / \mathrm{min}$.



\section{Figure 2.14 Temperature variation in direct heating for the local control with an inlet air velocity of $3 \mathrm{~m} / \mathrm{s}$.}

By checking the temperature distribution right after the system is turned OFF, the results show a highly non-uniform temperature distribution, which causes the temperature around the person to dissipate and drop rapidly when the system is turned OFF. Figure 2.15 shows a vertical and a horizontal cross-section at the middle of the room for a temperature distribution. The temperature distribution is shown for the room after the system is turned OFF close to the end of the operation hour. The straight lines on the contour plots show the location of the temperature plots. The plots and contour plot show a high-temperature fluctuation which is the main reason for 
the rapid temperature drop. However, for the second drop the controlled space has better temperature distribution because of the air pulse when the air is turned ON.

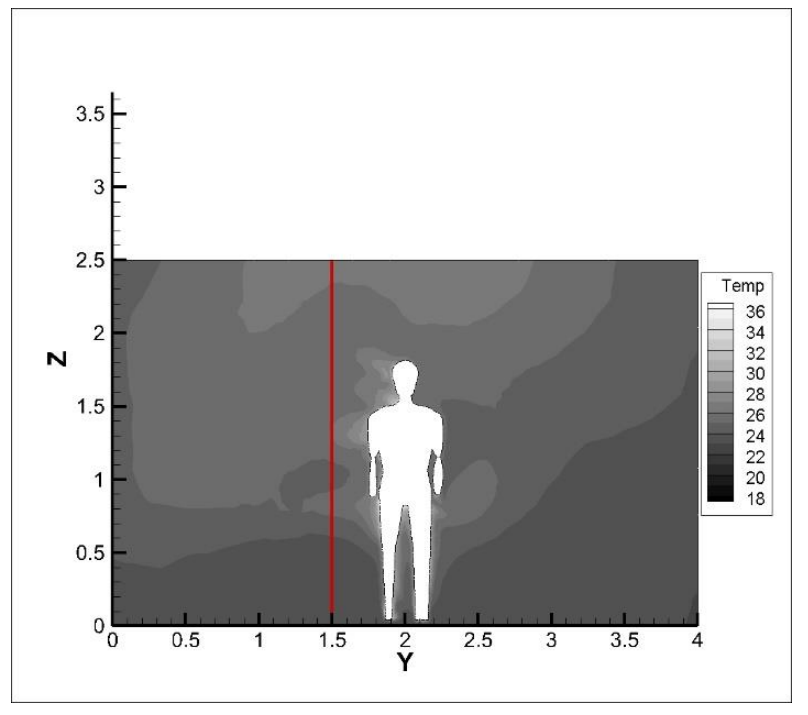

a) Vertical slice.

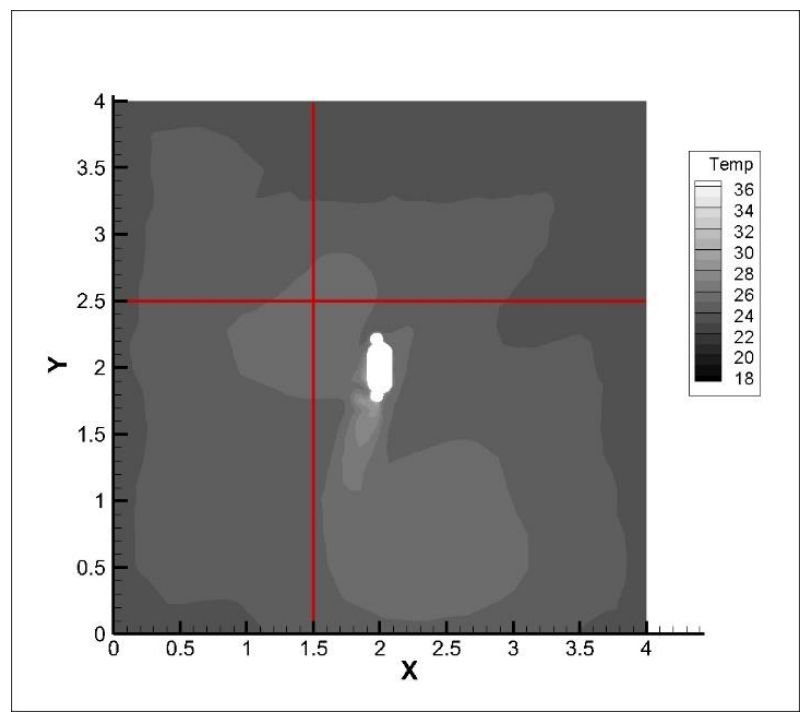

c) Horizontal slices



b) Temperature variation along the height.



d) Temperature variation along $\mathrm{X}$ and $\mathrm{Y}$.

Figure 2.15 Vertical and horizontal slices in the middle of the controlled space and temperature variation along the controlled space (for direct heating with inlet velocity of $3 \mathrm{~m} / \mathrm{s})$. 
Figure 2.16 shows the diagonal velocity contour and the velocity vectors around the person for $1 \mathrm{~m} / \mathrm{s}$ and $3 \mathrm{~m} / \mathrm{s}$ cases. When the inlet air velocity is $1 \mathrm{~m} / \mathrm{s}$ (Figure 2.16.a), the inlet air has high enough inertia to overcome the buoyancy effects. Therefore, the flow curves up towards the person's head instead of flowing directly to the center of the person's body and provide a better mixing. On the other hand, when the inlet air velocity is $3 \mathrm{~m} / \mathrm{s}$, the inlet air has enough inertia to overcome the buoyancy effects and contact the person's hip directly (Figure 2.16.a). As a result, the average temperature around the person warms up faster than the rest of the room, which leads to the instability of the control system because of a rapid drop in temperature when the system is turned OFF.

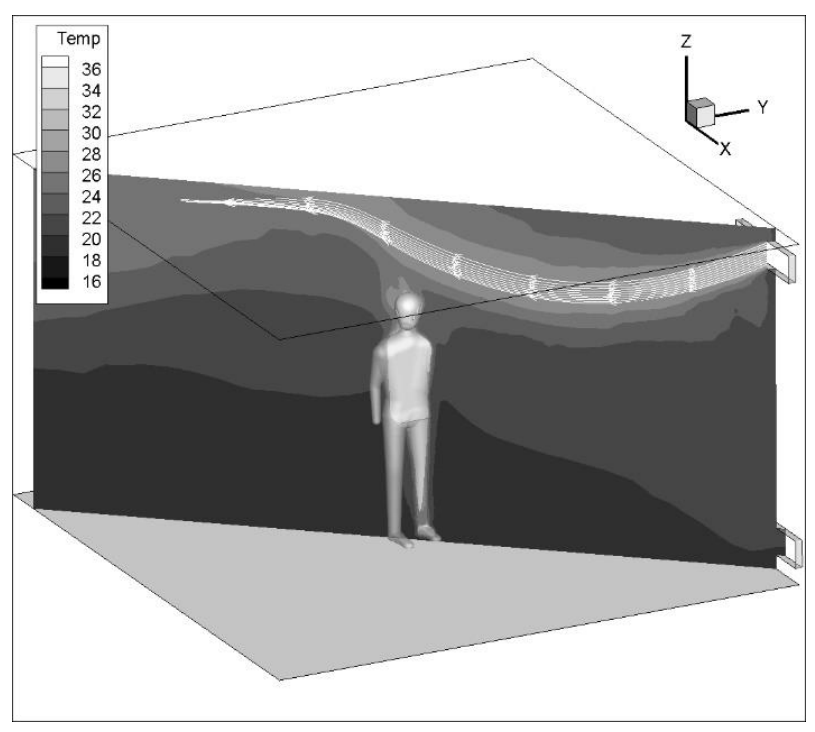

a. $1 \mathrm{~m} / \mathrm{s}$ directed air.

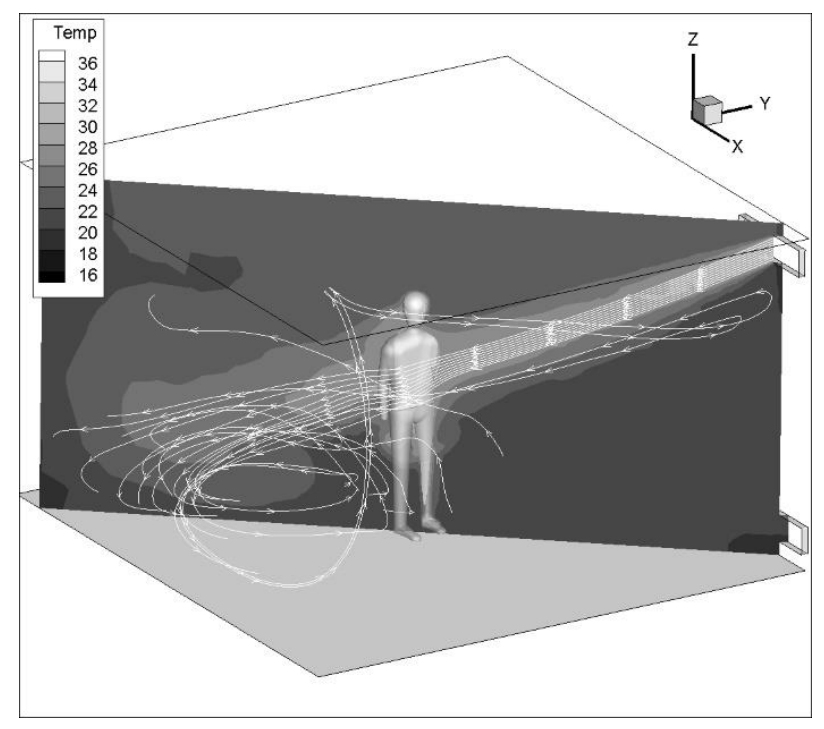

b. $3 \mathrm{~m} / \mathrm{s}$ directed air.

\section{Figure 2.16 Contour plot of temperature distribution and velocity vector for a directed $1 \mathrm{~m} / \mathrm{s}$ of air and directed $3 \mathrm{~m} / \mathrm{s}$ of air.}

Temperature stratification is when controlled space has different temperatures along the height of the space. The temperature difference can cause discomfort for the people in the space. ASHRAE Standard 55 requires that temperature difference from head to foot of a person should not exceed $3^{\circ} \mathrm{C}$. Therefore, the stratification levels of the local and the sensor controlled systems are compared with each other for heating and cooling conditions and with a low inlet velocity. A 
vertical slice in the middle of the room is extracted and shown in Figure 2.17.a. Because of the semi-symmetric temperature around the person, the temperature variation is measured along one vertical line, $0.5 \mathrm{~m}$ to the right of the person (see Figure 2.17.b). Three different times in the last cycle of the operation are considered: (i) before the system is turned $\mathrm{ON}$, (ii) in the middle of the period, and (iii) when the system is turned OFF.

Figure 2.18-i shows temperature variation along the vertical line from the floor to $2 \mathrm{~m}$ height for very slow inlet velocity. The sensor control results in a higher temperature in all threetime frames as shown in Figure 2.18 (i-a). By calculating the temperature slope for each control system at each time frame, Figure 2.18 (i-b), the local control shows a better control by bringing the slope down to $0.2 \mathrm{C} / \mathrm{m}$ by the end of the operation while sensor control does not.

Figure 2.18-ii shows vertical temperature variation for the indirect heating system with inlet velocity of $0.4 \mathrm{~m} / \mathrm{s}$ and a wall thickness of $20 \mathrm{~cm}$. Figure 2.18 (ii-a) shows the temperature variation along the controlled space up to $2 \mathrm{~m}$ height. The slope of the temperature in general increases with time (Figure 2.18 (ii-b)), but the rate is higher for the local control. By the end of the operation, both control systems have a rate of about $1.2^{\circ} \mathrm{C} / \mathrm{m}$.

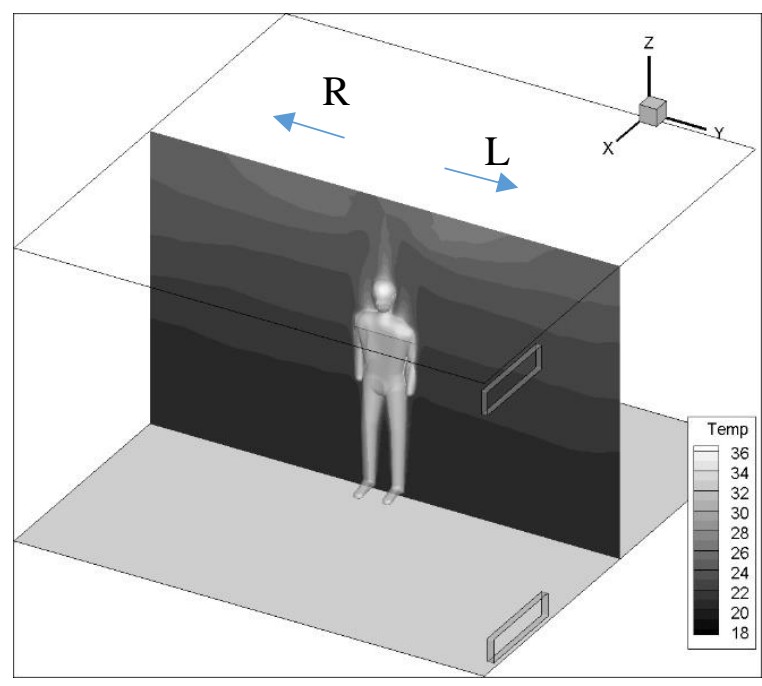

a. Slice location

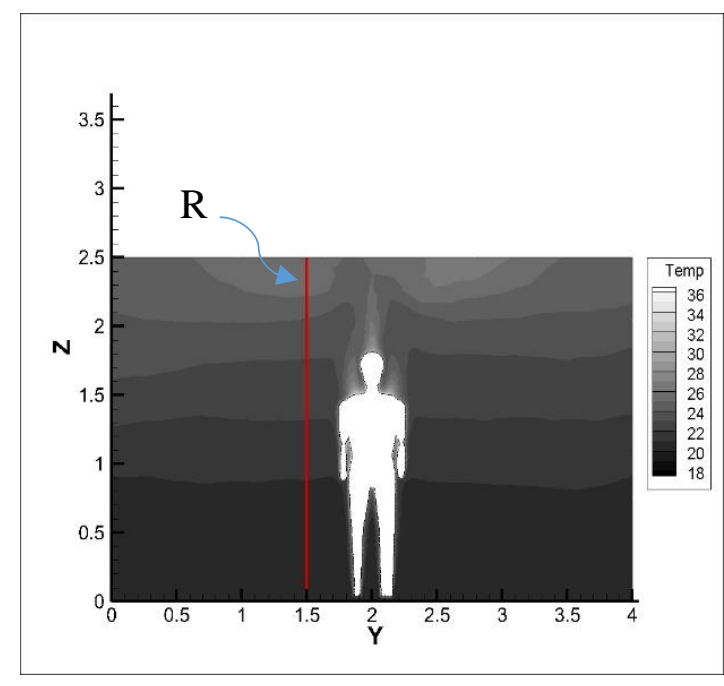

b. Vertical lines locations 
Figure 2.17 Location of the vertical slice in the middle of the controlled space and vertical line where the temperature variation is plotted.

Figure 2.18-iii shows the vertical temperature variation for the cooling system with an inlet velocity of $0.4 \mathrm{~m} / \mathrm{s}$ and a wall thickness of $20 \mathrm{~cm}$. Both systems starts with almost the same temperature slope. However, the rate of increase in temperature is higher for the sensor control. Sensor control causes the temperature to increase and decrease by the end of the operating cycle. However, local control just continues to increase until it reaches almost $1{ }^{\circ} \mathrm{C} / \mathrm{m}$.

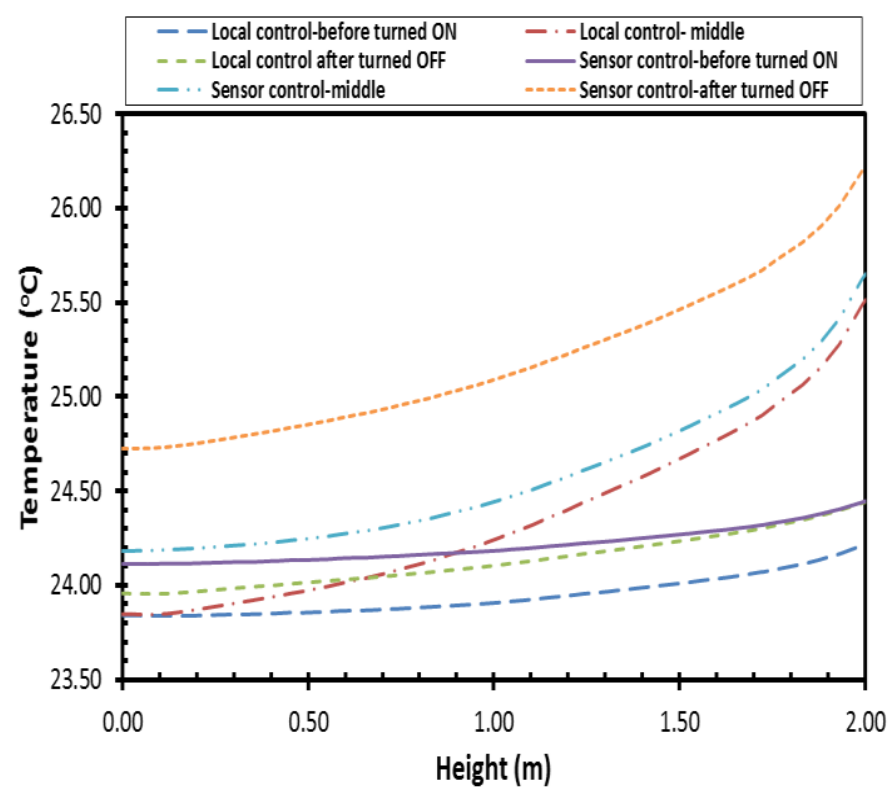

i-a) Heating, inlet velocity $=0.2 \mathrm{~m} / \mathrm{s}$, wall thickness $63 \mathrm{~cm}$

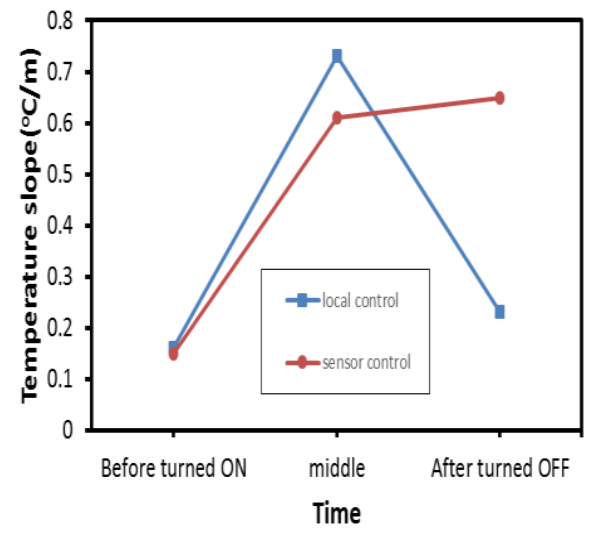

i-b) Heating, inlet velocity $=0.2$ $\mathrm{m} / \mathrm{s}$, wall thickness $63 \mathrm{~cm}$ 


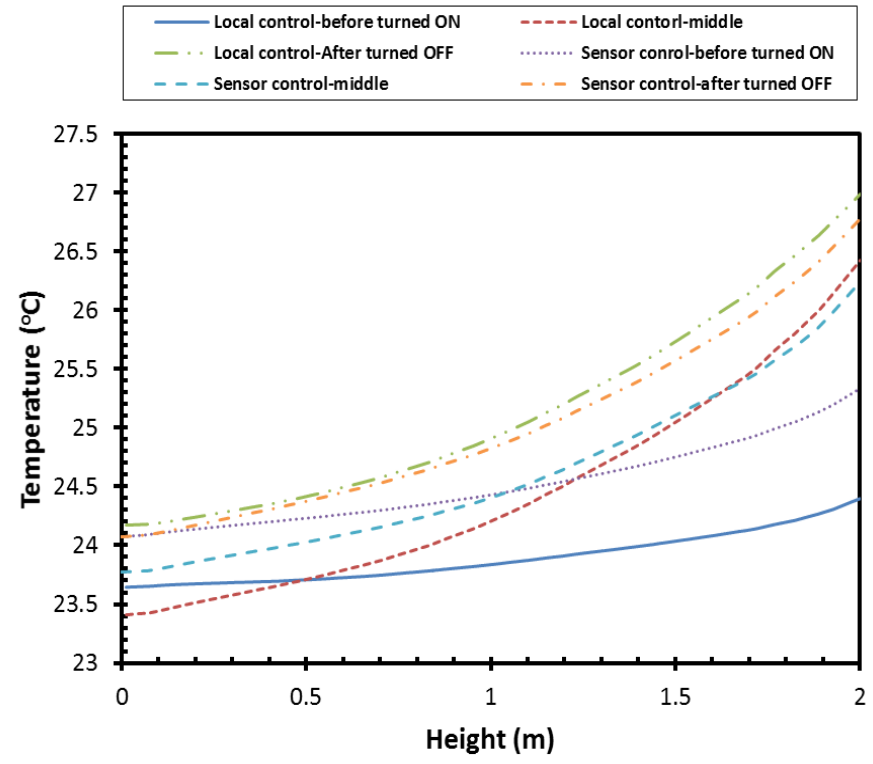

ii-a) Heating, inlet velocity $=0.4 \mathrm{~m} / \mathrm{s}$, wall thickness

$20 \mathrm{~cm}$

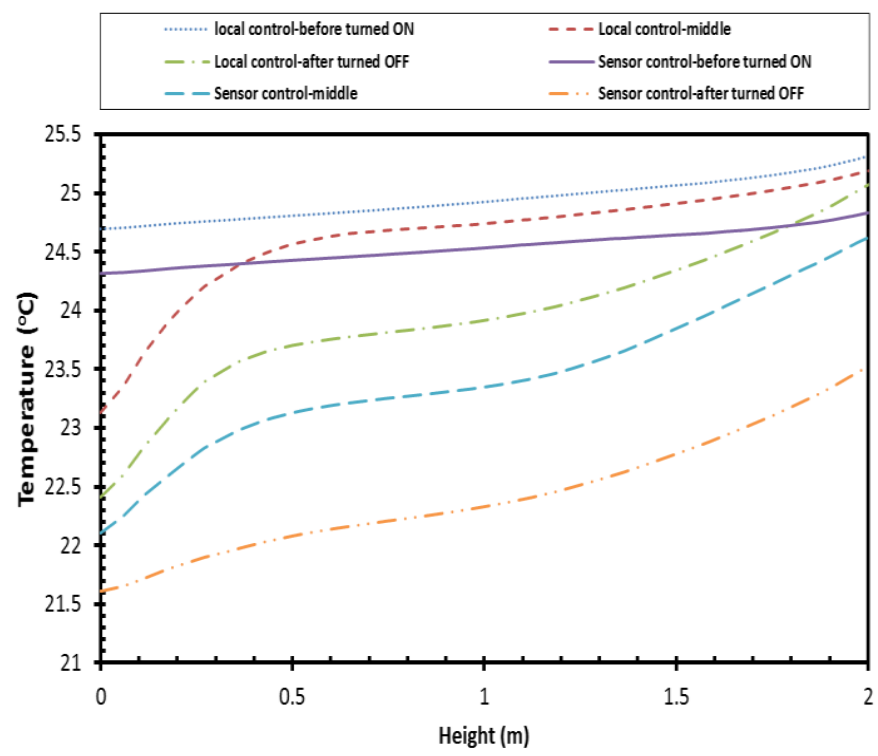

iii-a) Cooling, inlet velocity $=0.4 \mathrm{~m} / \mathrm{s}$, wall thickness

$20 \mathrm{~cm}$



ii-b) Heating, inlet velocity $=0.4$ $\mathrm{m} / \mathrm{s}$, wall thickness $20 \mathrm{~cm}$

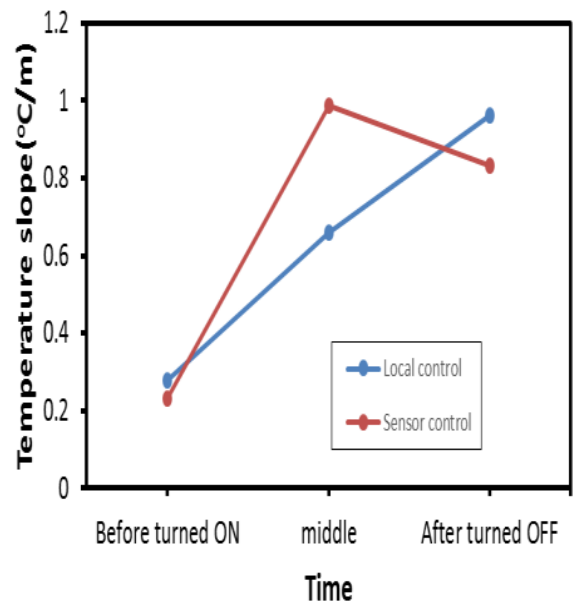

iii-b) Cooling, inlet velocity $=0.4$ $\mathrm{m} / \mathrm{s}$, wall thickness $20 \mathrm{~cm}$

Figure 2.18 Temperature variation along the line shown in figure 13 for different cases. 


\subsection{Summary and Conclusion}

A virtual thermostat is introduced which uses CFD to determine the distributive temperature inside an HVAC controlled space. The HVAC system is then controlled based on the temperature of any desired zone inside the controlled space. This is referred to as a locally controlled HVAC system. We have compared the energy consumption and thermal comfort of a sensor controlled HVAC system with a locally controlled system. Several cases with different inlet velocity, heating loads through the walls, and heating and cooling systems are tested. The following conclusions are made from the cases studied: (i) In the conventional sensor controlled HVAC systems, and for the tested conditions, up to $22 \%$ of the energy is used for unnecessary heating of the space. (ii) The sensor based control is sensitive to sensor location, people location, and inlet parameters. However, a locally controlled system is efficient by controlling only based on average temperature around a person. (iii) An HVAC system having a temperature sensor near the air outlet is less energy efficient than one having a temperature sensor near the air inlet as compared to an HVAC system with a local control. (iv) The average temperature around the person in the heating condition is higher for the sensor controlled system as compared to that of the locally controlled one. (v) Higher inlet air velocities in the heating cases result in larger deviation of the local temperature from a thermostat setting. However, a locally controlled system provides a better control as compared to the sensor control systems. (vi) In general, comfort time decreases as velocity increases, except for direct local control heating and sensor controlled cooling where comfort time increases with velocity. (vii) Direct heating with local control can cause system instability as velocity increases which can reduce the lifetime of HVAC system components. (iix) The local control with direct heating results in a non-uniform temperature distribution compared with the indirect heating. In general, a locally controlled system has a better energy efficiency, better thermal comfort and system stability than the sensor controlled one for low inlet velocity HVAC systems. However, at high inlet velocity systems, a locally controlled system may result in overheating and poor energy efficiency.

This study did not include other thermal comfort effects such as air humidity, and air velocity which can have an effect on the energy saving percentage. The main issue with such system is the computational time which can be improved by using higher speed computational resources and different computational fluid dynamic solver such as fast fluid dynamic, which is more stabilized 
Chapter 2. The advantages of local temperature control

compared with CFD but less accuracy. In addition, artificial neural networks can be used to reduce the number of CFD calculation which is going to be the aim of next study. The method can be used in stationary environments such as offices, bedrooms during sleeping time, meat chilled refrigerated to estimate how long the meat carcasses need to reach the preferred temperature, and in greenhouses to have the more controllable environment. 


\section{Chapter 3 A Coupled CFD-ANN Method to Control a Special Temperature Distribution ${ }^{12}$}

\subsection{Introduction}

All thermostat devices have single point measuring temperature sensors to provide feedback to the thermostat devices. The single point measuring sensors do not represent the entire controlled domain. Based on chapter 2, up to $22 \%$ energy saving, increases on human thermal comfort, and HVAC system stability can be improved by controlling the temperature around a person inside a controlled space rather than the average temperature around the thermostat which seats on walls or close to a return duct. The method which has been used to estimate the average temperature around the person is computational fluid dynamic (CFD). CFD is used to estimate the temperature distribution inside a controlled space based on the boundary conditions (such as the inlet temperature and velocity, the outside temperature, and people's location). The average temperature around the person is extracted from the data obtained from the CFD calculations. The average temperature is then used to turn the HVAC system ON or OFF when it reaches a preferred condition. The output results are operation time (such as the first ON time, average OFF time, and average $\mathrm{ON}$ time) of the HVAC system. The main problem with using CFD for real-time control of $\mathrm{HVAC}$ is the computational time, which can reach from 10 hours to 24 hours or more, depending on the control space complexity, for a one-hour operation of HVAC system. CFD solver has to run each time the conditions of the controlled space are changed, for example, if the person moves from one location to another location, or if the outside temperature is changed, or if the inlet air conditions are changed or a combination of them. One way to reduce the computational time is to use another feasible method, such as zonal method and empirical model. The main problem with the zonal method and similar methods are the accuracy and computational time related with complex controlled space. The empirical model is developed to improve the accuracy of temperature control at the target location [61], [62]. The empirical coefficients are identified using CFD and least square estimation. The main problem with this method is that it is limited to specific conditions. Therefore, in this study, we have solved this problem by reducing the number of times

\footnotetext{
12 The content in this chapter is under review in the Applied Energy journal.
} 
CFD solver needs to run. In order to do that, each time CFD simulation is run, CFD outputs are used to generate training data for an artificial neural network (ANN) for regression purposes, which is then used to estimate the operation time of the HVAC system for a new condition in a matter of seconds. The reason for using ANN is because of the nonlinearity and fuzziness of the problem.

ANN coupled with CFD and genetic algorithm (GA) has been used for HVAC design and optimization [63]-[66]. ANN is usually coupled with GA for optimization purpose. For example, ANN coupled with GA is used to design heat exchanger by Akbari et al. [67]. Madadi and Balaji [68], have coupled CFD with ANN and micro-GA to optimize the location of a number of discrete heating sources inside cooled controlled space to minimize the maximum temperature of the heating source. Zhou and Haghighat [51], [52] used CFD with conjunction with GA and ANN to optimize the ventilation systems in an office environment to improve human thermal comfort and indoor air quality (IAQ) without losing energy consumption. Song et al [69] coupled velocity propagation method (VPM), which zonal based model, with ANN to reduce the optimization process time when CFD is used instead. Marvuglia et al [70] coupled ANN with the fuzzy logic controller to regulate the thermal comfort in an office by predicting the indoor temperature from weather conditions (such as relative humidity and wind speed). Zhang and You [71], [72] coupled ANN with GA and CFD to optimize the design of the inlet air supply parameters of the controlled space (inlet velocity magnitude and direction, and inlet temperature). Xue et al [25] coupled ANN with GA and CFD to optimize the inlet flow control conditions of an airplane cabin. The coupling mechanism was designed in a way to reduce the required training data from CFD simulation. Magnier and Haghighat [73] combined ANN with GA. ANN is trained using results from TRNSYS, which is CFD solver for HVAC system. They combined passive solar building design with thermostat setting, by count extra parameters such as building thermal mass and windows sizes. Song et al. [74] coupled ANN with CFD with GA to optimize temperature distribution in a data center by optimizing the inlet temperature and inlet flow rate. Many other applications of using CFD coupled with ANN model and GA algorithm can be found in [75]-[78].

In this study, we have coupled CFD with ANN to reduce the number of CFD simulations required for controlling an HVAC system. An HVAC controlled room with a person standing inside it is simulated at different boundary conditions and with the person at different locations. 
The simulation results are the average temperatures around the person. The rate of temperature change, average OFF time, average $\mathrm{ON}$ time, and the maximum temperature cycles are extracted from the average temperatures. The extracted results are then used to train ANN model. The main purpose of this study is to determine the feasibility and accuracy of ANN for a virtual local temperature control in an HVAC controlled space. The ANN model outputs are compared with the CFD results to determine the ANN model accuracy.

\subsection{Modeling approach to reduce the computational time}

CFD has been used for design and research purposes for several decades to determine fluid velocities and temperatures in a wide variety of spaces and geometries. For instance, it has been used in the HVAC industry to determine the proper location of the HVAC outlets and its inlet velocities for a uniform distribution of heat. CFD is currently is accurate enough that its predictions are close to the measurement values, at least for systems like HVAC systems. However, CFD has not been used to measure (e.g., theoretically predict) flow velocities and temperatures. The main reason for this is the long computational times that are needed to simulate large spaces.

In particular, CFD has not been used for real-time modeling in cases that simple alternatives are available for real time measurement. For instance, the temperature inside a space can be easily measured by a temperature sensor, whereas a significant amount of computations are needed to determine a local temperature in a space using CFD.

One way of solving this issue is by using regression models to predict the operation time when the conditions are changed without the need of running CFD. One of those regression models which has been used extensively in building related studies is ANN. In this study, we have used MATLAB 2014b [79] as the modeling platform for ANN. The model used in this study is a multilayers feedforward ANN model, which is good for prediction. The accuracy of ANN prediction depends on several factors such as the features (parameters) of the training inputs data, the size of the networks including numbers of hiding layers and number of nodes in the layer, and the training algorithm. All those factors are problem-related. Therefore, in this study, we will test two different features inputs configuration with different network sizes, and different training algorithms. 
The procedure of training the ANN is using CFD for 3D model of a room with a standing person inside it. The room is heated from $20^{\circ} \mathrm{C}$ to $25^{\circ} \mathrm{C}$ and maintained at temperatures between $24^{\circ} \mathrm{C}$ and $25^{\circ} \mathrm{C}$. CFD solver estimates the temperature distribution inside the controlled space and extracts the average temperature around the person. Estimated temperature distribution and velocity vectors for one case are shown in Figure 3.1 and the average temperature variation around a person is shown in Figure 3.2.

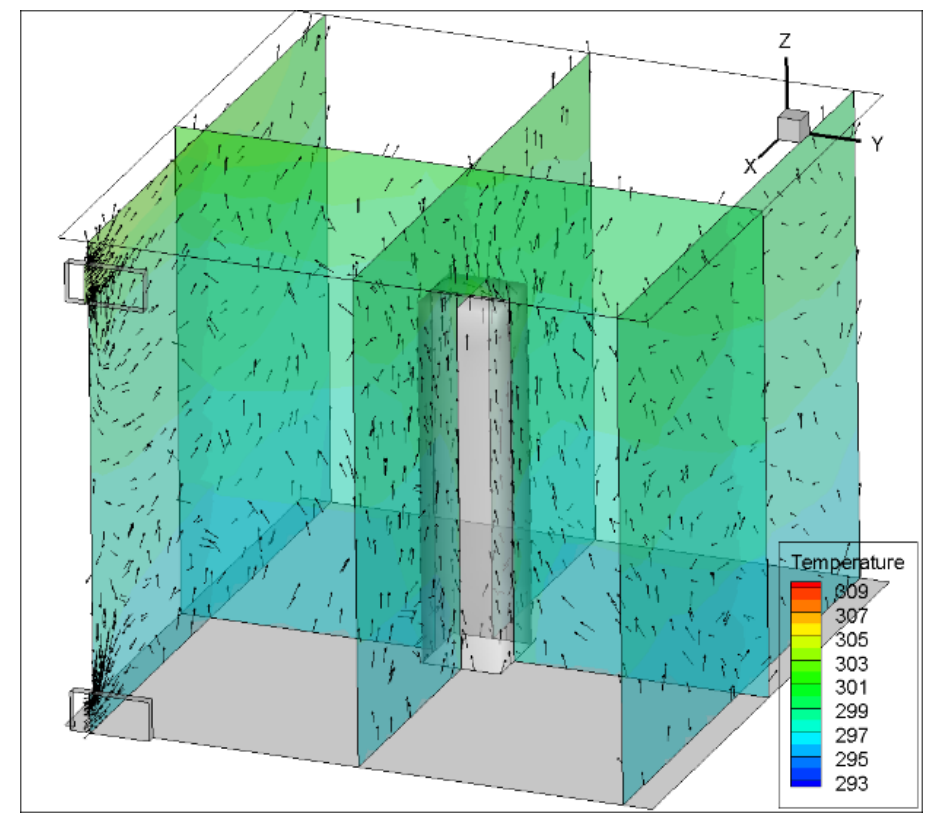

Figure3.1 temperature distribution and velocity vectors around a person standing at the center of a room, with HVAC air inlet velocity of $0.4 \mathrm{~m} / \mathrm{s}$, inlet temperature $30^{\circ} \mathrm{C}$, outside temperature $10^{\circ} \mathrm{C}$.

In this chapter, the operation times refers to the average OFF time, the average ON time, and the maximum temperature. Also, the initial rate of temperature change during the heat up is used to find the initial heat up time. The operation conditions of the system are the inlet velocity and inlet temperature, and the outside temperature. The operation times are extracted from the average temperature variation around the person. The CFD modeling is applied to a room subject to different boundary conditions and with the person in different locations inside the room. One hundred ninety-four cases have been simulated. The generated cases are used to train the ANN model. Two input parameter configurations have been tested on ANN model. In the first configuration, the inputs parameters are the outside temperature, the inlet temperature, the inlet 
velocity, and the person location. In the second configuration, the input parameters are the outside temperature, the rate of temperature change, and the person location. The network outputs for the first configuration are the rate of temperature change, the average ON/OFF time, and the maximum temperature. In the second configuration, the outputs are the inlet velocity and temperature, the average $\mathrm{ON} / \mathrm{OFF}$ time, and the maximum temperature. The inputs and outputs for the two configurations are shown in Figure 3.3. The reason for using different input configurations is that the user can have both options, by either entering the inlet operation conditions of the system and obtaining the output in terms of the operation time of the system or entering the rate of temperature change and obtaining both the operating time and operation conditions of the system.

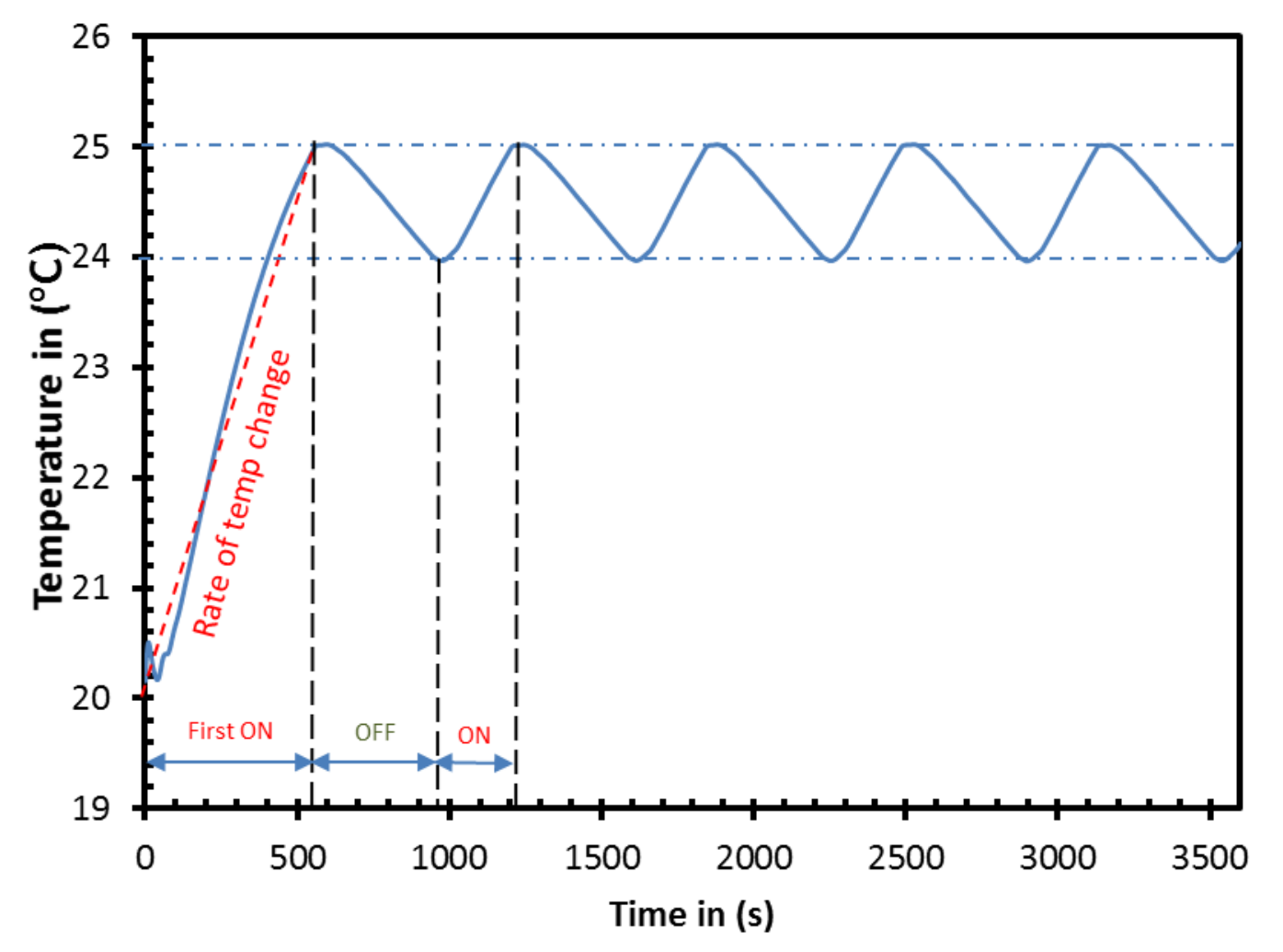

Figure 3.2. The average temperature variation around a person standing at the center of a room, with HVAC air inlet velocity of $0.4 \mathrm{~m} / \mathrm{s}$, inlet temperature $30^{\circ} \mathrm{C}$, outside temperature $10^{\circ} \mathrm{C}$.

After training ANN models, the trained ANN model will be used to estimate the operation time of test cases and compare the output with the CFD results. The outputs of different ANN size 
and inputs is compared with the CFD results. Figure 3.4 shows the flow chart of the training and testing.

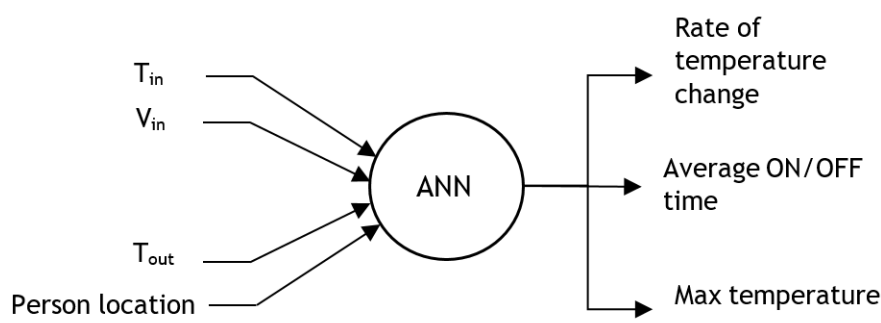

(a)

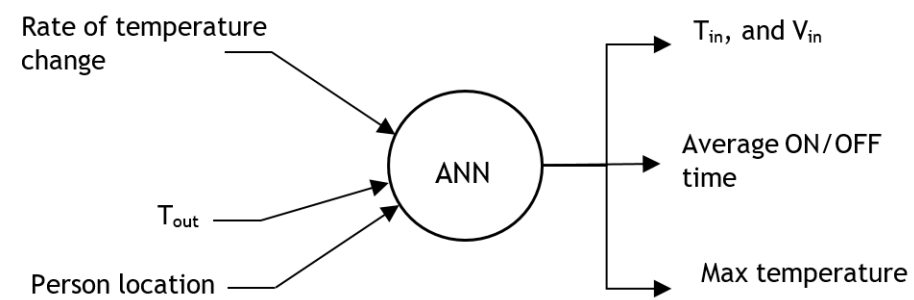

(b)

Figure 3.3. Inputs and outputs parameters for ANN

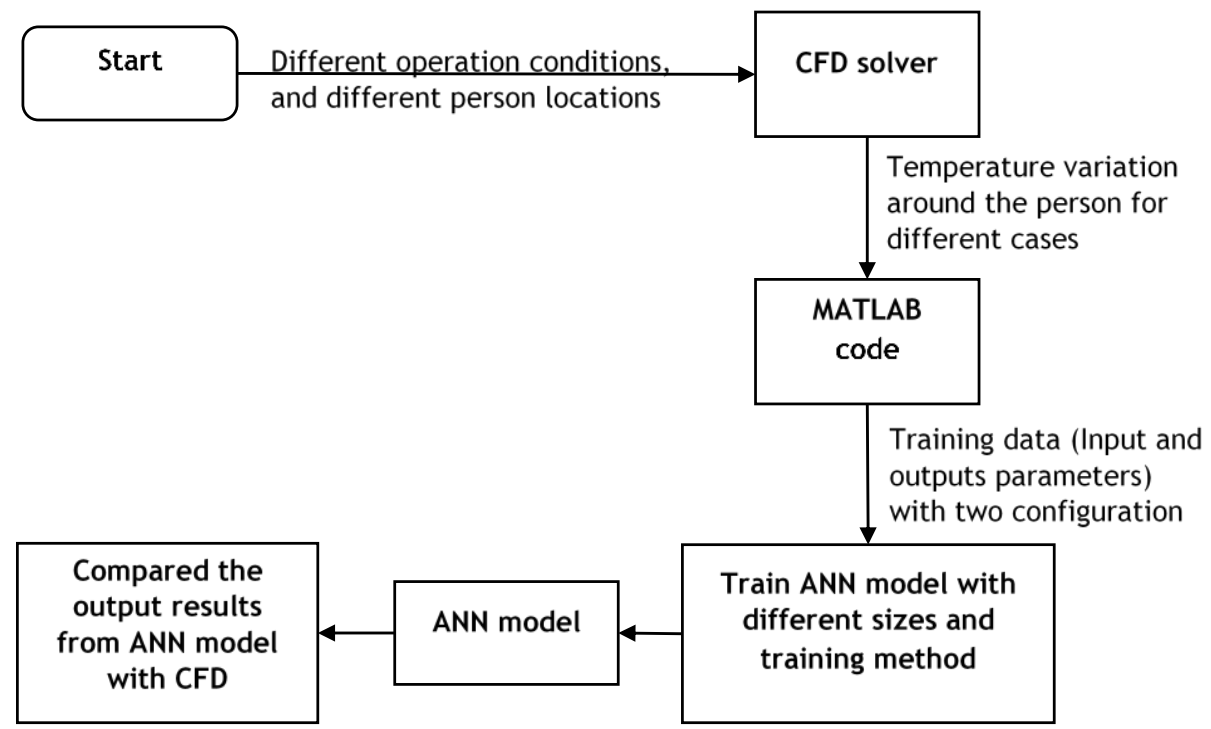

Figure 3.4. Flow chart shows the process steps for training the ANN. 


\subsection{Controlled space}

A $3 \mathrm{~m} \times 3 \mathrm{~m} \times 2.5 \mathrm{~m}$ room is constructed using ANSYS DesignModeler 15.0.

Figure 3.5 shows the 3D model of the room with a person standing at a different location inside the room. The center of the coordinate system is set at the center of the floor.

Figure 3.5 shows the person standing at different locations: (a) the person is standing at the center of the room, (b) the person is standing at $x=-1 \mathrm{~m}$ and $\mathrm{y}=-1 \mathrm{~m}$ from the center, (c) the person is standing at $\mathrm{x}=1 \mathrm{~m}$ and $\mathrm{y}=1 \mathrm{~m}$ from the center, and (d) the person is standing at $\mathrm{x}=-1 \mathrm{~m}$ and $\mathrm{y}=1 \mathrm{~m}$ from the center. The person is represented as a box instead of a full human body to reduce the computational time. The red arrow represents the inlet and the blue one represents the outlets. In the present study, "inlet" refers to the air inlet duct, which HVAC system uses to deliver air into the controlled space; and "outlet" refers to the air outlet duct, where air leaves the controlled space. The center of the outlet is at $(1.5 \mathrm{~m},-1.5 \mathrm{~m}, 0.2 \mathrm{~m})$ and the center of the inlet is at $(1.5 \mathrm{~m},-1.5 \mathrm{~m}$, $2.1 \mathrm{~m}$ ), respectively. This arrangement is chosen to prevent flow going directly from the inlet to the outlet without circulating in the room and that the outlet is near the stagnate zone to remove unwanted warm or cold air from the room. However, the inlet and the outlet layouts are not designed to optimize the HVAC system performance. The cross-sectional area of both the inlet and the outlet is $0.2 \times 0.4 \mathrm{~m}^{2}$. A locally controlled HVAC system uses the temperature in the desired location to control the HVAC. In the present study, the average temperature around the person in the room is used to control the HVAC by turning it ON or OFF. The average temperature is obtained based on a cell volume average of a spherical zone with a radius of $90 \mathrm{~cm}$ around the person (this radius covers an $180 \mathrm{~cm}$ tall person). The human body is set to be at a constant temperature of $37^{\circ} \mathrm{C}$. The outside temperature of the room is set to different temperatures $0^{\circ} \mathrm{C}$, $5^{\circ} \mathrm{C}, 10^{\circ} \mathrm{C}, 15^{\circ} \mathrm{C}, 20^{\circ} \mathrm{C}$. The walls of the room are assumed to be made of wood with a thermal conductivity of $0.173 \mathrm{~W} /(\mathrm{m} \mathrm{K})$ and thickness of $30 \mathrm{~cm}$. The top and the bottom walls of the room are assumed to be insulated. The inlet velocity and temperature are set to different values. 


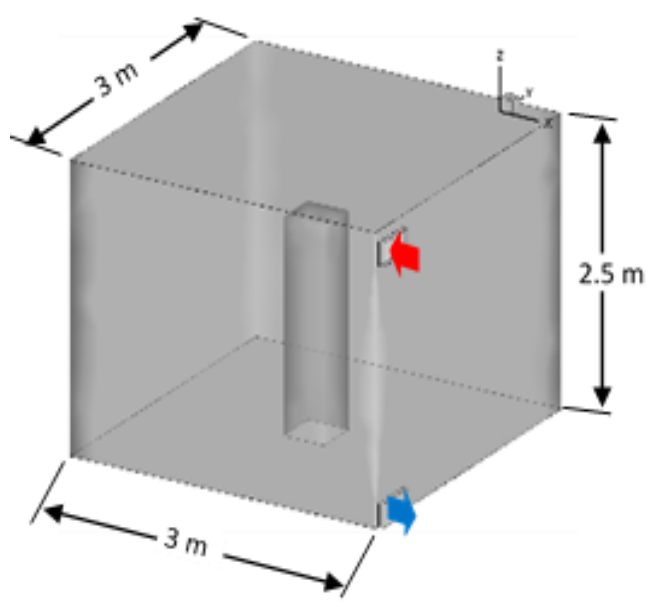

(a)

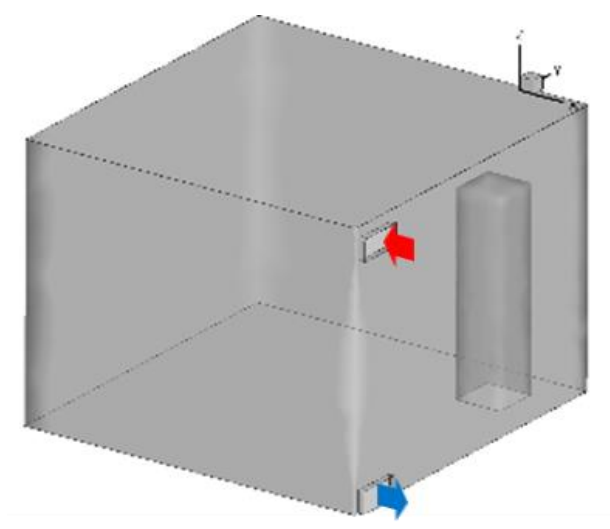

(C)

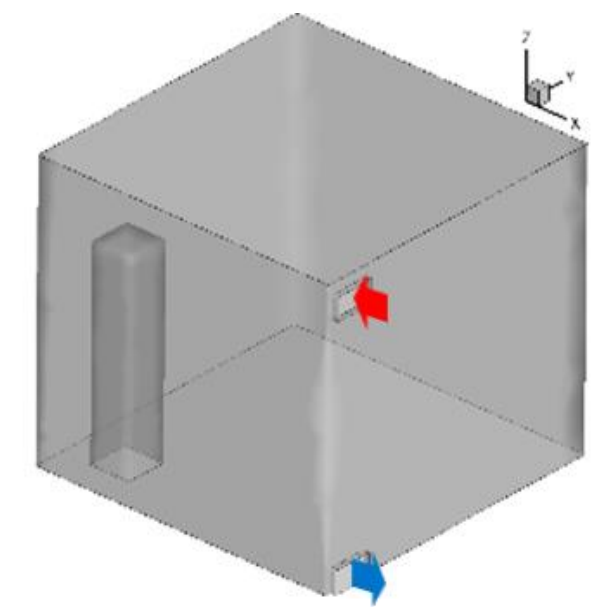

(b)

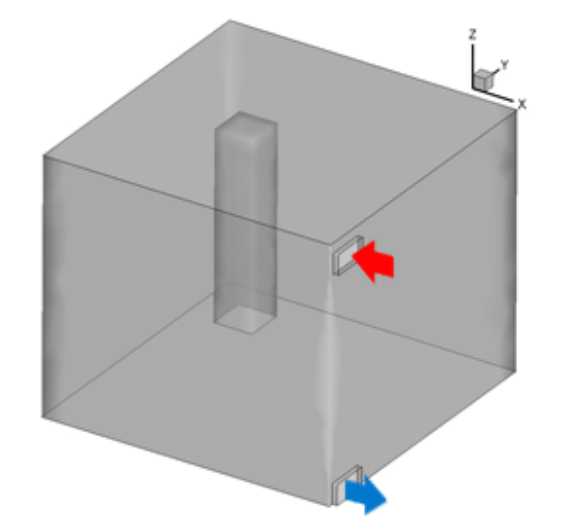

(d)

Figure 3.5. Configuration of heating HVAC system with person at different locations

\subsection{CFD simulation}

Advance Proximity and Curvature sizing algorithm are used to generate a grid with approximately 47,832 tetrahedral elements. Grid convergence index (GCI) is used to show grid refinement effect on the average temperatures around the person and around the conventional thermostat. Three different grid sizes are used $(244,417,92,257$, and 47,832$)$ to estimate the GCI index. The average temperature around the person is calculated for the three different meshes and 
for 60 seconds. The case which has been tested is when the person is in the middle of the room. The inlet air velocity is $0.2 \mathrm{~m} / \mathrm{s}$ and the inlet temperature is $30^{\circ} \mathrm{C}$. The outside temperature is $10^{\circ} \mathrm{C}$. The approximate relative error, extrapolated relative error, and the grid convergence are calculated and averaged over time as shown in Table 3.1. Sub/superscripts refer to the grid size starting from 1 as fine, 2 as a medium, and 3 as a coarse. All the equations which have been used to calculate GCI are shown in reference [80]. Based on the results, the coarse mesh is chosen because of its low GCI and to reduce time cost.

Table 3.1. Mesh refinery study

\begin{tabular}{|c|c|c|c|c|c|c|}
\hline \multirow{2}{*}{$\begin{array}{l}\text { Location of the } \\
\text { average temperature }\end{array}$} & \multicolumn{2}{|c|}{$\begin{array}{l}\text { Approximate } \\
\text { relative error }\end{array}$} & \multicolumn{2}{|c|}{$\begin{array}{l}\text { Extrapolated } \\
\text { relative error }\end{array}$} & \multicolumn{2}{|c|}{$\begin{array}{l}\text { The grid convergence } \\
\text { index }\end{array}$} \\
\hline & $e_{a}^{21} \%$ & $e_{a}^{32} \%$ & $e_{e x t}^{21} \%$ & $e_{e x t}^{32} \%$ & $G C I_{\text {fine }}^{21} \%$ & GCI $I_{\text {coarse }}^{32} \%$ \\
\hline Person & 0.0601 & 0.0708 & 0.3123 & 0.3474 & 0.3665 & 0.4096 \\
\hline
\end{tabular}

ANSYS FLUENT 15.0.7 is used as the CFD simulation platform. The simulation is performed on a DELL-XPS with eight $3.4 \mathrm{GHz}$ CPU and $32 \mathrm{~GB}$ of RAM. No slip and penetration conditions are imposed on the walls and the person's body. The outside wall temperature is assumed to remain constant and three different temperatures have been used zero degrees $\mathrm{C}, 5^{\circ} \mathrm{C}$, $10^{\circ} \mathrm{C}, 15^{\circ} \mathrm{C}$, and $20^{\circ} \mathrm{C}$. The floor and the ceiling of the room are insulated. The surface temperature of the human body is taken as $37^{\circ} \mathrm{C}$. Different HVAC fan settings are used to provide inlet air velocities. The turbulent intensity is assumed to be $5 \%$ at the inlet. The inlet flow temperature is set to different values between $25^{\circ} \mathrm{C}$ to $35^{\circ} \mathrm{C}$.

Chen [60] tested five different turbulent models in a ventilated space and found renormalization group $(\mathrm{RNG}) \kappa-\varepsilon$ model to be the best model since it counts for both high and low Reynolds numbers. Therefore, RNG $\kappa-\varepsilon$ model with standard wall functions for near wall treatment is used. Boussinesq approximation is used to simulate the buoyancy effect of the air with constant density coefficient of $1.225 \mathrm{~kg} / \mathrm{m}^{3}$ and a constant thermal expansion coefficient 0.0032 
$1 / \mathrm{k}$. In addition, under relaxation factors of 0.7 for pressure and 0.3 for momentum are used. The convergence residual magnitude for the continuity and the momentum are set to be $10^{-4}$, while residual of energy is $10^{-6}$. The time step is chosen based on the error convergence. Time step of 1 second and 100 max iteration per time step is found sufficient to reach the above desirable residual error for the whole 1 hour. The code has been validate on previous work (refers to [80]). Therefore, there is no attempted to show the validation again in this paper.

\subsection{Training data generated by CFD}

The CFD model is used to generate a number of training data for ANN model and to estimate the operation time of the HVAC system for the controlled space. The operation time of the heating HVAC system is estimated for a person at four different locations with different inlet velocities and inlet temperature, and outside temperature ${ }^{13}$. Different outside temperatures are tested: $0{ }^{\circ} \mathrm{C}, 5^{\circ} \mathrm{C}, 10^{\circ} \mathrm{C}, 15^{\circ} \mathrm{C}$, and $20^{\circ} \mathrm{C}$. For each outside temperature 3 different inlets speed are used: $0.2 \mathrm{~m} / \mathrm{s}, 1 \mathrm{~m} / \mathrm{s}, 2 \mathrm{~m} / \mathrm{s}$. For each outside temperature and inlet speed, 3 different inlet temperature are used: $25^{\circ} \mathrm{C}, 30^{\circ} \mathrm{C}, 35^{\circ} \mathrm{C}$. In the table, the rate of temperature change $\left(\mathrm{T}_{\text {Rate }}\right)$ is the rate of temperature change around the person from the start of heating until the average temperature reaches the maximum temperature $\left({ }^{\circ} \mathrm{C} /\right.$ minute) OFF is the average OFF time of the HVAC system in minutes. ON is the average ON time for the HVAC system in minutes. Maximum temperature $\left(\mathrm{T}_{\max }\right)$ is the maximum reached an average temperature around the person during the one hour in $\left({ }^{\circ} \mathrm{C}\right)$. Figure 3.2, clarifies those parameters. Those parameters are arranged in two ways to simulate the two configurations mentioned above Figure 3.3.

\subsection{ANN training and testing}

The training data are shuffled and randomly divided into two groups: $90 \%$ percentage of the training data are used for training purpose, and the rest, 10\%, are used for testing, which

13 Appendix C. Operation conditions of the HVAC system for the controlled space. 
reduces overfitting/under fitting. In addition, three totally different test cases are generated to check the percentage of error that trained model will have when introduced to new situations. The three cases are shown in Table 3.2. In the first case, only the operation conditions and outside condition are changed. In the second case, the location of the person is changed. In the third case, both the operation conditions and person location are changed. Different ANN model sizes are tested. The choice of size is based on the minimum regression error, the maximum number of effective parameters (gmak), and the minimum error with the three test cases. The training model is considered to reach convergence when a mean square error (mse) and the number of effective parameters are stabilized over certain iteration. Figure 3.6, shows ANN model with 3 hidden layers and one output layer. Each hidden layer has 10 nodes and the output layer has 4 nodes. The inputs, in this case, are 5 parameters. The input and output have been mapped to range between [-1, 1], which gives faster convergence, and then the outputs mapped back. For all ANN model, the transformation function of the hidden layer is a sigmoid transfer function and for the output layer is a linear transfer function, which is recommended by MATLAB for regression purpose. Three different training algorithms are tested: Levenberg-Marquardt, Bayesian Regularization, and Scaled Conjugate Gradient. The reason for chosen those algorithms is because they are recommended by MATLAB for regression purpose. In the next section, results and discussion only the results of the best size, and training algorithm will be shown.

Table 3.2 Three test cases

\begin{tabular}{cccccc}
\hline Case & $\mathbf{V}_{\text {in }}(\mathbf{m} / \mathbf{s})$ & $\mathbf{T}_{\text {in }}\left({ }^{\mathbf{0}} \mathbf{C}\right)$ & $\mathbf{T}_{\mathbf{o}}\left({ }^{\mathbf{0}} \mathbf{C}\right)$ & $\mathbf{X}(\mathbf{m})$ & $\mathbf{Y}(\mathbf{m})$ \\
\hline $\mathbf{1}$ & 0.7 & 28 & 13 & -1 & -1 \\
\hline $\mathbf{2}$ & 1 & 30 & 10 & 0 & 1 \\
\hline $\mathbf{3}$ & 1.2 & 32 & 6 & 0 & 1 \\
\hline
\end{tabular}




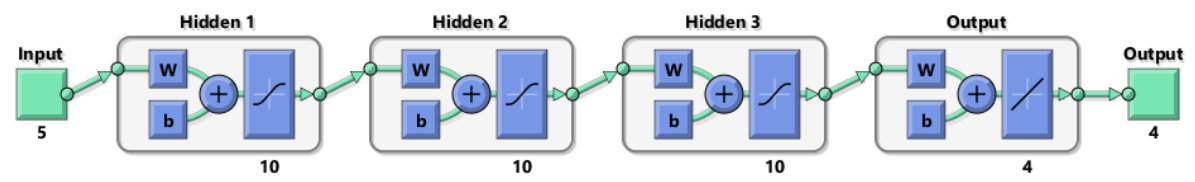

Figure 3.6. ANN model with 3 hidden layers and one output layer.

\subsection{Results and discussion}

Figure 3.7 shows temperature variation inside controlled space when outside temperature is $20{ }^{\circ} \mathrm{C}$ and inlet velocity $0.2 \mathrm{~m} / \mathrm{s}$ and inlet temperature is $30^{\circ} \mathrm{C}$. Each location shows contour plots of temperature in two vertical slices around the person captured at three different times (100 seconds, 1800 seconds, and 3600 seconds). The figure shows clearly how temperature distribution is different at different locations.

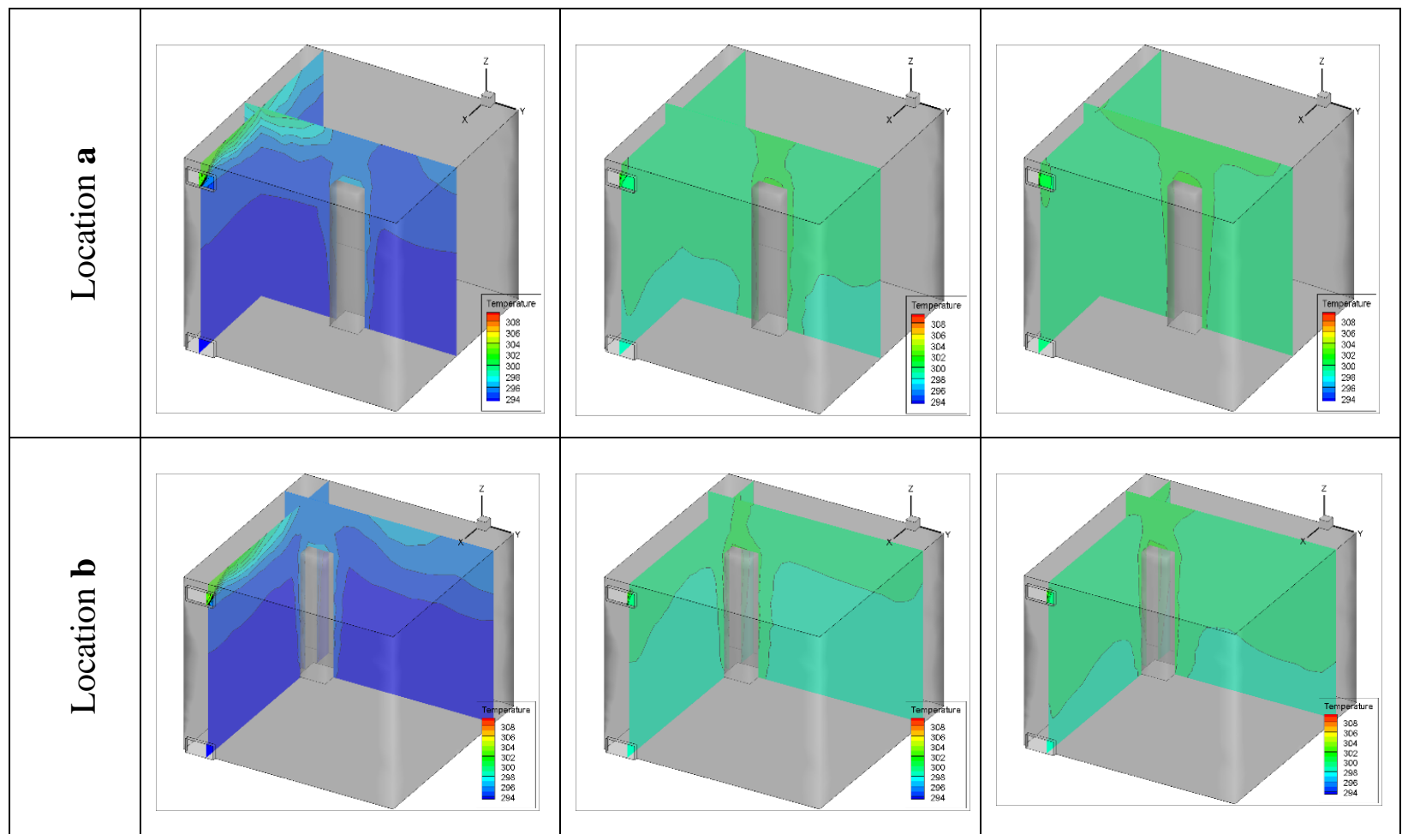






Figure 3.7 Temperature variation inside controlled space when outside temperature is 20

${ }^{\circ} \mathrm{C}$ and inlet velocity $0.2 \mathrm{~m} / \mathrm{s}$ and inlet temperature is $30{ }^{\circ} \mathrm{C}$.

The first training data are made from 120 cases where the outside temperature was changed $0{ }^{\circ} \mathrm{C}, 10^{\circ} \mathrm{C}$, and $20^{\circ} \mathrm{C}$. However, $10^{\circ} \mathrm{C}$ difference is found to be not sufficient to have a good prediction. Therefore, the temperature difference is reduced to $5{ }^{\circ} \mathrm{C}$, and the outside temperatures tested are $0{ }^{\circ} \mathrm{C}, 5{ }^{\circ} \mathrm{C}, 10^{\circ} \mathrm{C}, 15^{\circ} \mathrm{C}, 20^{\circ} \mathrm{C}$. Adding those outside temperatures led to 194 cases instead of 120 cases increased the prediction accuracy.

\subsubsection{First configuration}

The first configuration is referred to the configuration shown in Figure 3.3 (a). In this configuration, the input parameters are the operation condition and person location. Different ANN model size and training algorithms are tested. The best training algorithm has been found to be Bayesian Regularization. The best size has been found to be 3 hidden layers and one output layer as shown in Figure 3.6. Each layer has 10 nodes except for the output that has 4. For training, 175 cases out of 194 cases have been selected randomly and the rest are used for testing, as shown in 
Figure 3.8. The ANN output in the figure refers to the ANN model output and CFD output refers to the results from the CFD model. The closer the $\mathrm{R}$ (correlation coefficient ${ }^{14}$ ) value to 1 the better prediction are. The training shows $R$ value of 0.999989 and test $R$ value of 0.99213 which are a good prediction. The training performance is showed in Figure 3.9 (a).
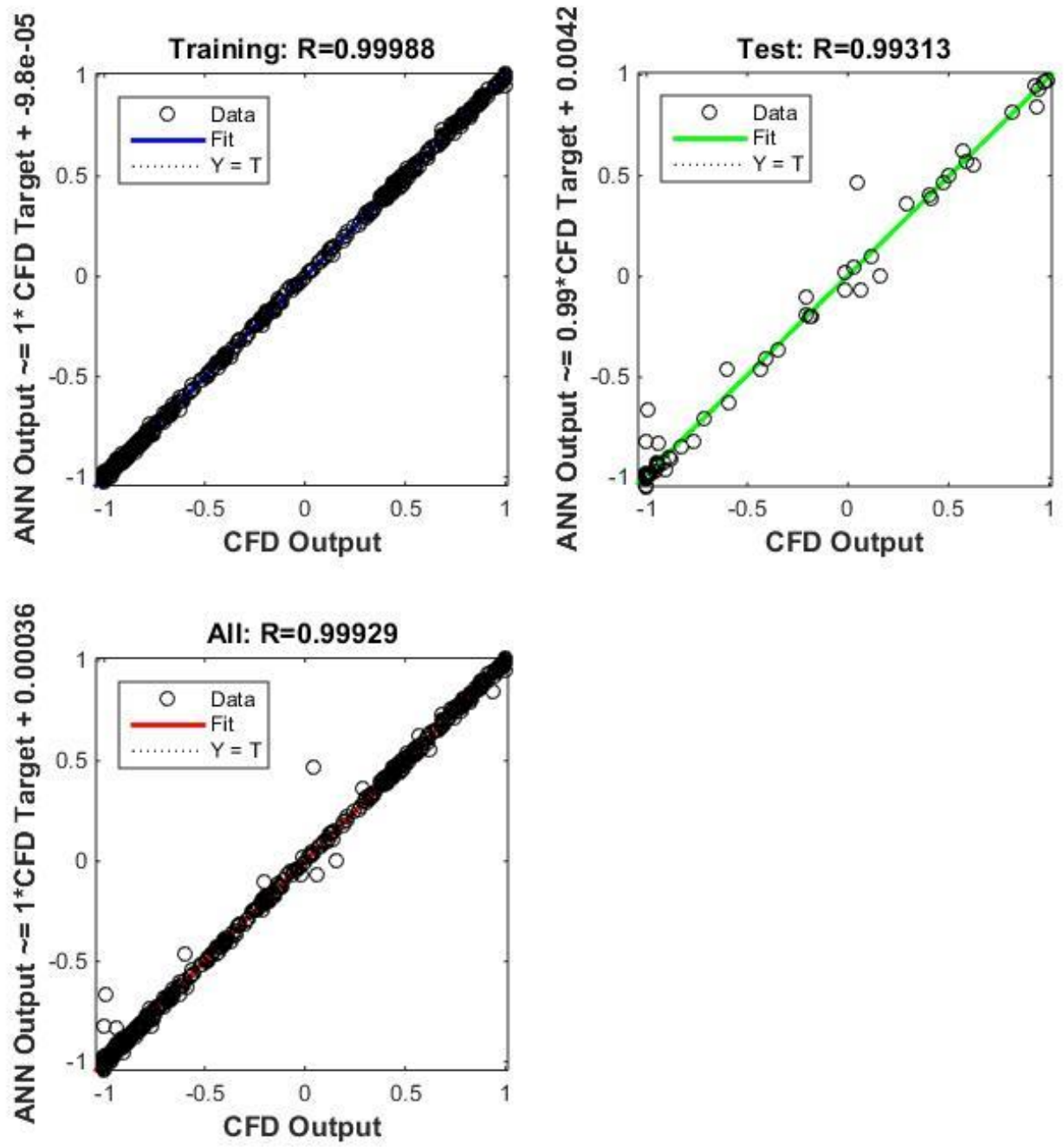

Figure 3.8. Regression of the training and testing

${ }^{14} R=\frac{\sum_{m} \sum_{n}\left(A_{m n}-\bar{A}\right)\left(B_{m n}-\bar{B}\right)}{\sqrt{\left(\sum_{m} \sum_{n}\left(A_{m n}-\bar{A}\right)^{2}\right)\left(\sum_{m} \sum_{n}\left(B_{m n}-\bar{B}\right)^{2}\right)}}$ Where A and B are two matrices, $\bar{A}$ and $\bar{B}$ are the means. 
The best training performance reached a value of $10^{-4}$ at epoch 1420 while test performance reached $10^{-2}$. The training status is shown in Figure 3.9 (b). The training stopped when the mse, number of effective parameters, and gradient are stabilized at $10^{-4}, 316.3$, and $1.05 \times 10^{-05}$ respectively. The model is further tested with the cases shown in Table 3.2. The results and comparison are shown in Table 3.3. ANN prediction error $\triangle E=C F D-A N N$ while the error percentage is calculated by $\frac{(A N N-C F D)}{C F D} \times 100$. The ANN model results are close to the expected values from CFD calculation. Figure 3.10 shows ANN prediction error of the first input configuration for the 3 test cases. The highest error is for predicting the average OFF time which range from 0.06 to -0.46 minutes. In the first case the OFF time is over estimated the average OFF time while for the other two cases the average OFF times are under estimated. The second highest error is for predicting the average temperature rate of change which range from 0.02 to 0.07 ${ }^{\circ} \mathrm{C} / \mathrm{min}$. In the second case the average temperature rate of change is over estimated while under estimate for the other two cases. The prediction error for the $\mathrm{ON}$ time ranges between 0.033 to 0.8 minutes. The error in predicting the maximum temperature ranges between 0.02 to $0.09{ }^{\circ} \mathrm{C}$.

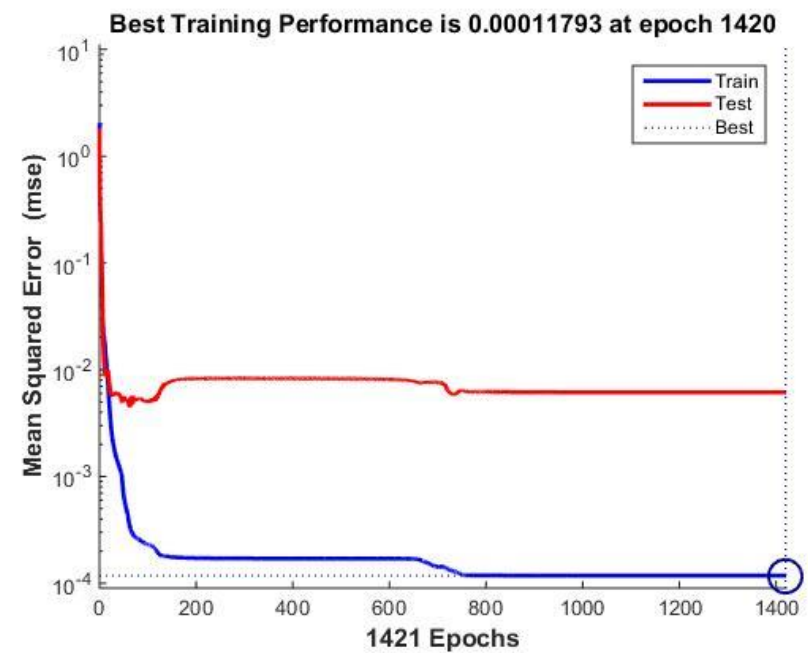

(a) Training performance
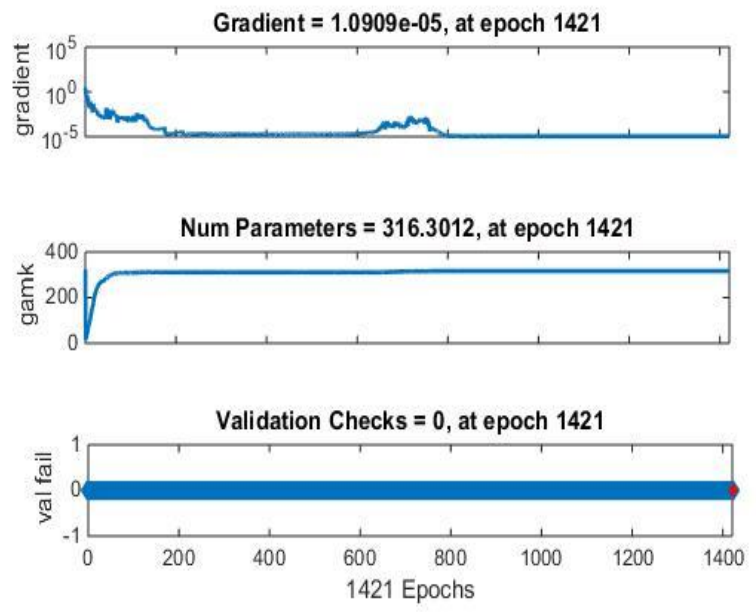

(b) Training status

Figure 3.9. Training performance and status 


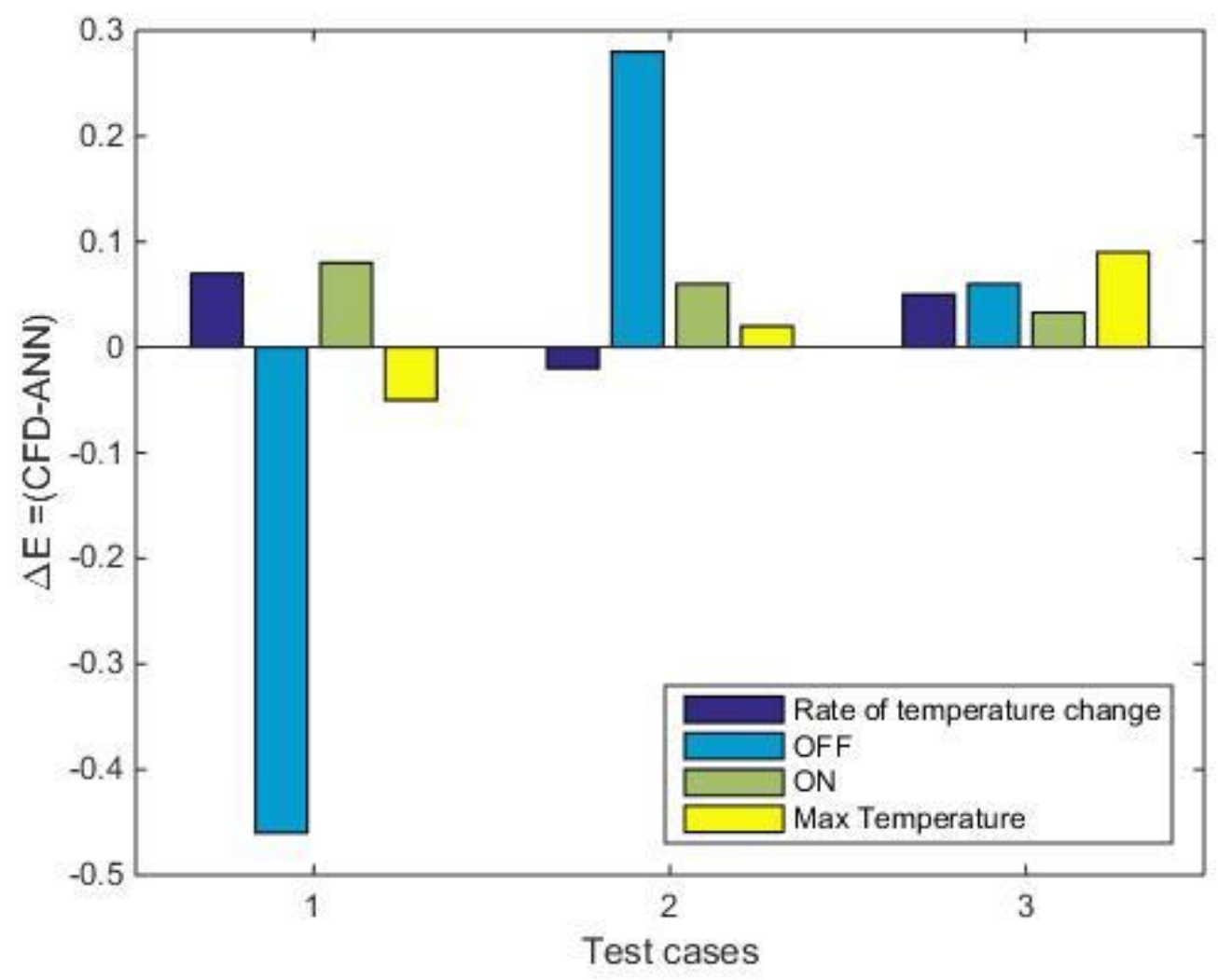

Figure 3.10 ANN prediction error of the first input configuration for the 3 test cases 
Table 3.3. Comparison between the ANN and CFD for the three test cases

\begin{tabular}{|c|c|c|c|c|c|c|c|c|c|c|c|c|}
\hline & \multicolumn{4}{|c|}{ Test1 } & \multicolumn{4}{|c|}{ Test2 } & \multicolumn{4}{|c|}{ Test3 } \\
\hline & $T_{\text {Rate }}$ & OFF & ON & $\mathbf{T}_{\max }$ & TRate & OFF & ON & $\mathbf{T}_{\max }$ & TRate & OFF & ON & $\mathbf{T}_{\max }$ \\
\hline & ${ }^{\circ} \mathrm{C} / \mathrm{min}$ & $\min$ & $\min$ & ${ }^{\circ} \mathrm{C}$ & ${ }^{\circ} \mathrm{C} / \mathrm{min}$ & $\min$ & $\min$ & ${ }^{\circ} \mathrm{C}$ & ${ }^{\circ} \mathrm{C} / \mathrm{min}$ & $\min$ & $\min$ & ${ }^{\circ} \mathrm{C}$ \\
\hline CFD & 1.02 & 7.6 & 2.11 & 25.01 & 1.81 & 6.33 & 1.35 & 25.21 & 2.47 & 4.71 & 0.983 & 25.34 \\
\hline $\mathbf{A N N}$ & 1.07 & 8.06 & 2.03 & 25.06 & 1.83 & 6.05 & 1.29 & 25.19 & 2.42 & 4.65 & 0.95 & 25.25 \\
\hline$\Delta \mathbf{E}$ & 0.07 & -0.46 & 0.08 & -0.05 & -0.02 & 0.28 & 0.06 & 0.02 & 0.05 & 0.06 & 0.033 & 0.09 \\
\hline Error \% & 6.86 & 6.05 & 3.79 & 0.2 & 1.92 & 4.42 & 4.44 & 0.079 & 2.33 & 1.27 & 3.36 & 0.33 \\
\hline
\end{tabular}




\subsubsection{Second configuration}

In this case, the user specifies the rate of temperature change and the system provides the inlet conditions to satisfy the user input constraints, see Figure 3.3 (b). Different ANN model size and training algorithms are tested. The best training algorithm has been found to be Bayesian Regularization. The best size has been found to be 3 hidden layers and one output layer, see Figure 3.11. The first hidden and third layers have 10 nodes on each of them, the second hidden layer has 15 , and the output layer has 5 . However, because there are many ways to satisfy the same rate of temperature change, it is difficult to train the ANN model with high prediction capability. The results of the best prediction model of this configuration are shown in Figure 3.12 and the training and test performance are shown in Figure 3.13.The R value of testing regression is around 0.67 , which is lower than recommended value by MATLAB $R \geq 0.98$. The mse value for the training is $10^{-2}$ and for the testing it reached $10^{-1}$. Those value are not very good.



Figure 3.11. ANN model for the second configuration 

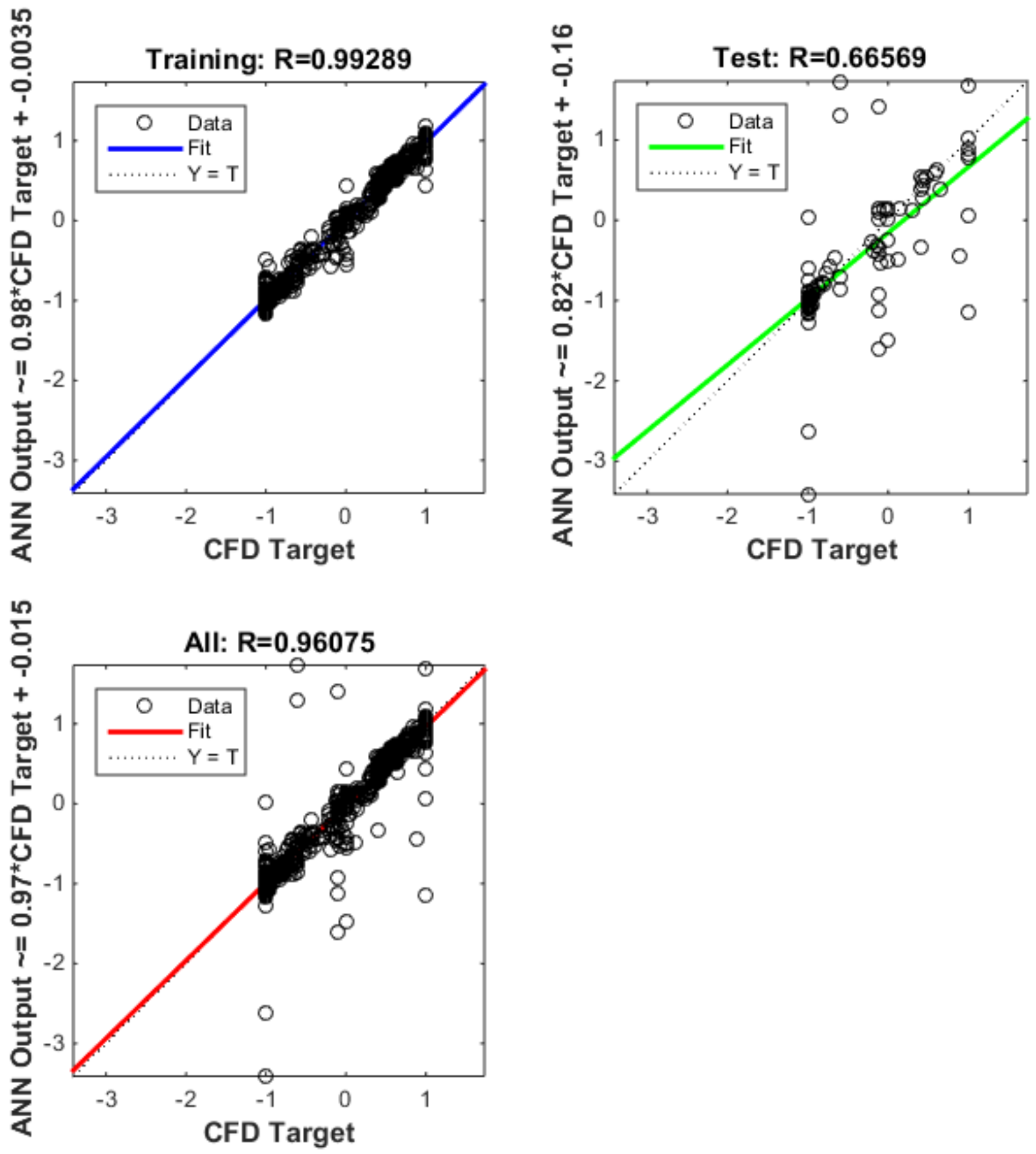

Figure 3.12. Regression results of second ANN configuration 


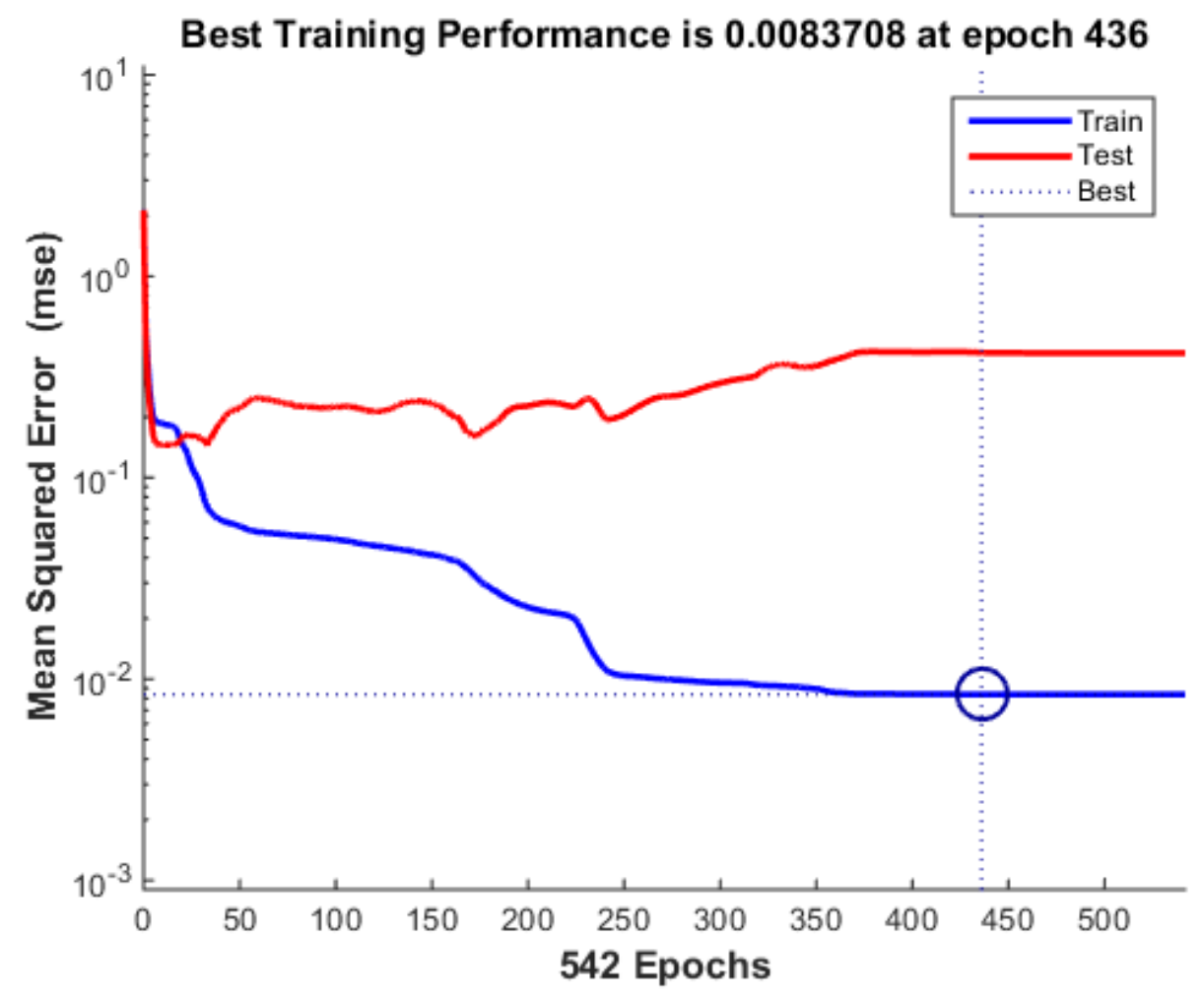

Figure 3.13. Training and test performance

\subsection{Summary and conclusion}

A CFD-based virtual thermostat for local temperature control can reduce energy consumption by $22 \%$. However, the CFD calculations, based on the current computational powers, take relatively long times and are not practical for an instantaneous temperature control. This paper presents test results on an alternative method, which uses ANN to replace the CFD calculations after an initial training period. The training data are generated by 194 CFD simulations for different operation conditions of HVAC system for a room with a person standing at different locations in the room. The best ANN training algorithm is found to be Bayesian Regularization algorithm. The best ANN model size is with 3 hidden layers and one output layer. Two different input configuration have been tested. For the first input configuration, the best ANN size is $10 \times 10 \times 10 \times 4$ neurons. The maximum error of ANN 
prediction in the first input configuration is less than $7 \%$ of the three test cases, which corresponds to around $0.07^{\circ} \mathrm{C} / \mathrm{min}$ prediction error of the average rate of temperature change. The $\mathrm{R}$ value is above 0.99 for the training and test cases. However, for the second input configuration, the ANN model failed to predict the right value due to the number of possible ways a single condition can be satisfied. ANN model reduced the time required for the realtime control from 24 hours to few seconds. The 194 cases are conducted in around 3 months period, which means the system needs to run for at least 3 months to gather enough data for an accurate prediction by ANN model. The system gets more accurate as more training data is added. 


\section{Chapter 4 The effect of person location inside the controlled space on energy consumption with a local temperature control}

\subsection{Introduction}

In this chapter, we analyze the generated data which have been used for training the ANN model in the previous chapter. The energy required to keep the person comfortable in different locations have been compared with the energy required to keep the same person in the middle location at the same boundary conditions. Four different locations have been analyzed. The locations are labeled as $\mathbf{a}, \mathbf{b}, \mathbf{c}$, and $\mathbf{d}$ as shown in Figure 4.1. Location $\mathbf{a}$ is when the person standing in the middle, location $\mathbf{b}$ is when the person standing next to the inlet, location $\mathbf{c}$ is when the person is standing at the corner beside the inlet, and location $\mathbf{d}$ is when the person standing at the corner diagonally beside the inlet. The room size is $3 \mathrm{~m} \times 3 \mathrm{~m} \times 2.5 \mathrm{~m}$. The red arrow is the inlet and blue arrow is the outlet. Different inlet velocity, inlet temperature, and outside temperature is used. The system is controlled based on the local average temperature around the person. Therefore, when the average temperature around the person reaches $25^{\circ} \mathrm{C}$, the system turns OFF and turn $\mathrm{ON}$ when the average temperature goes below $24{ }^{\circ} \mathrm{C}$.

\subsection{Energy analysis}

The percentage of energy difference is calculated by comparing the required time to heat and maintain a person standing in middle to the comfort range with required time to heat and maintain a person standing at other different locations with the same boundary conditions:

$$
\frac{\left(t_{\text {person in middle }}-t_{\text {person in other location }}\right)}{t_{\text {person in middle }}} \times 100
$$

The percentage of energy difference is calculated and plotted for different boundary conditions as shown in the figures in the appendix ${ }^{15}$. Each plot shows energy percentage for the three different location locations (b, c, and $\mathbf{d}$ ) compared with location a (middle). The negative

\footnotetext{
15 Appendix D. Energy difference percentage based on person location
} 
Chapter 4. The effect of person location inside the controlled space on energy consumption with a local temperature control

percentage means that the person on the other locations requires more energy to reach the comfort range compared with middle location. On the other hand, the positive percentage means that the person in the other locations requires less energy to reach the comfort range compared with the middle location, such as Figure 4.2. All the cases have been categorized into three categories as shown in Table 4.1. The first category is positive energy difference, the second category is negative energy difference, and the last category is mixed between negative and positive energy difference.



(a)

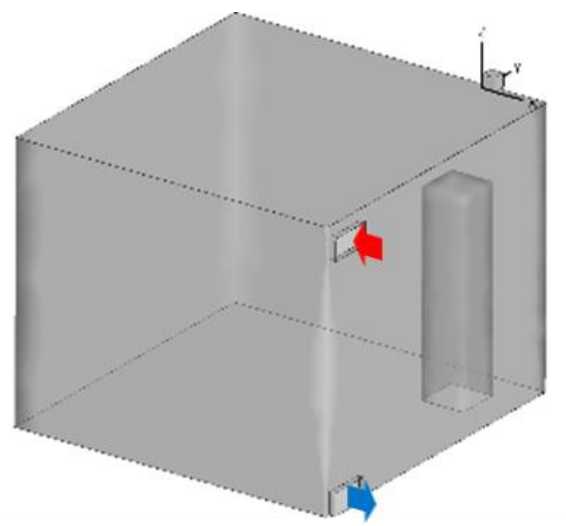

(C)

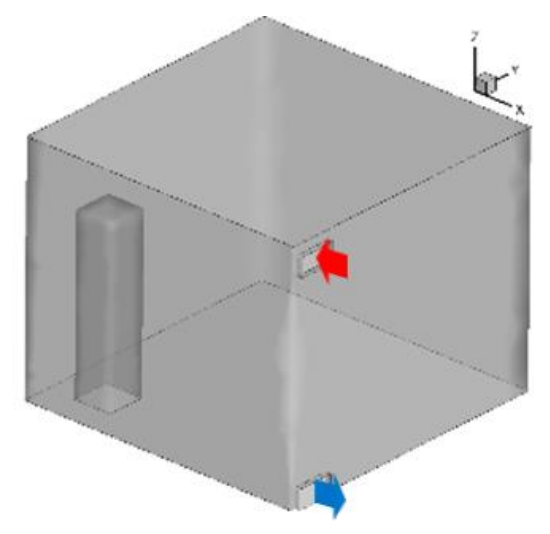

(b)

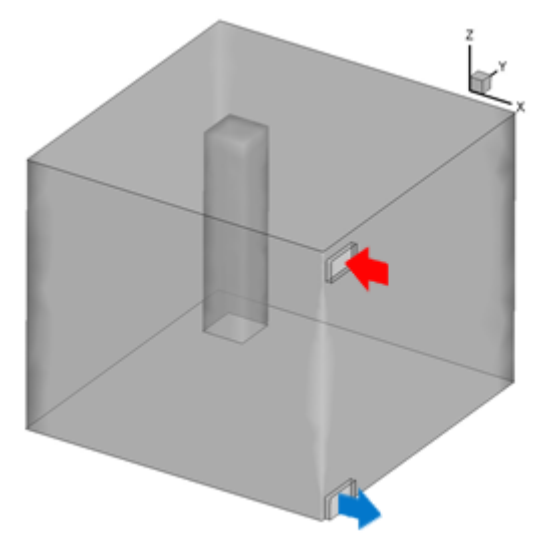

d)

Figure 4.1 room configuration and person locations 
Chapter 4. The effect of person location inside the controlled space on energy consumption with a local temperature control

Table 4.1 The effect of person location on energy with respect to the person location at the center of the room based on equation 12

\begin{tabular}{|c|c|c|c|c|c|c|c|c|}
\hline \multicolumn{3}{|c|}{ Positive energy difference } & \multicolumn{3}{|c|}{ Negative energy difference } & \multicolumn{3}{|c|}{ Mixed energy difference } \\
\hline $\begin{array}{c}V_{\text {in }} \\
(\mathrm{m} / \mathrm{s})\end{array}$ & $\begin{array}{l}\text { Tine }_{\text {in }} \\
\left({ }^{\circ} \mathrm{C}\right)\end{array}$ & $\begin{array}{l}\mathbf{T}_{\text {out }} \\
\left({ }^{\circ} \mathbf{C}\right)\end{array}$ & $\begin{array}{c}V_{\text {in }} \\
(\mathbf{m} / \mathbf{s})\end{array}$ & $\begin{array}{c}\mathbf{T}_{\text {in }} \\
\left({ }^{\circ} \mathrm{C}\right)\end{array}$ & $\begin{array}{l}\mathbf{T}_{\text {out }} \\
\left({ }^{\circ} \mathbf{C}\right)\end{array}$ & $\begin{array}{c}V_{\text {in }} \\
(\mathbf{m} / \mathbf{s})\end{array}$ & $\begin{array}{c}\mathrm{T}_{\text {in }} \\
\left({ }^{\circ} \mathrm{C}\right)\end{array}$ & $\begin{array}{l}\mathbf{T}_{\text {out }} \\
\left({ }^{\circ} \mathrm{C}\right)\end{array}$ \\
\hline 0.2 & 35 & 5 & 0.2 & 35 & 20 & 1 & 35 & 15 \\
\hline 1 & 35 & 20 & 0.2 & 35 & 15 & 1 & 35 & 10 \\
\hline 1 & 30 & 20 & 0.2 & 30 & 20 & 1 & 30 & 0 \\
\hline 2 & 35 & 20 & 0.2 & 30 & 15 & 1 & 25 & 20 \\
\hline 2 & 35 & 15 & 1 & 35 & 5 & 2 & 30 & 15 \\
\hline 2 & 35 & 5 & 1 & 30 & 15 & 2 & 25 & 15 \\
\hline 2 & 35 & 0 & 1 & 35 & 0 & & & \\
\hline 2 & 35 & 10 & 1 & 30 & 10 & & & \\
\hline 2 & 30 & 20 & 1 & 30 & 5 & & & \\
\hline 2 & 30 & 10 & 1 & 25 & 15 & & & \\
\hline 2 & 30 & 5 & & & & & & \\
\hline 2 & 25 & 20 & & & & & & \\
\hline 2 & 30 & 5 & & & & & & \\
\hline
\end{tabular}


Chapter 4. The effect of person location inside the controlled space on energy consumption with a local temperature control

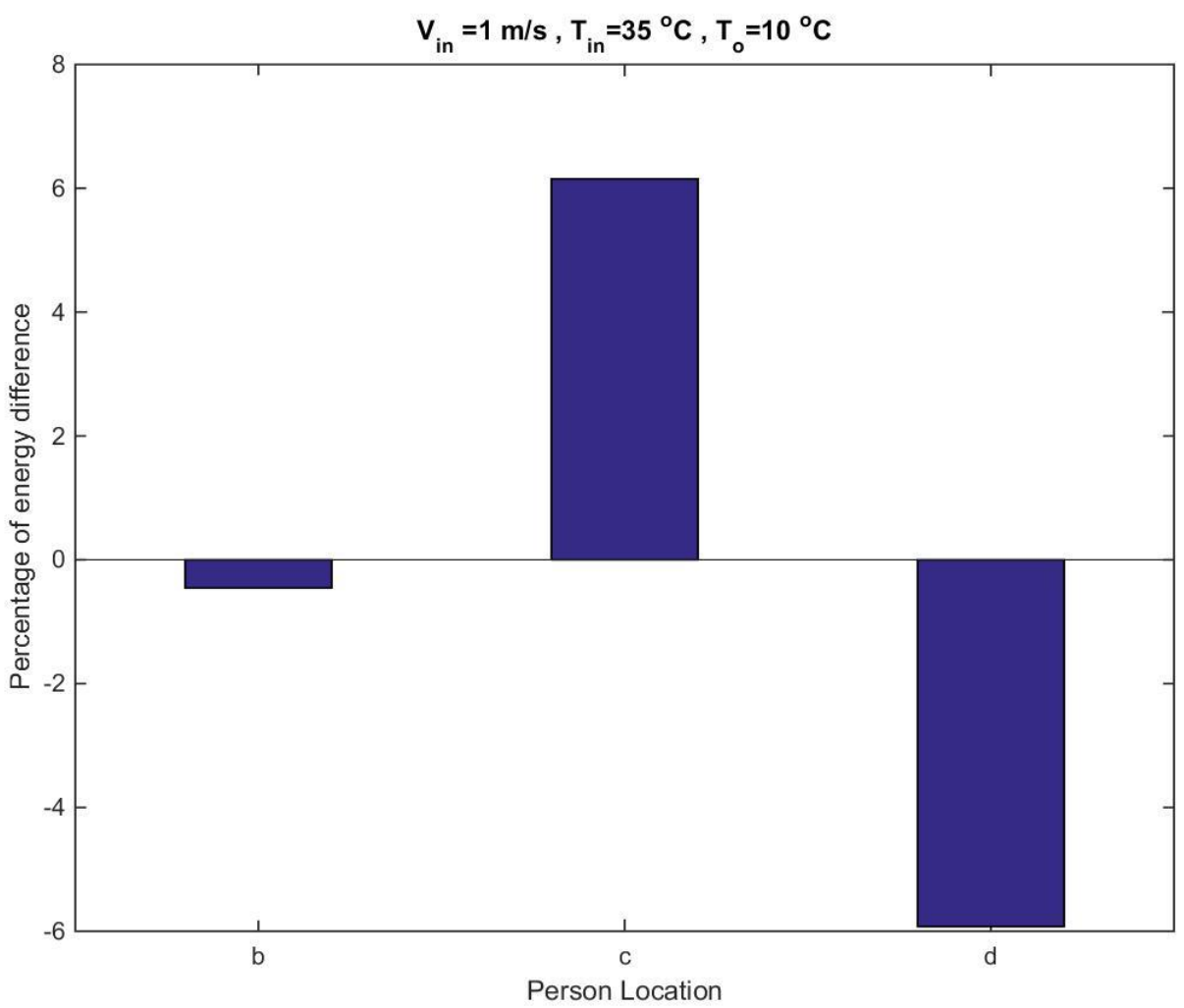

Figure 4.2 Energy difference percentage of different location compared with middle location with inlet velocity $=1 \mathrm{~m} / \mathrm{s}$, inlet temperature $=35^{\circ} \mathrm{C}$, and outside temperature $=10{ }^{\circ} \mathrm{C}$

The empty figures mean the system run for the entire hour for all location without turning OFF which mean there is not any energy difference between the locations Figure 4.3. The reason is because of the heat losses from the walls greater than the heat gain by the system. Therefore, the system did not reach $25^{\circ} \mathrm{C}$ and run for the entire hour. For example, when the inlet velocity 0.2 $\mathrm{m} / \mathrm{s}$, inlet temperature $27^{\circ} \mathrm{C}$, and outside temperature is zero degree Celsius, the iso-surface of warm air of two temperature values $24^{\circ} \mathrm{C}$ and $25^{\circ} \mathrm{C}$ reach maximum half of the upper corner of the room as an hour passed (see Figure 4.4). 
Chapter 4. The effect of person location inside the controlled space on energy consumption with a local temperature control

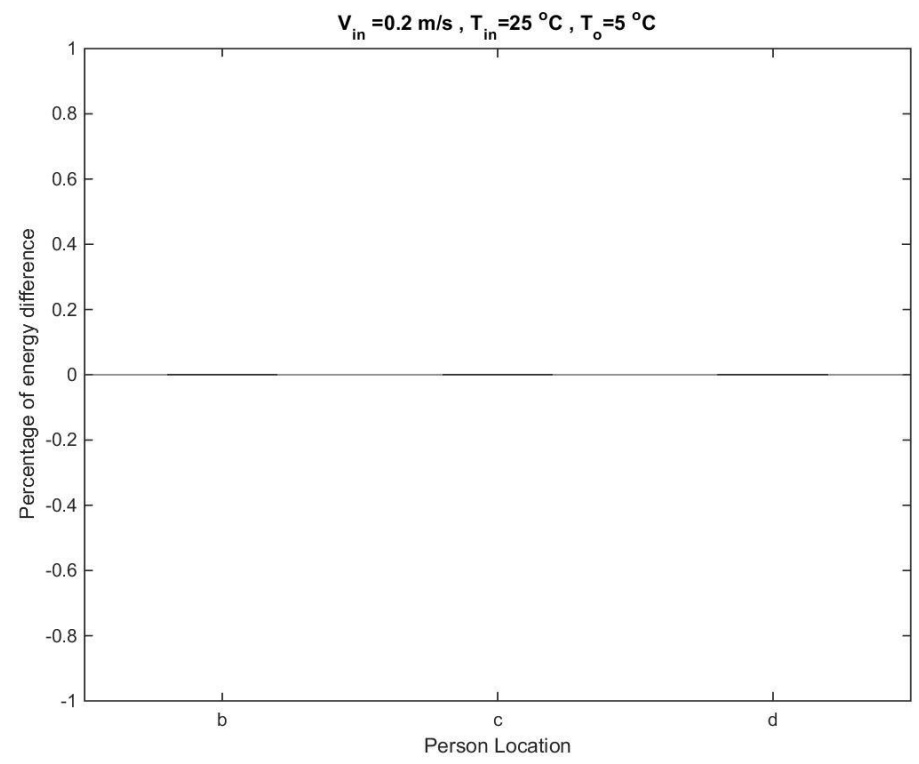

Figure 4.3 Energy difference percentage of different location compared with middle location with inlet velocity $=0.2 \mathrm{~m} / \mathrm{s}$, inlet temperature $=25^{\circ} \mathrm{C}$, and outside temperature $=5$ ${ }^{\circ} \mathrm{C}$

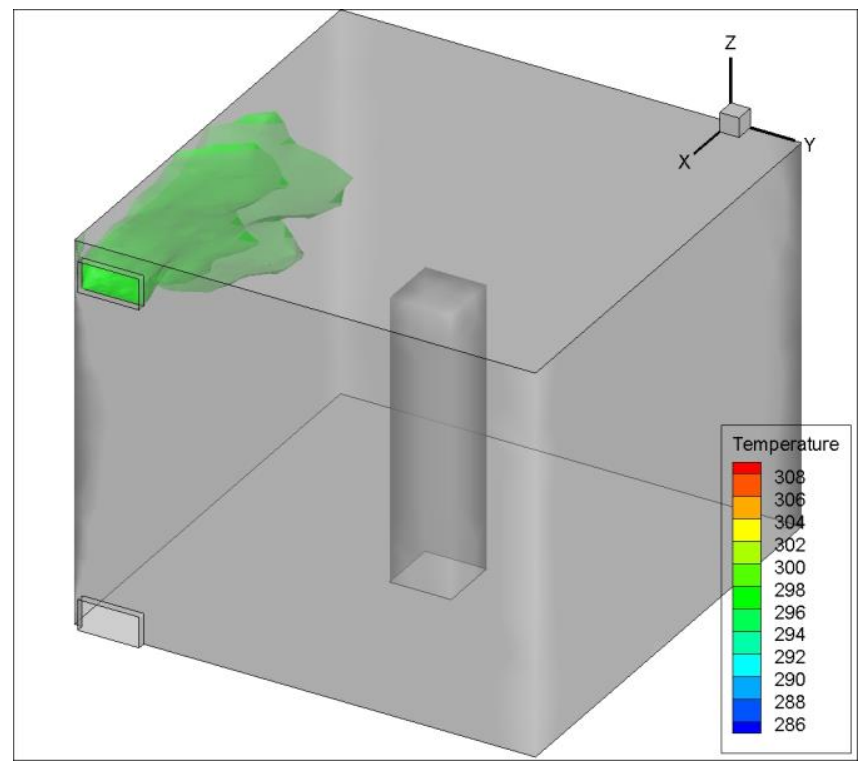

Figure 4.4 iso-surface of two temperature value $24^{\circ} \mathrm{C}$ and $25^{\circ} \mathrm{C}$ for a room with person standing in the middle, inlet velocity $0.2 \mathrm{~m} / \mathrm{s}$, inlet temperature $27^{\circ} \mathrm{C}$, and outside temperature zero degree Celsius 
Chapter 4. The effect of person location inside the controlled space on energy consumption with a local temperature control

The highest energy differences compared with the middle location, for all the test cases, are when the outside temperature is $15^{\circ} \mathrm{C}$. For example, in case of $V_{\text {in }}=1 \mathrm{~m} / \mathrm{s}, T_{\text {in }}=25^{\circ} \mathrm{C}$, and $T_{o}=15^{\circ} \mathrm{C}$ the person at location $\mathbf{c}$, standing at the corner beside the inlet, consume noticeable amount of energy in compared when the person standing on the other two locations (Figure 4.5). By looking at the temperature variation around the person at different locations as shown in Figure 4.6. The figure shows that when the person at location $\mathbf{c}$, the system run for the entire hour because the maximum average temperature around the person is $24.9^{\circ} \mathrm{C}$.

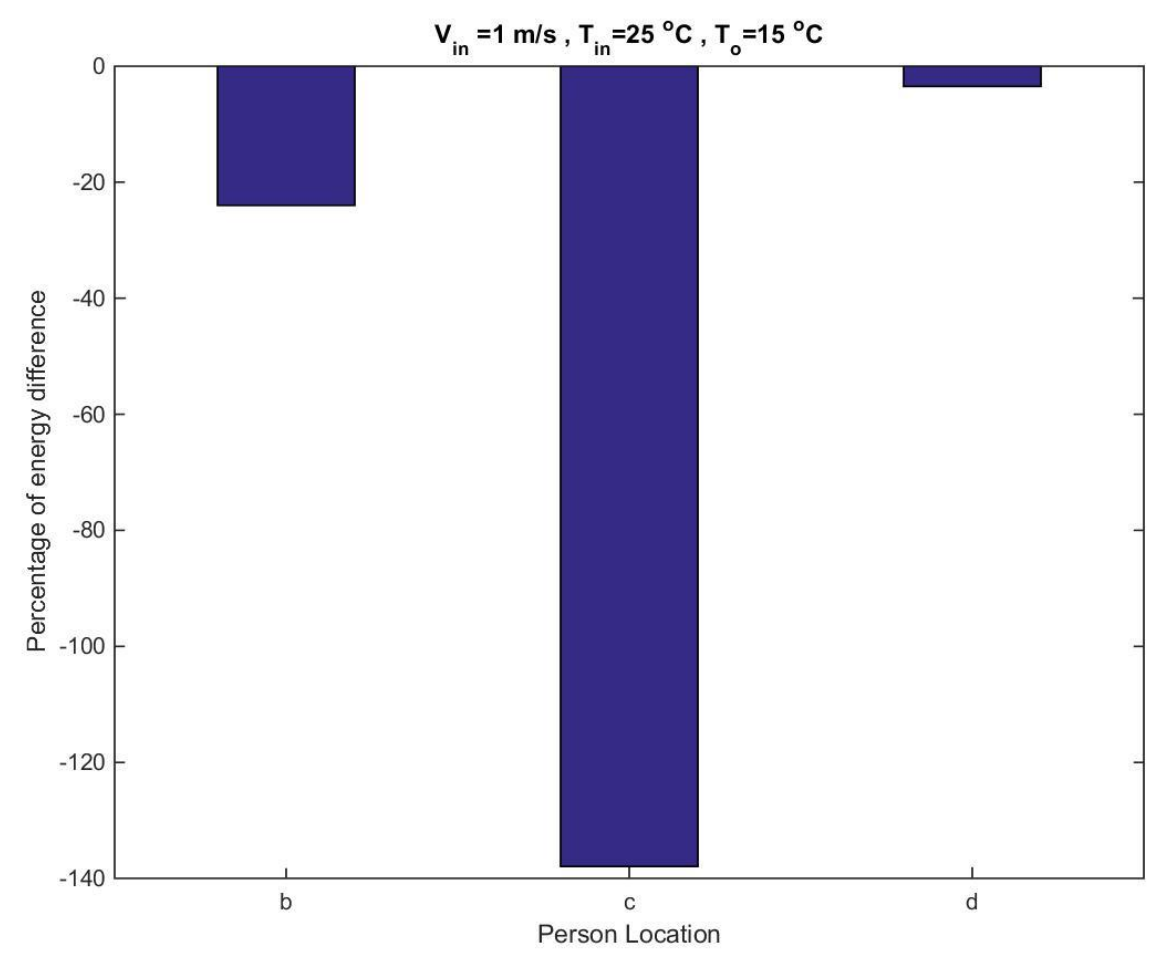

Figure 4.5 Energy difference percentage of different location compared with middle location with inlet velocity $=1 \mathrm{~m} / \mathrm{s}$, inlet temperature $=25^{\circ} \mathrm{C}$, and outside temperature $=15$ ${ }^{\circ} \mathrm{C}$ 
Chapter 4. The effect of person location inside the controlled space on energy consumption with a local temperature control

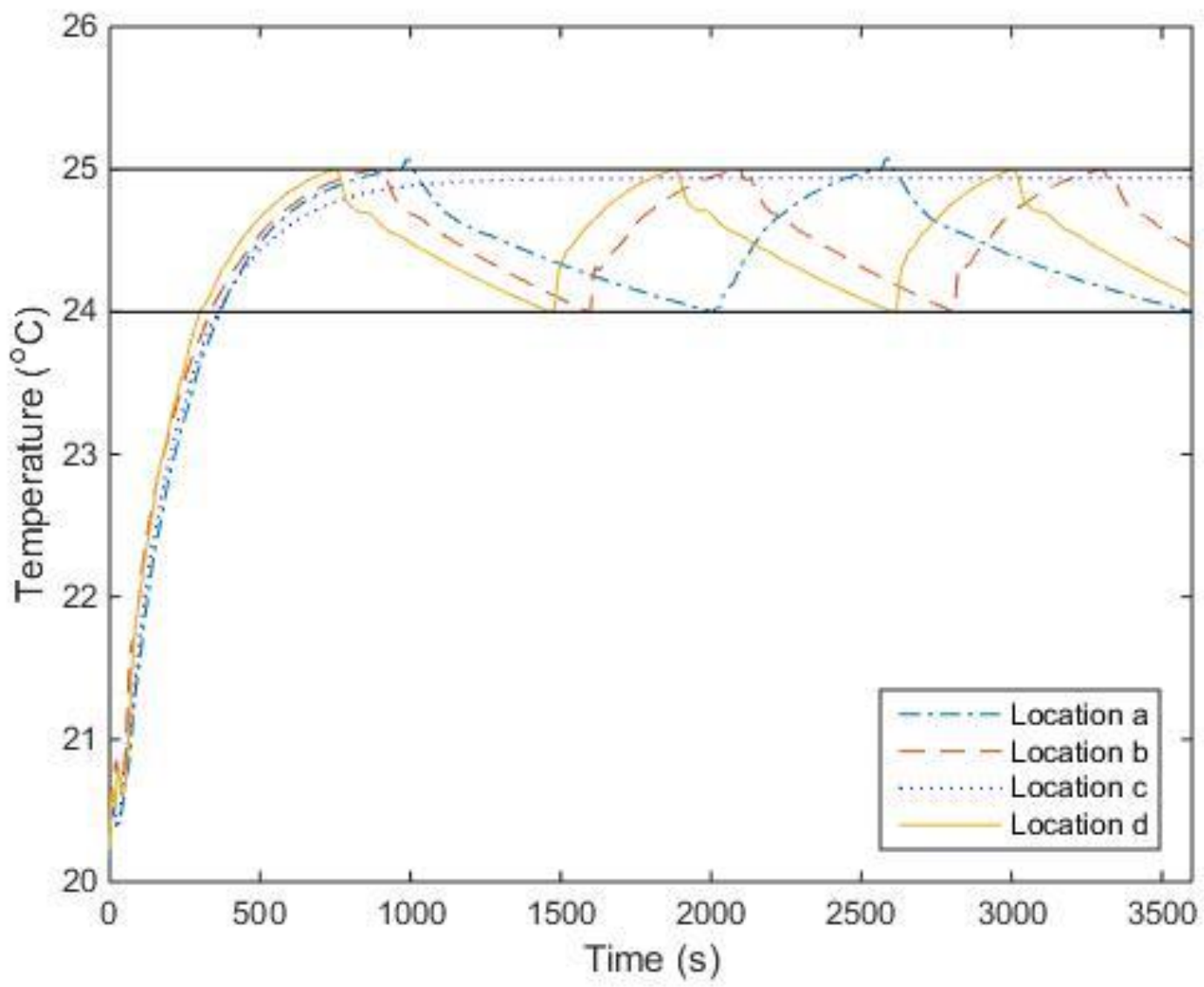

Figure 4.6 average temperature variation around the person at different locations with inlet velocity $=1 \mathrm{~m} / \mathrm{s}$, inlet temperature $=25^{\circ} \mathrm{C}$, and outside temperature $=15^{\circ} \mathrm{C}$.

For more understanding of the warm air behavior inside the room iso-surface of the temperature of two values $24{ }^{\circ} \mathrm{C}$ and $25^{\circ} \mathrm{C}$ are shown in Figure 4.7 for a person at different locations. Each location is shown at different time frames (100 s, $1800 \mathrm{~s}, 3600 \mathrm{~s})$. Warm air is formed around the person when the person is not in the middle for the first $100 \mathrm{~s}$. As the time passes on, the warm air is more localized when the person standing next to the inlet air. For the person standing in the middle, the temperature is more spread out around the middle of the person. For the other two locations, the warm air is more likely around the person and spread out on the upper part of the room. 
Chapter 4. The effect of person location inside the controlled space on energy consumption with a local temperature control

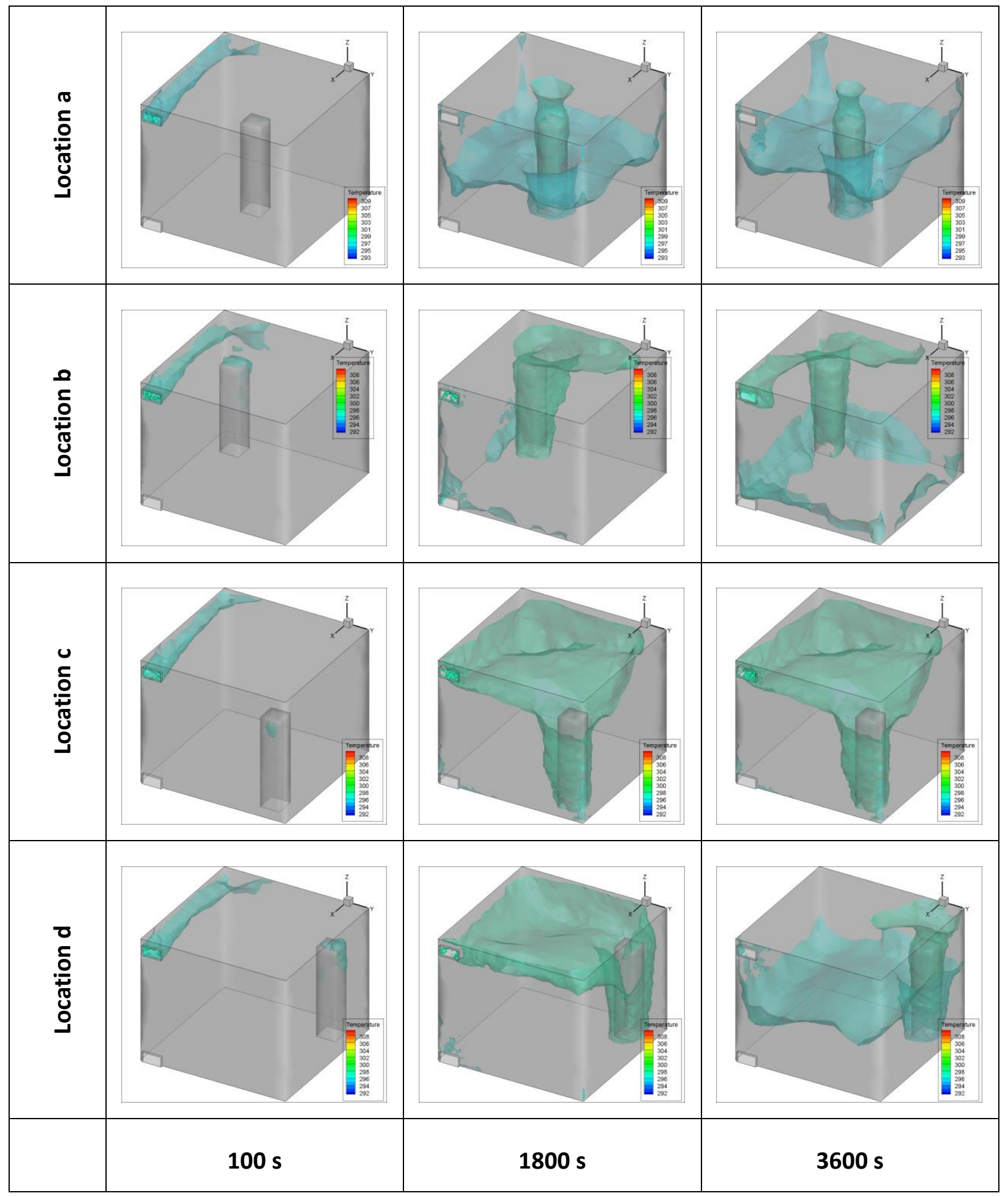


Chapter 4. The effect of person location inside the controlled space on energy consumption with a local temperature control

\section{Figure 4.7 iso-surfaces of temperature values of $24^{\circ} \mathrm{C}$ and $25^{\circ} \mathrm{C}$ for the person at different locations. The inlet velocity is $1 \mathrm{~m} / \mathrm{s}$, inlet temperature is $25^{\circ} \mathrm{C}$, and outside temperature is $15^{\circ} \mathrm{C}$}

Controlling the temperature around the person at location $\mathbf{b}$, next to the inlet, requires the highest energy consumption compared with the other two locations when the inlet velocity is low or medium and outside temperature is $15^{\circ} \mathrm{C}$ or higher (see figures in the appendix ${ }^{16}$ ). However, in case 16 when the inlet velocity is $1 \mathrm{~m} / \mathrm{s}$, the inlet temperature is $30^{\circ} \mathrm{C}$, and outside temperature is $15{ }^{\circ} \mathrm{C}$ location $\mathbf{d}$ requires more energy; in addition, in case 21 when inlet temperature is $25{ }^{\circ} \mathrm{C}$ instead, location c requires more energy. At low inlet velocity and high outside temperature the location c, corner beside the inlet, has the lowest energy difference percentage (refer to the figures in the appendix ${ }^{17}$ ). In general, as the inlet velocity increases the more energy difference percentage it is. In case of $V_{\text {in }}=0.2 \mathrm{~m} / \mathrm{s}, T_{\text {in }}=35^{\circ} \mathrm{C}$, and $T_{o}=15^{\circ} \mathrm{C}$ the person at location $\mathbf{b}$, standing next to inlet, consume noticeable amount of energy in compared when the person standing on the other two locations Figure 4.8. The average temperature variation around the person at different locations are shown in Figure 4.9. The person in middle has more overheating but slower temperature dropping rate which lead to less energy consumption compared with the other locations. In addition, the average temperature around the person in locations $\mathbf{b}$ has lower overheating but temperature drops faster than other location which lead to more operation time and extra energy.

\footnotetext{
16 Appendix D. Energy difference percentage based on person location. Figures number 2,6, and 12

17 Appendix D. Energy difference percentage based on person location. Figures number 1, 2, 4, and 6
} 
Chapter 4. The effect of person location inside the controlled space on energy consumption with a local temperature control

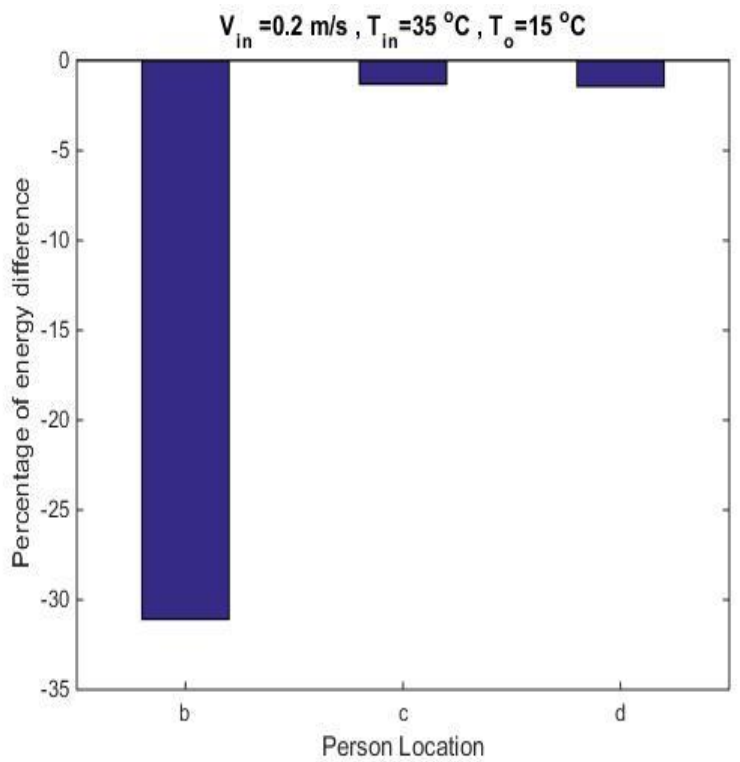

Figure 4.8 Energy difference percentage of different location compared with middle location with inlet velocity $=0.2 \mathrm{~m} / \mathrm{s}$, inlet temperature $=35^{\circ} \mathrm{C}$, and outside temperature $=15$ ${ }^{\circ} \mathbf{C}$

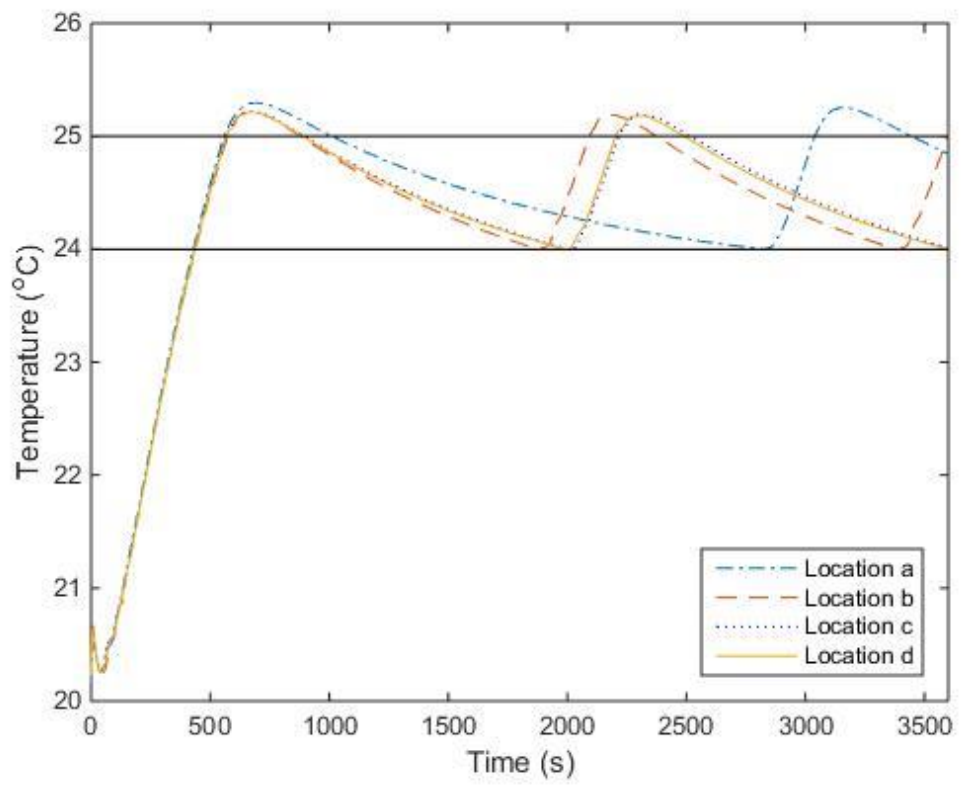

Figure 4.9 average temperature variation around the person at different locations with inlet velocity $=0.2 \mathrm{~m} / \mathrm{s}$, inlet temperature $=35^{\circ} \mathrm{C}$, and outside temperature $=15^{\circ} \mathrm{C}$ 
Chapter 4. The effect of person location inside the controlled space on energy consumption with a local temperature control

The rapid temperature drop in location b compared with location a can be seen in Figure 4.10. This figure shows the temperature distribution at two planes inside a room subject to inlet velocity of $0.2 \mathrm{~m} / \mathrm{s}$, the inlet temperature of $35^{\circ} \mathrm{C}$, and outside temperature of $15^{\circ} \mathrm{C}$. The comparison is at three different time frames (100s, 1800s, and 3600s). The temperature distribution of the two locations shows that the colder air, light green, spreads faster around the person when the person standing next to the inlet (location a).
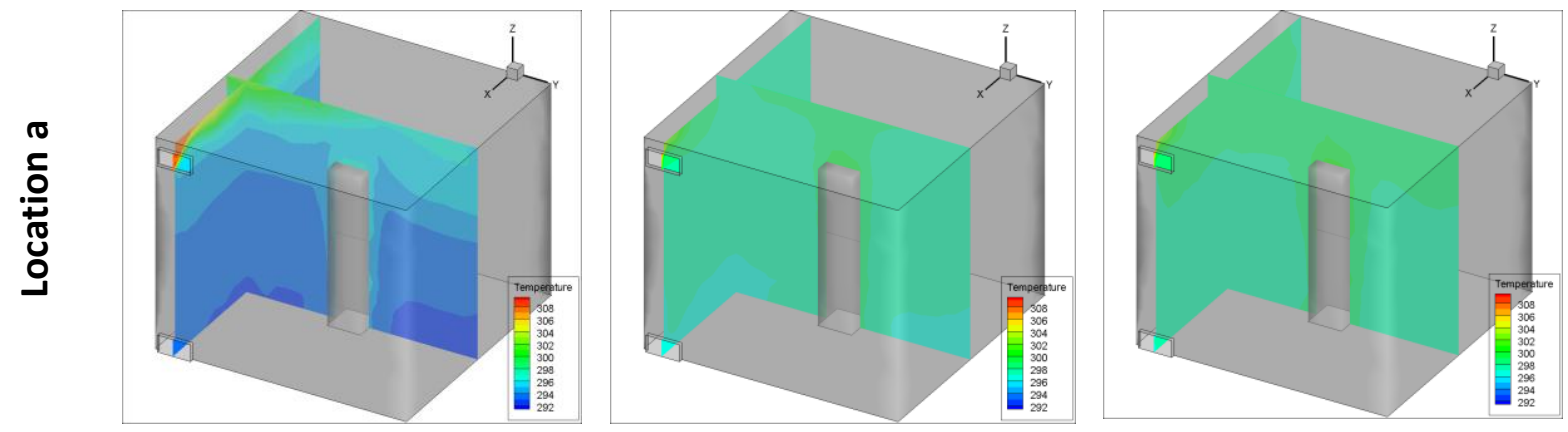

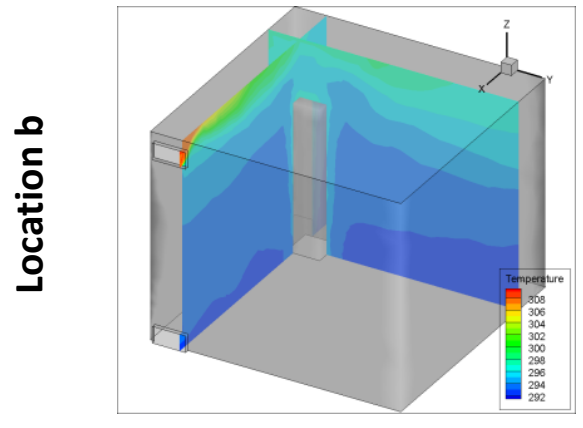

$100 \mathrm{~s}$

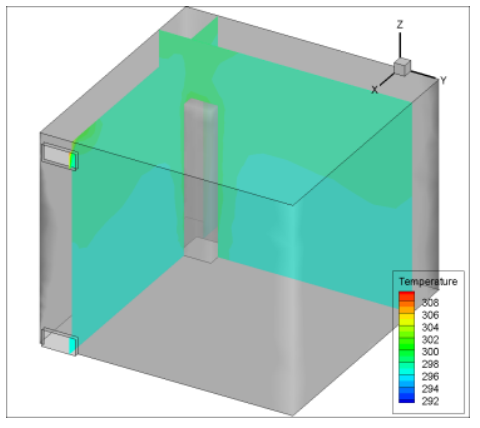

$1800 \mathrm{~s}$

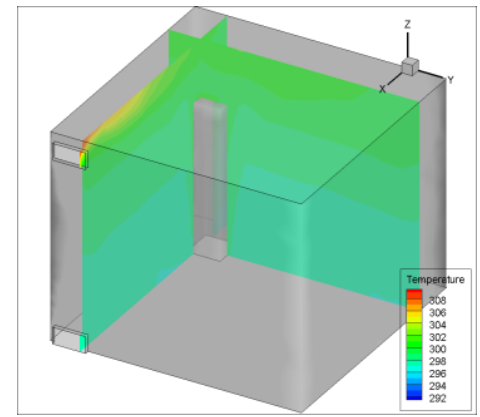

$3600 \mathrm{~s}$

Figure 4.10 temperature distribution inside a room with inlet velocity $=0.2 \mathrm{~m} / \mathrm{s}$, inlet temperature $=35^{\circ} \mathrm{C}$, and outside temperature $=15^{\circ} \mathrm{C}$. The controlling is based on two locations: middle (location a) and next to the inlet (location b)

When the inlet velocity is high $(2 \mathrm{~m} / \mathrm{s})$, generally controlling person in the middle of the room consume more energy compared when the person standing at other locations. However, in some cases such as when outside temperature is $15^{\circ} \mathrm{C}$ and inlet temperature $30{ }^{\circ} \mathrm{C}$ or $25^{\circ} \mathrm{C}$, the percentage of energy different vary from positive to negative depends on the location, see Figure 4.11. 
Chapter 4. The effect of person location inside the controlled space on energy consumption with a local temperature control
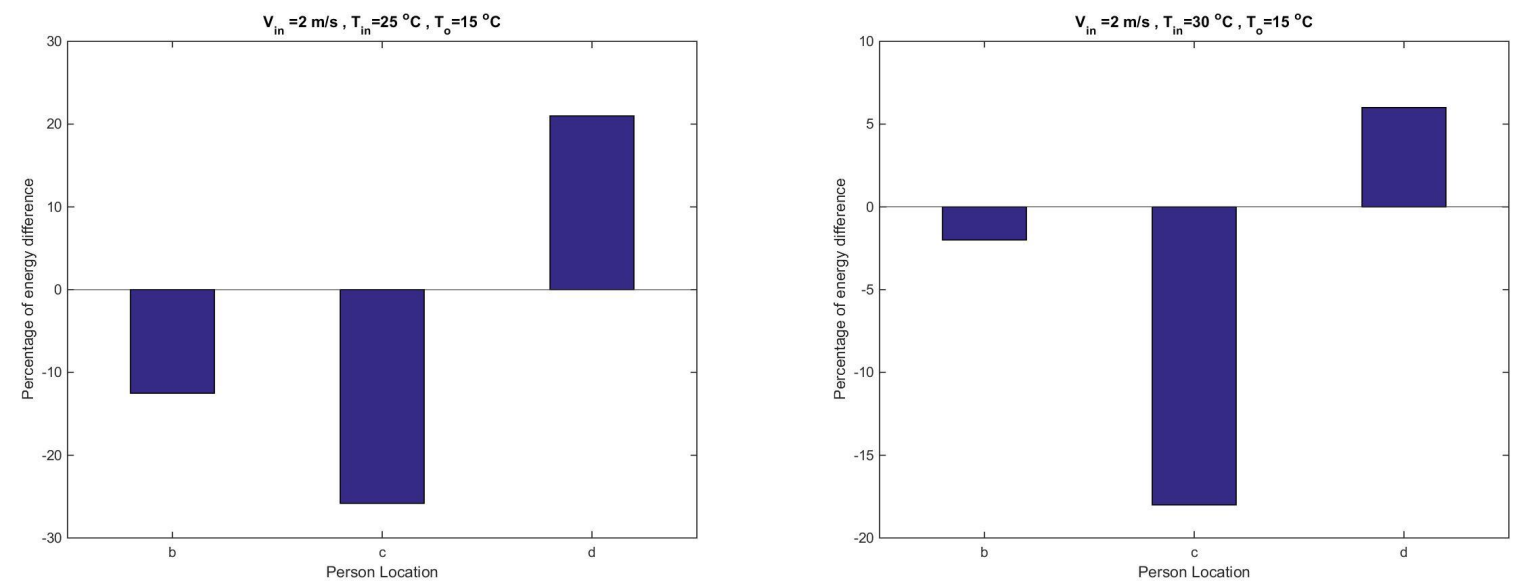

Figure 4.11 Energy difference percentage of different locations compared with middle location when inlet velocity $=2 \mathrm{~m} / \mathrm{s}$, inlet temperature $=30$ and $25^{\circ} \mathrm{C}$, and outside temperature $=15^{\circ} \mathrm{C}$

Generally, at low inlet velocity $(0.2 \mathrm{~m} / \mathrm{s})$ controlling person standing in middle consume less energy compared with the person standing at other locations. However, when outside temperature is $5{ }^{\circ} \mathrm{C}$ and inlet temperature is $35^{\circ} \mathrm{C}$ controlling person standing in middle consume more energy compared with other locations Figure 4.12.

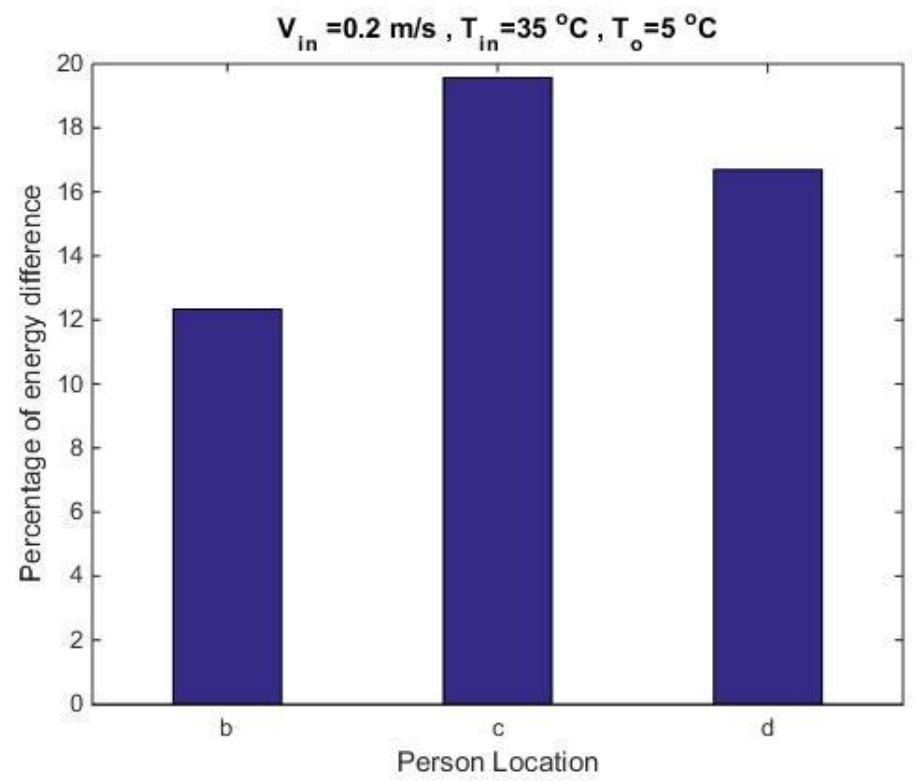


Chapter 4. The effect of person location inside the controlled space on energy consumption with a local temperature control

Figure 4.12 Energy difference percentage of different location compared with middle location with inlet velocity $=0.2 \mathrm{~m} / \mathrm{s}$, inlet temperature $=35^{\circ} \mathrm{C}$, and outside temperature $=$ $5^{\circ} \mathrm{C}$

At medium inlet velocity $(1 \mathrm{~m} / \mathrm{s})$ most of the cases of controlling person standing in the middle consume more energy compared with other locations such as case shown in Figure 4.13-a. However, some other cases the energy consumption vary from positive or negative depend on the boundary conditions and locations such as Figure 4.13-b. When the inlet temperature $35{ }^{\circ} \mathrm{C}$ and outside temperature of $15{ }^{\circ} \mathrm{C}$ (Figure 4.13-b), controlling the person at location $\mathbf{b}$ requires more energy compared with the other locations. Comparison of the average temperature variation for all locations for the case in Figure 4.13-b is shown in Figure 4.14. The average temperature variation shows that controlling person standing in middle leads to overshoot and slow dropping rate of the average temperature around the person which cause less operation time and less energy consumption. However, controlling based on location $b$ has the less overshoot and fast dropping rate which cause extra operation time and energy consumption.

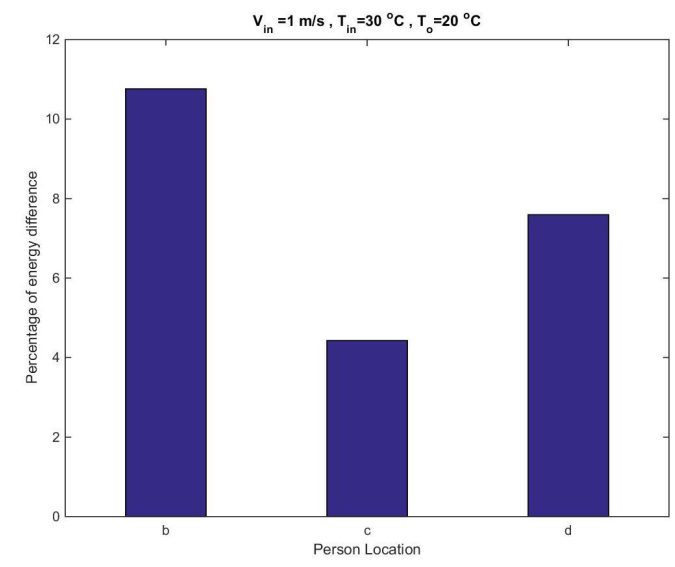

(a)

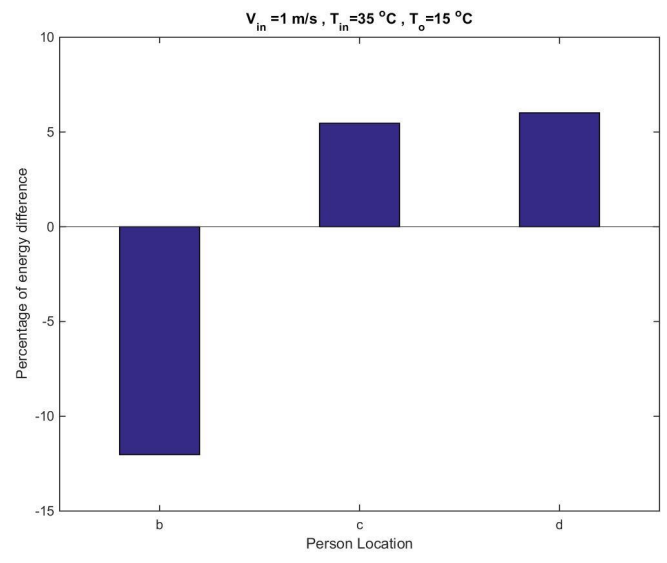

(b)

Figure 4.13 Energy difference percentage of different location compared with middle location with inlet velocity $=1 \mathrm{~m} / \mathrm{s}$, inlet temperature $=30$ and $35^{\circ} \mathrm{C}$, and outside temperature $=15$ and $20^{\circ} \mathrm{C}$ 
Chapter 4. The effect of person location inside the controlled space on energy consumption with a local temperature control

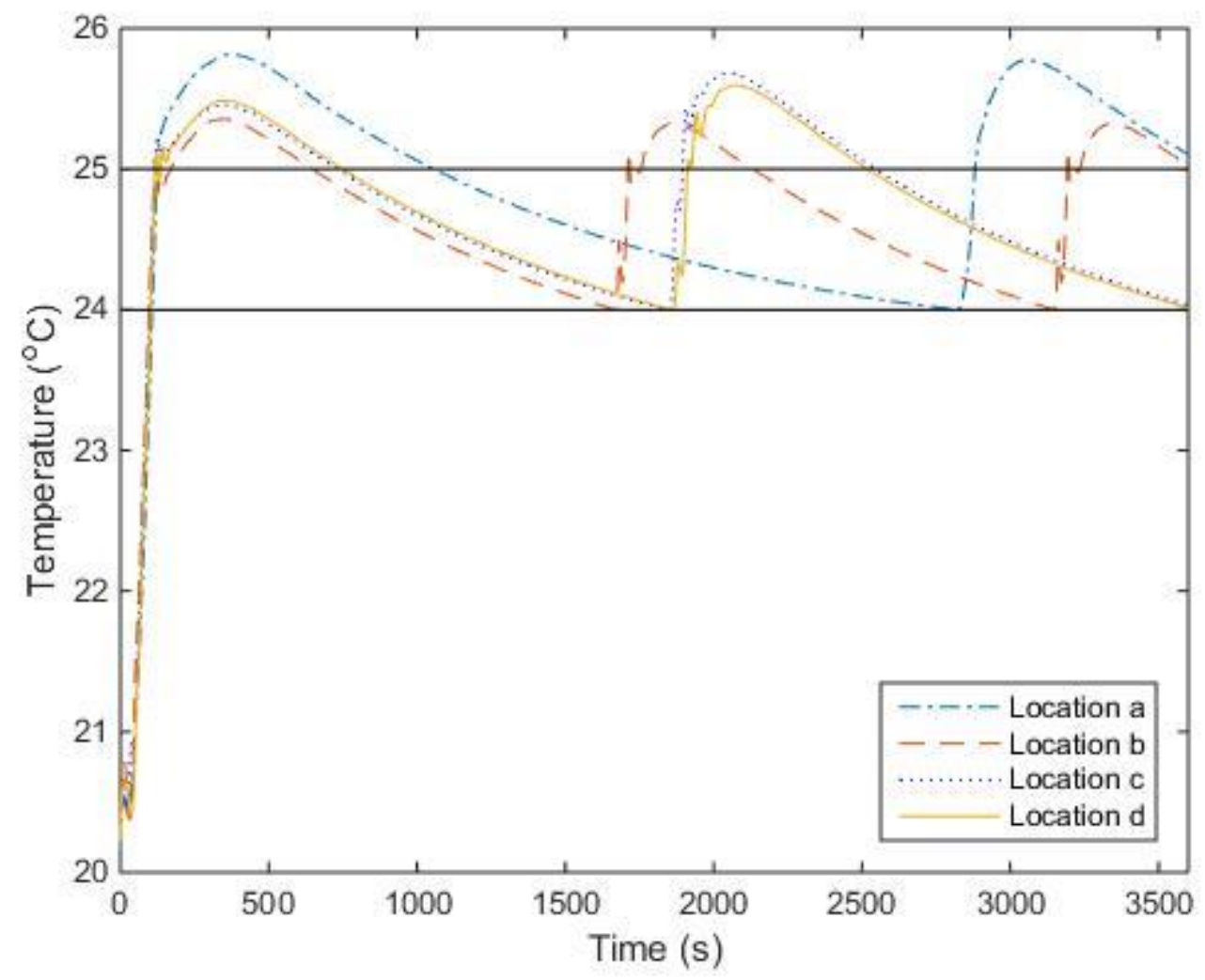

Figure 4.14 average temperature variation around the person at different locations with inlet velocity $=1 \mathrm{~m} / \mathrm{s}$, inlet temperature $=35^{\circ} \mathrm{C}$, and outside temperature $=15^{\circ} \mathrm{C}$

For more understanding of warm air behavior inside the room iso-surface of temperature values $24^{\circ} \mathrm{C}$ and $25^{\circ} \mathrm{C}$ are shown in Figure 4.15 for inlet velocity of $1 \mathrm{~m} / \mathrm{s}$, the inlet temperature of $35^{\circ} \mathrm{C}$, and outside temperature of $15^{\circ} \mathrm{C}$. For the first 100 seconds, all the locations have similar iso-surface temperature of sheet-like shape. As the time goes the iso-surface temperature turned to the flour like shape with more warm air surrounding the person. 
Chapter 4. The effect of person location inside the controlled space on energy consumption with a local temperature control

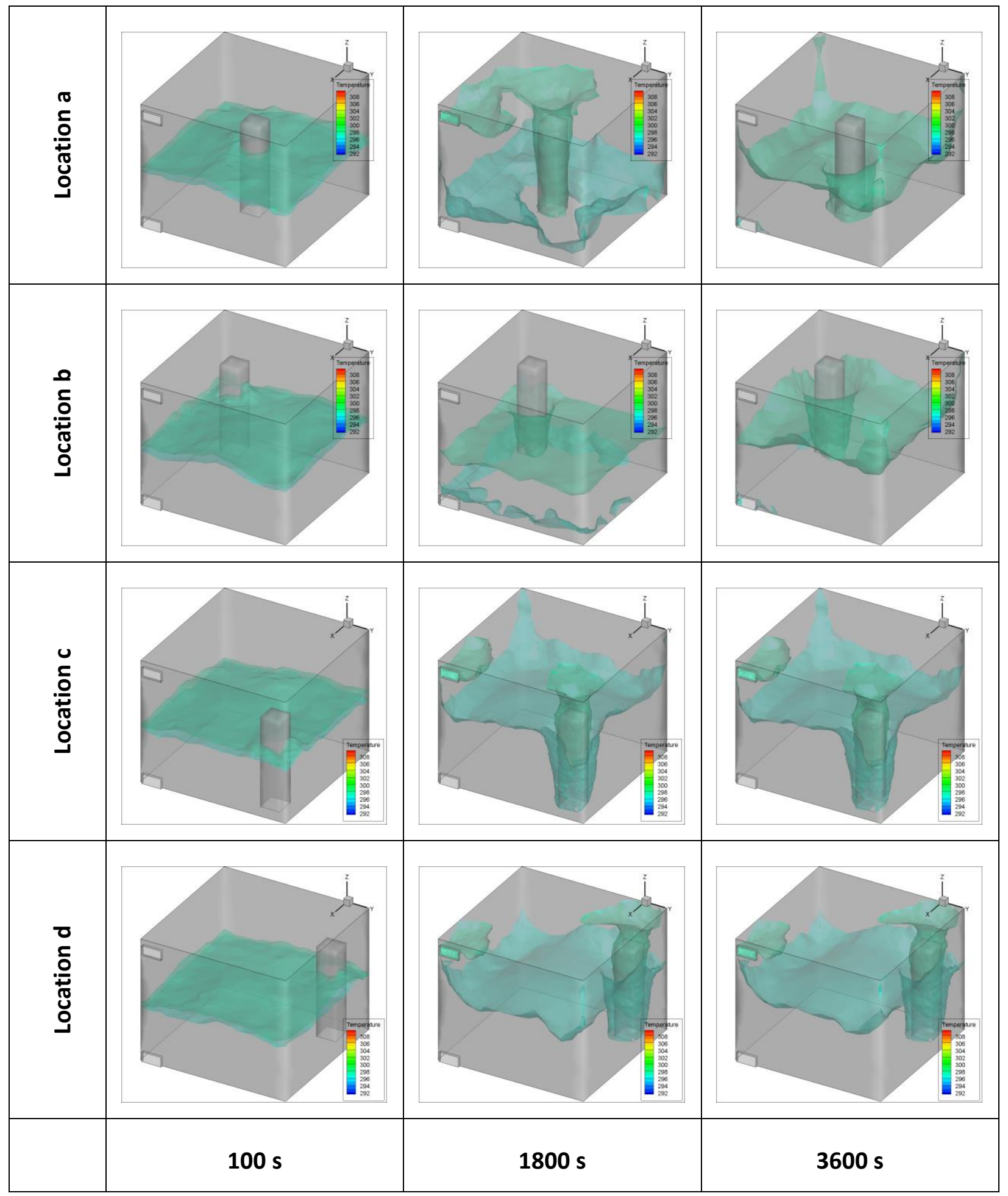


Chapter 4. The effect of person location inside the controlled space on energy consumption with a local temperature control

Figure 4.15 4.16 iso-surfaces of temperature values of $24^{\circ} \mathrm{C}$ and $25{ }^{\circ} \mathrm{C}$ for the person at the different location. The inlet velocity is $1 \mathrm{~m} / \mathrm{s}$, inlet temperature is $35{ }^{\circ} \mathrm{C}$, and outside temperature is $15^{\circ} \mathrm{C}$

\subsection{Summary and conclusion}

The effect of person location inside the controlled space on energy consumption using local temperature control has been shown in this chapter. The energy consumption of a person at different locations has been compared with energy consumption of a person standing in the middle at the same boundary conditions. The analysis has been conducted in term of percentage of energy difference, average temperature variation, and warm air behavior inside the controlled space. The study showed that the energy required to heat a person up to a comfort temperature range compared with a person standing in middle vary from a couple of percentages to $140 \%$ depend on the boundary conditions and person location. The variation either positive where a person standing in middle requires more energy, negative where the person on other location requires more energy or mixed positive and negative. There is not any general mechanism that can predict that behavior and they are totally conditions dependent. Therefore, using CFD for local control can be very useful in determining the need operation conditions to satisfy human thermal comfort conditions. 


\section{Chapter 5 Device components and its working methodology}

\subsection{Introduction}

The main object of the present device is to control the temperature of a particular location or a zone, instead of using a single point measuring sensors far away from a targeted location. Since it is not feasible to put temperature sensors throughout the whole space, temperature controlled by simulating the air behavior inside the controlled space using a computational fluid dynamic methodology. The result is like having a number of movable single point measuring sensors inside a specified location, instead of a single temperature measurement far away from the interest zone. A numerical fluid solver used to determine air behavior inside the controlled space. This information is used to estimate the average condition (for example average temperature) around the targeted location. As a result, the average condition used to determine when to turn ON and OFF the HVAC system. We showed that up to $22 \%$ of energy can be saved by using a control system that can predict the temperature around the person. In addition, a better thermal comfort and more HVAC system stability achieved compared with a conventional thermostat.

In this chapter, we are presenting a virtual thermostat, which can control HVAC system based on a local temperature. The chapter introduces the methodology and the thermostat system that can control temperature around a person or in a target location using CFD. The device is used to estimate the operation conditions of an HVAC system.

\subsection{Description of the device}

The present system is a virtual thermostat, which can control the temperature at a target zone or location in an HVAC controlled space. This system operates based on a theoretical calculation of the temperature inside the space using a computational fluid dynamic (CFD). The HVAC system used has an inlet duct and an outlet duct; however, the system can be used on any type of HVAC system. The system comprises of the following parts as shown in Figure 5.1:

a. A three-dimensional scanner such as "A Microsoft Kinect" to scan and generate a 3D point cloud raw data of a controlled space boundary. The Kinect scanner installed on a pan-tilt platform, which has two servomotors, one of them is to rotate the $3 \mathrm{D}$ scanner by $180^{\circ}$ degrees horizontally and the other one is to tilt it up and down. 
b. A set of single point temperature sensors (thermistors) to measure air temperature at certain locations in the space. One sensor is set in the air inlet duct to measure the air inlet temperature. The other sensor is set on a wall in the controlled space. The sensor on the wall used to estimate the initial temperature of the space and to calibrate the results from the numerical solver by comparing the average temperature estimation around the sensor from the solver with a real reading from temperature sensor itself.

c. An air velocity sensor (anemometer) to measure the air inlet velocity.

d. A microcontroller (Arduino) to control the servomotors, and to read the temperature and velocity of the air.

e. A computational fluid dynamic solver (such as OpenFOAM) to determine the spatial temperature distribution across the controlled space by solving the NavierStokes (NS) and energy equations.

f. A computer to act as the main processing unit of the device and as an input unit. Linux operating system is used and all the programming is done using Python.

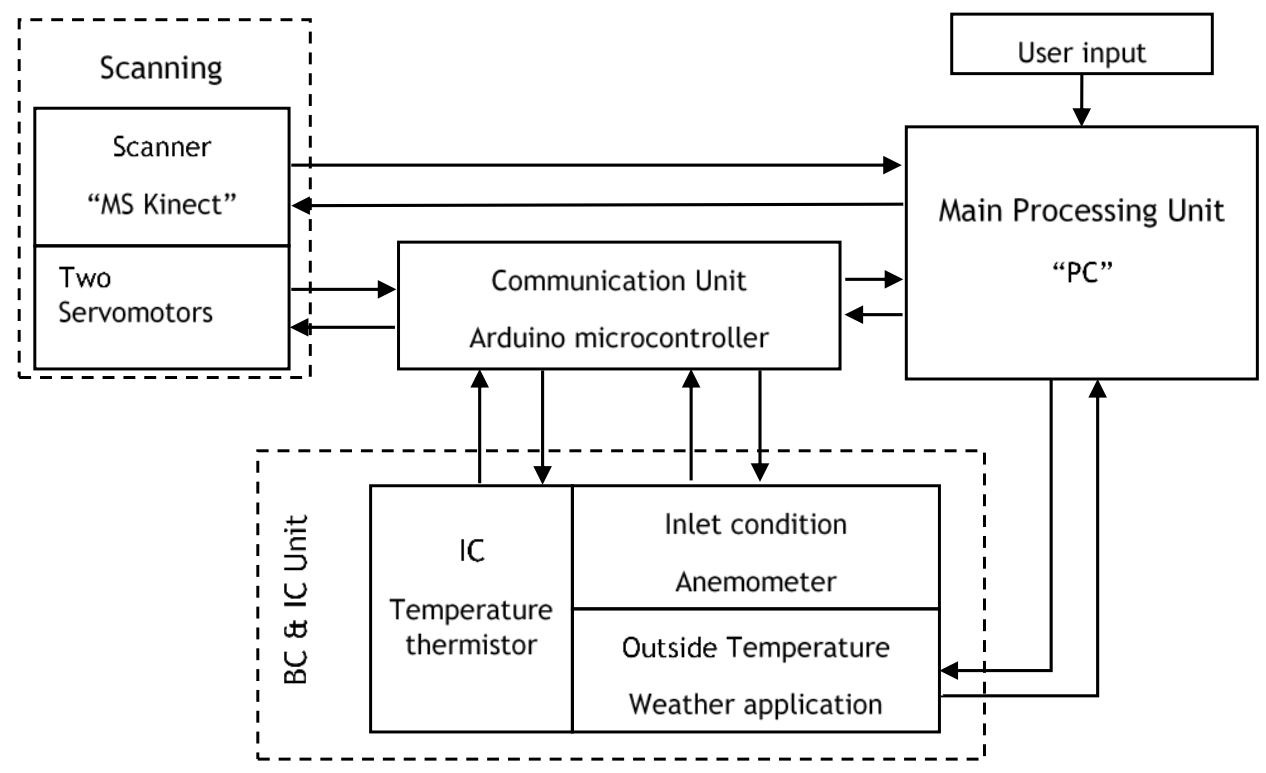

Figure 5.1 Components of the virtual thermostat device. 


\subsubsection{Operating methodology}

The present virtual thermostat controls an HVAC system using the temperature at any specified location in a space. Figure 5.2, shows the main operational steps of the present system:

1- When the virtual thermostat device starts, Kinect reconstructs 3D model of the controlled space, which include people location.

2- The 3D model of the space is sent to a mesh generator (built-on OpenFoam) to produce finite volume grid for the controlled space domain.

3- The boundary and the initial conditions of the grid have to be set up, which include the inlet condition, the outside temperature, the initial air temperature, the wall thermal resistance.

4- After the boundary and the initial conditions are set, the virtual thermostat starts to estimate the temperature distribution inside the controlled space using OpenFoam by solving the Navier-Stoke and the energy equations for every time step.

5- The device calculates the volumetric average temperature at the target location.

6- The control unit compares the average target temperature with a user specification range. Based on this comparison, the HVAC unit turns ON/OFF. In addition, the control unit has to change the inlet condition of the CFD simulation solver by changing the boundary condition settings.

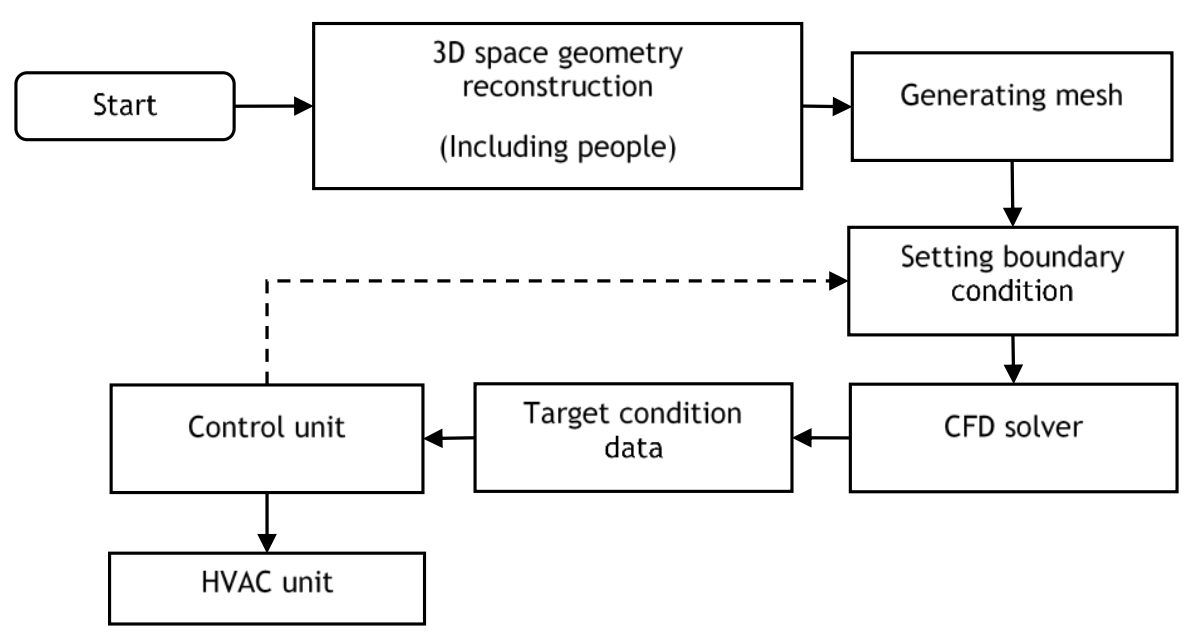

Figure 5.2. Simplified flow chart to show the main steps in the virtual thermostat device. 
With reference to Figure 5.3, the HVAC control unit is a logical unit that decides when to turn the HVAC unit ON and OFF, when to start the next time step for the CFD solver unit, and when to change the $\mathrm{BC}$ and IC unit inlet conditions. The unit receives two information; one is the target temperature range $\left(\mathrm{T}_{\mathrm{H}}\right.$ and $\left.\mathrm{T}_{\mathrm{L}}\right)$ from the user input, and the other is the average temperature of the target location $\left(\mathrm{T}_{\text {local }}\right)$. $\mathrm{T}_{\mathrm{H}}$ is the highest temperature, and $\mathrm{T}_{\mathrm{L}}$ is the lowest temperature that the controlled space should reach. The unit starts by comparing $\mathrm{T}_{\text {local }}$ with $\mathrm{T}_{\mathrm{H}}$ and $\mathrm{T}_{\mathrm{L}}$. If $\mathrm{T}_{\text {local }}$ is in between $\mathrm{T}_{\mathrm{H}}$ and $\mathrm{T}_{\mathrm{L}}$ (yes), then the unit just keeps the system as is and continues to the next time step by sending a signal to the CFD solver unit. If $\mathrm{T}_{\text {local }}$ is not in between (No), then the unit checks the status of the HVAC unit. If the HVAC unit is $\mathrm{ON}$, then $\mathrm{T}_{\mathrm{H}}$ will be compared with $\mathrm{T}_{\text {local }}$. If $\mathrm{T}_{\text {local }}$ is larger than or equal to $\mathrm{T}_{\mathrm{H}}$ the unit will turn the HVAC unit OFF. If $\mathrm{T}_{\text {local }}$ is less than $\mathrm{T}_{\mathrm{H}}$, the unit keeps the system as is. If the status of the HVAC unit is OFF, the unit will compare $\mathrm{T}_{\text {local }}$ with $\mathrm{T}_{\mathrm{L}}$. If $\mathrm{T}_{\text {local }}$ is less than or equal $\mathrm{T}_{\mathrm{L}}$, the unit will turn the HVAC unit $\mathrm{ON}$. If $\mathrm{T}_{\text {local }}$ is higher than $\mathrm{T}_{\mathrm{L}}$ the unit will keep the system as is.

Figure 5.4 provides an example to clarify the operation time of a heating HVAC system with a person standing in the middle of room and by showing when the system is ON and when it is OFF. The system turns $\mathrm{ON}$ and $\mathrm{OFF}$ depending on the preferred air condition range. The acceptable temperature range for a user, in this case, is between $24^{\circ} \mathrm{C}$ and $25^{\circ} \mathrm{C}$. The temperature increases from $20{ }^{\circ} \mathrm{C}$ at time zero to $25^{\circ} \mathrm{C}$ in around 11 minutes. During this time, the HVAC system is ON. After this time ( $\mathrm{t}=11$ minutes), the HVAC system turns OFF for around 5 minutes before it turns $\mathrm{ON}$ again, since the average temperature drops below $24{ }^{\circ} \mathrm{C}$. This process is repeated.

\subsubsection{Computational System}

The virtual thermostat has to estimate air temperature distribution inside the controlled space by solving the Navier-Stokes and the energy equations for this transient, buoyant, turbulent, compressible fluids and heat transfer problem. OpenFoam [81] is used as the solver. The turbulent model is Reynolds-Averaged Simulation (RAS) with RNGkEpsilon model. Boussinesq approximation model is used for the buoyancy effects of the air with a constant density coefficient of $1.225 \mathrm{~kg} / \mathrm{m}^{3}$ and a constant thermal expansion coefficient of $0.0032 \mathrm{l} / \mathrm{k}$. Constant transport model for dynamic viscosity and Prandtl number are used. The boundary conditions are set as 
Chapter 5. Device components and its working methodology

follows: The inlet pressure is set to zero pressure gradient, the user specifies inlet velocity and temperature, outside temperature is set using weather forecast application, and the temperature of the people inside the space is set to a constant and uniform temperature of $37^{\circ} \mathrm{C}$. The initial air temperature of the controlled space is measured using $10 \mathrm{k}$ thermistor connected with Arduino. The thermistor is calibrated using Steinhart-Hart equation at three different temperatures zero, 25 ${ }^{\circ} \mathrm{C}$, and $60{ }^{\circ} \mathrm{C}$.

For mesh generation, OpenFOAM has the ability to generate 3-dimensional hexahedra (hex) and split-hexahedra (split-hex) mesh by triangulating surface geometries in Stereolithography (STL) format. The geometry of the space is generated using Kinect, which will be described next.

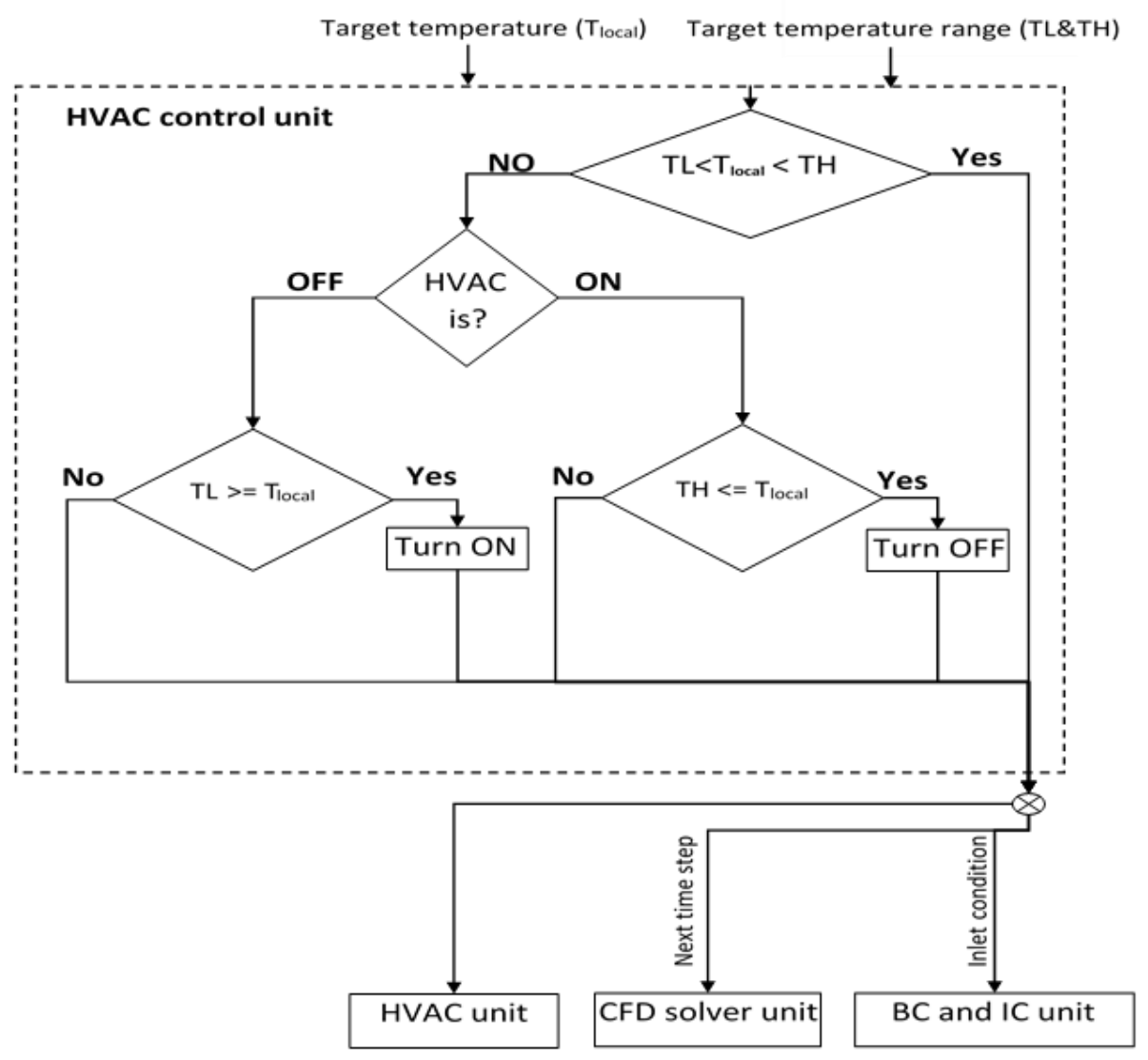

Figure 5.3. Flow chart of control unit 
Chapter 5. Device components and its working methodology

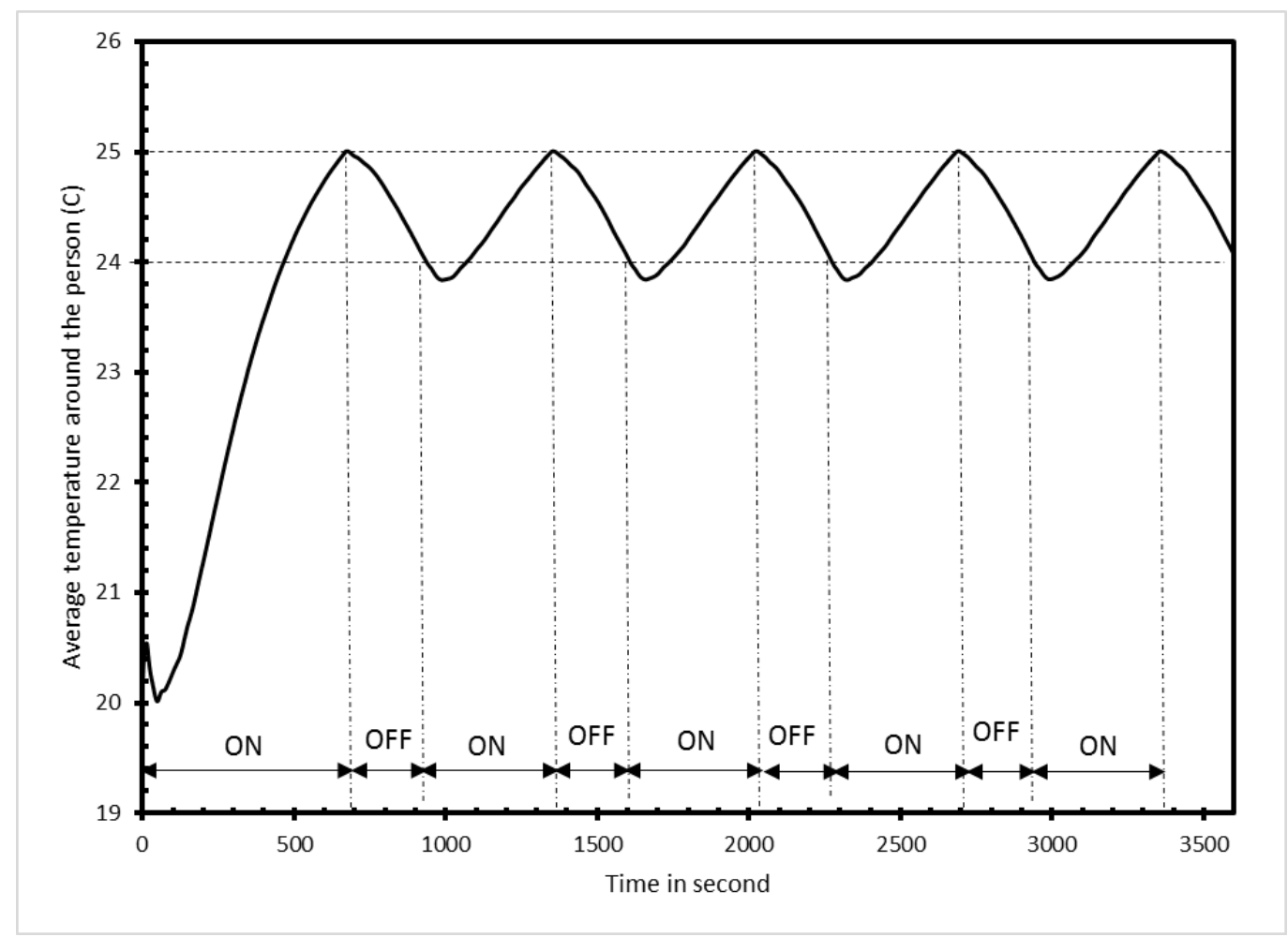

Figure 5.4. Temperature variation around the person to explain operation time

\subsubsection{Scanner setting}

Xbox Kinect sensor from Microsoft is used for the 3D reconstruction. This device has the ability to generate RGBD data by using scattered light and triangulation algorithm. The 3D point cloud, generated by Kinect, suffers from noise, cluttering, and occlusion (Figure 5.5). These problems create incomplete, distorted, and not accurate 3D geometry. Therefore, to overcome these problems each part in the 3D geometry is automatically replaced by a 3D STL model. For example, a standing person inside the controlled space is replaced with a box in STL format, which has the same height of the person and $40 \mathrm{~cm}$ by $40 \mathrm{~cm}$ in cross section.

Kinect for windows device has $43^{\circ}$ vertical by $57^{\circ}$ horizontal field of view, which may not cover the entire controlled space. Therefore, two servomotors are used, one to rotate the Kinect $180^{\circ}$ horizontally and the other to tilt it $180^{\circ}$ vertically. The two motors are controlled using an Arduino microcontroller device. Kinect sensor starts to find the wall distance by using the depth data at each wall side. From the depth map, the wall distance is measured using the most common distance in the depth data and by averaging this distance at different depth frame wall distance can 
be estimated. The distances of all the controlled space's boundaries are used to create STL file for space.

After creating the controlled space's boundaries, the Kinect start to scan the room from the right to the left. If a person is found, Kinect provides a head position to the reference of the Kinect coordinate, which is converted to the coordinates of the controlled space. The person will be represented as a box in STL format. In the case of more than one person inside the controlled space, extra boxes representing the people are added to the same STL file. The STL files which contain the controlled space boundaries and people's location are imported to OpenFoam for meshing and CFD calculation.

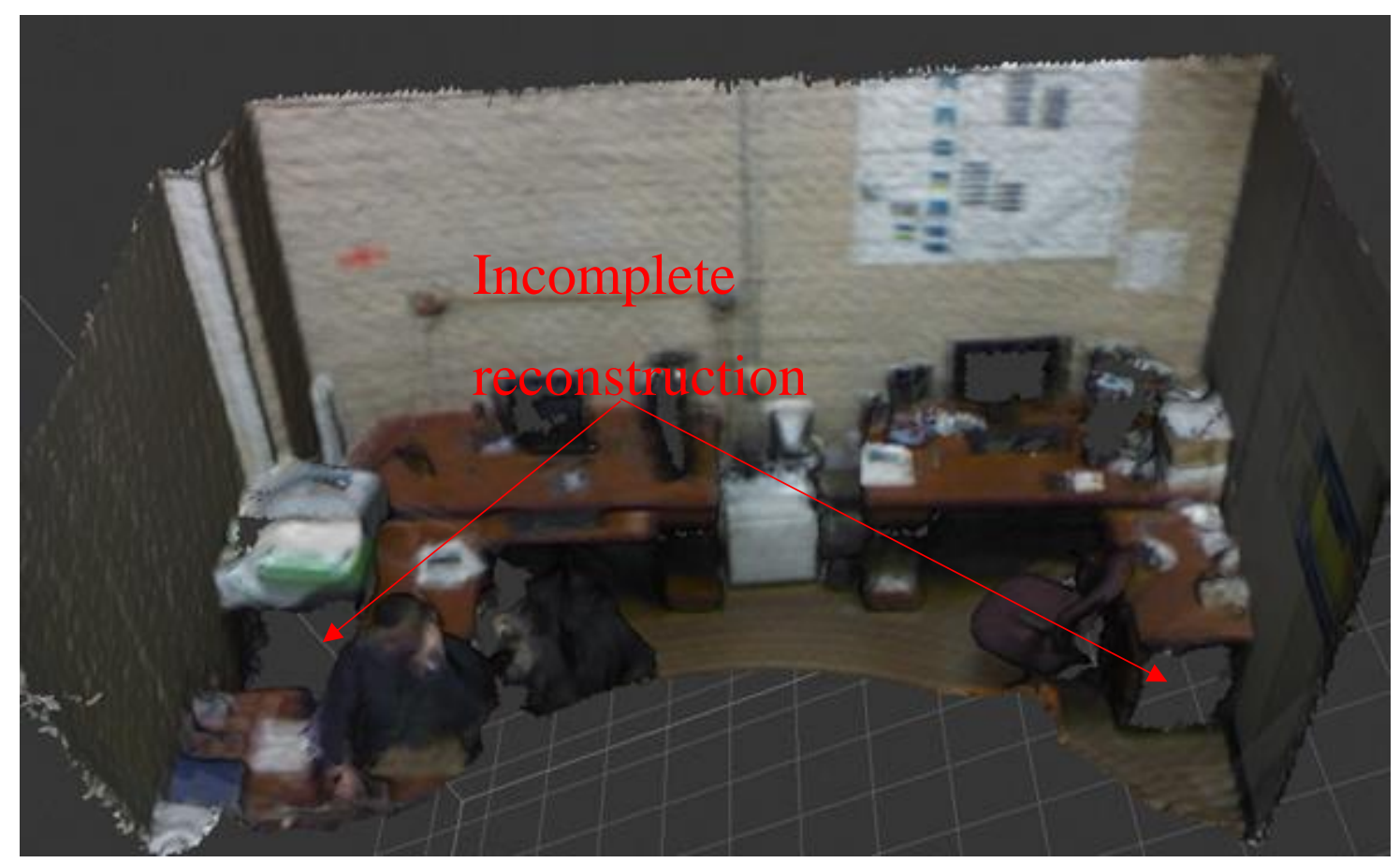

Figure 5.5 three dimension model of MUSSL Lab at University of Toronto reconstructed using Microsoft Kinect

The procedure for real-time human pose in NITE, which is a high-level library for skeleton tracking, is described in Figure 5.6. OpenNI and NITE start by looking for people in the Kinect field of view. When a person is detected, the standard person pose detection is started so that the person's skeleton can be calibrated and tracked. If the calibration fails, the system repeats the 
person pose detection again until the calibration is accomplished. When the calibration is accomplished, the system starts to track the person.

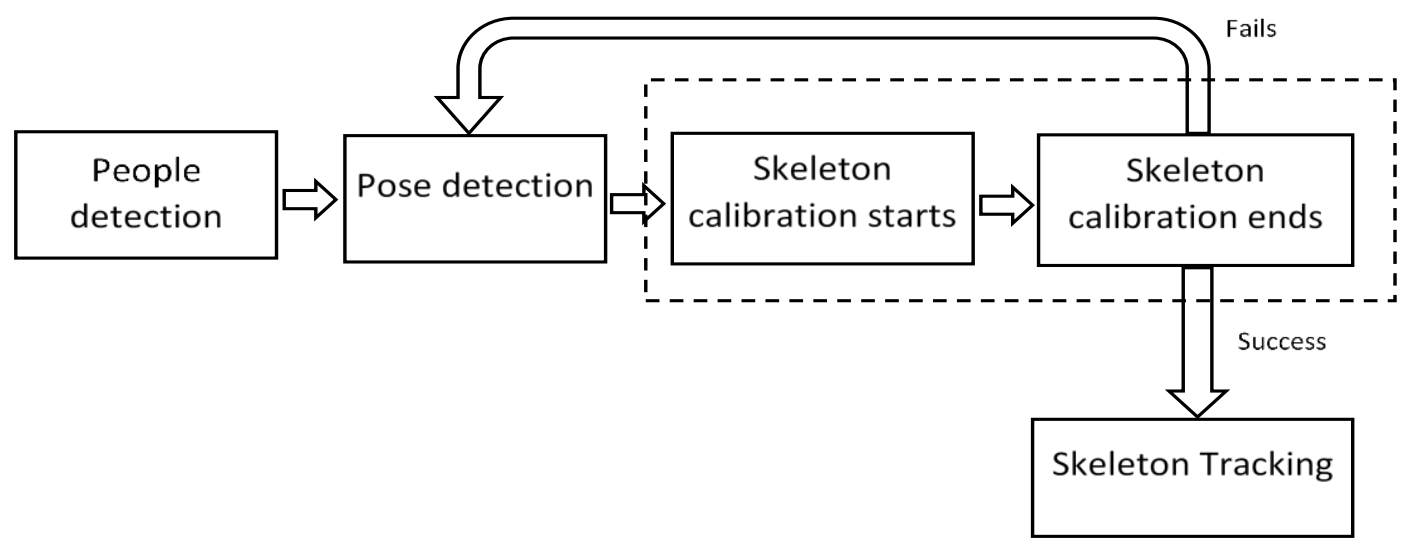

Figure 5.6. Shows flow chart of skeleton tracking steps.

\subsection{Device inputs}

Figure 5.7, shows the virtual thermostat user interface. The virtual thermostat user interface is divided into four steps: the first step is Room scan, the second step is target condition and location, the third step is the inlet condition, and the final step is for calculation and control.

In the first step, the user has three buttons, the first button is to find the room dimension, the second button is to find people location, the last button which can be used to do both; measuring room dimension and people location in the sequence.

For the second step, the user has to specify the temperature range of preferred condition, and the location of the target zone. For the target zone, the user has two options, the first one is to control the temperature around the person, and the second one is to control based on zone specification. One option should be selected at the time. In the first option, the user has to select which person should be used by the virtual thermostat for temperature control. The second option is to specify the preferred zone by providing a starting and an ending point of the target zone box. In the case of more than one person, it is easier to use a target zone, rather than a person, which can cover all the people in the zone. 


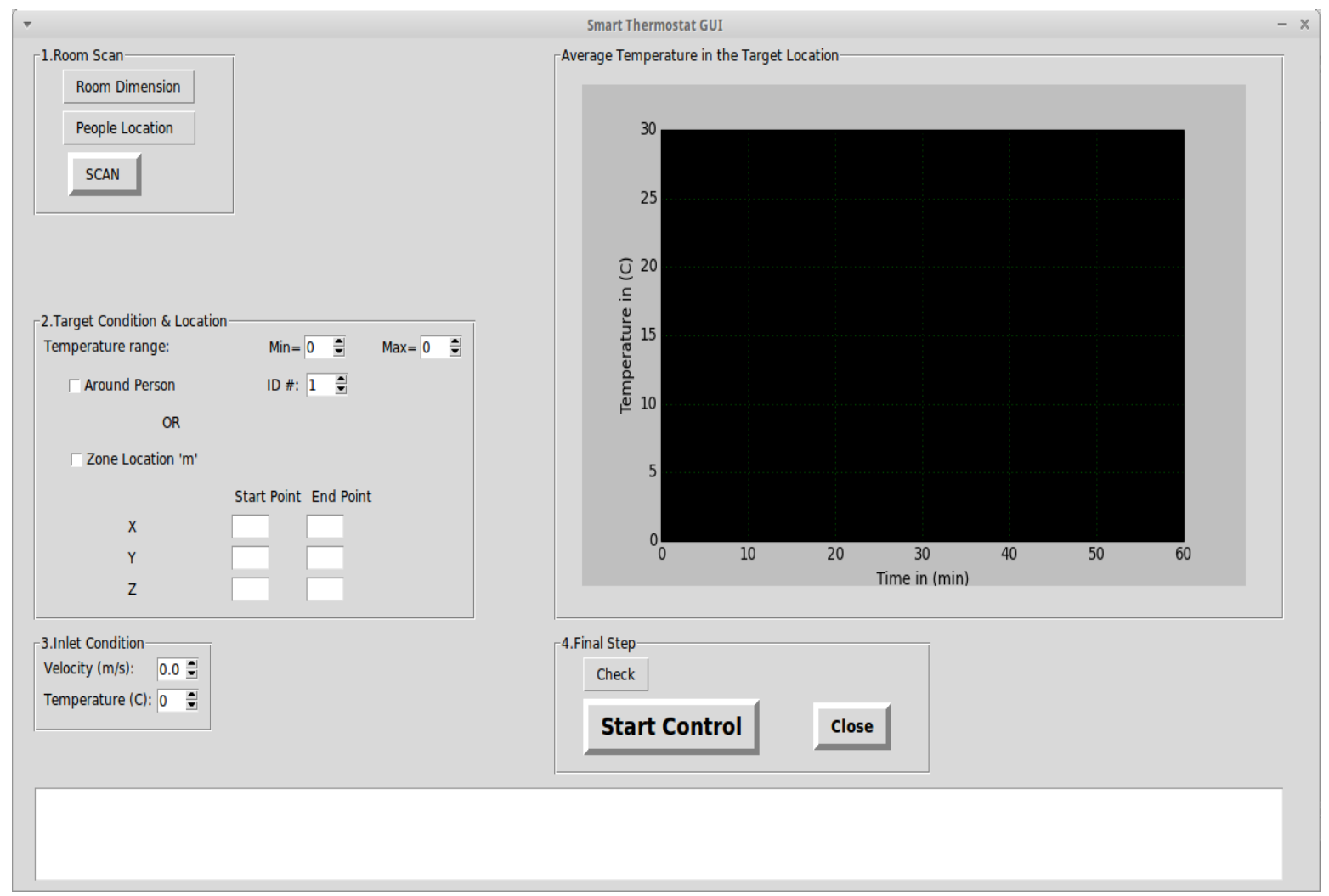

Figure 5.7. Shows the virtual thermostat user interface.

The third step is inlet condition specification where the user can change the fan speed and air inlet temperature. The final step has two options: The first option is a check button where the user can check if the inlet condition is enough to reach the target zone in the preferred time. The second option is to start controlling if the user likes the inlet condition specification. In addition, the start button can be used to do a control without using the check button, in which case the device just uses whatever inlet specification has been used.

The upper right corner of the virtual thermostat GUI is to plot the average temperature of the target location. The lower white box is used to show other information, such as the room dimensions, and a number of people in the space ${ }^{18}$.

18 Appendix F. Python source code of the device 


\subsection{The device output and results}

The device has been used to estimate the operation condition of an HVAC system for a $\operatorname{room}(3 \mathrm{~m}, 3 \mathrm{~m}, 2.5 \mathrm{~m})$ shown in Figure 5.8. The operation condition of the heating HVAC system has been tested on a person at three different locations with different inlet velocities and temperatures. The location of the person is measured from the center of the room. The outside temperatures were $20,10,0^{\circ} \mathrm{C}$. The wall is made of wood with a thermal conductivity of $0.173 \mathrm{~W} /(\mathrm{m} \mathrm{K})$ and thickness $0.3 \mathrm{~m}$. Table 5.1 shows five different cases with different inlet velocities, inlet temperature, outside temperature, and outside temperatures. The device has not been tested in a real test chamber with HVAC system on it.

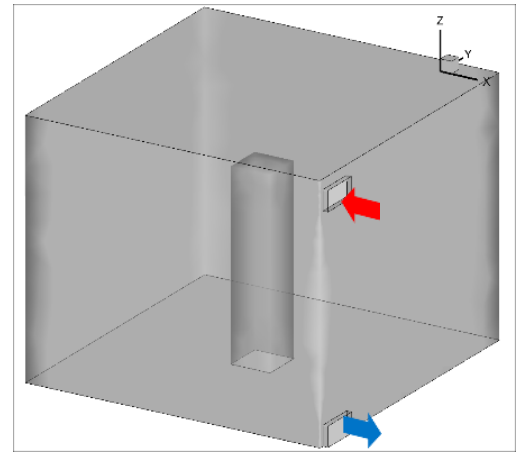

(a)

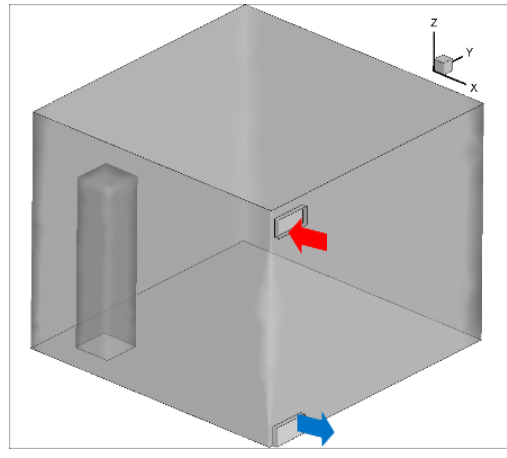

(b)

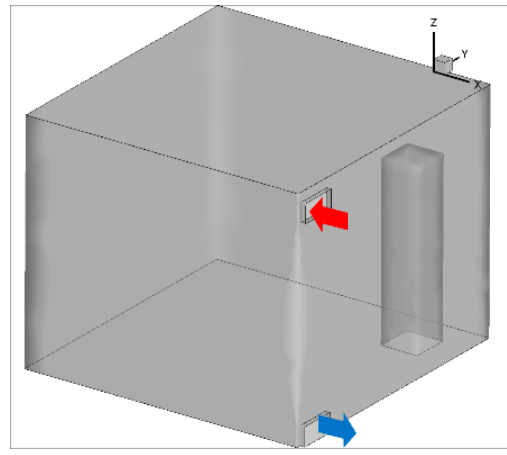

(C)

Figure 5.8. Test cases for the person standing at different locations.

In Table 5.1 the parameters are the temperature rate, which is the rate of temperature change around the person from the start of heating until the average temperature reaches the maximum temperature. First $\mathrm{ON}$ is the time that the HVAC system needs to run to reaches the maximum temperature. OFF time is the average time that the HVAC system stays OFF. A number of OFF cycles is the number of times that the system turns OFF during one hour. ON time is the average time for the system to stay $\mathrm{ON}$ after the first $\mathrm{ON}$ time. A number of $\mathrm{ON}$ cycles is the number of times that the system turns ON after the first ON. Maximum temperature is the maximum average temperature around the person during the one hour. Figure 5.9 clarifies the mentioned parameters. 
Chapter 5. Device components and its working methodology

Table 5.1. Inputs and operation conditions

\begin{tabular}{ccccccccccccc}
\hline User Input & \multicolumn{1}{c}{$\begin{array}{c}\text { From Kinect and } \\
\text { weather app }\end{array}$} & \multicolumn{1}{c}{ Output Results from the device } \\
\hline $\begin{array}{c}\text { Inlet } \\
\text { Velocity }\end{array}$ & $\begin{array}{c}\text { Inlet } \\
\text { Temp }\end{array}$ & $\begin{array}{c}\text { Outside } \\
\text { Temp }\end{array}$ & $\mathbf{X}$ & $\mathbf{Y}$ & $\begin{array}{c}\text { Temp } \\
\text { Rate }\end{array}$ & $\begin{array}{c}\text { First } \\
\text { ON }\end{array}$ & $\begin{array}{c}\text { OFF } \\
\text { time }\end{array}$ & $\begin{array}{c}\text { \# OFF } \\
\text { cycles }\end{array}$ & $\begin{array}{c}\text { ON } \\
\text { time }\end{array}$ & $\begin{array}{c}\text { \# ON } \\
\text { cycles }\end{array}$ & $\begin{array}{c}\text { Max } \\
\text { Temp }\end{array}$ \\
\hline $\mathbf{0 . 4}$ & 30 & 10 & 0 & 0 & 0.58 & 9.31 & 6.43 & 5 & 4.312 & 4 & 25.02 \\
\hline $\mathbf{1}$ & 30 & 0 & 0 & 0 & 1.53 & 3.71 & 2.65 & 13 & 1.702 & 13 & 25.09 \\
\hline $\mathbf{1}$ & 25 & 20 & -1 & -1 & 0.54 & 8.06 & 51.95 & 1 & 0 & 0 & 26.10 \\
\hline $\mathbf{0 . 2}$ & 30 & 0 & -1 & -1 & 0.02 & 60 & 0 & 0 & 0 & 0 & 21.34 \\
\hline $\mathbf{0 . 5}$ & 30 & 0 & 1 & 1 & 0.42 & 13.16 & 2.38 & 5 & 8.320 & 4 & 25.00 \\
\hline
\end{tabular}

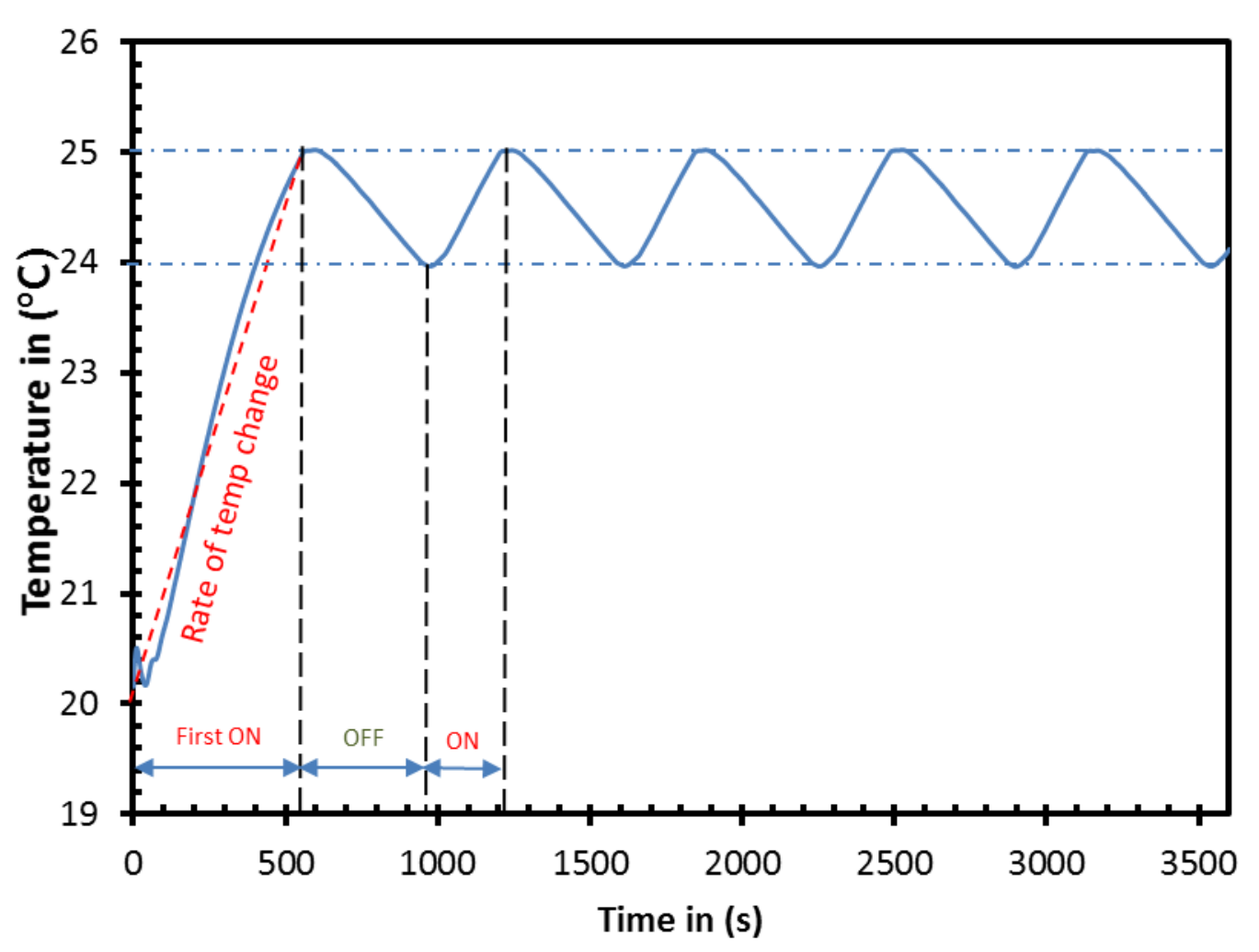

Figure 5.9. Average temperature variation around the person with inlet velocity of $0.4 \mathrm{~m} / \mathrm{s}$, inlet temperature $30^{\circ} \mathrm{C}$, outside temperature $10{ }^{\circ} \mathrm{C}$, and the person location is at the center. 
Chapter 5. Device components and its working methodology

Figure 5.10 shows the average temperature around the person at four different cases with different inlet condition, outside temperature, and person location. The operation conditions depend on those parameters. In case 2, Figure 5.10 (a), the inlet velocity is $1 \mathrm{~m} / \mathrm{s}$, the inlet temperature is $30^{\circ} \mathrm{C}$, outside temperature is zero ${ }^{\circ} \mathrm{C}$, and the person location is in the middle of the room.

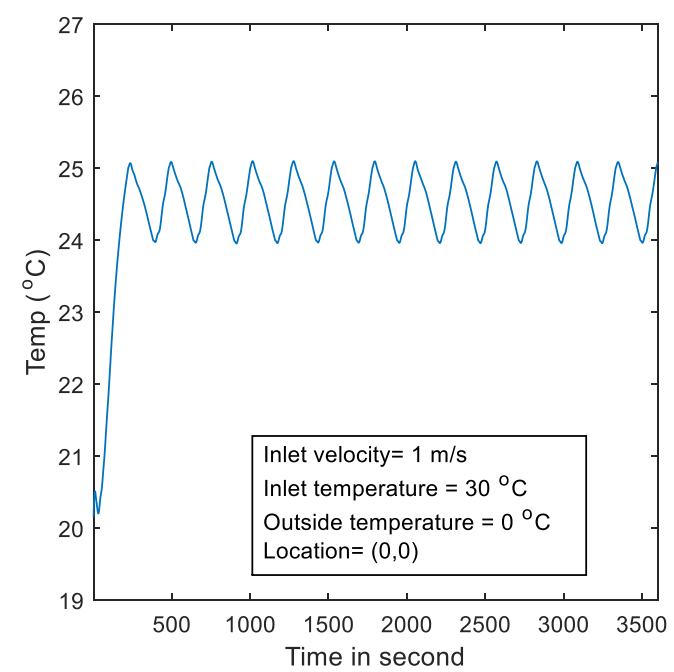

(a)

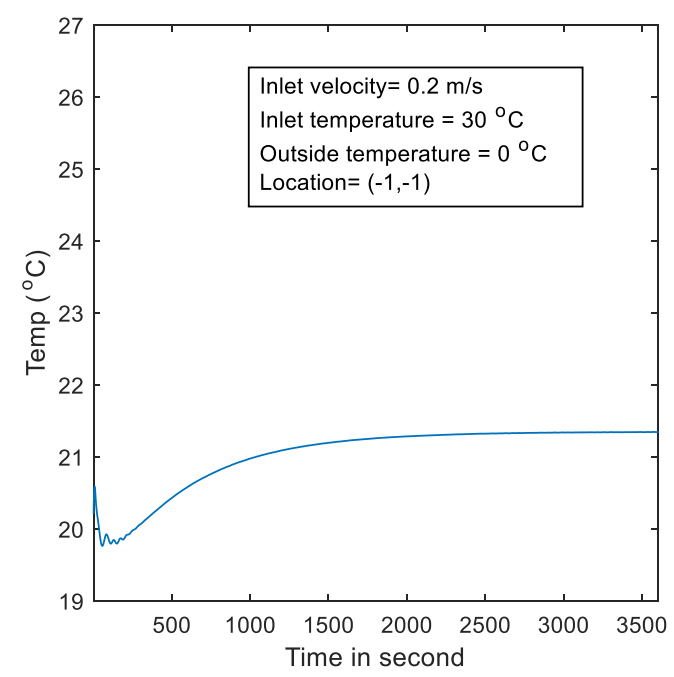

(c)

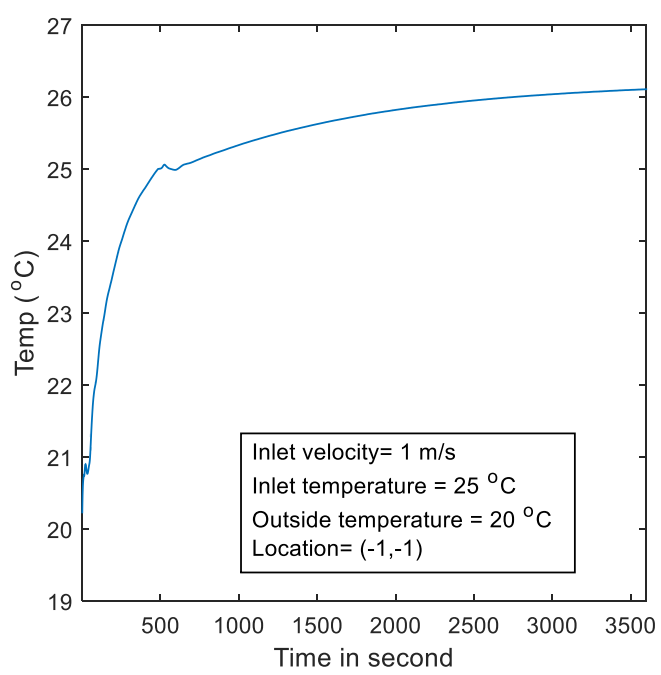

(b)



(d)

Figure 5.10. The average temperature plots around the person for different operation condition. 
The operation conditions are as follows: The first ON time is around 3.716 minutes, the average OFF time is 2.65 minutes, the average ON time is 1.702 , and the system needs to turn ON and OFF 13 times each. In Figure 5.10 (b) the inlet velocity is $1 \mathrm{~m} / \mathrm{s}$, the inlet temperature is 25 ${ }^{\circ} \mathrm{C}$, outside temperature is $20^{\circ} \mathrm{C}$, and the person is in the far corner from the inlet (see Figure 5.8 (c)). The operation condition is different in this case: the first ON time is around 8 minutes, and the system turns OFF for the rest of the hour because the average temperature did not reach the preferred condition. In Figure 5.10 (c) the inlet velocity is $0.2 \mathrm{~m} / \mathrm{s}$, the inlet temperature is $30{ }^{\circ} \mathrm{C}$, the outside temperature is zero ${ }^{\circ} \mathrm{C}$, and the person is next to the air inlet (see Figure $5.8(\mathrm{~b})$ ). In this case, the system run for the entire hour because the average temperature around the person has not reached the specified temperature $25^{\circ} \mathrm{C}$. On the other hands, in Figure 5.10 (d) if the inlet velocity is changed slightly higher to $0.5 \mathrm{~m} / \mathrm{s}$ and the person moved to far corner from the inlet with the same outside temperature and inlet temperature, the system totally has different operation conditions. The first time $\mathrm{ON}$ is around 13 minutes, the average OFF time is 2.38 minutes, average ON time is $8.32 \mathrm{~min}$.

\subsection{Summary and Conclusions}

In this paper, we introduced a virtual thermostat device and its working methodology, which utilizes computational fluid dynamic (CFD) to control the HVAC system. The main goals are to improve human thermal comfort, energy saving, and the HVAC system operation. The virtual thermostat determines the average temperature for any particular zone inside the HVAC controlled space. It then uses that calculated temperature as a feedback to control the HVAC system. The main components of the device are: a 3D scanner to reconstructs the controlled space, a CFD solver to determine the temperature distribution throughout the controlled space, and a computer to act as the main processing unit. It is shown that this device can save between 5-22\% of energy, depending on the operating conditions [80]. The virtual thermostat recognizes any movements inside the space or changes to the surrounding conditions and adjusts the HVAC system to minimize wasted energy for heating and cooling of undesired spaces. 


\section{Chapter 6 Closure}

\subsection{Summary and conclusion}

Improving energy consumption of an HVAC system and human thermal comfort inside control space can lead to an enormous reduction in the greenhouse effect and improvement in health and work quality of individuals. With this motivation, the current invention is aimed to reduce the energy consumption of HVAC system and improve human thermal comfort by focusing on an average temperature in target location inside the controlled space rather than temperature around a thermostat located far away from it. The device has been called virtual thermostat. The virtual thermostat estimates temperature distribution inside a controlled space using CFD solver. CFD simulate air velocity and temperature distribution inside a controlled space numerical by solving N-S and energy equations. The average temperature in target location is extracted from CFD results. The average temperature is used as feedback to turn the system ON or OFF. The device consists of two main component 3D scanner, to reconstruct 3D space \& locate people, and computer to act as the main processor and run CFD solver on it. One of the main issues of such approach is the respond time of the system. The computational time of CFD solver is very high. In addition, the device needs to run CFD calculation whenever a change occurs to the boundary conditions even though the change is very small. The problem has been solved using artificial neural network (ANN) model. The model is trained using old CFD calculations of the controlled space. The model has been used to estimate new operation conditions in few second instead of hours or days.

We conducted a CFD simulation study to check the advantages of local control in term of energy saving, human thermal comfort, and system instability. The study is conducted by comparing two control systems: one thermostat seating away from a target location (conventional thermostat) and the other is local temperature control. The two systems have been compared for an hour operation time. The following conclusions are made from the cases studied: (i) Up to $22 \%$ of energy can be saved if local control is used instead of the conventional thermostat. (ii) Virtual thermostat device is not sensitive to the device location.(iii) The average temperature around the person in the heating condition is higher for the sensor controlled system as compared to that of the locally controlled one. (iv) The time percentage which occupant spend on the comfort range is between $60 \%-90 \%$ for all the tested cases of the local control. However, for conventional 
thermostat control, the percentage vary from almost zero percent to $90 \%$ depend on the operation conditions. (v) The local control is more stable compared with conventional control. However, for high-speed direct heating local control can be unstable. In general, a locally controlled system has a better energy efficiency, better thermal comfort and system stability than the conventional controlled one when the inlet velocity is low.

One of the main issues of the virtual thermostat is the computational time. The average temperature in a target location inside controlled space depends on operation conditions, boundary conditions, and the location of the target location inside controlled space. Any change in one of those conditions results in a change in the average temperature in the target location. Therefore, CFD calculation is required to estimate those changes. To overcome those challenges, we proposed a way to utilize those information by training ANN model. Whenever CFD simulation is conducted, the inputs and output results is used to train ANN model. In other words, CFD results are used to train the virtual thermostat on how to respond to any change of the controlled space conditions. In this study 194 cases have been generated over a period of 3 months. Those results have been used to train two different ANN input configurations. The first model uses the operation conditions, person location, and outside temperature as inputs parameters to estimate operation time. The second model uses the preferred temperature rate, outside temperature, and person location to estimate the operation conditions and operation time. The study showed that the ANN model has been able to predict the first configuration with very good accuracy and failed in predicting the second input configuration. The best ANN training algorithm is found to be Bayesian Regularization algorithm. For the first input configuration, the best ANN size is 10 x 10 $\mathrm{x} 10 \mathrm{x} 4$ neurons. The maximum error of ANN prediction in the first input configuration is less than $7 \%$ for the three test cases, which corresponds to around $0.07^{\circ} \mathrm{C} / \mathrm{min}$ prediction error of the average rate of temperature change.

People location in local temperature control system can effect energy saving. Energy saving is totally depends on the boundary conditions of the controlled space. The energy saving can vary from couple of percentage to $140 \%$. CFD base control has the ability to detect those changes and control HVAC system accordingly. 


\subsection{Future work and recommendation}

In this work, we had proven the potential of local control in comparison with conventional control and we solved one of the main problems with such a method which is the computational time. The computational time has been reduced by reducing the number of times CFD solver requires to run. The CFD results are used as training base of ANN model. However, there are a number of another issue which will be our future work:

1- The training period for such a device is around 3 months. The required training data are around 194 cases and each 3 case need around one day or more to finish the calculation of one hour period. Therefore, the aim is to reduce this time by using less accurate numerical solver but more stable one. The best candidate is fast fluid dynamic (FFD) which can boost the speed. In addition, the main processor unit will be built in GPU instead of using CPU. Those two additions will increase the calculation speed to around 1500 times.

2- The second issue is related to the scanning mechanism. The current device uses Microsoft Kinect for scanning and locating people. Kinect has a narrow field of view which requires the device to scan whenever motion is detected. This way of scanning can be very annoying to people inside the controlled space. Therefore, next work will be on improving the scanning mechanism.

3- After solving those problems, the virtual thermostat needs to be tested in real life cases. The testing can be divided into two stages. The first stage is to test it in controlled environments (test chamber) to have a more detailed estimate of the device accuracy. The second stage is to test it in a number of residency houses for a year or so to estimate the energy saving. 


\section{Bibliography}

[1] "Residential Energy Consumption Survey Survey (RECS )," U.S. Energy Information Administration (eia), 2012. [Online]. Available:

https://www.eia.gov/todayinenergy/detail.php?id=10271\&src $=\_$Consumption Residential Energy Consumption Survey (RECS)-b1.

[2] F. Y. Naïma Behidj, Monique Brugger, Rosita Kwan, Stéphane Leblanc, Yantao Liu, Michael Warbanski, "Energy Efficiency Trends in Canada 1990 to 2009," Natural Resources Canada, 2011. [Online]. Available: http://oee.nrcan.gc.ca/publications/statistics/trends11/pdf/trends.pdf.

[3] International Facility Management Association (IFMA), “Temperature Wars: Savings vs. Comfort," 2009. [Online]. Available: http://www.ifma.org/docs/defaultsource/surveys/hvacsurvey2009.pdf?sfvrsn=2).

[4] R. Yang and M. W. Newman, "Living with an intelligent thermostat: Advanced control for heating and cooling systems," in UbiComp'12 - Proceedings of the 2012 ACM Conference on Ubiquitous Computing, 2012, pp. 1102-1107.

[5] P.-L. Rau, Y. Gong, H.-J. Huang, and J. Wen, “A Systematic Study for Smart Residential Thermostats: User Needs for the Input, Output, and Intelligence Level,” Buildings, vol. 6, no. 2, p. 19, 2016.

[6] M. M. Manning, M. C. Swinton, F. Szadkowski, J. Gusdorf, and K. Ruest, "The effects of thermostat setback and setup on seasonal energy consumption at the CCHT research facility," ASHRAE Trans., vol. 113 PART 1, pp. 630-641, 2005.

[7] Nest, "Nest Learning Thermostat,” 2016. [Online]. Available: https://nest.com.

[8] J. Scott, A. J. B. Brush, J. Krumm, B. Meyers, M. Hazas, S. Hodges, and N. Villar, "PreHeat: Controlling Home Heating Using Occupancy Prediction," in Proceedings of UbiComp 2011, 2011.

[9] M. Pritoni, A. K. Meier, C. Aragon, D. Perry, and T. Peffer, "Energy efficiency and the 
Bibliography

misuse of programmable thermostats: The effectiveness of crowdsourcing for understanding household behavior,” Energy Res. Soc. Sci., vol. 8, pp. 190-197, 2015.

[10] M. Gupta, S. S. Intille, and K. Larson, “Adding GPS-Control to Traditional Thermostats: An Exploration of Potential Energy Savings and Design Challenges," in Pervasive Computing: 7th International Conference, Pervasive 2009, Nara, Japan, May 11-14, 2009. Proceedings, H. Tokuda, M. Beigl, A. Friday, A. J. B. Brush, and Y. Tobe, Eds. Berlin, Heidelberg: Springer Berlin Heidelberg, 2009, pp. 95-114.

[11] S. Lee, Y. Chon, Y. Kim, R. Ha, and H. Cha, "Occupancy Prediction Algorithms for Thermostat Control Systems Using Mobile Devices," IEEE Trans. Smart Grid, vol. 4, no. 3, pp. 1332-1340, 2013.

[12] V. Erickson, S. Achleitner, and A. Cerpa, "POEM: power-efficient occupancy-based energy management system," in Proceedings of the 12th, 2013, pp. 203-216.

[13] W. J. Fisk, D. Faulkner, and D. P. Sullivan, "A pilot study of the accuracy of CO2 sensors in commercial buildings," IAQ Conf., no. October, pp. 1-11, 2008.

[14] D. Pisharoty, R. Yang, M. W. Newman, and K. Whitehouse, "ThermoCoach: Reducing Home Energy Consumption with Personalized Thermostat Recommendations," in Proceedings of the 2Nd ACM International Conference on Embedded Systems for EnergyEfficient Built Environments, 2015, pp. 201-210.

[15] H. Zhang, E. Arens, D. Kim, E. Buchberger, F. Bauman, and C. Huizenga, "Comfort, perceived air quality, and work performance in a low-power task-ambient conditioning system," Cent. Built Environ., Jul. 2009.

[16] P. X. Gao and S. Keshav, "SPOT: A Smart Personalized Office Thermal Control System," Proc. 2013 Int. Conf. Futur. Energy Syst. (e-Energy '13), p. 237, 2013.

[17] J. Zhang, R. G. Lutes, G. Liu, and M. R. Brambley, "Energy Savings for OccupancyBased Control (OBC) of Variable-Air-Volume (VAV) Systems," Pacific Northwest National Laboratory (PNNL), 24-Jan-2013. [Online]. Available: 
Bibliography

http://www.osti.gov/servlets/purl/1063080/.

[18] P. Zhou and G. Huang, "Experimental Study of Energy Saving Potential in Mixing and Displacement Ventilation with Wireless Sensor Networks," Procedia Eng., vol. 121, pp. 1497-1504, 2015.

[19] Y. Agarwal, B. Balaji, S. Dutta, R. K. Gupta, and T. Weng, "Duty-cycling buildings aggressively: The next frontier in HVAC control," in Proceedings of the 10th ACM/IEEE International Conference on Information Processing in Sensor Networks, 2011, pp. 246257.

[20] A. Persily, A. Musser, S. Emmerich, and M. Taylor, "Simulations of Indoor Air Quality and Ventilation Impacts of Demand Controlled Ventilation in Commercial and Institutional Buildings.," National Institute of Standards and Technology, 2003. [Online]. Available: http://fire.nist.gov/bfrlpubs/build03/PDF/b03074.pdf.

[21] V. Dhummi, D. Demetriou, H. J. Palanthandalam-Madapusi, H. E. Khalifa, and C. Isik, "Robust occupancy-based distributed demand control ventilation," Int. J. Vent., vol. 9, no. 4, pp. 359-369, 2011.

[22] F. Oldewurtel, D. Sturzenegger, and M. Morari, "Importance of occupancy information for building climate control," Appl. Energy, vol. 101, pp. 521-532, 2013.

[23] S. Goyal, H. A. Ingley, and P. Barooah, “Occupancy-based zone-climate control for energy-efficient buildings: Complexity vs. performance," Appl. Energy, vol. 106, pp. 209221, 2013.

[24] H. J. Weber, "Portable air comfort system thermostat enabling personal localized control of room temperature," US5839654 A, Nov-1998.

[25] Y. Xue, Z. J. Zhai, and Q. Chen, "Inverse prediction and optimization of flow control conditions for confined spaces using a CFD-based genetic algorithm," Build. Environ., vol. 64, pp. 77-84, 2013.

[26] Z. Lin, T. T. Chow, C. F. Tsang, K. F. Fong, and L. S. Chan, "CFD study on effect of the 


\section{Bibliography}

air supply location on the performance of the displacement ventilation system," Build. Environ., vol. 40, no. 8, pp. 1051-1067, Aug. 2005.

[27] E. Atam and L. Helsen, "Control-Oriented Thermal Modeling of Multizone Buildings: Methods and Issues: Intelligent Control of a Building System," IEEE Control Syst., vol. 36, no. 3, pp. 86-111, 2016.

[28] E. Wurtz, L. Mora, and C. Inard, "An equation-based simulation environment to investigate fast building simulation," Build. Environ., vol. 41, no. 11, pp. 1571-1583, 2006.

[29] W. Zuo and Q. Chen, "Fast and informative flow simulations in a building by using fast fluid dynamics model on graphics processing unit," Build. Environ., vol. 45, no. 3, pp. 747-757, 2010.

[30] W. Zuo and Q. Chen, "Real-time or faster-than-real-time simulation of airflow in buildings," Indoor Air, vol. 19, no. 1, pp. 33-44, 2009.

[31] M. Jin, W. Zuo, and Q. Chen, "Simulating Natural Ventilation in and Around Buildings by Fast Fluid Dynamics.," Numer. Heat Transf. Part A Appl., vol. 64, no. 4, pp. 273-289, 2014.

[32] M. Jin, W. Zuo, and Q. Chen, "Improvements of Fast Fluid Dynamics for Simulating Air Flow in Buildings," Numer. Heat Transf. Part B Fundam., vol. 62, no. 6, pp. 419-438, 2012.

[33] P. H. Shaikh, N. B. M. Nor, P. Nallagownden, I. Elamvazuthi, and T. Ibrahim, "A review on optimized control systems for building energy and comfort management of smart sustainable buildings," Renew. Sustain. Energy Rev., vol. 34, pp. 409-429, 2014.

[34] W. Zuo and Q. Chen, "Improvements on the Fast Fluid Dynamic Model for Indoor Airflow Simulation,” SimBuild 2010, pp. 539-546, 539.

[35] F. J. Trujillo and Q. T. Pham, "A computational fluid dynamic model of the heat and moisture transfer during beef chilling," Int. J. Refrig., vol. 29, no. 6, pp. 998-1009, 2006. 


\section{Bibliography}

[36] Z. Hu and D. W. Sun, "CFD simulation of heat and moisture transfer for predicting cooling rate and weight loss of cooked ham during air-blast chilling process," J. Food Eng., vol. 46, no. 3, pp. 189-197, 2000.

[37] B. Xia and D.-W. Sun, "Applications of computational fluid dynamics (cfd) in the food industry: a review," Comput. Electron. Agric., vol. 34, no. 1-3, pp. 5-24, 2002.

[38] T. Norton and D.-W. Sun, "Computational fluid dynamics (CFD) - an effective and efficient design and analysis tool for the food industry: A review," Trends Food Sci. Technol., vol. 17, no. 11, pp. 600-620, 2006.

[39] A. Motamedzadegan, "CFD Application on Food Industry; Energy Saving on the Bread Oven,” Iran. J. Energy Environ., vol. 3, no. 3, pp. 259-263, 2012.

[40] A. G. Gerber, R. Dubay, and A. Healy, "CFD-based predictive control of melt temperature in plastic injection molding," Appl. Math. Model., vol. 30, no. 9, pp. 884-903, 2006.

[41] S. Murakami, S. Kato, and T. Kim, "Coupled simulation of convicton, radiation, and HVAC control for attaining a given PMV value,” Build. Environ., vol. 36, no. 6, pp. 701709, 2001.

[42] M. Bartak, I. Beausoleil-Morrison, J. A. Clarke, J. Denev, F. Drkal, M. Lain, I. A. Macdonald, A. Melikov, Z. Popiolek, and P. Stankov, "Integrating CFD and building simulation,” Build. Environ., vol. 37, no. 8-9, pp. 865-871, Aug. 2002.

[43] Z. Zhai, Q. Chen, P. Haves, and J. H. Klems, "On approaches to couple energy simulation and computational fluid dynamics programs," Build. Environ., vol. 37, no. 8-9, pp. 857864, Aug. 2002.

[44] Z. J. Zhai and Q. Y. Chen, "Performance of coupled building energy and CFD simulations," Energy Build., vol. 37, no. 4, pp. 333-344, Apr. 2005.

[45] Z. Zhai, "Application of Computational Fluid Dynamics in Building Design: Aspects and Trends," Indoor Built Environ., vol. 15, no. 4, pp. 305-313, Aug. 2006. 


\section{Bibliography}

[46] I. Beausoleil-Morrison, "The adaptive conflation of computational fluid dynamics with whole-building thermal simulation," Energy Build., vol. 34, no. 9, pp. 857-871, Oct. 2002.

[47] D. Kim, J. Braun, J. Borggaard, and E. Cliff, “Coupled CFD / Building Envelope Model for the Purdue Living Lab Indoor-air Model," in High Performance Buildings Conference, 2012, vol. 2012, pp. 1-10.

[48] Y. Chen and H. Chen, "Application of computation Fluid dynamic for high energy efficiency design with human comfort of CAD-VAV and UFAD systems," National Center for Energy Management and Building Technologies, 2009. [Online]. Available: http://nemionline.org/site/en/resource/index/view/resource/25.

[49] G. M. Stavrakakis, P. L. Zervas, H. Sarimveis, and N. C. Markatos, “Optimization of window-openings design for thermal comfort in naturally ventilated buildings," Appl. Math. Model., vol. 36, no. 1, pp. 193-211, 2012.

[50] G. M. Stavrakakis, P. L. Zervas, H. Sarimveis, and N. C. Markatos, "Development of a computational tool to quantify architectural-design effects on thermal comfort in naturally ventilated rural houses," Build. Environ., vol. 45, no. 1, pp. 65-80, 2010.

[51] L. Zhou and F. Haghighat, "Optimization of ventilation system design and operation in office environment, Part I: Methodology,” Build. Environ., vol. 44, no. 4, pp. 651-656, Apr. 2009.

[52] L. Zhou and F. Haghighat, "Optimization of ventilation systems in office environment, Part II: Results and discussions,” Build. Environ., vol. 44, no. 4, pp. 657-665, 2009.

[53] G. Tan and L. R. Glicksman, "Application of integrating multi-zone model with CFD simulation to natural ventilation prediction,” Energy Build., vol. 37, no. 10, pp. 10491057, Oct. 2005.

[54] S. I. Tanabe, K. Kobayashi, J. Nakano, Y. Ozeki, and M. Konishi, "Evaluation of thermal comfort using combined multi-node thermoregulation $(65 \mathrm{MN})$ and radiation models and 
Bibliography

computational fluid dynamics (CFD)," Energy Build., vol. 34, no. 6, pp. 637-646, 2002.

[55] A. Mistriotis, G. P. A. Bot, P. Picuno, and G. Scarascia-Mugnozza, "Analysis of the efficiency of greenhouse ventilation using computational fluid dynamics," Agric. For. Meteorol., vol. 85, no. 3-4, pp. 217-228, Jul. 1997.

[56] H. J. Steeman, A. Janssens, J. Carmeliet, and M. De Paepe, "Modelling indoor air and hygrothermal wall interaction in building simulation: Comparison between CFD and a well-mixed zonal model," Build. Environ., vol. 44, no. 3, pp. 572-583, Mar. 2009.

[57] T.-T. Chow and X.-Y. Yang, "Performance of ventilation system in a non-standard operating room,” Build. Environ., vol. 38, no. 12, pp. 1401-1411, Dec. 2003.

[58] P. Nielsen, S. Murakami, S. Kato, C. Topp, and J.-H. Yang, "Benchmark tests for a computer simulated person," Aalborg University, 2003. [Online]. Available: http://homes.civil.aau.dk/pvn/cfd-benchmarks/csp_benchmark_test/Benchmark Tests_071103.pdf.

[59] I. Celik, U. Ghia, P. Roache, and Christopher, "Procedure for Estimation and Reporting of Uncertainty Due to Discretization in CFD Applications," J. Fluids Eng., vol. 130, no. 7, p. $78001,2008$.

[60] Q. Chen, "Comparison of different k - $\varepsilon$ models for indoor air flow computations," Numer. Heat Transf. Part B Fundam., vol. 28, no. 3, pp. 353-369, Oct. 1995.

[61] T. Zerihun Desta, K. Janssens, A. Van Brecht, J. Meyers, M. Baelmans, and D. Berckmans, "CFD for model-based controller development," Build. Environ., vol. 39, no. 6, pp. 621-633, 2004.

[62] Z. Sun and S. Wang, "A CFD-based test method for control of indoor environment and space ventilation,” Build. Environ., vol. 45, no. 6, pp. 1441-1447, Jun. 2010.

[63] Z. Du, X. Jin, and Y. Yang, "Fault diagnosis for temperature, flow rate and pressure sensors in VAV systems using wavelet neural network," Appl. Energy, vol. 86, no. 9, pp. 1624-1631, 2009. 


\section{Bibliography}

[64] B. Thomas and M. Soleimani-Mohseni, "Artificial neural network models for indoor temperature prediction: Investigations in two buildings," Neural Comput. Appl., vol. 16, no. 1, pp. 81-89, 2007.

[65] R. Yokoyama, T. Wakui, and R. Satake, "Prediction of energy demands using neural network with model identification by global optimization," Energy Convers. Manag., vol. 50, no. 2, pp. 319-327, 2009.

[66] J. W. Moon, J. H. Lee, and S. Kim, "Evaluation of artificial neural network-based temperature control for optimum operation of building envelopes," Energies, vol. 7, no. 11, pp. 7245-7265, 2014.

[67] S. Akbari, H. B. Hemingson, D. Beriault, C. J. Simonson, and R. W. Besant, “Application of neural networks to predict the steady state performance of a Run-Around Membrane Energy Exchanger,” Int. J. Heat Mass Transf., vol. 55, no. 5-6, pp. 1628-1641, 2012.

[68] R. R. Madadi and C. Balaji, "Optimization of the location of multiple discrete heat sources in a ventilated cavity using artificial neural networks and micro genetic algorithm," Int. J. Heat Mass Transf., vol. 51, no. 9-10, pp. 2299-2312, 2008.

[69] Z. Song, B. T. Murray, and B. Sammakia, "A dynamic compact thermal model for data center analysis and control using the zonal method and artificial neural networks," Appl. Therm. Eng., vol. 62, no. 1, pp. 48-57, 2014.

[70] A. Marvuglia, A. Messineo, and G. Nicolosi, "Coupling a neural network temperature predictor and a fuzzy logic controller to perform thermal comfort regulation in an office building," Build. Environ., vol. 72, pp. 287-299, 2014.

[71] T.-H. Zhang and X.-Y. You, "Inverse design of aircraft cabin environment by coupling artificial neural network and genetic algorithm," HVAC\&R Res., vol. 20, no. 7, pp. 836$843,2014$.

[72] T. Zhang and X. You, "Applying neural networks to solve the inverse problem of indoor environment," Indoor Built Environ., vol. 23, no. 8, pp. 1187-1195, 2014. 


\section{Bibliography}

[73] L. Magnier and F. Haghighat, "Multiobjective optimization of building design using TRNSYS simulations, genetic algorithm, and Artificial Neural Network," Build. Environ., vol. 45, no. 3, pp. 739-746, 2010.

[74] Z. Song, B. T. Murray, and B. Sammakia, "Airflow and temperature distribution optimization in data centers using artificial neural networks," Int. J. Heat Mass Transf., vol. 64, pp. 80-90, 2013.

[75] K. Li, W. Xue, C. Xu, and H. Su, "Optimization of ventilation system operation in office environment using POD model reduction and genetic algorithm," Energy Build., vol. 67, pp. 34-43, 2013.

[76] C. C. António and C. F. Afonso, "Air temperature fields inside refrigeration cabins: A comparison of results from CFD and ANN modelling," Appl. Therm. Eng., vol. 31, no. 67, pp. 1244-1251, 2011.

[77] A. Viano, G. Ottino, L. Ratto, and G. Spataro, "Coupled CFD-ANN Procedure for Extending Heat Transfer Correlations out of Their Range of Validity," Proc. ASME TurboExpo, p. GT2012-69707, 2012.

[78] I. Haryanto, T. S. Utomo, N. Sinaga, C. A. Rosalia, and A. P. Putra, "Optimization of Maximum Lift to Drag Ratio on Airfoil Design Based on Artificial Neural Network Utilizing Genetic Algorithm,” Appl. Mech. Mater., vol. 493, pp. 123-128, 2014.

[79] MathWorks, "Matlab Neural Networks Toolbox.” [Online]. Available: http://www.mathworks.com/products/neural-network/.

[80] M. Alhashme and N. Ashgriz, "A Virtual Thermostat for Local Temperature Control," Energy Build., vol. 126, pp. 323-339, May 2016.

[81] OpenFoam, “CFD solver," 2016. [Online]. Available: http://www.openfoam.com/.

[82] ANSYS Inc, “ANSYS Fluent theory guide,” vol. 15317, no. November, pp. 724-746, 2013. 


\section{Bibliography}

[83] B. E. Launder and D. B. Spalding, "The numerical computation of turbulent flows," Comput. Methods Appl. Mech. Eng., vol. 3, no. 2, pp. 269-289, 1974. 


\section{Appendices}

\section{Appendix A. Governing Equations}

Symbols

\begin{tabular}{ll}
$\rho$ & Density, $\frac{K g}{m^{3}}$ \\
$\vec{v}$ & Velocity vector \\
$t$ & Time in second \\
$S_{m}$ & Mass source term \\
$p$ & Static pressure \\
$\vec{g}$ & Gravitational body force \\
$\vec{F}$ & External body force \\
$\overline{\bar{\tau}}$ & Stress tensor \\
$\mu$ & Molecular viscosity \\
$E$ & Total energy \\
$T$ & Temperature \\
$k$ & Effective conductivity \\
$S_{h}$ & Heat source \\
\hline
\end{tabular}


Appendix A. Governing Equations

All the equations have been taking from ANSYS FLUENT theory guide [82].

\section{Mass conservation equation}

$\frac{\partial \rho}{\partial t}+\nabla \cdot(\rho \vec{v})=S_{m}$

\section{Momentum conservation equations}

$\frac{\partial}{\partial t}(\rho \vec{v})+\nabla \cdot(\rho \vec{v} \vec{v})=-\nabla p+\nabla \cdot(\overline{\bar{\tau}})+\rho \vec{g}+\vec{F}$

Where

$\overline{\bar{\tau}}=\mu\left(\nabla \vec{v}+\nabla \vec{v}^{T}\right)$

\section{Energy equations}

$$
\frac{\partial}{\partial t}(\rho E)+\nabla \cdot(\rho \vec{v}(\rho E+p))=\nabla \cdot\left(k \nabla T+\left(\overline{\bar{\tau}}_{\epsilon j f} \cdot \vec{v}\right)\right)+S_{h}
$$

Total Energy

$$
E=h-\frac{p}{\rho}+\frac{v^{2}}{2}
$$




\section{Appendix B. Standard wall functions}

All the equations are from ANSYS Fluent Theory Guide [82].

Symbols

$\kappa=0.4187$ Von Karman constant,

$E \quad=9.793$ empirical constant

$U_{p} \quad$ Mean velocity of the fluid at the wall-adjacent cell centroid, $\mathrm{P}$

$K_{p} \quad$ Turbulence kinetic energy at the wall-adjacent cell centroid, $\mathrm{P}$

$y_{p} \quad$ Distance from the centroid of the wall-adjacent cell to the wall, $\mathrm{P}$

$\mu \quad$ Dynamic viscosity of the fluid

$\rho \quad$ Density of the fluid

$C_{p} \quad$ Specific heat of fluid

$\dot{q} \quad$ Wall heat flux

$T_{p} \quad$ Temperature at the wall-adjacent cell centroid, $\mathrm{P}$

$T_{w} \quad$ Temperature at the wall

$\operatorname{Pr} \quad$ Molecular PrandtI number $\left(\mu C_{p} / k f\right)$

$\mathrm{Pr}_{t} \quad$ Turbulent Prandtl number (0.85 at the wall)

A Van Driest constant (=26) 
Appendix B. Standard wall functions

\section{$U_{c} \quad$ Mean velocity magnitude at $y^{*}=y_{T}^{*}$}

\section{Momentum}

The law-of-the-wall for mean velocity is

$U^{*}=\frac{1}{\kappa} \ln \left(E y^{*}\right)$

Where the dimensionless velocity is

$U^{*} \equiv \frac{U_{p} C_{\mu}^{\frac{1}{4}} k_{p}^{\frac{1}{2}}}{\frac{\tau_{w}}{\rho}}$

The dimensionless distance from the wall is

$U^{*} \equiv \frac{\rho C_{\mu}^{\frac{1}{4}} k_{p}^{\frac{1}{2}} y_{p}}{\mu}$

\section{Energy}

The law-of-the-wall implemented in ANSYS Fluent has the following composite form:

$T^{*} \equiv \frac{\left(T_{w}-T_{p}\right) \rho c_{p} C_{\mu}^{\frac{1}{4}} K_{p}^{\frac{1}{2}}}{\dot{q}}$

$= \begin{cases}P_{r y}^{*}+\frac{1}{2} \rho \operatorname{Pr} \frac{C_{\mu}^{1 / 4} K_{p}^{1 / 2}}{\dot{q}} U_{p}^{2} & \left(y^{*}<y_{T}^{*}\right) \\ \operatorname{Pr}_{t}\left[\frac{1}{\kappa} \ln \left(E y^{*}\right)+P\right]+\frac{1}{2} \rho \frac{C_{\mu}^{1 / 4} K_{p}^{1 / 2}}{\dot{q}}\left\{\operatorname{Pr}_{t} U_{p}^{2}+\left(P r-P r_{t}\right) U_{c}^{2}\right\} & \left(y^{*}>y_{T}^{*}\right)\end{cases}$

Where $\mathrm{P}$ is computed using

$P=9.24\left[\left(\frac{P r}{P r_{t}}\right)^{3 / 4}-1\right]\left[1+0.28 e^{-0.007 \operatorname{Pr} / \operatorname{Pr}_{t}}\right]$

For rough walls $\mathrm{P}$ is computed using

$P_{\text {rough }}=3.15 P P^{0.695}\left(\frac{1}{E^{\prime}}-\frac{1}{E}\right)^{0.359}+\left(\frac{E^{\prime}}{E}\right)^{0.6} P$ 
Appendix B. Standard wall functions

Where $E^{\prime}$ is the wall function constant modified for rough walls. 
Appendix C. Operation conditions of the HVAC system for the controlled space.

\begin{tabular}{ccccccccc}
$\mathbf{V}$ in & $\mathbf{T}_{\text {in }}$ & $\mathbf{T}_{\mathbf{0}}$ & $\mathbf{X}$ & $\mathbf{Y}$ & $\mathbf{T}$ Rate & $\mathbf{O F F}$ & $\mathbf{O N}$ & $\mathbf{T}_{\text {Max }}$ \\
$\mathbf{m} / \mathbf{s}$ & ${ }^{\mathbf{}} \mathbf{C}$ & ${ }^{\mathbf{}} \mathbf{C}$ & $\mathbf{m}$ & $\mathbf{m}$ & ${ }^{\mathbf{}} \mathbf{C} / \mathbf{m i n}$ & $\mathbf{m i n}$ & $\mathbf{m i n}$ & ${ }^{{ }^{\mathbf{C}}}$ \\
\hline 0.4 & 30 & 10 & 0 & 0 & 0.583497 & 6.43 & 4.3125 & 25.02252 \\
\hline 0.4 & 25 & 10 & 0 & 0 & 0.033204 & 0 & 0 & 23.52551 \\
\hline 0.4 & 27 & 10 & 0 & 0 & 0.045934 & 0 & 0 & 24.84143 \\
\hline 0.4 & 35 & 10 & 0 & 0 & 0.955255 & 8.763333 & 2.495833 & 25.23554 \\
\hline 1 & 35 & 10 & 0 & 0 & 2.30196 & 10.04 & 1.033333 & 25.44354 \\
\hline 1 & 30 & 10 & 0 & 0 & 1.78883 & 6.878571 & 1.391667 & 25.22784 \\
\hline 1 & 25 & 10 & 0 & 0 & 0.028693 & 0 & 0 & 24.63681 \\
\hline 1 & 27 & 10 & 0 & 0 & 0.801819 & 5.175 & 2.975 & 25.1095 \\
\hline 2 & 27 & 10 & 0 & 0 & 1.696231 & 4.461667 & 0.931667 & 25.23886 \\
\hline & 30 & 10 & 0 & 0 & 2.667178 & 7.264286 & 0.697619 & 25.91995 \\
\hline
\end{tabular}


Appendix C. Operation conditions of the HVAC system for the controlled space.

\begin{tabular}{|c|c|c|c|c|c|c|c|c|}
\hline$V_{\text {in }}$ & $\mathbf{T}_{\text {in }}$ & $\mathbf{T}_{\mathbf{o}}$ & $\mathbf{X}$ & $\mathbf{Y}$ & $\mathbf{T}_{\text {Rate }}$ & OFF & ON & $\mathbf{T}_{\text {Max }}$ \\
\hline $\mathrm{m} / \mathrm{s}$ & ${ }^{\circ} \mathrm{C}$ & ${ }^{\circ} \mathrm{C}$ & $\mathbf{m}$ & $\mathbf{m}$ & ${ }^{\circ} \mathrm{C} / \mathrm{min}$ & $\min$ & $\min$ & ${ }^{\circ} \mathrm{C}$ \\
\hline 2 & 35 & 10 & 0 & 0 & 4.463232 & 11.04667 & 0.586667 & 26.2258 \\
\hline 2 & 35 & 0 & 0 & 0 & 4.22603 & 4.578788 & 0.633333 & 25.99411 \\
\hline 2 & 30 & 0 & 0 & 0 & 2.41219 & 2.827083 & 0.732292 & 25.72195 \\
\hline 2 & 27 & 0 & 0 & 0 & 1.35518 & 1.894444 & 1.238889 & 25.19119 \\
\hline 1 & 27 & 0 & 0 & 0 & 0.144261 & 1.933333 & 34.25 & 25.00012 \\
\hline 1 & 30 & 0 & 0 & 0 & 1.531227 & 2.65 & 1.702564 & 25.0965 \\
\hline 1 & 35 & 0 & 0 & 0 & 2.18395 & 3.971212 & 1.133333 & 25.19171 \\
\hline 0.2 & 35 & 0 & 0 & 0 & 0.054382 & 0 & 0 & 23.90259 \\
\hline 0.2 & 30 & 0 & 0 & 0 & 0.023862 & 0 & 0 & 21.56696 \\
\hline 0.2 & 27 & 0 & 0 & 0 & 0.005805 & 0 & 0 & 20.49014 \\
\hline 0.2 & 27 & 20 & 0 & 0 & 0.374192 & 46.53333 & 0 & 26.54843 \\
\hline
\end{tabular}


Appendix C. Operation conditions of the HVAC system for the controlled space.

\begin{tabular}{|c|c|c|c|c|c|c|c|c|}
\hline$V_{\text {in }}$ & $T_{\text {in }}$ & $\mathbf{T}_{\mathbf{o}}$ & $\mathbf{X}$ & $\mathbf{Y}$ & $\mathbf{T}_{\text {Rate }}$ & OFF & ON & $\mathbf{T}_{\text {Max }}$ \\
\hline $\mathrm{m} / \mathrm{s}$ & ${ }^{\mathbf{o}} \mathrm{C}$ & ${ }^{\circ} \mathrm{C}$ & $\mathbf{m}$ & $\mathbf{m}$ & ${ }^{\circ} \mathrm{C} / \mathrm{min}$ & $\min$ & $\min$ & ${ }^{\circ} \mathrm{C}$ \\
\hline 0.2 & 30 & 20 & 0 & 0 & 0.513001 & 50 & 0 & 26.6528 \\
\hline 0.2 & 35 & 20 & 0 & 0 & 0.697888 & 52.63333 & 0 & 26.83456 \\
\hline 1 & 35 & 20 & 0 & 0 & 2.44306 & 58.01667 & 0 & 26.92072 \\
\hline 1 & 30 & 20 & 0 & 0 & 1.990508 & 57.38333 & 0 & 26.70752 \\
\hline 1 & 25 & 20 & 0 & 0 & 0.570578 & 51.5 & 0 & 26.54947 \\
\hline 2 & 25 & 20 & 0 & 0 & 0.981226 & 55.16667 & 0 & 26.52954 \\
\hline 2 & 30 & 20 & 0 & 0 & 2.993986 & 58.3 & 0 & 26.73013 \\
\hline 2 & 35 & 20 & 0 & 0 & 4.685333 & 58.85 & 0 & 26.92889 \\
\hline 2 & 35 & 20 & -1 & -1 & 4.220096 & 59.01667 & 0 & 26.45136 \\
\hline 2 & 30 & 20 & -1 & -1 & 3.161253 & 58.7 & 0 & 26.237 \\
\hline 2 & 25 & 20 & -1 & -1 & 0.957265 & 55.56667 & 0 & 26.10306 \\
\hline
\end{tabular}


Appendix C. Operation conditions of the HVAC system for the controlled space.

\begin{tabular}{|c|c|c|c|c|c|c|c|c|}
\hline$V_{\text {in }}$ & $T_{\text {in }}$ & $\mathbf{T}_{\mathbf{o}}$ & $\mathbf{X}$ & $\mathbf{Y}$ & $T_{\text {Rate }}$ & OFF & ON & $\mathbf{T}_{\text {Max }}$ \\
\hline $\mathrm{m} / \mathrm{s}$ & ${ }^{\mathbf{o}} \mathrm{C}$ & ${ }^{\circ} \mathrm{C}$ & $\mathbf{m}$ & $\mathbf{m}$ & ${ }^{\circ} \mathrm{C} / \mathrm{min}$ & $\min$ & $\min$ & ${ }^{\circ} \mathrm{C}$ \\
\hline 1 & 25 & 20 & -1 & -1 & 0.5414 & 51.95 & 0 & 26.10934 \\
\hline 1 & 30 & 20 & -1 & -1 & 2.158309 & 57.66667 & 0 & 26.26703 \\
\hline 1 & 35 & 20 & -1 & -1 & 2.712912 & 58.18333 & 0 & 26.50201 \\
\hline 0.2 & 25 & 20 & -1 & -1 & 0.228547 & 38.95 & 0 & 26.00827 \\
\hline 0.2 & 30 & 20 & -1 & -1 & 0.491757 & 49.58333 & 0 & 26.24396 \\
\hline 0.2 & 35 & 20 & -1 & -1 & 0.68537 & 52.51667 & 0 & 26.46988 \\
\hline 0.2 & 25 & 10 & -1 & -1 & 0.029281 & 0 & 0 & 22.34183 \\
\hline 0.2 & 30 & 10 & -1 & -1 & 0.059949 & 0 & 0 & 24.75256 \\
\hline 0.2 & 35 & 10 & -1 & -1 & 0.404374 & 6.404167 & 5.866667 & 25.05374 \\
\hline 1 & 25 & 10 & -1 & -1 & 0.024721 & 0 & 0 & 24.57712 \\
\hline 1 & 30 & 10 & -1 & -1 & 1.937868 & 4.445 & 0.915 & 25.07327 \\
\hline
\end{tabular}


Appendix C. Operation conditions of the HVAC system for the controlled space.

\begin{tabular}{|c|c|c|c|c|c|c|c|c|}
\hline$V_{\text {in }}$ & $T_{\text {in }}$ & $\mathbf{T}_{\mathbf{o}}$ & $\mathbf{X}$ & $\mathbf{Y}$ & $\mathbf{T}_{\text {Rate }}$ & OFF & $\mathbf{O N}$ & $\mathbf{T}_{\text {Max }}$ \\
\hline $\mathbf{m} / \mathbf{s}$ & ${ }^{\circ} \mathrm{C}$ & ${ }^{\circ} \mathrm{C}$ & $\mathbf{m}$ & $\mathbf{m}$ & ${ }^{\circ} \mathrm{C} / \mathrm{min}$ & $\min$ & $\min$ & ${ }^{\circ} \mathrm{C}$ \\
\hline 1 & 35 & 10 & -1 & -1 & 2.55768 & 7.219048 & 0.766667 & 25.10342 \\
\hline 2 & 25 & 10 & -1 & -1 & 0.012089 & 0 & 0 & 24.93213 \\
\hline 2 & 30 & 10 & -1 & -1 & 3.032871 & 2.101282 & 0.182692 & 25.13974 \\
\hline 2 & 35 & 10 & -1 & -1 & 5.811891 & 2.634921 & 0.133333 & 25.48853 \\
\hline 2 & 25 & 0 & -1 & -1 & 0.011987 & 0 & 0 & 24.39175 \\
\hline 2 & 30 & 0 & -1 & -1 & 2.684917 & 2.103788 & 0.543182 & 25.4501 \\
\hline 2 & 35 & 0 & -1 & -1 & 5.499687 & 1.018269 & 0.132692 & 25.46732 \\
\hline 1 & 35 & 0 & -1 & -1 & 2.398001 & 2.663725 & 0.760784 & 25.07428 \\
\hline 1 & 30 & 0 & -1 & -1 & 1.703398 & 1.538406 & 0.97803 & 25.02966 \\
\hline 1 & 25 & 0 & -1 & -1 & 0.019553 & 0 & 0 & 23.43344 \\
\hline 0.2 & 25 & 0 & -1 & -1 & -0.00842 & 0 & 0 & 20.57819 \\
\hline
\end{tabular}


Appendix C. Operation conditions of the HVAC system for the controlled space.

\begin{tabular}{|c|c|c|c|c|c|c|c|c|}
\hline$V_{\text {in }}$ & $T_{\text {in }}$ & $\mathbf{T}_{\mathbf{o}}$ & $\mathbf{X}$ & $\mathbf{Y}$ & $T_{\text {Rate }}$ & OFF & ON & $\mathbf{T}_{\text {Max }}$ \\
\hline $\mathbf{m} / \mathbf{s}$ & ${ }^{\circ} \mathrm{C}$ & ${ }^{\circ} \mathrm{C}$ & $\mathbf{m}$ & $\mathbf{m}$ & ${ }^{\circ} \mathrm{C} / \mathrm{min}$ & $\min$ & $\min$ & ${ }^{\circ} \mathrm{C}$ \\
\hline 0.2 & 30 & 0 & -1 & -1 & 0.021416 & 0 & 0 & 21.34262 \\
\hline 0.2 & 35 & 0 & -1 & -1 & 0.051393 & 0 & 0 & 23.68457 \\
\hline 1.22 & 30.6 & 19 & 0 & 0 & 2.489393 & 57.88333 & 0 & 26.13849 \\
\hline 0.5 & 35 & 0 & -1 & -1 & 1.022304 & 3.372222 & 2.664815 & 25.05154 \\
\hline 0.5 & 30 & 0 & -1 & -1 & 0.397156 & 2.3625 & 9.070833 & 25.00076 \\
\hline 1.26 & 29.3 & 19 & 0 & 0 & 2.165747 & 57.48333 & 0 & 26.08829 \\
\hline 0.5 & 25 & 0 & -1 & -1 & 0.016499 & 0 & 0 & 21.88144 \\
\hline 0.7 & 27 & 15 & 0 & 0 & 0.800006 & 22.35 & 3 & 25.06757 \\
\hline 0.2 & 25 & 0 & 1 & 1 & -0.00904 & 0 & 0 & 20.58023 \\
\hline 0.2 & 30 & 0 & 1 & 1 & 0.020959 & 0 & 0 & 21.46228 \\
\hline 0.2 & 35 & 0 & 1 & 1 & 0.052854 & 0 & 0 & 23.78565 \\
\hline
\end{tabular}


Appendix C. Operation conditions of the HVAC system for the controlled space.

\begin{tabular}{|c|c|c|c|c|c|c|c|c|}
\hline$V_{\text {in }}$ & $T_{\text {in }}$ & $\mathbf{T}_{\mathbf{o}}$ & $\mathbf{X}$ & $\mathbf{Y}$ & $\mathbf{T}_{\text {Rate }}$ & OFF & $\mathbf{O N}$ & $\mathbf{T}_{\text {Max }}$ \\
\hline $\mathbf{m} / \mathbf{s}$ & ${ }^{\circ} \mathrm{C}$ & ${ }^{\circ} \mathrm{C}$ & $\mathbf{m}$ & $\mathbf{m}$ & ${ }^{\circ} \mathrm{C} / \mathrm{min}$ & $\min$ & $\min$ & ${ }^{\circ} \mathrm{C}$ \\
\hline 0.5 & 25 & 0 & 1 & 1 & 0.015851 & 0 & 0 & 21.86447 \\
\hline 0.5 & 30 & 0 & 1 & 1 & 0.428093 & 2.38 & 8.320833 & 25.00125 \\
\hline 0.5 & 35 & 0 & 1 & 1 & 1.007755 & 3.433333 & 2.648148 & 25.04651 \\
\hline 1 & 35 & 0 & 1 & 1 & 2.331493 & 3.451282 & 1.008974 & 25.32501 \\
\hline 1 & 30 & 0 & 1 & 1 & 1.565927 & 2.252222 & 1.491111 & 25.10541 \\
\hline 1 & 25 & 0 & 1 & 1 & 1.565927 & 2.252222 & 1.491111 & 25.10541 \\
\hline 2 & 30 & 0 & 1 & 1 & 3.103968 & 1.854667 & 0.45 & 25.22913 \\
\hline 2 & 25 & 0 & 1 & 1 & 0.011375 & 0 & 0 & 24.19858 \\
\hline 2 & 35 & 0 & 1 & 1 & 4.618827 & 3.183333 & 0.415625 & 25.67084 \\
\hline 2 & 35 & 10 & 1 & 1 & 4.709631 & 7.602381 & 0.4 & 25.74295 \\
\hline 2 & 30 & 10 & 1 & 1 & 3.328404 & 5.07 & 0.466667 & 25.18692 \\
\hline
\end{tabular}


Appendix C. Operation conditions of the HVAC system for the controlled space.

\begin{tabular}{|c|c|c|c|c|c|c|c|c|}
\hline$V_{\text {in }}$ & $\mathbf{T}_{\text {in }}$ & $\mathbf{T}_{\mathbf{o}}$ & $\mathbf{X}$ & $\mathbf{Y}$ & $\mathbf{T}_{\text {Rate }}$ & OFF & ON & $\mathbf{T}_{\text {Max }}$ \\
\hline $\mathrm{m} / \mathrm{s}$ & ${ }^{\circ} \mathrm{C}$ & ${ }^{\circ} \mathrm{C}$ & $\mathbf{m}$ & $\mathbf{m}$ & ${ }^{\circ} \mathrm{C} / \mathrm{min}$ & $\min$ & $\min$ & ${ }^{\circ} \mathrm{C}$ \\
\hline 2 & 25 & 10 & 1 & 1 & 0.012893 & 0 & 0 & 24.77365 \\
\hline 1 & 25 & 10 & 1 & 1 & 0.024036 & 0 & 0 & 24.39029 \\
\hline 1 & 30 & 10 & 1 & 1 & 1.828265 & 5.822917 & 1.247917 & 25.21243 \\
\hline 1 & 35 & 10 & 1 & 1 & 2.474849 & 8.730556 & 0.966667 & 25.34668 \\
\hline 0.2 & 35 & 10 & 1 & 1 & 0.408305 & 6.5375 & 5.733333 & 25.03265 \\
\hline 0.2 & 30 & 10 & 1 & 1 & 0.060529 & 0 & 0 & 24.82373 \\
\hline 0.2 & 25 & 10 & 1 & 1 & 0.029655 & 0 & 0 & 22.40155 \\
\hline 0.2 & 25 & 20 & 1 & 1 & 0.234097 & 39.45 & 0 & 26.10733 \\
\hline 0.2 & 30 & 20 & 1 & 1 & 0.49897 & 49.78333 & 0 & 26.32764 \\
\hline 0.2 & 35 & 20 & 1 & 1 & 0.687188 & 52.58333 & 0 & 26.54807 \\
\hline 1 & 35 & 20 & 1 & 1 & 2.60485 & 58.13333 & 0 & 26.58307 \\
\hline
\end{tabular}


Appendix C. Operation conditions of the HVAC system for the controlled space.

\begin{tabular}{|c|c|c|c|c|c|c|c|c|}
\hline$V_{\text {in }}$ & $\mathbf{T}_{\text {in }}$ & $\mathbf{T}_{\mathbf{o}}$ & $\mathbf{X}$ & $\mathbf{Y}$ & $\mathbf{T}_{\text {Rate }}$ & OFF & ON & $\mathbf{T}_{\text {Max }}$ \\
\hline $\mathrm{m} / \mathrm{s}$ & ${ }^{\circ} \mathrm{C}$ & ${ }^{\circ} \mathrm{C}$ & $\mathbf{m}$ & $\mathbf{m}$ & ${ }^{\circ} \mathrm{C} / \mathrm{min}$ & $\min$ & $\min$ & ${ }^{\circ} \mathrm{C}$ \\
\hline 1 & 30 & 20 & 1 & 1 & 2.036418 & 57.5 & 0 & 26.35077 \\
\hline 1 & 25 & 20 & 1 & 1 & 0.516772 & 51.03333 & 0 & 26.20374 \\
\hline 2 & 25 & 20 & 1 & 1 & 0.961359 & 55.33333 & 0 & 26.22629 \\
\hline 2 & 30 & 20 & 1 & 1 & 3.622291 & 58.58333 & 0 & 26.36923 \\
\hline 2 & 35 & 20 & 1 & 1 & 4.888903 & 59.06667 & 0 & 26.58408 \\
\hline 0.2 & 35 & 20 & -1 & 1 & 0.685733 & 52.53333 & 0 & 26.53516 \\
\hline 0.2 & 30 & 20 & -1 & 1 & 0.49485 & 49.7 & 0 & 26.33814 \\
\hline 0.2 & 25 & 20 & -1 & 1 & 0.231702 & 39.23333 & 0 & 26.10419 \\
\hline 1 & 35 & 20 & -1 & 1 & 2.56656 & 58.1 & 0 & 26.59665 \\
\hline 1 & 30 & 20 & -1 & 1 & 2.126983 & 57.58333 & 0 & 26.3577 \\
\hline 1 & 25 & 20 & -1 & 1 & 0.610115 & 52.43333 & 0 & 26.18402 \\
\hline
\end{tabular}


Appendix C. Operation conditions of the HVAC system for the controlled space.

\begin{tabular}{|c|c|c|c|c|c|c|c|c|}
\hline$V_{\text {in }}$ & $\mathbf{T}_{\text {in }}$ & $\mathbf{T}_{\mathbf{o}}$ & $\mathbf{X}$ & $\mathbf{Y}$ & $T_{\text {Rate }}$ & OFF & ON & $\mathbf{T}_{\text {Max }}$ \\
\hline $\mathbf{m} / \mathbf{s}$ & ${ }^{\circ} \mathbf{C}$ & ${ }^{\circ} \mathrm{C}$ & $\mathbf{m}$ & $\mathbf{m}$ & ${ }^{\circ} \mathrm{C} / \mathrm{min}$ & $\min$ & $\min$ & ${ }^{\circ} \mathrm{C}$ \\
\hline 2 & 25 & 20 & -1 & 1 & 1.104868 & 56.21667 & 0 & 26.19663 \\
\hline 2 & 30 & 20 & -1 & 1 & 3.514821 & 58.78333 & 0 & 26.32776 \\
\hline 2 & 35 & 20 & -1 & 1 & 4.337422 & 58.95 & 0 & 26.53033 \\
\hline 2 & 35 & 10 & -1 & 1 & 5.141707 & 3.557778 & 0.181111 & 26.03824 \\
\hline 2 & 30 & 10 & -1 & 1 & 3.265163 & 2.437879 & 0.216667 & 25.56241 \\
\hline 2 & 25 & 10 & -1 & 1 & 0.681322 & 2.613889 & 1.966667 & 25.00443 \\
\hline 1 & 25 & 10 & -1 & 1 & 0.023945 & 0 & 0 & 24.65717 \\
\hline 1 & 30 & 10 & -1 & 1 & 1.93873 & 5.116667 & 1.083333 & 25.07285 \\
\hline 1 & 35 & 10 & -1 & 1 & 2.426414 & 8.55 & 0.952778 & 25.35959 \\
\hline 0.2 & 35 & 10 & -1 & 1 & 0.407762 & 6.369444 & 5.72 & 25.02939 \\
\hline 0.2 & 30 & 10 & -1 & 1 & 0.041996 & 0 & 0 & 24.79419 \\
\hline
\end{tabular}


Appendix C. Operation conditions of the HVAC system for the controlled space.

\begin{tabular}{|c|c|c|c|c|c|c|c|c|}
\hline$V_{\text {in }}$ & $T_{\text {in }}$ & $\mathbf{T}_{\mathbf{o}}$ & $\mathbf{X}$ & $\mathbf{Y}$ & $\mathbf{T}_{\text {Rate }}$ & OFF & $\mathbf{O N}$ & $\mathbf{T}_{\text {Max }}$ \\
\hline $\mathbf{m} / \mathbf{s}$ & ${ }^{\circ} \mathrm{C}$ & ${ }^{\circ} \mathrm{C}$ & $\mathbf{m}$ & $\mathbf{m}$ & ${ }^{\circ} \mathrm{C} / \mathrm{min}$ & $\min$ & $\min$ & ${ }^{\circ} \mathrm{C}$ \\
\hline 0.2 & 25 & 10 & -1 & 1 & 0.021563 & 0 & 0 & 22.38117 \\
\hline 0.2 & 25 & 0 & -1 & 1 & -0.009 & 0 & 0 & 20.57477 \\
\hline 0.2 & 30 & 0 & -1 & 1 & 0.022212 & 0 & 0 & 21.40399 \\
\hline 0.2 & 35 & 0 & -1 & 1 & 0.052732 & 0 & 0 & 23.76465 \\
\hline 1 & 35 & 0 & -1 & 1 & 2.314022 & 3.563889 & 1.05 & 25.21765 \\
\hline 1 & 30 & 0 & -1 & 1 & 1.724037 & 1.862281 & 1.212037 & 25.04028 \\
\hline 1 & 25 & 0 & -1 & 1 & 0.018114 & 0 & 0 & 23.59555 \\
\hline 2 & 25 & 0 & -1 & 1 & 0.011524 & 0 & 0 & 24.70273 \\
\hline 2 & 35 & 0 & -1 & 1 & 5.071256 & 1.267063 & 0.174603 & 26.29398 \\
\hline 2 & 30 & 0 & -1 & 1 & 3.036384 & 0.848538 & 0.208187 & 25.64584 \\
\hline 0.2 & 25 & 5 & 0 & 0 & 0.012364 & 0 & 0 & 20.86285 \\
\hline
\end{tabular}


Appendix C. Operation conditions of the HVAC system for the controlled space.

\begin{tabular}{|c|c|c|c|c|c|c|c|c|}
\hline$V_{\text {in }}$ & $\mathbf{T}_{\text {in }}$ & $\mathbf{T}_{\mathbf{o}}$ & $\mathbf{X}$ & $\mathbf{Y}$ & $\mathbf{T}_{\text {Rate }}$ & OFF & $\mathbf{O N}$ & $\mathbf{T}_{\text {Max }}$ \\
\hline $\mathbf{m} / \mathbf{s}$ & ${ }^{\circ} \mathbf{C}$ & ${ }^{\circ} \mathrm{C}$ & $\mathbf{m}$ & $\mathbf{m}$ & ${ }^{\circ} \mathrm{C} / \mathrm{min}$ & $\min$ & $\min$ & ${ }^{\circ} \mathrm{C}$ \\
\hline 0.2 & 30 & 5 & 0 & 0 & 0.043202 & 0 & 0 & 23.2692 \\
\hline 0.2 & 35 & 5 & 0 & 0 & 0.231191 & 3.975 & 13.05 & 25.00021 \\
\hline 0.2 & 35 & 15 & 0 & 0 & 0.564788 & 37.81667 & 3.55 & 25.29382 \\
\hline 0.2 & 30 & 15 & 0 & 0 & 0.346478 & 25.61667 & 6.016667 & 25.06128 \\
\hline 0.2 & 25 & 15 & 0 & 0 & 0.052097 & 0 & 0 & 24.33142 \\
\hline 1 & 25 & 15 & 0 & 0 & 0.258947 & 17.43333 & 9.183333 & 25.07785 \\
\hline 1 & 30 & 15 & 0 & 0 & 1.898816 & 28.2 & 1.216667 & 25.26617 \\
\hline 1 & 35 & 15 & 0 & 0 & 2.384686 & 45 & 0.966667 & 25.815 \\
\hline 2 & 35 & 15 & 0 & 0 & 4.566903 & 47.56667 & 0.566667 & 26.40219 \\
\hline 2 & 30 & 15 & 0 & 0 & 2.905728 & 31.65 & 0.666667 & 25.91644 \\
\hline 2 & 25 & 15 & 0 & 0 & 0.690446 & 15.69444 & 3.133333 & 25.05811 \\
\hline
\end{tabular}


Appendix C. Operation conditions of the HVAC system for the controlled space.

\begin{tabular}{|c|c|c|c|c|c|c|c|c|}
\hline$V_{\text {in }}$ & $T_{\text {in }}$ & $\mathbf{T}_{\mathbf{o}}$ & $\mathbf{X}$ & $\mathbf{Y}$ & $\mathbf{T}_{\text {Rate }}$ & OFF & $\mathbf{O N}$ & $\mathbf{T}_{\text {Max }}$ \\
\hline $\mathbf{m} / \mathbf{s}$ & ${ }^{\circ} \mathrm{C}$ & ${ }^{\circ} \mathrm{C}$ & $\mathbf{m}$ & $\mathbf{m}$ & ${ }^{\circ} \mathrm{C} / \mathrm{min}$ & $\min$ & $\min$ & ${ }^{\circ} \mathrm{C}$ \\
\hline 2 & 25 & 5 & 0 & 0 & 0.014536 & 0 & 0 & 24.69717 \\
\hline 2 & 30 & 5 & 0 & 0 & 2.541745 & 3.973611 & 0.7 & 25.80563 \\
\hline 2 & 35 & 5 & 0 & 0 & 4.3454 & 6.50625 & 0.616667 & 26.11185 \\
\hline 1 & 35 & 5 & 0 & 0 & 2.249256 & 5.8 & 1.097917 & 25.2583 \\
\hline 1 & 30 & 5 & 0 & 0 & 1.670099 & 3.865 & 1.531667 & 25.15454 \\
\hline 1 & 25 & 5 & 0 & 0 & 0.028148 & 0 & 0 & 24.1582 \\
\hline 0.2 & 25 & 5 & 0 & 0 & 0.012364 & 0 & 0 & 20.86285 \\
\hline 0.2 & 30 & 5 & 0 & 0 & 0.043202 & 0 & 0 & 23.2692 \\
\hline 0.2 & 35 & 5 & 0 & 0 & 0.231191 & 3.975 & 13.05 & 25.00021 \\
\hline 2 & 35 & 15 & -1 & -1 & 6.080909 & 9.776667 & 0.133333 & 25.49085 \\
\hline 2 & 30 & 15 & -1 & -1 & 3.130959 & 8.116667 & 0.166667 & 25.20618 \\
\hline
\end{tabular}


Appendix C. Operation conditions of the HVAC system for the controlled space.

\begin{tabular}{|c|c|c|c|c|c|c|c|c|}
\hline$V_{\text {in }}$ & $\mathbf{T}_{\text {in }}$ & $\mathbf{T}_{\mathbf{o}}$ & $\mathbf{X}$ & $\mathbf{Y}$ & $T_{\text {Rate }}$ & OFF & ON & $\mathbf{T}_{\text {Max }}$ \\
\hline $\mathbf{m} / \mathbf{s}$ & ${ }^{\circ} \mathrm{C}$ & ${ }^{\circ} \mathrm{C}$ & $\mathbf{m}$ & $\mathbf{m}$ & ${ }^{\circ} \mathrm{C} / \mathrm{min}$ & $\min$ & $\min$ & ${ }^{\circ} \mathrm{C}$ \\
\hline 2 & 25 & 15 & -1 & -1 & 0.729087 & 11.23333 & 2.916667 & 25.0199 \\
\hline 1 & 25 & 15 & -1 & -1 & 0.25964 & 11.91667 & 8.308333 & 25.00049 \\
\hline 1 & 30 & 15 & -1 & -1 & 2.040944 & 15.26111 & 0.861111 & 25.09729 \\
\hline 1 & 35 & 15 & -1 & -1 & 2.640467 & 24.925 & 0.75 & 25.35535 \\
\hline 0.2 & 35 & 15 & -1 & -1 & 0.551729 & 21.58333 & 3.65 & 25.22025 \\
\hline 0.2 & 30 & 15 & -1 & -1 & 0.321389 & 16.78333 & 6.65 & 25.0445 \\
\hline 0.2 & 25 & 15 & -1 & -1 & 0.049178 & 0 & 0 & 24.07819 \\
\hline 0.2 & 25 & 5 & -1 & -1 & 0.0093 & 0 & 0 & 20.61523 \\
\hline 0.2 & 30 & 5 & -1 & -1 & 0.040184 & 0 & 0 & 23.01578 \\
\hline 0.2 & 35 & 5 & -1 & -1 & 0.192478 & 3.658333 & 16.03333 & 25.00046 \\
\hline 1 & 35 & 5 & -1 & -1 & 2.469028 & 4.0625 & 0.777778 & 25.10938 \\
\hline
\end{tabular}


Appendix C. Operation conditions of the HVAC system for the controlled space.

\begin{tabular}{|c|c|c|c|c|c|c|c|c|}
\hline$V_{\text {in }}$ & $T_{\text {in }}$ & $\mathbf{T}_{\mathbf{o}}$ & $\mathbf{X}$ & $\mathbf{Y}$ & $\mathbf{T}_{\text {Rate }}$ & OFF & $\mathbf{O N}$ & $\mathbf{T}_{\text {Max }}$ \\
\hline $\mathbf{m} / \mathbf{s}$ & ${ }^{\circ} \mathrm{C}$ & ${ }^{\circ} \mathrm{C}$ & $\mathbf{m}$ & $\mathbf{m}$ & ${ }^{\circ} \mathrm{C} / \mathrm{min}$ & $\min$ & $\min$ & ${ }^{\circ} \mathrm{C}$ \\
\hline 1 & 30 & 5 & -1 & -1 & 1.82479 & 2.384314 & 0.936275 & 25.06009 \\
\hline 1 & 25 & 5 & -1 & -1 & 0.022136 & 0 & 0 & 24.00797 \\
\hline 2 & 25 & 5 & -1 & -1 & 0.013105 & 0 & 0 & 24.70075 \\
\hline 2 & 30 & 5 & -1 & -1 & 2.815355 & 2.977451 & 0.517708 & 25.48413 \\
\hline 2 & 35 & 5 & -1 & -1 & 5.635368 & 1.482432 & 0.133333 & 25.49512 \\
\hline 0.2 & 35 & 5 & 1 & 1 & 0.209627 & 3.708333 & 14.36667 & 25.00061 \\
\hline 0.2 & 30 & 5 & 1 & 1 & 0.041037 & 0 & 0 & 23.1069 \\
\hline 0.2 & 25 & 5 & 1 & 1 & 0.009948 & 0 & 0 & 20.67633 \\
\hline 1 & 25 & 5 & 1 & 1 & 0.021503 & 0 & 0 & 23.84897 \\
\hline 1 & 30 & 5 & 1 & 1 & 1.700698 & 3.308333 & 1.348611 & 25.14572 \\
\hline 1 & 35 & 5 & 1 & 1 & 2.400855 & 5.064815 & 0.996296 & 25.3139 \\
\hline
\end{tabular}


Appendix C. Operation conditions of the HVAC system for the controlled space.

\begin{tabular}{|c|c|c|c|c|c|c|c|c|}
\hline$V_{\text {in }}$ & $\mathbf{T}_{\text {in }}$ & $\mathbf{T}_{\mathbf{o}}$ & $\mathbf{X}$ & $\mathbf{Y}$ & $T_{\text {Rate }}$ & OFF & ON & $\mathbf{T}_{\text {Max }}$ \\
\hline $\mathbf{m} / \mathbf{s}$ & ${ }^{\circ} \mathrm{C}$ & ${ }^{\circ} \mathrm{C}$ & $\mathbf{m}$ & $\mathbf{m}$ & ${ }^{\circ} \mathrm{C} / \mathrm{min}$ & $\min$ & $\min$ & ${ }^{\circ} \mathrm{C}$ \\
\hline 2 & 35 & 5 & 1 & 1 & 4.635216 & 4.561111 & 0.415152 & 25.73996 \\
\hline 2 & 30 & 5 & 1 & 1 & 3.25106 & 2.878431 & 0.466667 & 25.13153 \\
\hline 2 & 25 & 5 & 1 & 1 & 0.012206 & 0 & 0 & 24.48962 \\
\hline 2 & 25 & 15 & 1 & 1 & 0.543359 & 14.23889 & 4.391667 & 25.02795 \\
\hline 2 & 30 & 15 & 1 & 1 & 3.431025 & 18.02222 & 0.461111 & 25.31818 \\
\hline 2 & 35 & 15 & 1 & 1 & 4.822877 & 25.925 & 0.383333 & 25.68994 \\
\hline 1 & 35 & 15 & 1 & 1 & 2.540389 & 28.75 & 0.933333 & 25.68338 \\
\hline 1 & 30 & 15 & 1 & 1 & 1.940083 & 19.31667 & 1.15 & 25.2514 \\
\hline 1 & 25 & 15 & 1 & 1 & 0.026539 & 0 & 0 & 24.93829 \\
\hline 0.2 & 25 & 15 & 1 & 1 & 0.049714 & 0 & 0 & 24.13574 \\
\hline 0.2 & 30 & 15 & 1 & 1 & 0.329635 & 17.80833 & 6.383333 & 25.02911 \\
\hline
\end{tabular}


Appendix C. Operation conditions of the HVAC system for the controlled space.

\begin{tabular}{|c|c|c|c|c|c|c|c|c|}
\hline$V_{\text {in }}$ & $\mathbf{T}_{\text {in }}$ & $\mathbf{T}_{\mathbf{o}}$ & $\mathbf{X}$ & $\mathbf{Y}$ & $\mathbf{T}_{\text {Rate }}$ & OFF & $\mathbf{O N}$ & $\mathbf{T}_{\text {Max }}$ \\
\hline $\mathbf{m} / \mathbf{s}$ & ${ }^{\circ} \mathbf{C}$ & ${ }^{\circ} \mathrm{C}$ & $\mathbf{m}$ & $\mathbf{m}$ & ${ }^{\circ} \mathrm{C} / \mathrm{min}$ & $\min$ & $\min$ & ${ }^{\circ} \mathrm{C}$ \\
\hline 0.2 & 35 & 15 & 1 & 1 & 0.556783 & 23.93333 & 3.6 & 25.21909 \\
\hline 0.2 & 35 & 5 & -1 & 1 & 0.201221 & 3.608333 & 14.85 & 25.00119 \\
\hline 0.2 & 30 & 5 & -1 & 1 & 0.041019 & 0 & 0 & 23.08011 \\
\hline 0.2 & 25 & 5 & -1 & 1 & 0.041019 & 0 & 0 & 20.63901 \\
\hline 1 & 25 & 5 & -1 & 1 & 0.021217 & 0 & 0 & 24.14734 \\
\hline 1 & 30 & 5 & -1 & 1 & 1.836206 & 2.846429 & 1.147619 & 25.05026 \\
\hline 1 & 35 & 5 & -1 & 1 & 2.367711 & 5.112963 & 1.012963 & 25.27371 \\
\hline 2 & 35 & 5 & -1 & 1 & 5.134741 & 1.828161 & 0.175862 & 26.38355 \\
\hline 2 & 30 & 5 & -1 & 1 & 3.126024 & 1.352632 & 0.216667 & 25.55356 \\
\hline 2 & 25 & 5 & -1 & 1 & 0.012843 & 0 & 0 & 24.96384 \\
\hline 2 & 25 & 15 & -1 & 1 & 0.903871 & 10.15 & 1.395833 & 25.07483 \\
\hline
\end{tabular}


Appendix C. Operation conditions of the HVAC system for the controlled space.

\begin{tabular}{|c|c|c|c|c|c|c|c|c|}
\hline$V_{\text {in }}$ & $T_{\text {in }}$ & $\mathbf{T}_{\mathbf{o}}$ & $\mathbf{X}$ & $\mathbf{Y}$ & $\mathbf{T}_{\text {Rate }}$ & OFF & $\mathbf{O N}$ & $\mathbf{T}_{\text {Max }}$ \\
\hline $\mathbf{m} / \mathbf{s}$ & ${ }^{\circ} \mathrm{C}$ & ${ }^{\circ} \mathrm{C}$ & $\mathbf{m}$ & $\mathbf{m}$ & ${ }^{\circ} \mathrm{C} / \mathrm{min}$ & $\min$ & $\min$ & ${ }^{\circ} \mathrm{C}$ \\
\hline 2 & 30 & 15 & -1 & 1 & 3.39924 & 10.05333 & 0.216667 & 25.54056 \\
\hline 2 & 35 & 15 & -1 & 1 & 5.121972 & 12.85 & 0.175 & 26.01712 \\
\hline 1 & 35 & 15 & -1 & 1 & 2.486153 & 29.03333 & 0.9 & 25.59732 \\
\hline 1 & 30 & 15 & -1 & 1 & 2.025138 & 17.62778 & 1.016667 & 25.11331 \\
\hline 1 & 25 & 15 & -1 & 1 & 0.330475 & 12.01667 & 6.8 & 25.00061 \\
\hline 0.2 & 25 & 15 & -1 & 1 & 0.049241 & 0 & 0 & 24.10309 \\
\hline 0.2 & 30 & 15 & -1 & 1 & 0.325546 & 17.58333 & 6.4 & 25.02475 \\
\hline 0.2 & 35 & 15 & -1 & 1 & 0.555491 & 23.48333 & 3.566667 & 25.2135 \\
\hline
\end{tabular}


Appendix D. Energy difference percentage based on person location
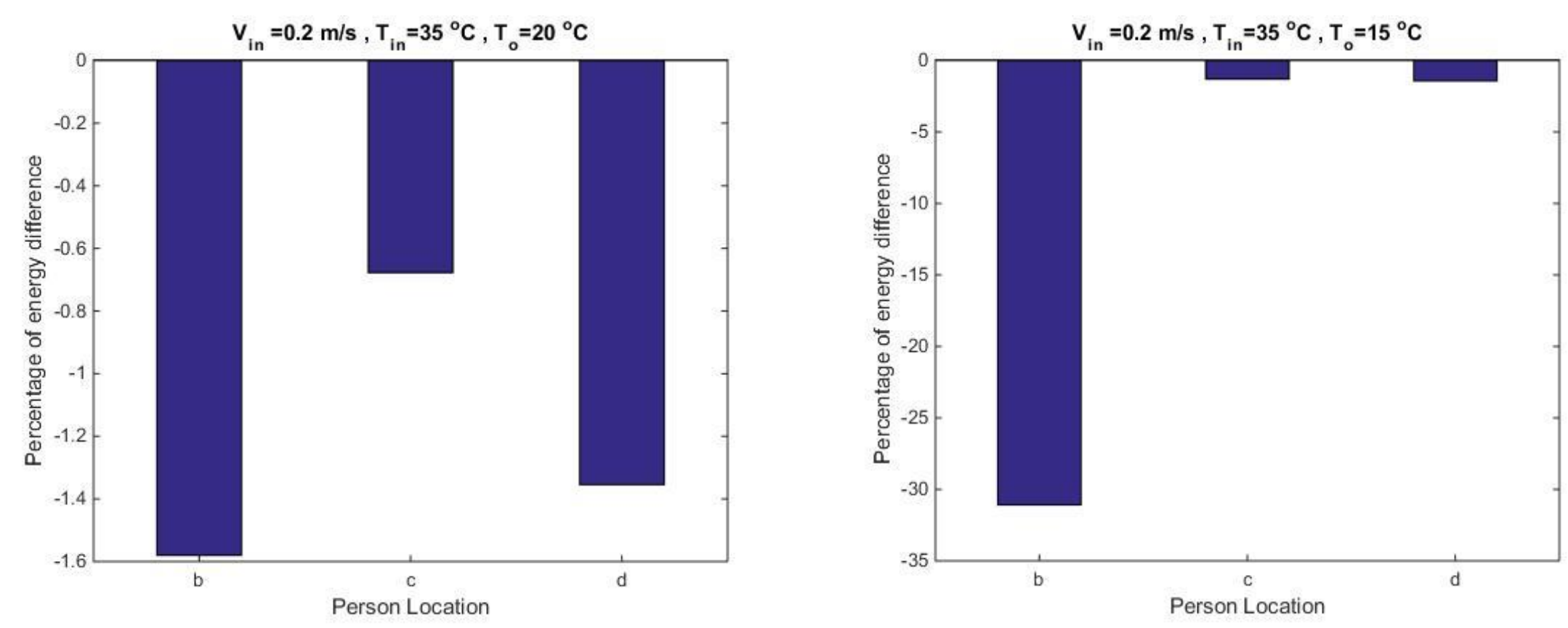

(1)

(2) 
Appendix D. Energy difference percentage based on person location
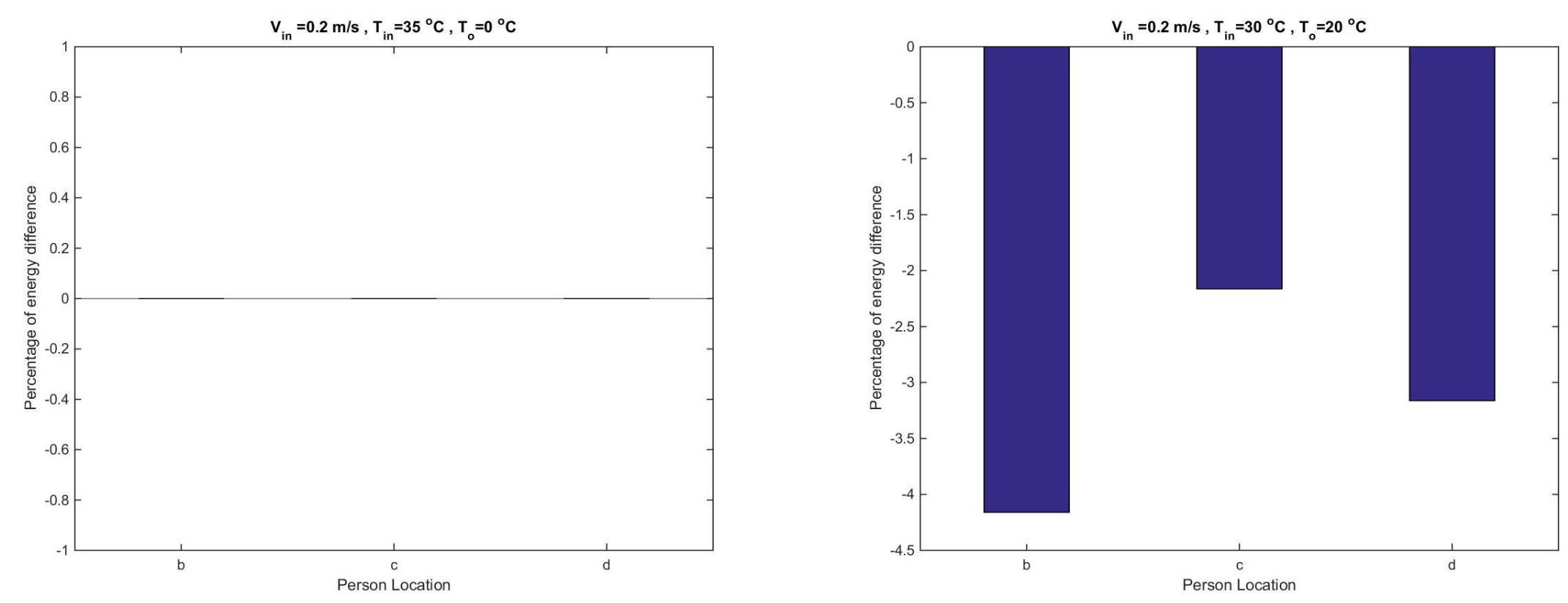

(3)

(4) 
Appendix D. Energy difference percentage based on person location
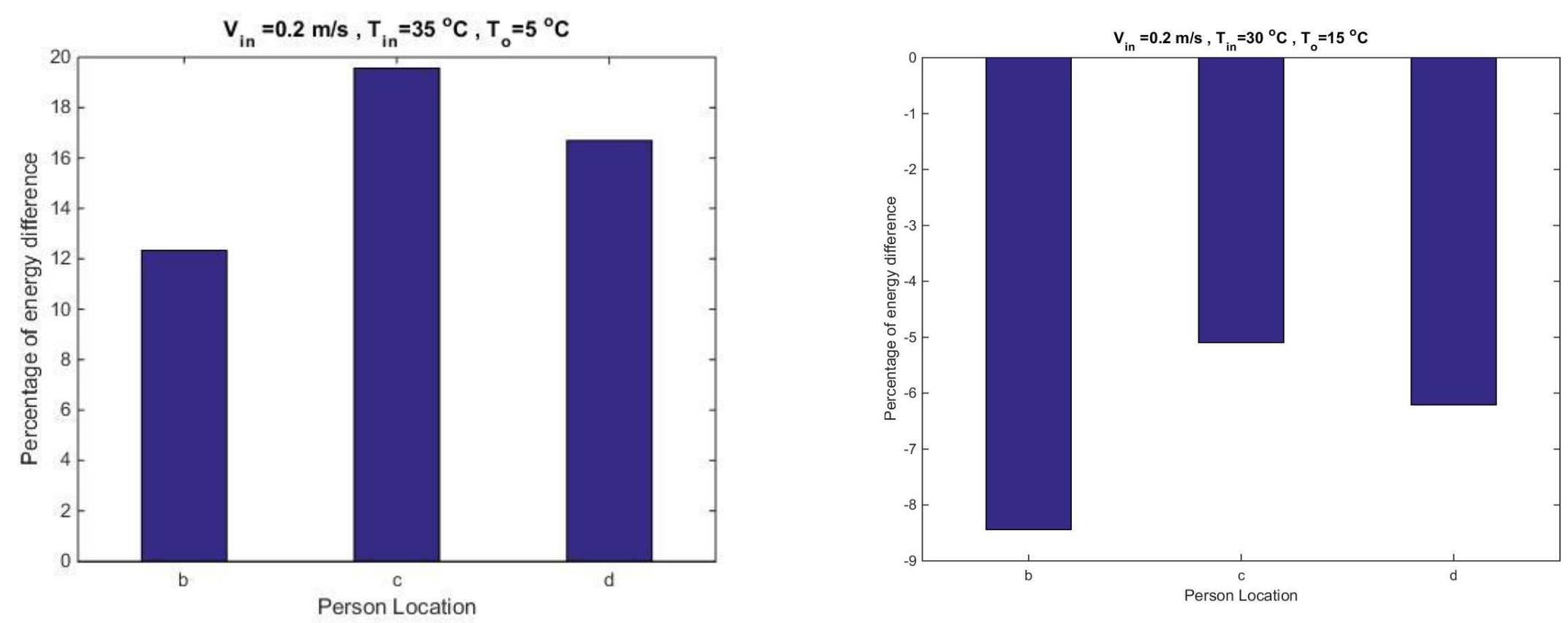

(5)

(6) 
Appendix D. Energy difference percentage based on person location


(7)

(8) 
Appendix D. Energy difference percentage based on person location
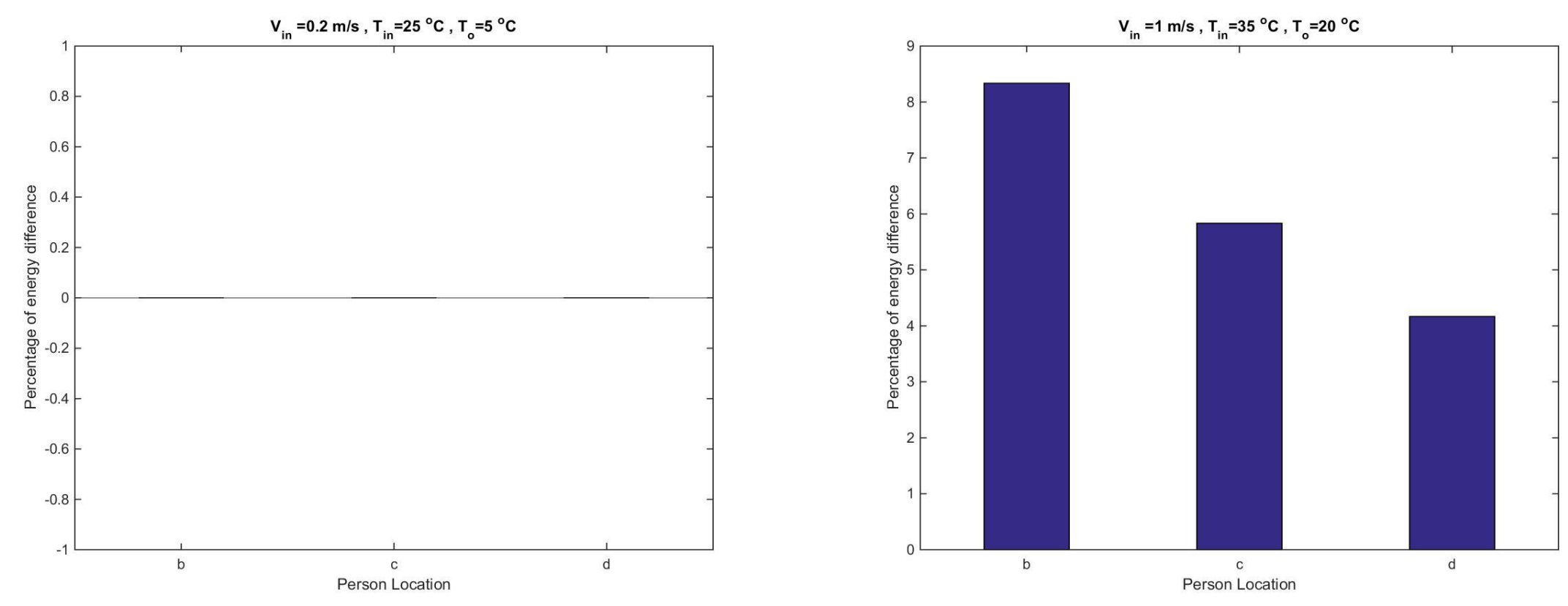

(9)

(10) 
Appendix D. Energy difference percentage based on person location
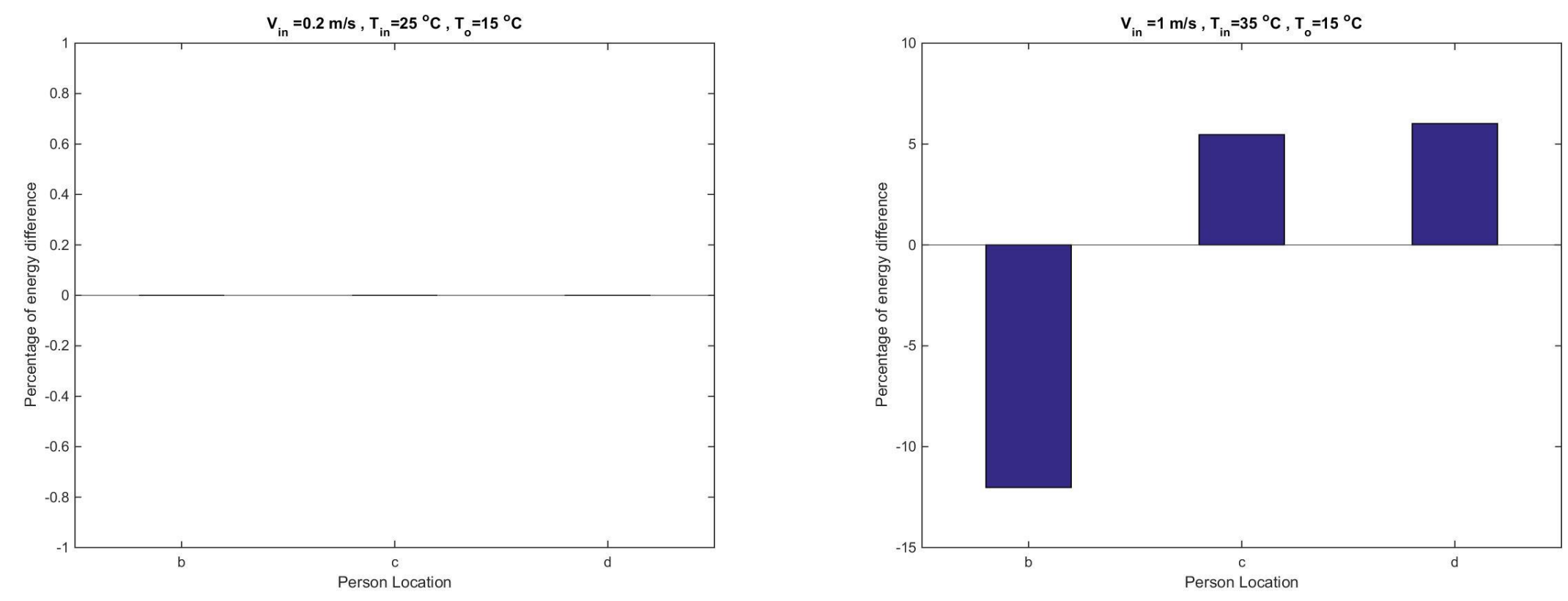

(11)

(12) 
Appendix D. Energy difference percentage based on person location
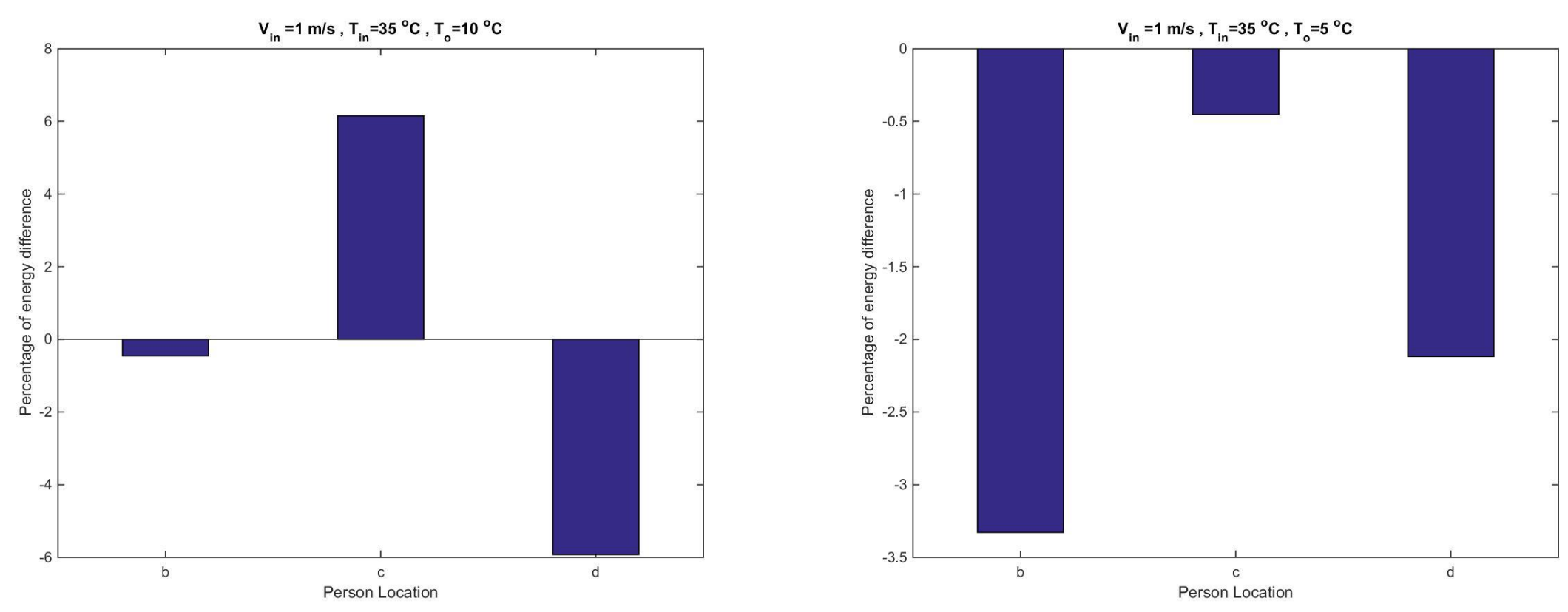

(13)

(14) 


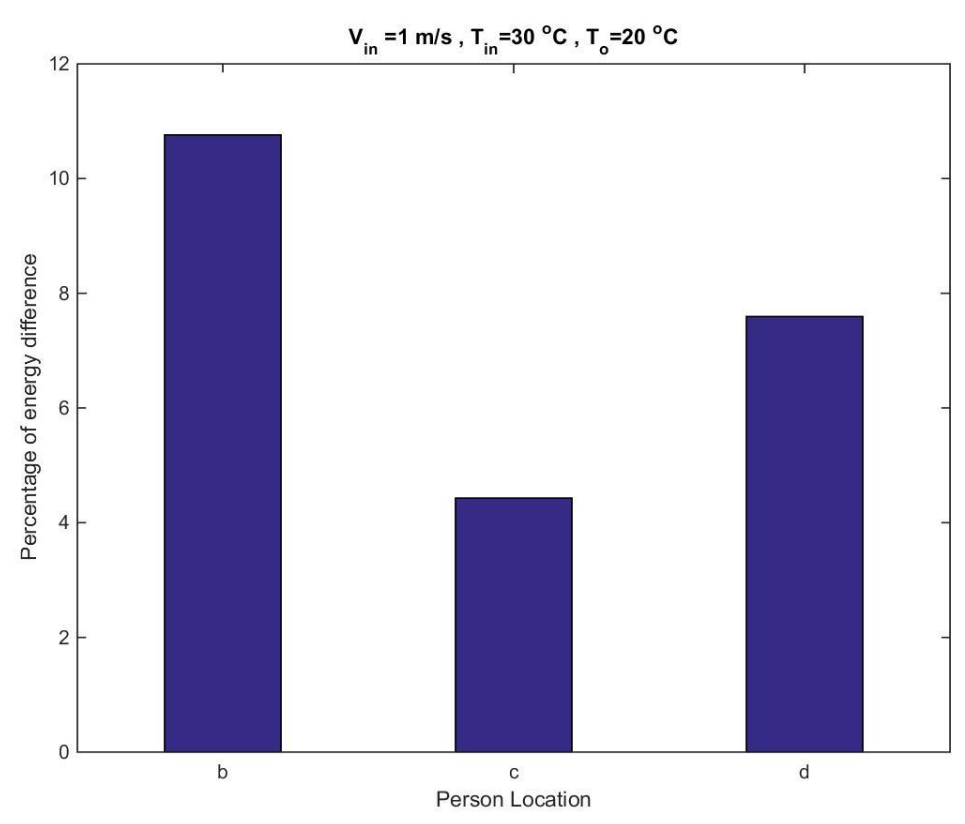

(15)

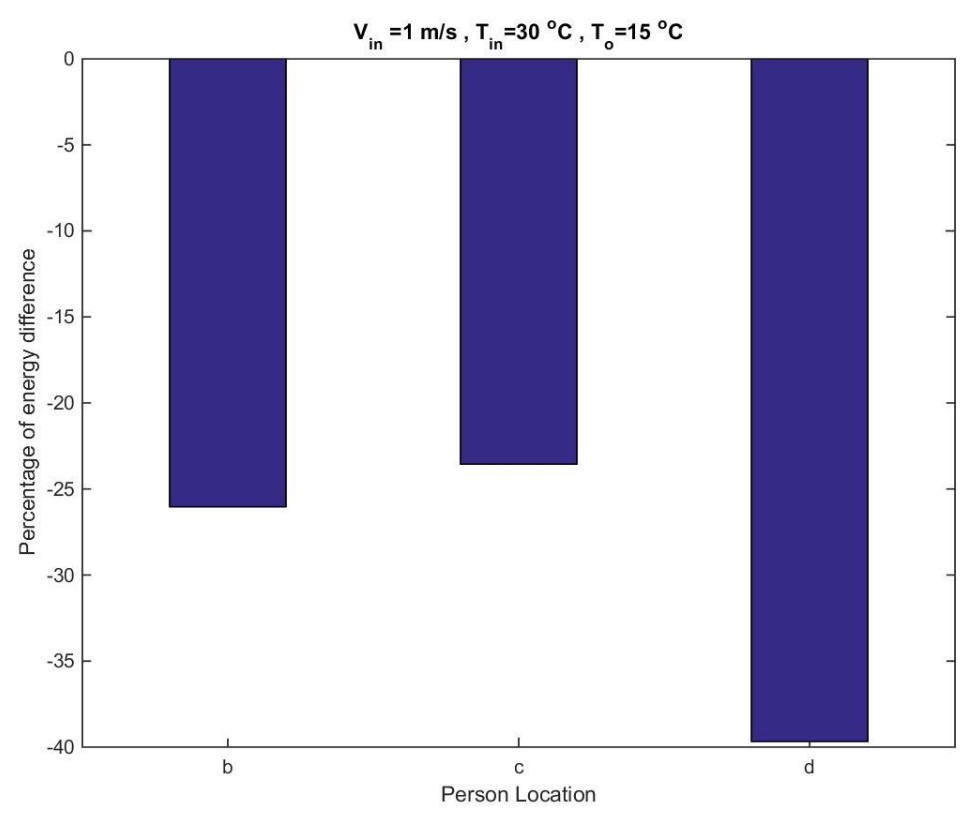

(16) 


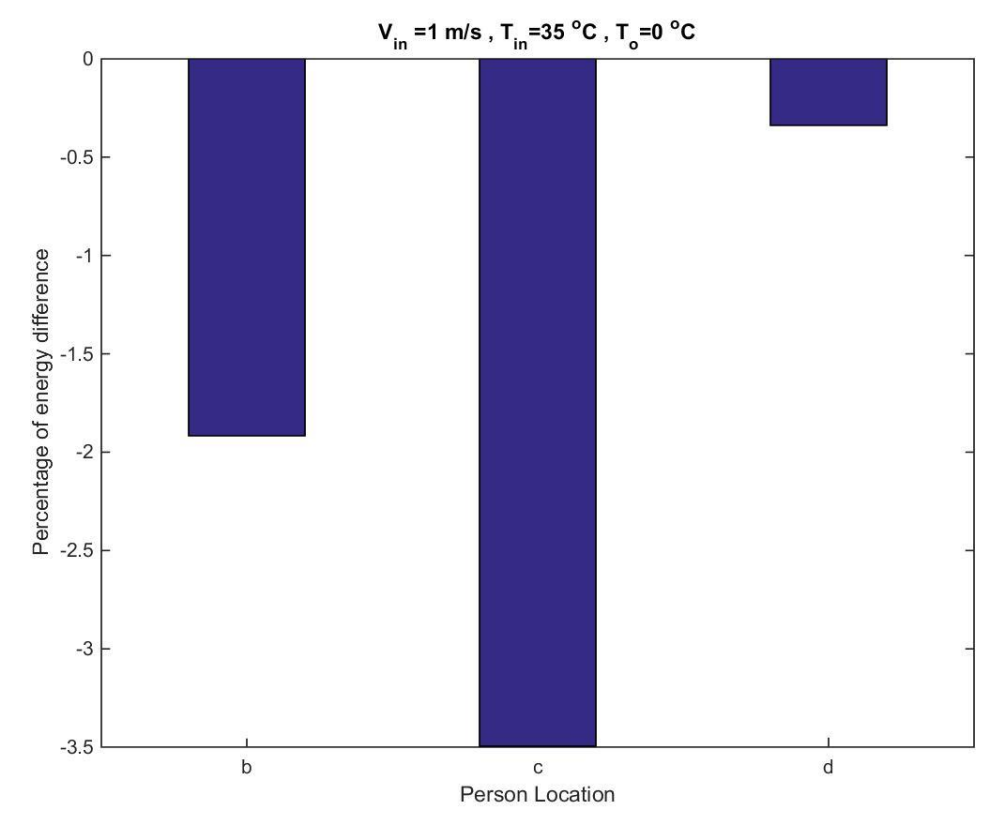

(17)

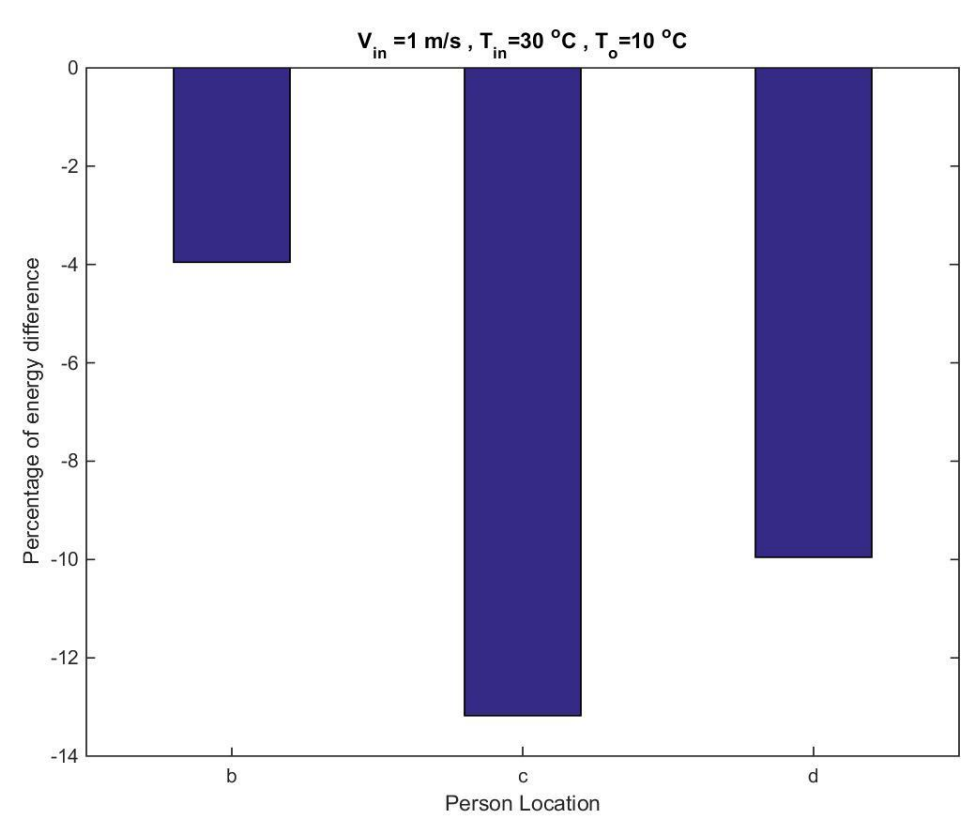

(18) 


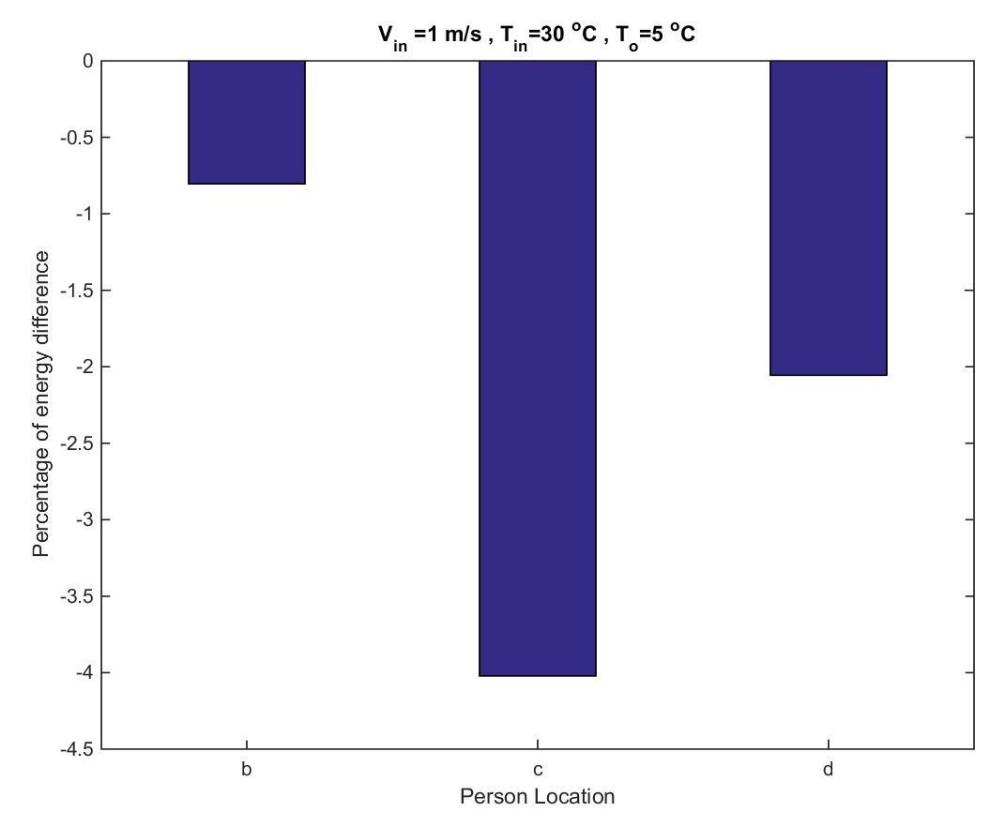

(19)

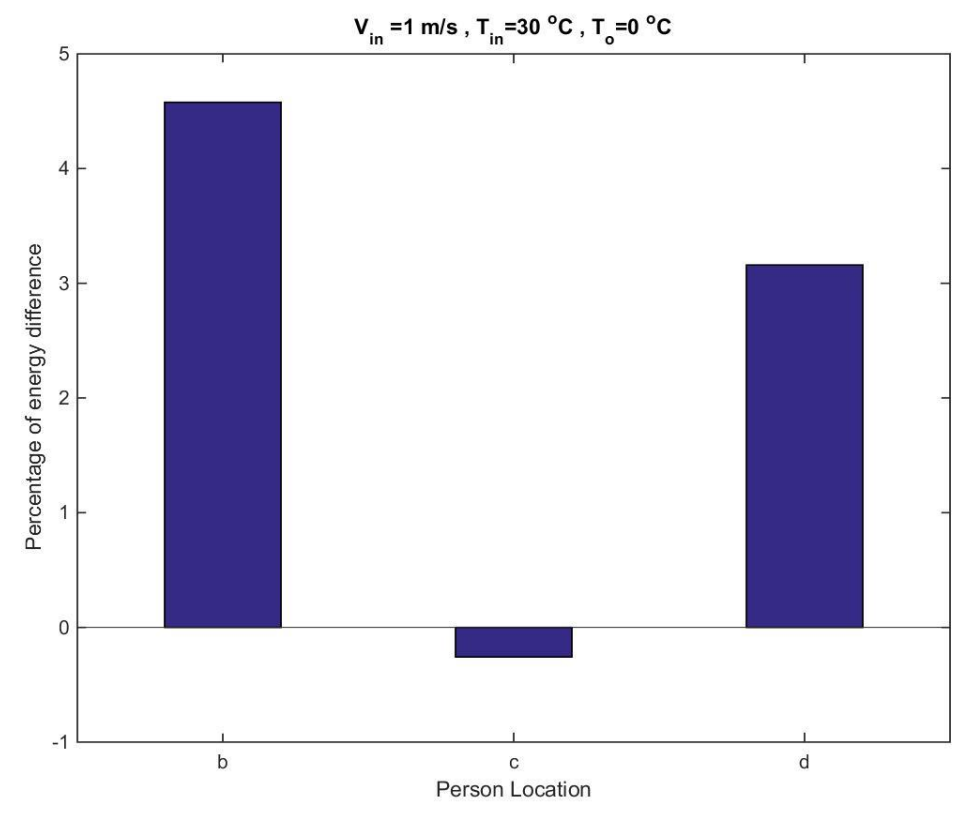

(20) 
Appendix D. Energy difference percentage based on person location
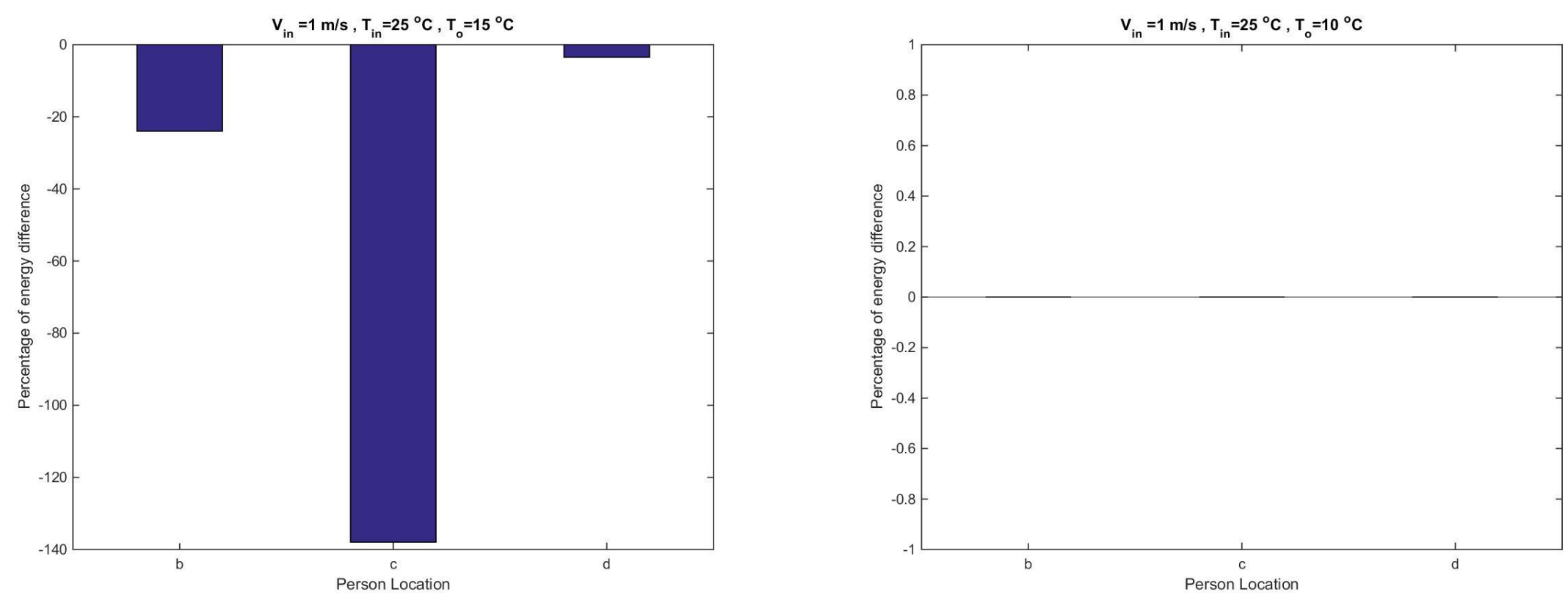

(21)

(22) 
Appendix D. Energy difference percentage based on person location
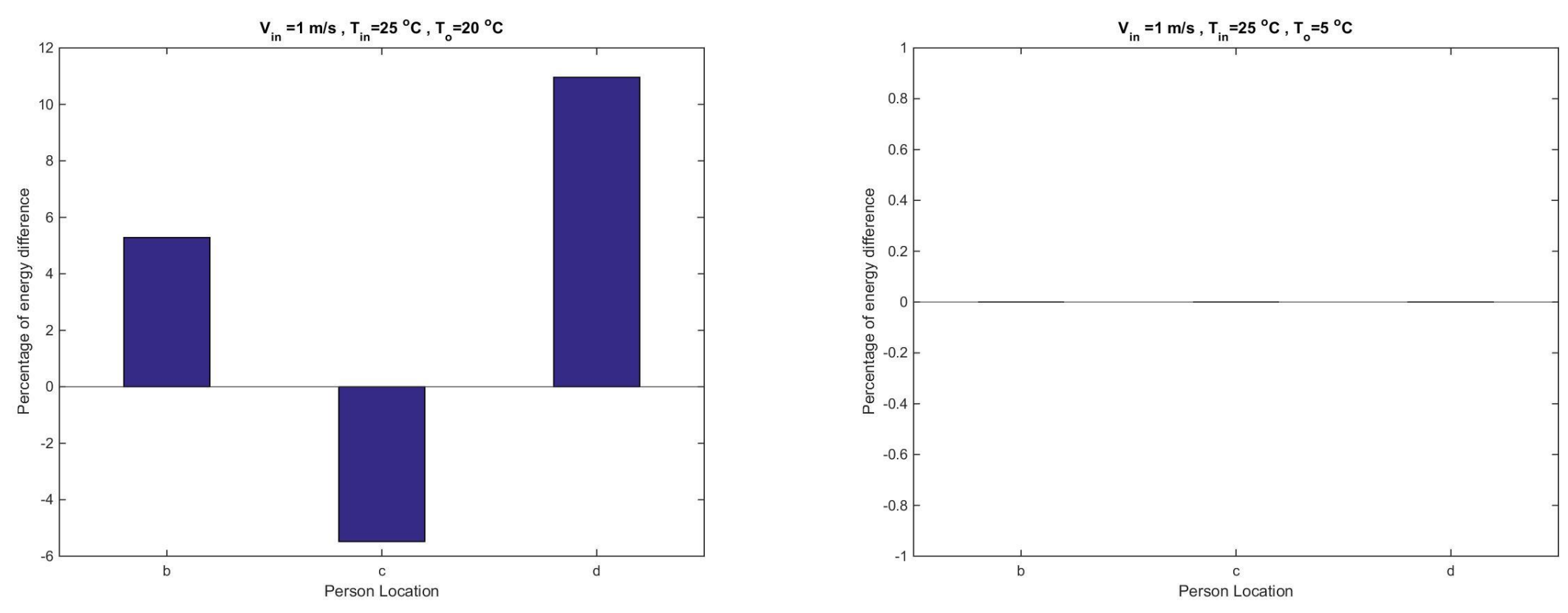

(23)

(24) 
Appendix D. Energy difference percentage based on person location
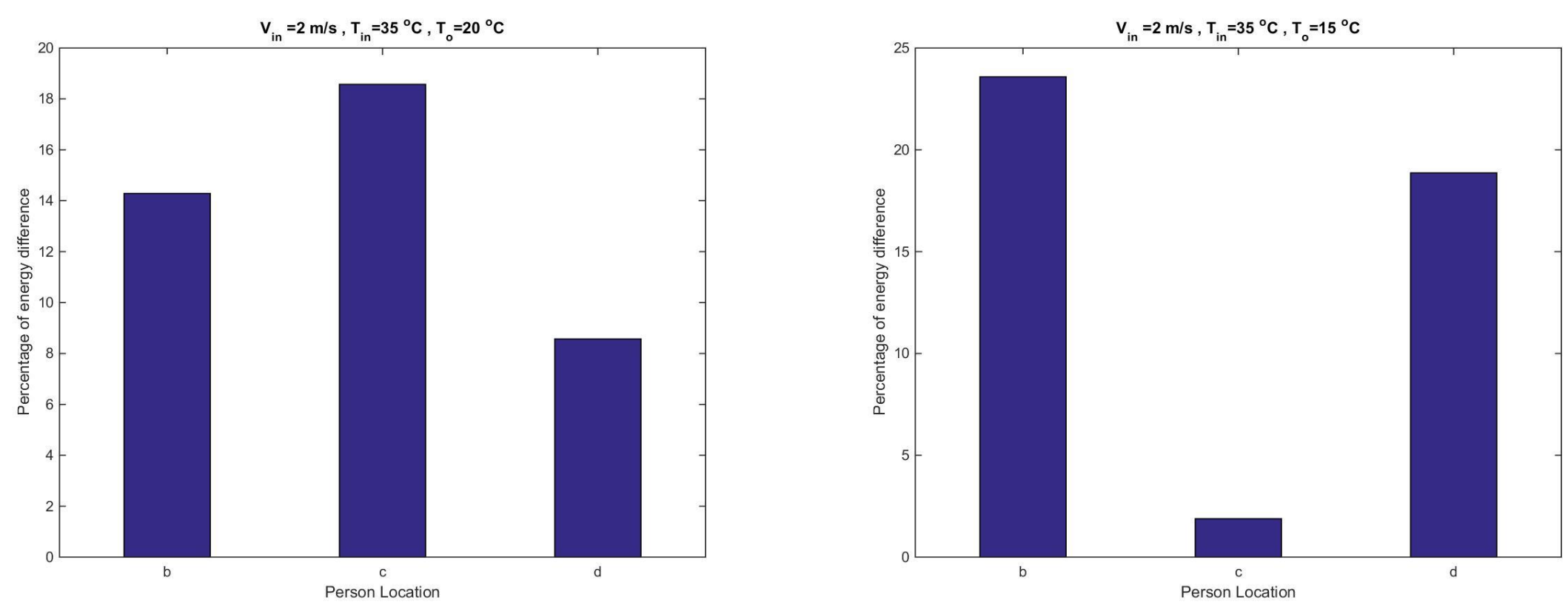

(25)

(26) 
Appendix D. Energy difference percentage based on person location
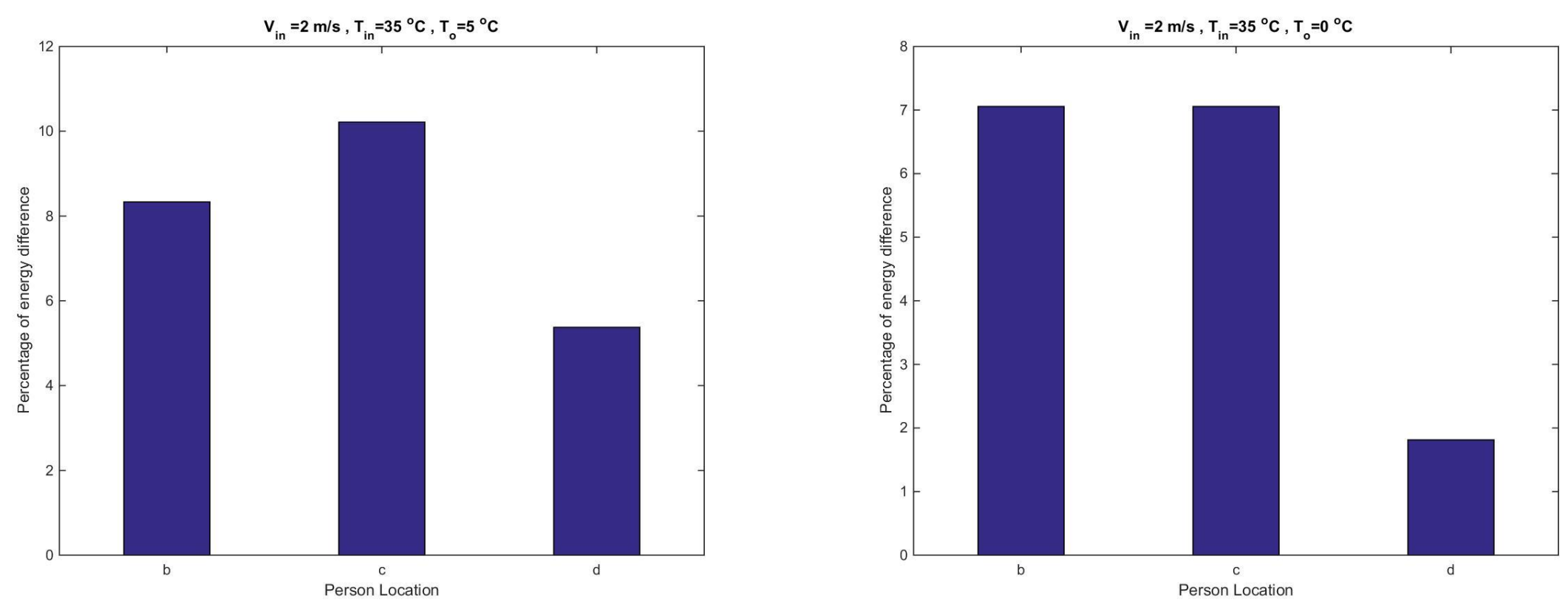

(27)

(28) 


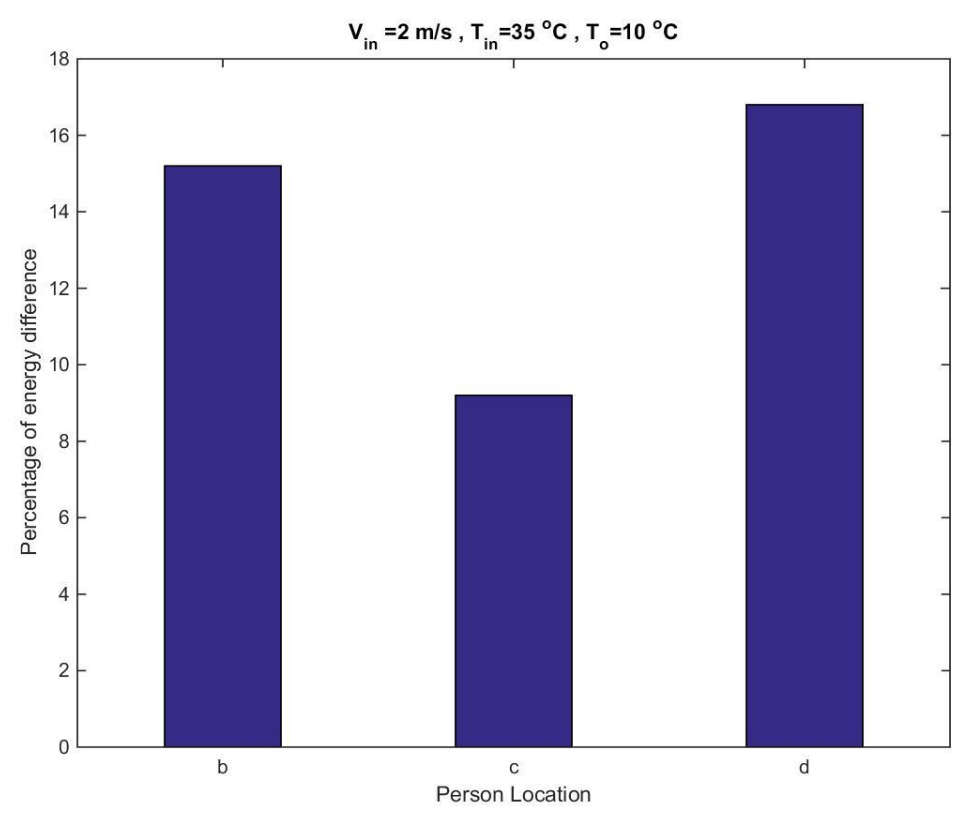

(29)

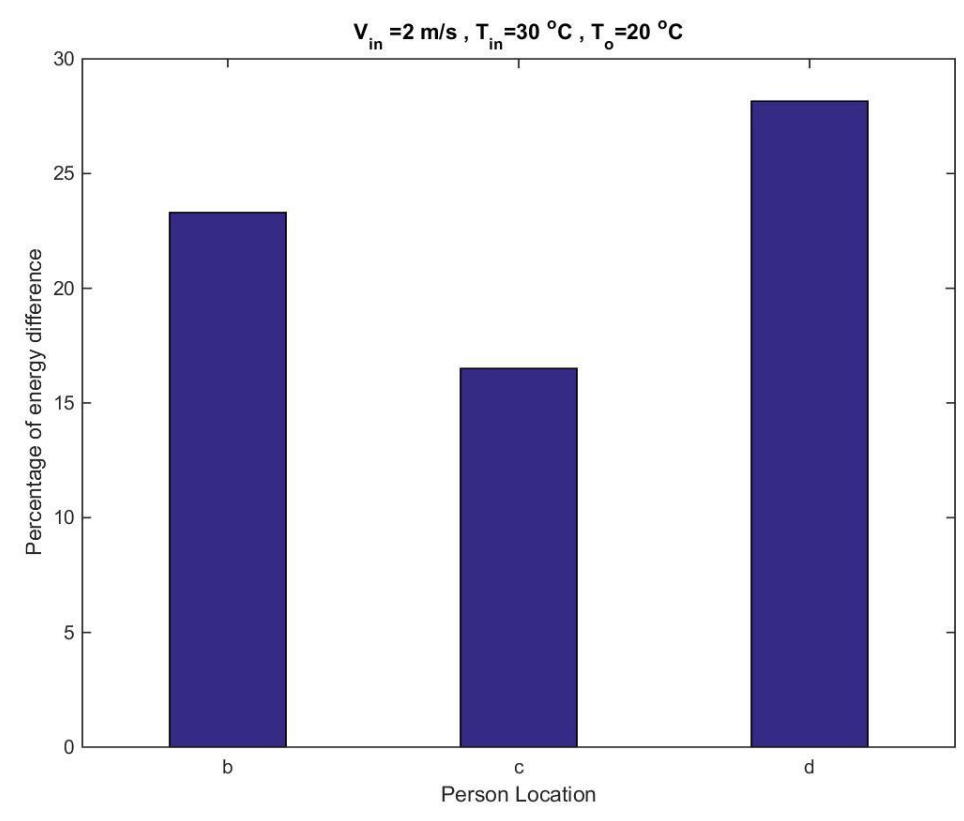

(30) 
Appendix D. Energy difference percentage based on person location
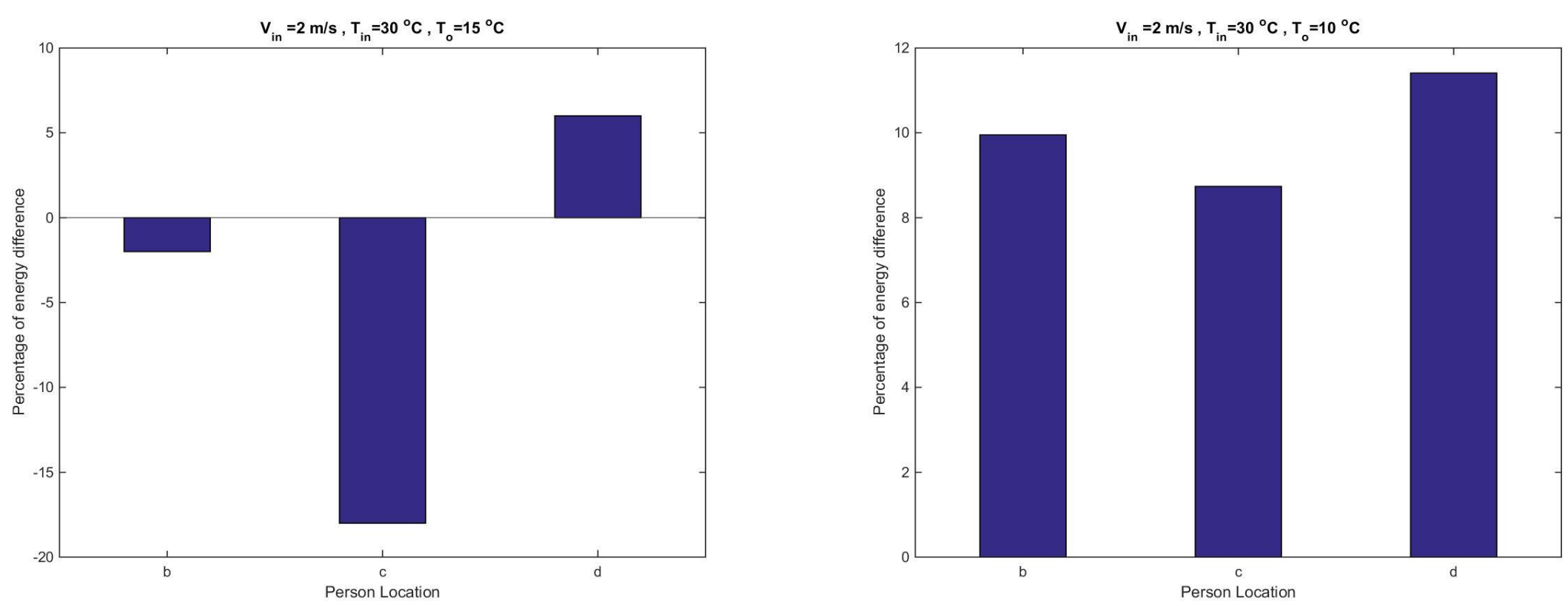

(31)

(32) 




(33)



(34) 


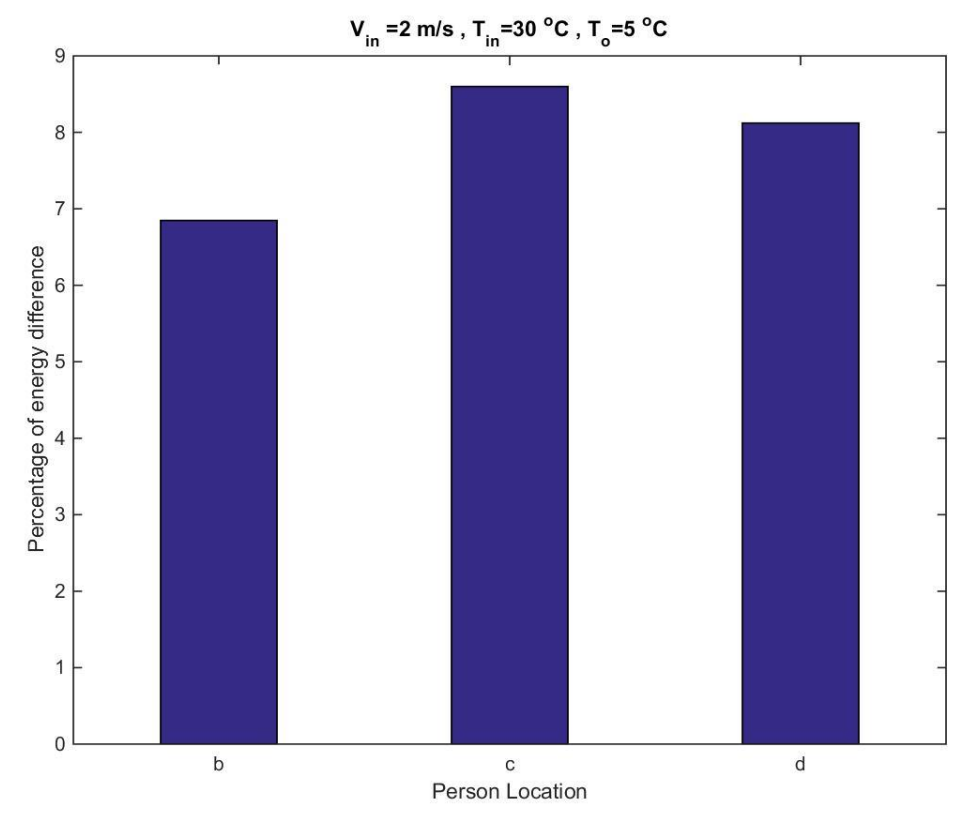

(35)

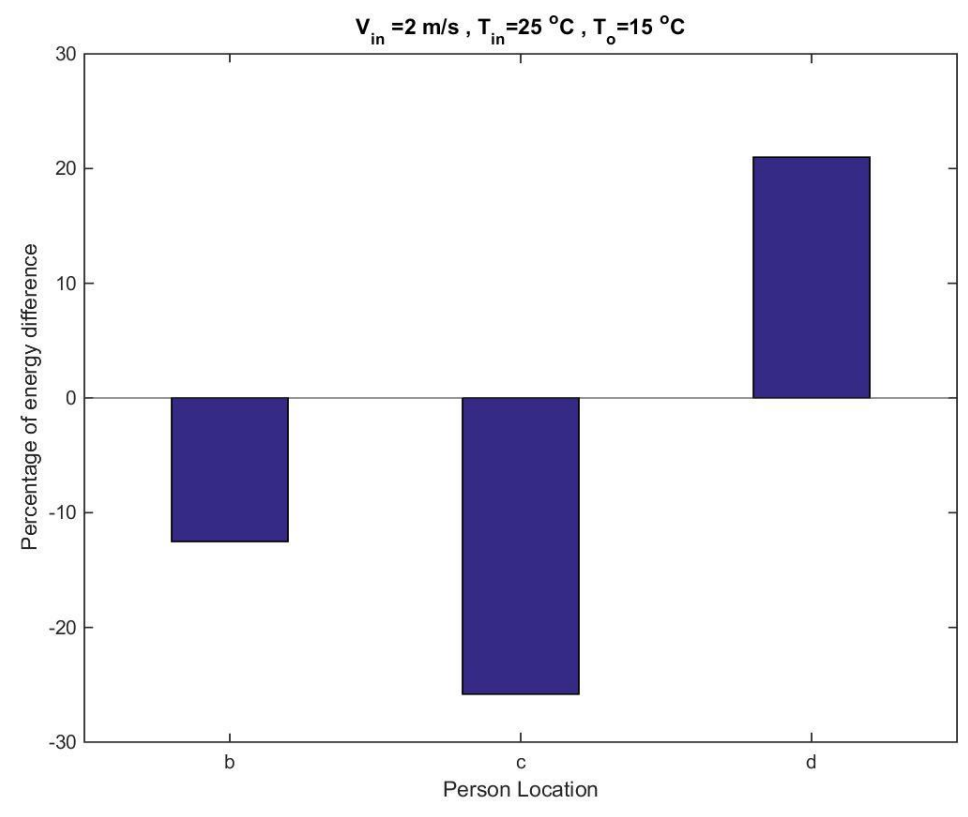

(36) 
Appendix D. Energy difference percentage based on person location



(37) 


\section{Appendix E. The UDF for controlling the temperature locally in ANSYS FLUENT}

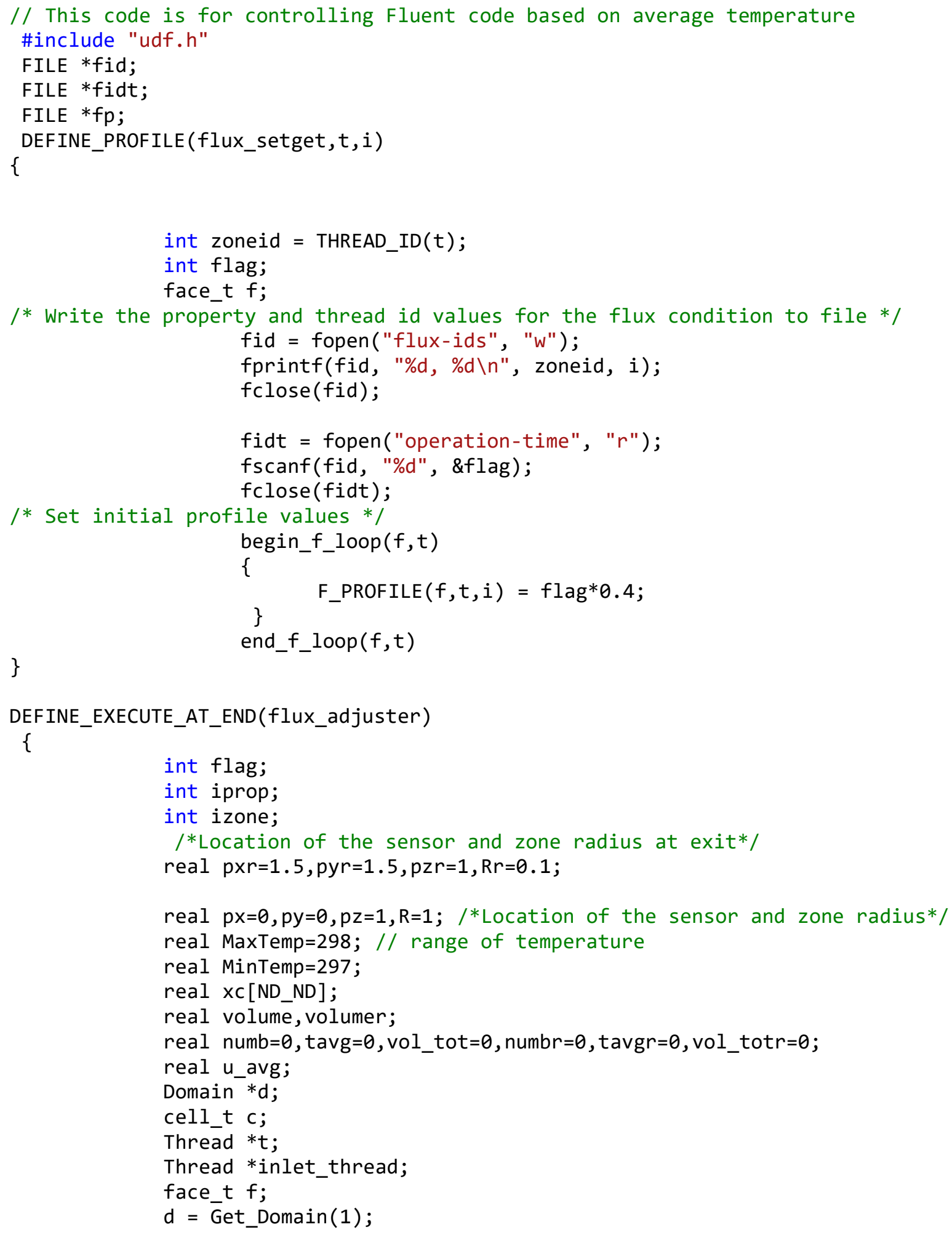


Appendix E. The UDF for controlling the temperature locally in ANSYS FLUENT




Appendix E. The UDF for controlling the temperature locally in ANSYS FLUENT

printf("This is the time for this point when the air truned ON: \%g \%g \%g \%g \n", CURRENT_TIME, tavg, numb, volume);

flag=1;

\}

$/ / \quad$ begin_f_loop(f,inlet_thread)\{

// F_PROFILE $(f$, inlet_thread, iprop $)=f l a g * 0.1$;

// 3

// end_f_loop $(f$, inlet_thread)

//// test

//

begin_f_loop( $f$,inlet_thread)\{

\}

u_avg=F_V(f,inlet_thread $)$;

end_f_loop(f,inlet_thread)

printf("inlet velocity: \%g \n", u_avg);

fidt = fopen("operation-time", "w");

fprintf(fid, "\%d \n", flag);

fclose(fidt);

$f p=$ fopen ("plot-data.txt", "a");

//the out put results are flow time, average temperature, air condition

operation time, inlet velocity, average temperature around the person

fprintf(fp, "\%g \% $f$ od $\backslash n "$, CURRENT_TIME, tavg-273,flag);

fclose $(f p)$;

\} 


\section{Appendix F. Python source code of the device}

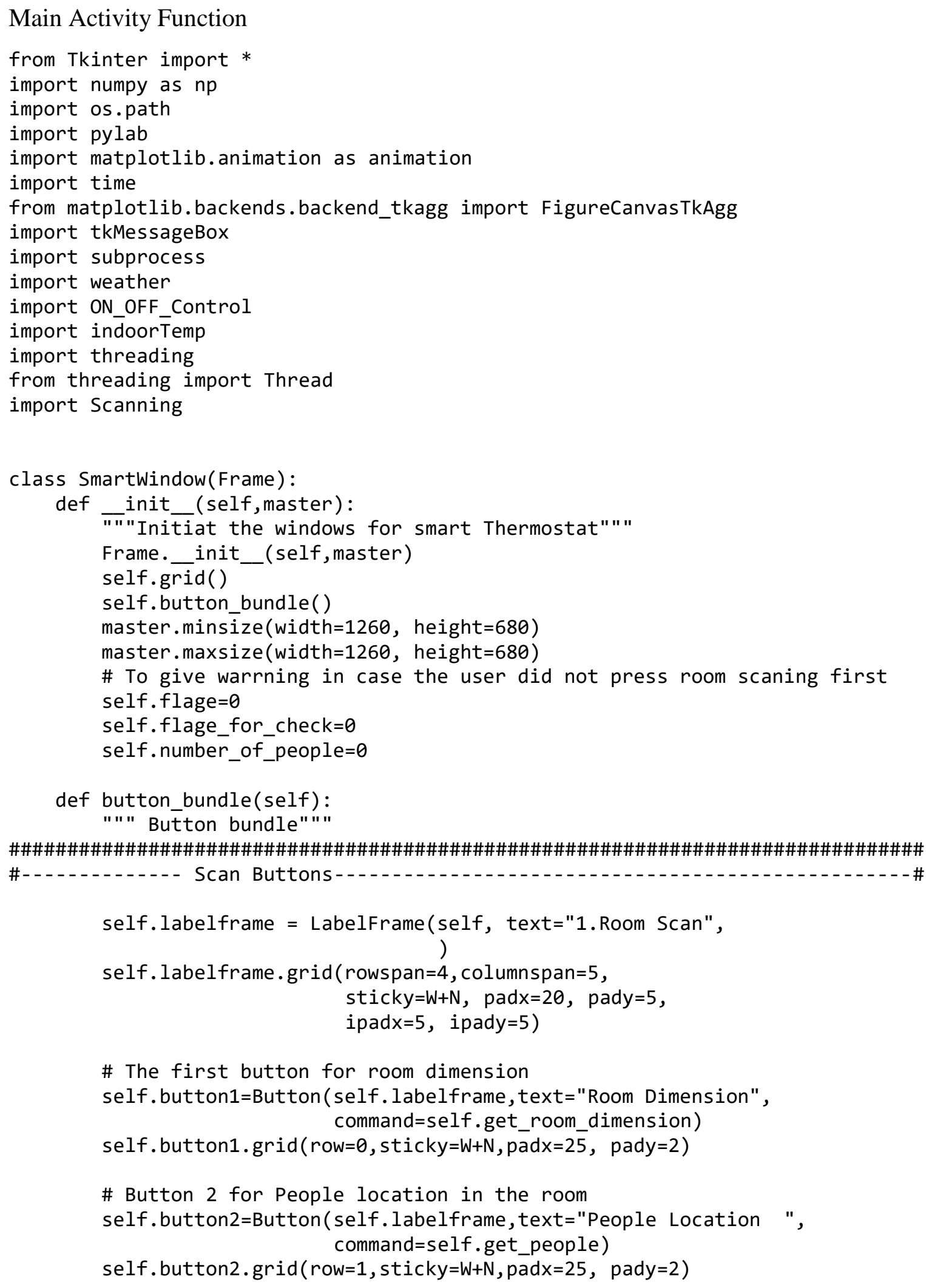


Appendix F. Python source code of the device

\# Button 3 for SCAN room and People

self. button3=Button ( self. labelframe, text="SCAN ", command=self.total_scan, bd=5)

self. button $3 . \operatorname{grid}($ row $=2$, sticky $=W+N, \operatorname{pad} \bar{x}=30$, pady $=2)$

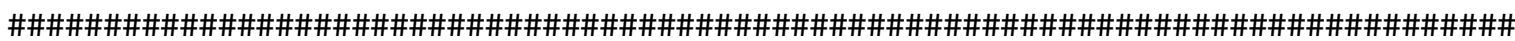

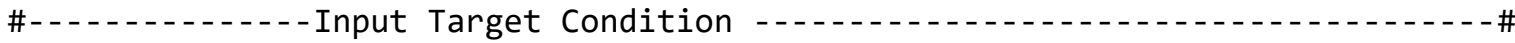
Location")

self.target_condition = LabelFrame (self, text="2. Target Condition \&

self.target_condition.grid(row $=2$, rowspan $=4$, columnspan $=5$, sticky $=W+N$, $\operatorname{pad} x=20$, pady $=5$,

\# Target Location button ipad $x=5$, ipady $=5$ )

self.label_=Label(self.target_condition, text=" Temperature range:")

self.label_.grid (row=0, column=0, sticky=NW, padx=2, pady=2)

self.label_=Label(self.target_condition, text=" $M i \bar{n}="$ )

self.label_.grid (row=0, column=1, sticky=E)

self.min_temp=Spinbox (self.target_condition, width=3, from_=0,to=40)

self.min_temp.grid(row $=0, \operatorname{column}=2$, sticky=w, pady $=2$ )

self.label_=Label(self.target_condition, text $="$ Max $="$ )

self.label_.grid (row=0, column=3, sticky=E)

self.max_temp=Spinbox (self.target_condition, width=3,from_=0, to=40)

self.max_temp.grid(row=0, column=4, sticky=w, pady $=2$ )

self.around_person = IntVar ()

self.check_person=Checkbutton(self.target_condition, text="Around Person", variable = self. around_person, onvalue $=1$, offvalue $=0$, height $=2$, width $=17$ )

self.check_person.grid(row=1, sticky=w)

self.label_numberofpeople=Label(self.target_condition,text=" ID \#:")

self.label_numberofpeople.grid ( $r o w=1, \operatorname{column}=1$, sticky=E, padx=2, pady=2)

self.personID=Spinbox (self.target_condition, width $=3$, from_=1, to $=6$ )

self. personID.grid( $r o w=1, \operatorname{column}=2$, sticky=W, $\operatorname{pad} x=2, \operatorname{pad} y=2)$

self.label_=Label(self.target_condition,text=" OR")

self.label_.grid ( row $=2$, column=0, columnspan=2, padx=2, pady=2)

self.zone $=\operatorname{IntVar}()$

self.check_zone=Checkbutton(self.target_condition,text="Zone Location 'm'", variable $=$ self. zone, onvalue $=1$, offvalue $=0$, height $=2$, width $=20$ )

self.check_zone.grid(row=3, sticky=w) 
Appendix F. Python source code of the device

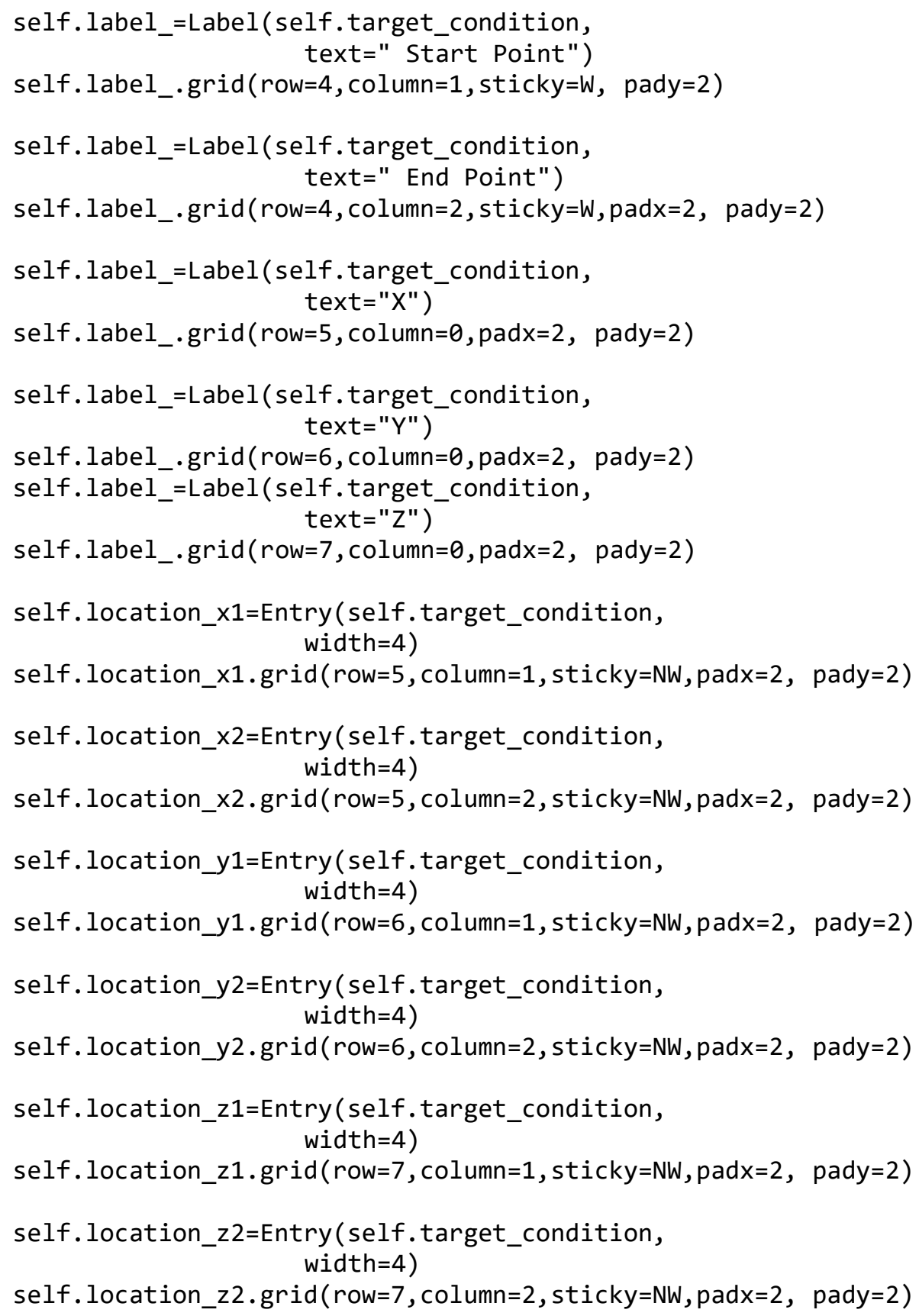


Appendix F. Python source code of the device

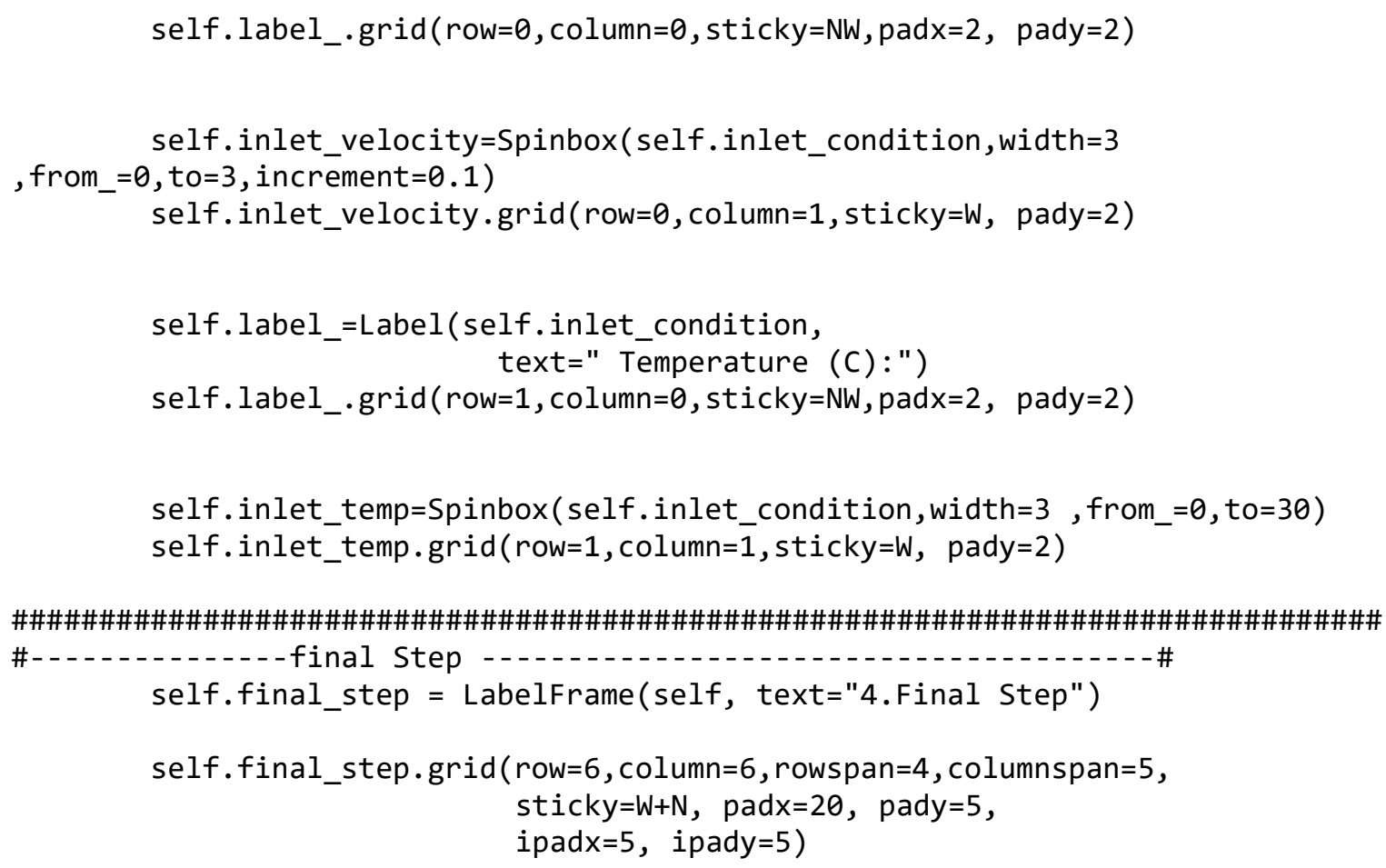

\# Check the temperature

self.button_check=Button (self.final_step,text="Check", command=self.run_two_functions) self. button_check.grid (row $=\bar{\theta}$, sticky $=W+N, \operatorname{pad} x=25$, pady $=2)$

\# Total control

self.button_control=Button(self.final_step,text="Start

Control", command=self.total_control, bd=5)

self.button_control.grid (row $=1$, sticky $=W+N$, padx $=25$, pady $=2$ )

self.button_control.config(font=("Symbol",14, 'bold'))

\# close the window

self. button_close_windows=Button ( self.final_step, text="Close", bd=5, command=self. close _GUI_window)

self.button_close_windows.grid (row $=1$, column=1, columnspan=2, padx=25, pady $=2$ )

self.button_close_windows.config(font=("Symbol", 10, 'bold'))

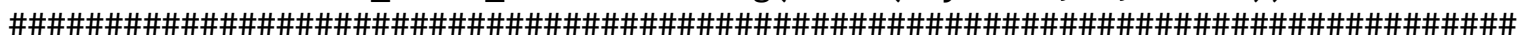

\#-1... output comments

self.text_note=Text ( self, width=170, height=4, wrap=wORD)

self.text_note.grid (row $=10$, column=0, rowspan=4, columnspan=9, pad $x=20$, pady $=5$,

ipadx=5, ipady=5)



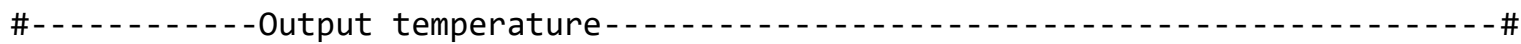
Location")

self.temp_frame $=$ LabelFrame $($ self, text="Average Temperature in the Target

self.temp_frame.grid (row=0, column=6, rowspan=4, columnspan=5, 
Appendix F. Python source code of the device

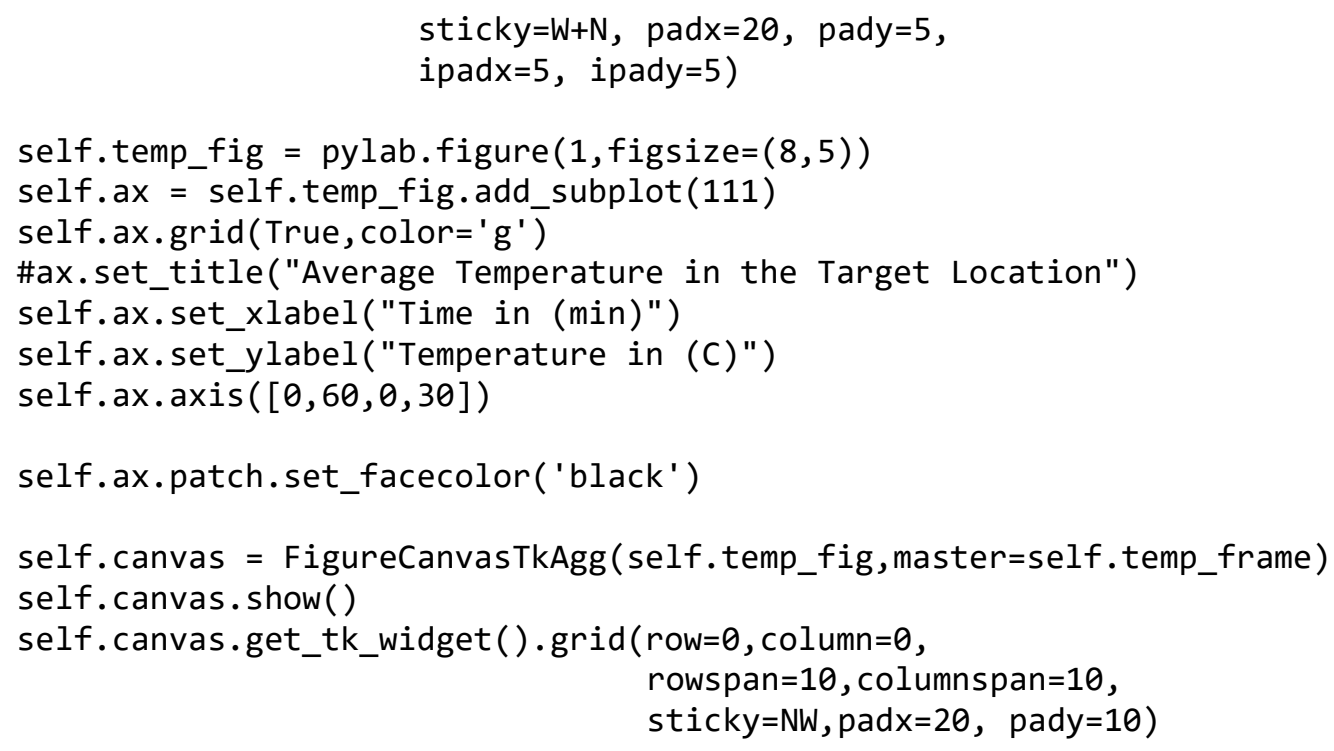

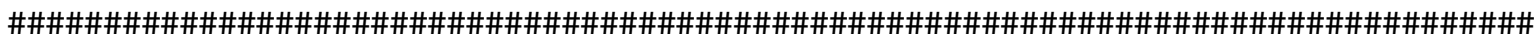

def total_control(self):

self.total_scan()

self.run_two_functions()


def close_GUI_window(self):

self.quit()

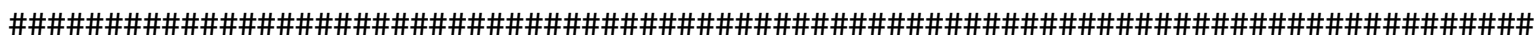

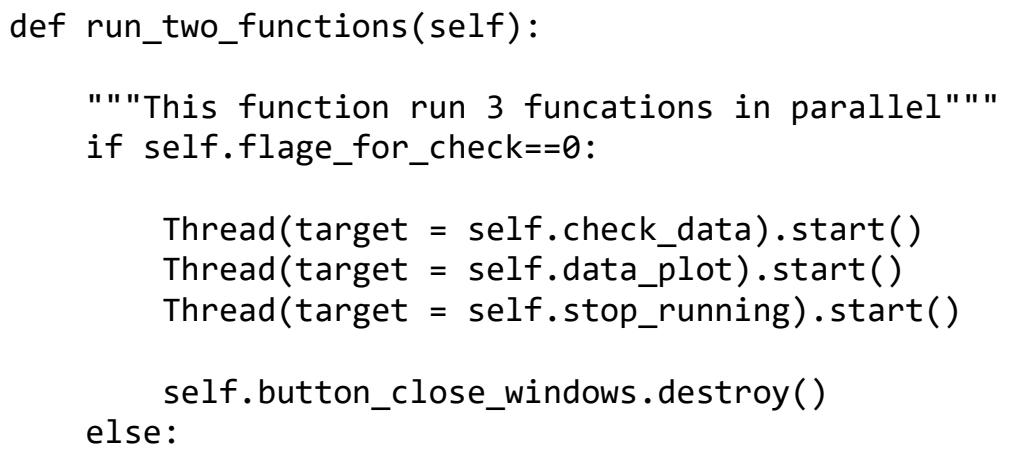


Appendix F. Python source code of the device

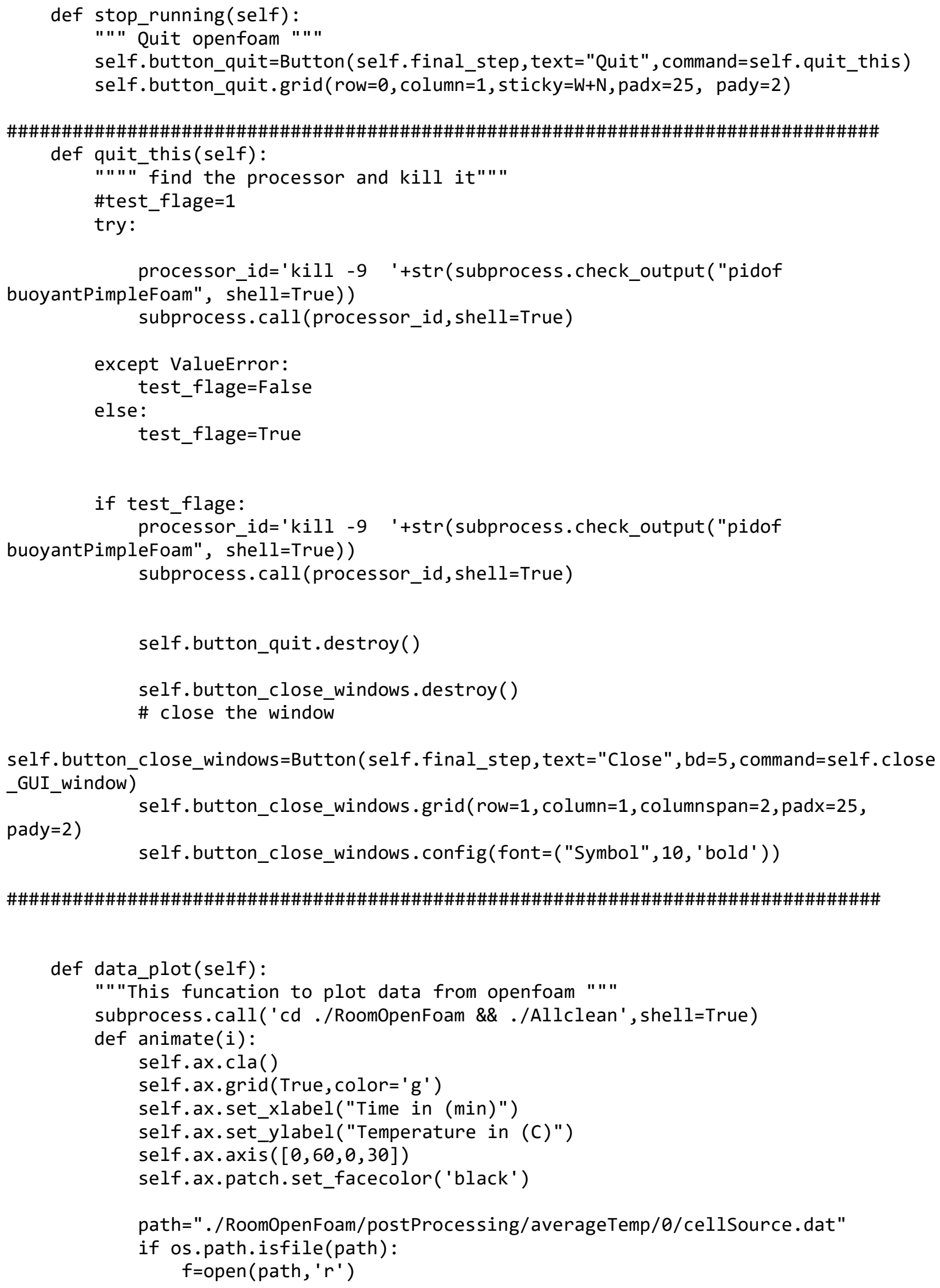


Appendix F. Python source code of the device

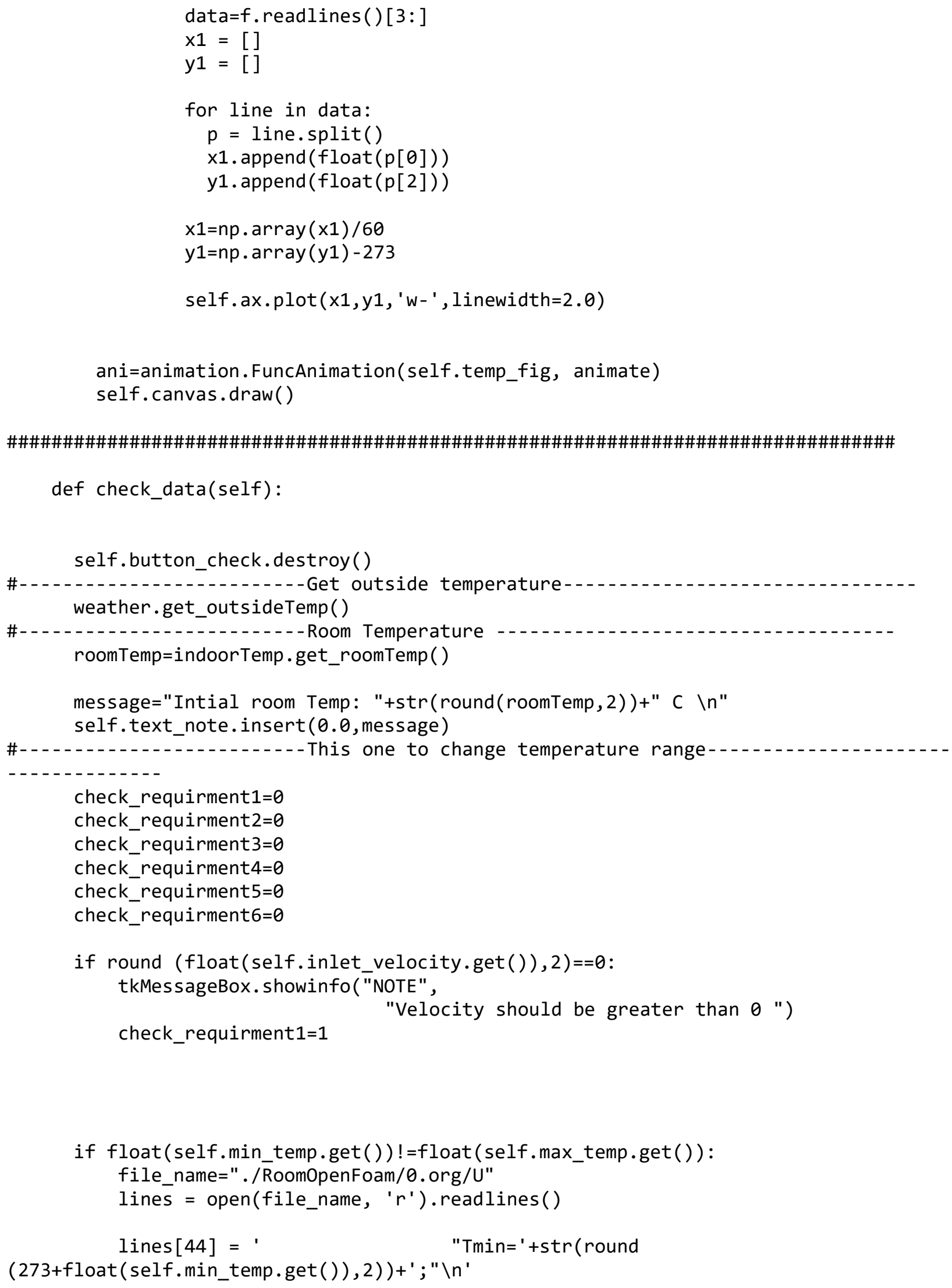


Appendix F. Python source code of the device

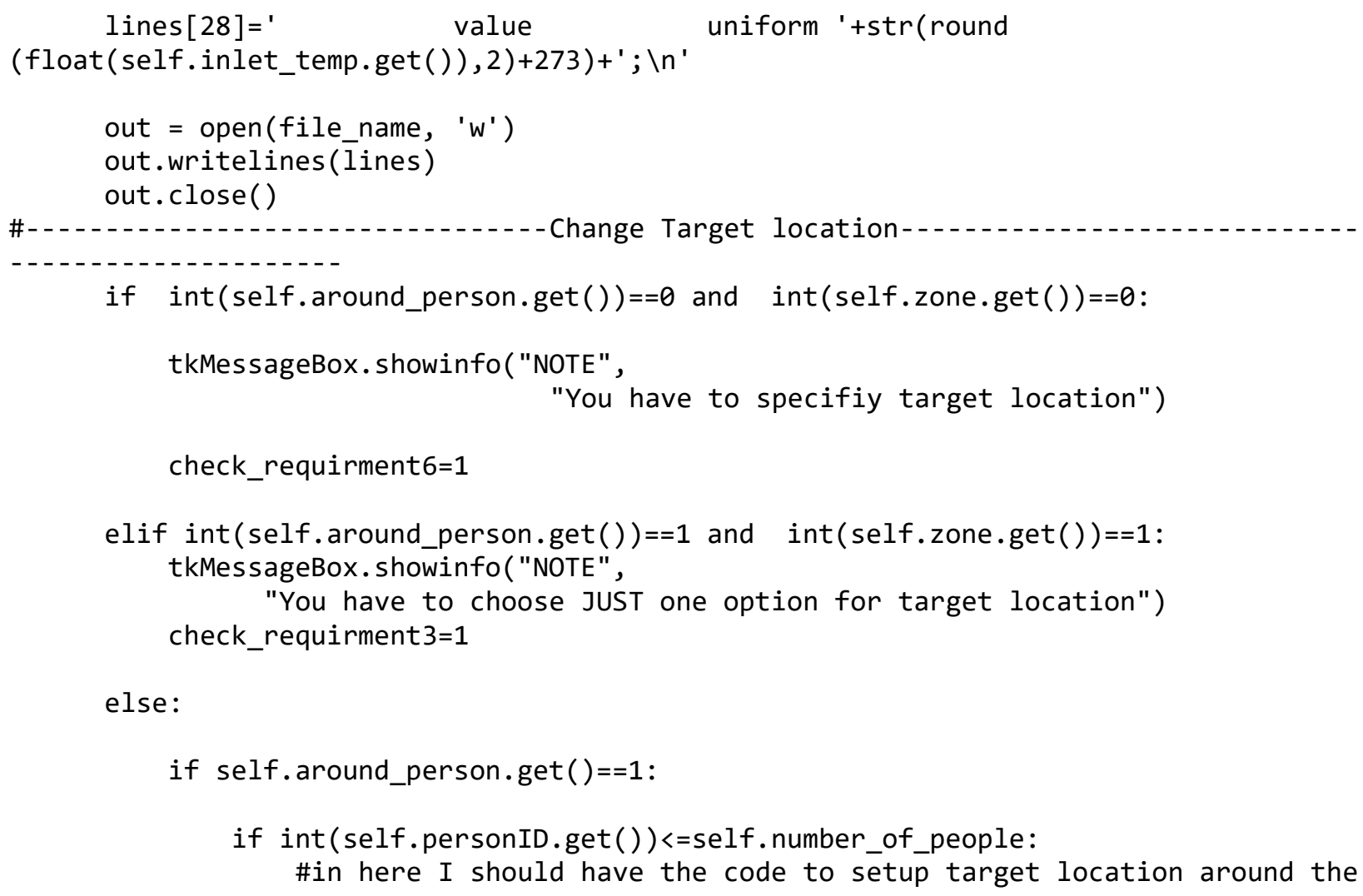

else:

tkMessageBox.showinfo("NOTE",

"Person ID is higher than people in the room !!")

check_requirment4=1

elif int (self.zone.get ()$)==1$ :

\#in here I should have the code to setup target zone 
Appendix F. Python source code of the device

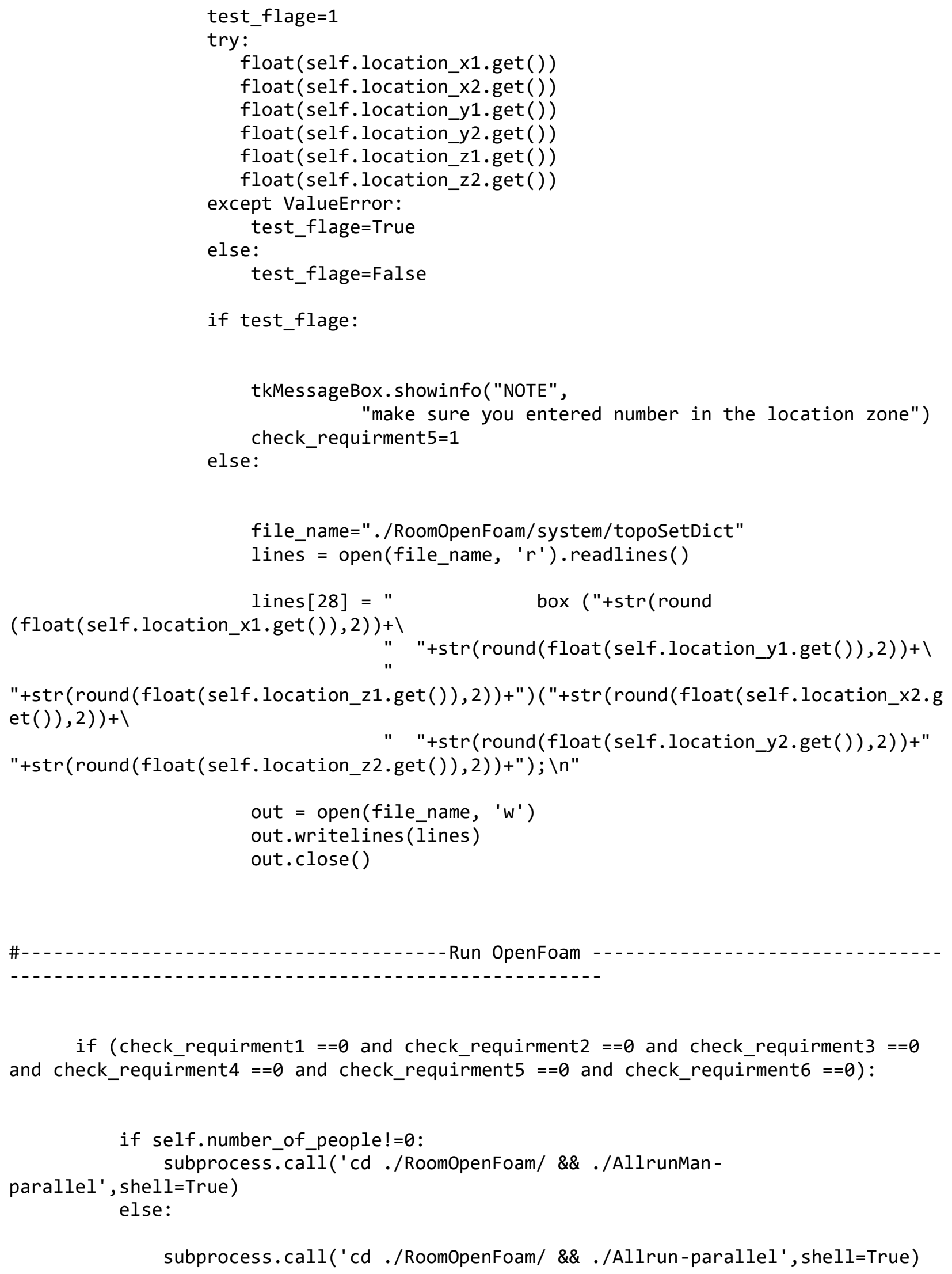


Appendix F. Python source code of the device

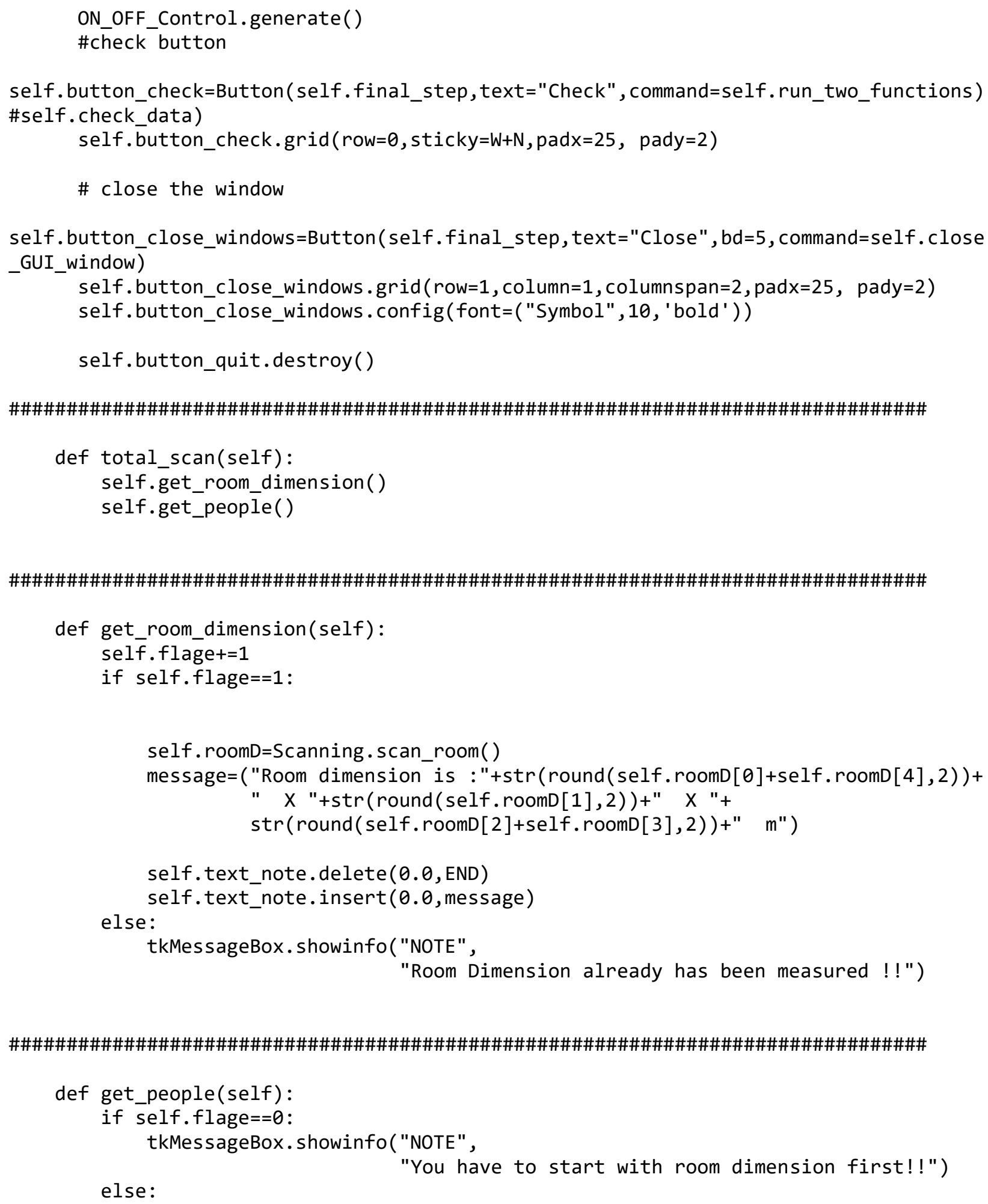


Appendix F. Python source code of the device





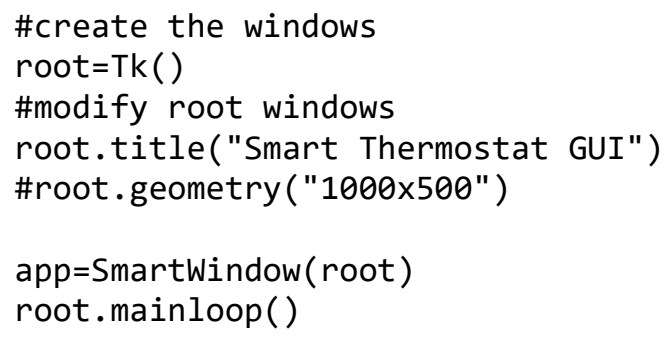

Temperature Function

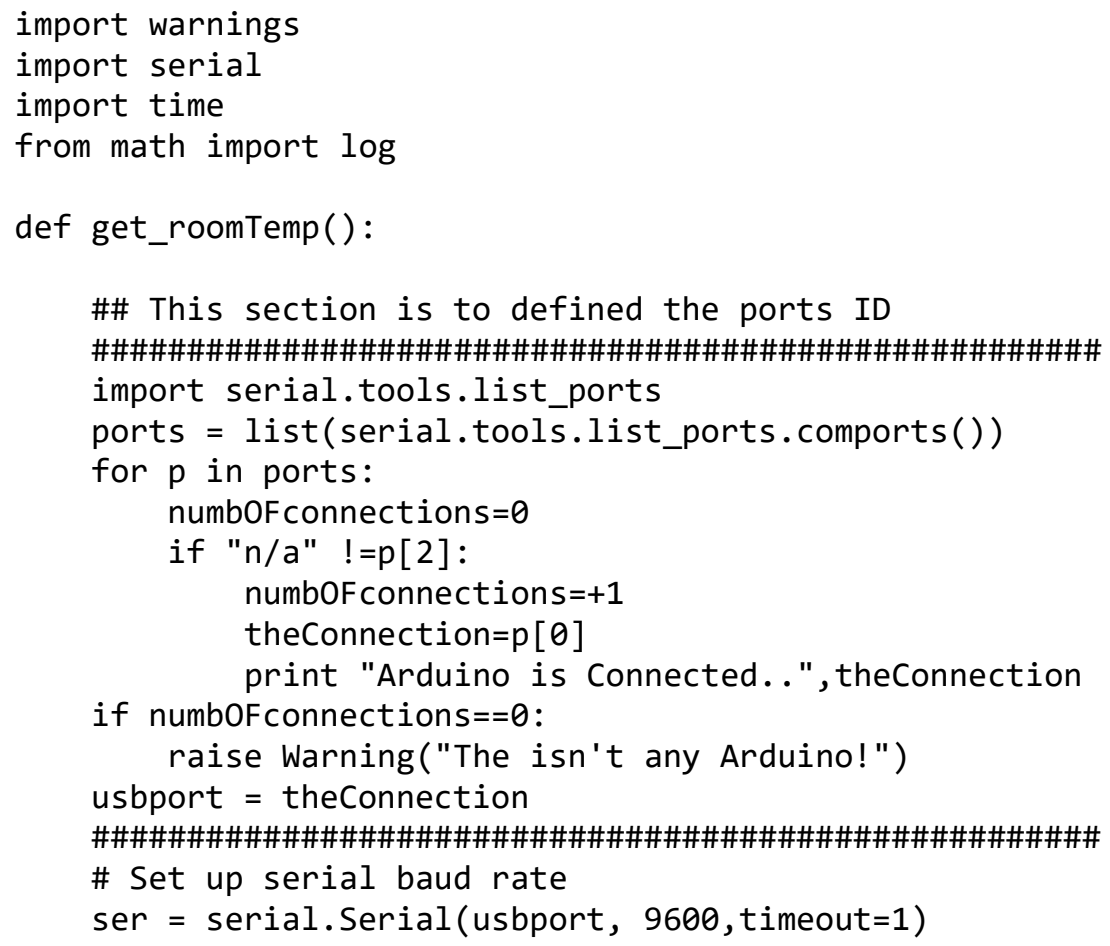


Appendix F. Python source code of the device

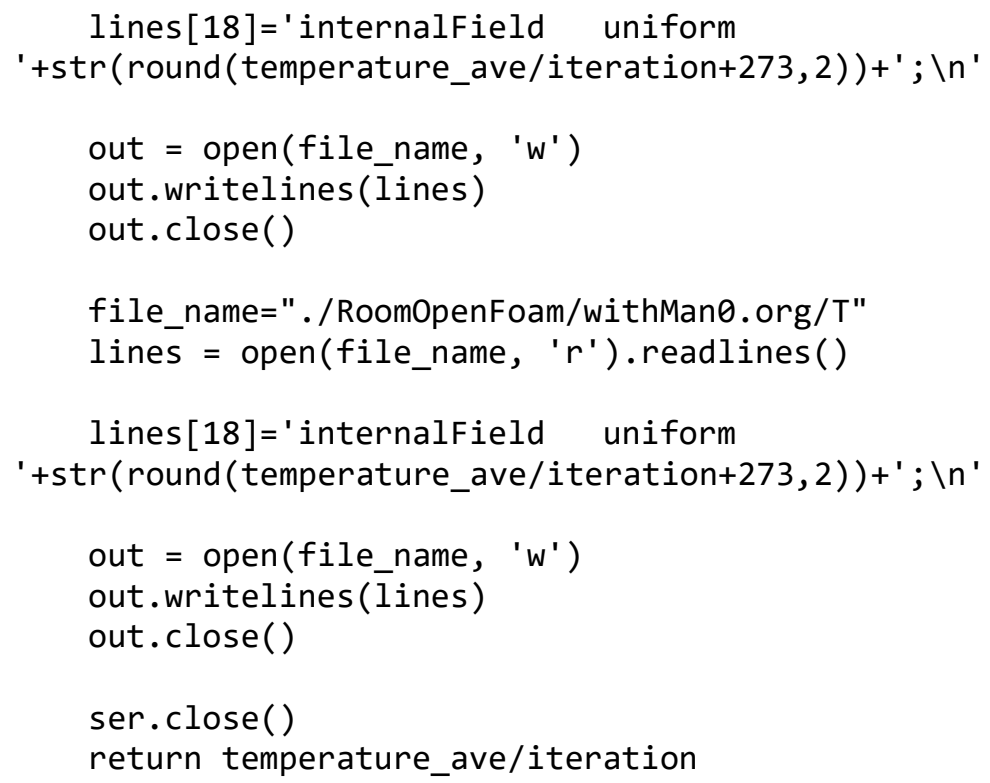

\section{Scanning Function}

\#NOTE: Before you start you need to import multipleserialservoControl to ardurino import sys

sys.path.append(' ./RoomAndPeopleRecon')

sys.path.append(' ./RoomstlFile')

import roomSTL

import manSTL

import os

import numpy as $\mathrm{np}$

import time

import wallDistance

import peoplePositions

import Servo

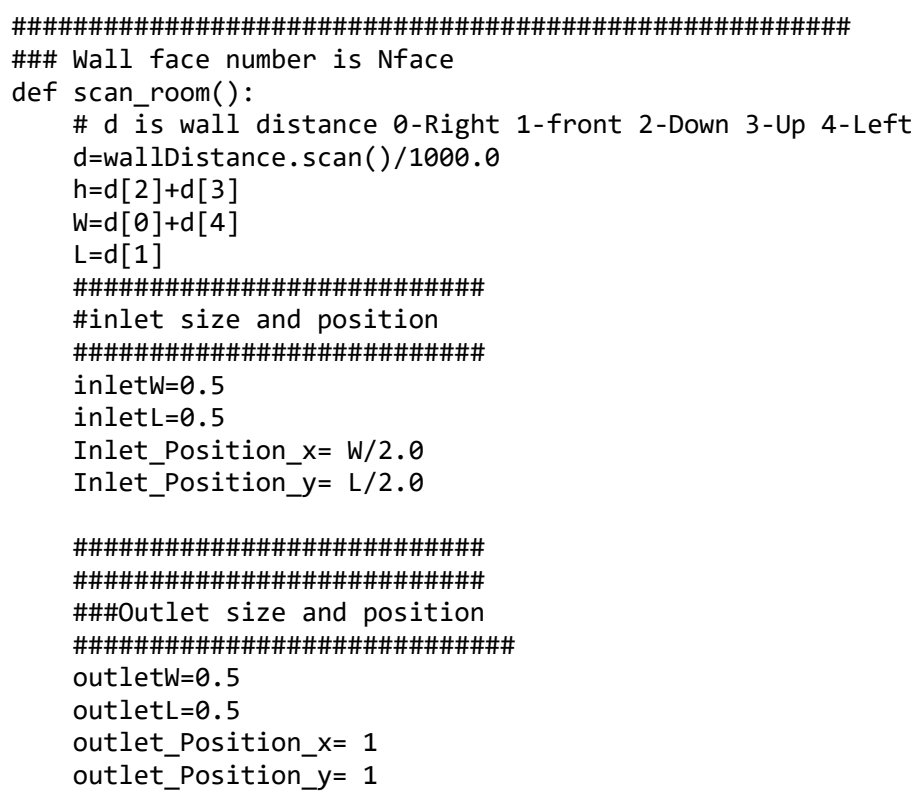


Appendix F. Python source code of the device

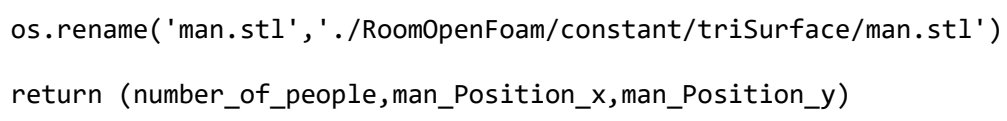

Servo Function

\#NOTE: Before you start you need to import multipleSerialservoControl to ardurino import warnings

import serial

import time

\#\# This section is to defined the ports ID

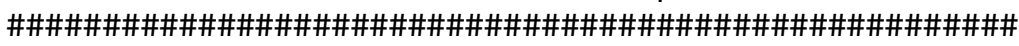

import serial.tools.list_ports

ports $=$ list (serial.tools.list_ports. $\operatorname{comports}())$

for $\mathrm{p}$ in ports:

numbOFconnections $=0$

if "n/a" !=p[2]:

numbOF connections $=+1$

theConnection $=p[\theta]$

print "Arduino is Connected..", theConnection

if numbOFconnections $==0$ :

raise Warning("The isn't any Arduino!")

usbport = theConnection



\# Set up serial baud rate

ser $=$ serial.Serial (usbport, 9600, timeout=1)

def move(servo, angle):

' 'Moves the specified servo to the supplied angle.

Arguments:

servo

the servo number to command, an integer from 1-4

angle

the desired servo angle, an integer from $\theta$ to 180

(e.g.) >> servo.move $(2,90)$

... \# "move servo \#2 to 90 degrees"'.'

if ( $0<=$ angle $<=180)$ :

ser.write $(\operatorname{chr}(255))$

ser.write(chr(servo))

else:

ser.write(chr(angle))

print("Servo angle must be an integer between $\theta$ and $180 . \backslash \mathrm{n}$ ")

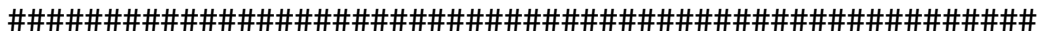

def init():

move $(3,0)$

move $(4,90)$

def $\operatorname{stop}()$ : 
Appendix F. Python source code of the device



Weather Function

Wall distance Function

" " "

This code is to find the distance of the walls from the kinect by finding the distance mode and selecting the most frequent mode to present the walls distanace 
Appendix F. Python source code of the device

import progressbar

import Servo

import time

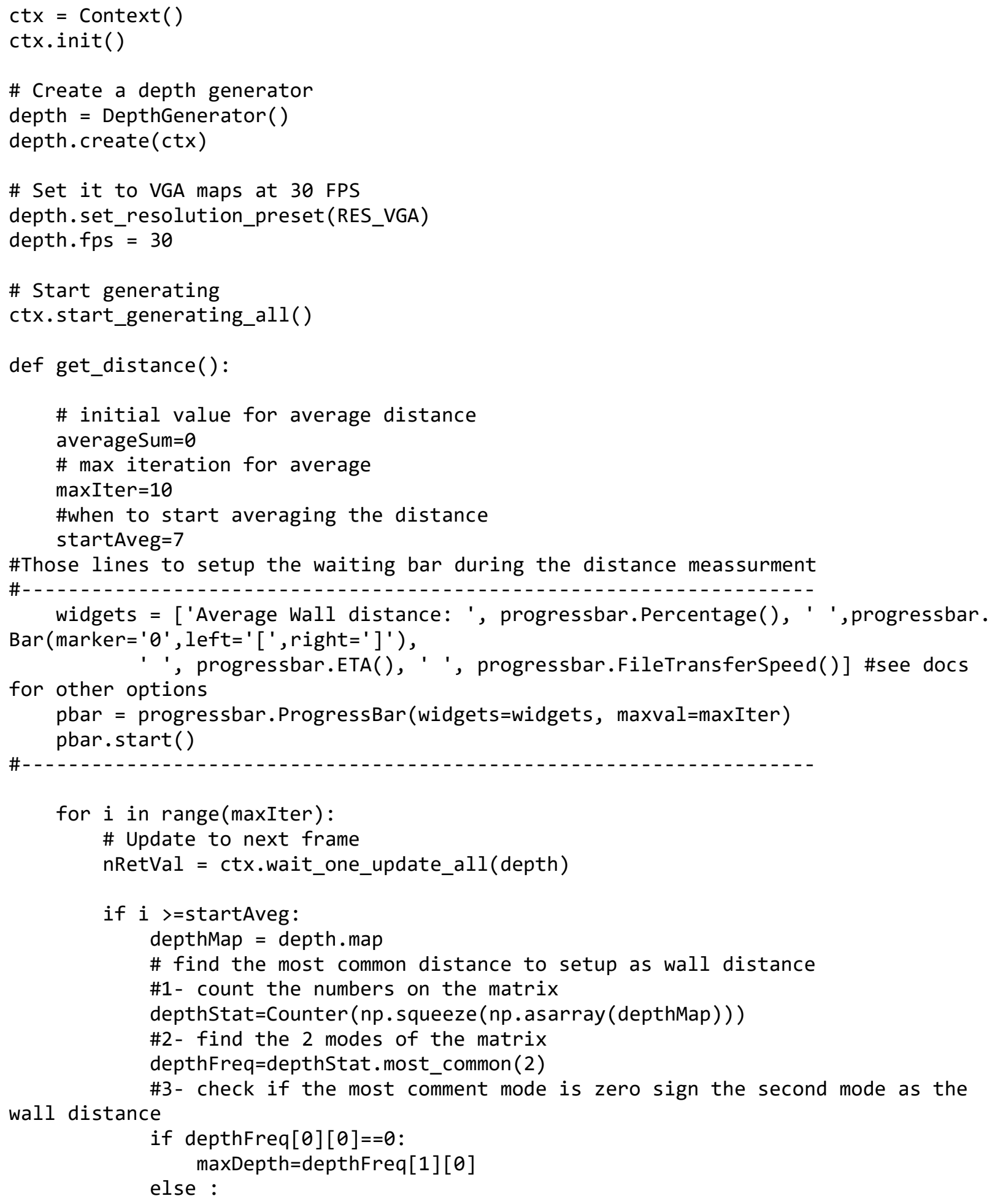


Appendix F. Python source code of the device

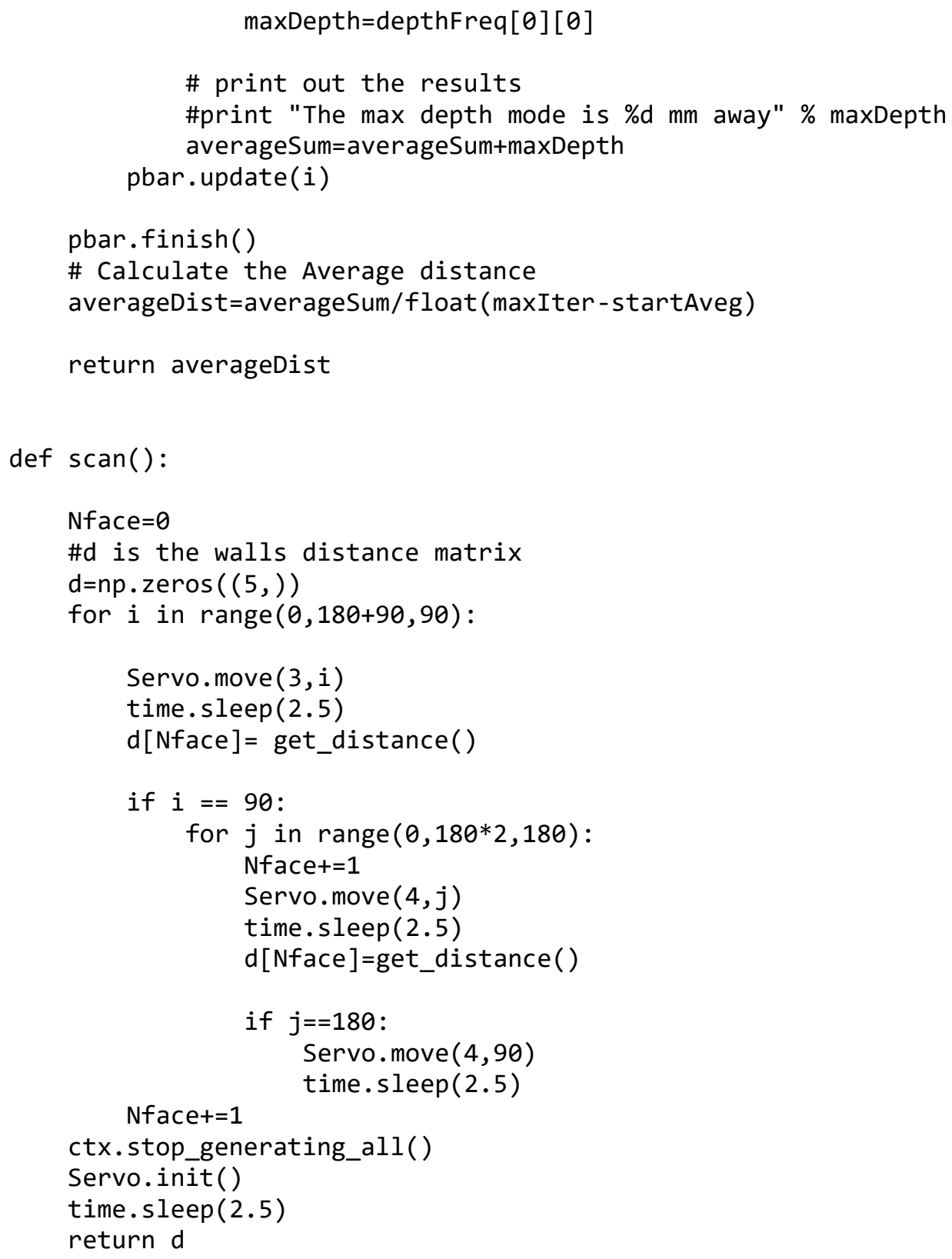

People Position Function

\#!/usr/bin/python

\#\# The equivalent of:

\#\# "Working with the Skeleton"

\#\# in the OpenNI user guide.

" " "

This shows how to identify when a new user is detected, look for a pose for that user, calibrate the users when they are in the pose, and track them. 
Appendix F. Python source code of the device

Specifically, it prints out the location of the users' head, as they are tracked.

" " "

from openni import *

import numpy as $\mathrm{np}$

import time

import Servo

import progressbar

def find_people():

\# Pose to use to calibrate the user

pose_to_use = 'Psi'

$\operatorname{ctx}=$ Context ()

ctx.init()

\# Create the user generator

user = UserGenerator ()

user.create (ctx)

\# Obtain the skeleton \& pose detection capabilities

skel_cap $=$ user.skeleton_cap

pose_cap = user.pose_detection_cap

\# Declare the callbacks

def new_user(src, id):

print "1/4 User \{\} detected. Looking for pose..." .format(id)

pose_cap.start_detection(pose_to_use, id)

def pose_detected(src, pose, id):

print $" 2 / 4$ Detected pose \{\} on user \{\} . Requesting calibration..."

. format (pose, id)

pose_cap.stop_detection(id)

skel_cap.request_calibration(id, True)

def calibration_start(src, id):

print "3/4 Calibration started for user \{\} ." .format(id)

def calibration_complete(src, id, status):

if status $==$ CALIBRATION_STATUS_OK:

.format(id)

print "4/4 User \{\} calibrated successfully! Starting to track."

else:

skel_cap.start_tracking(id)

print "ERR User \{\} failed to calibrate. Restarting process." .format(id)

new_user(user, id)

def lost_user(src, id):

print "--- User \{\} lost." .format(id)

\# Register them

user.register_user_cb(new_user, lost_user)

pose_cap.register_pose_detected_cb(pose_detected) 
Appendix F. Python source code of the device

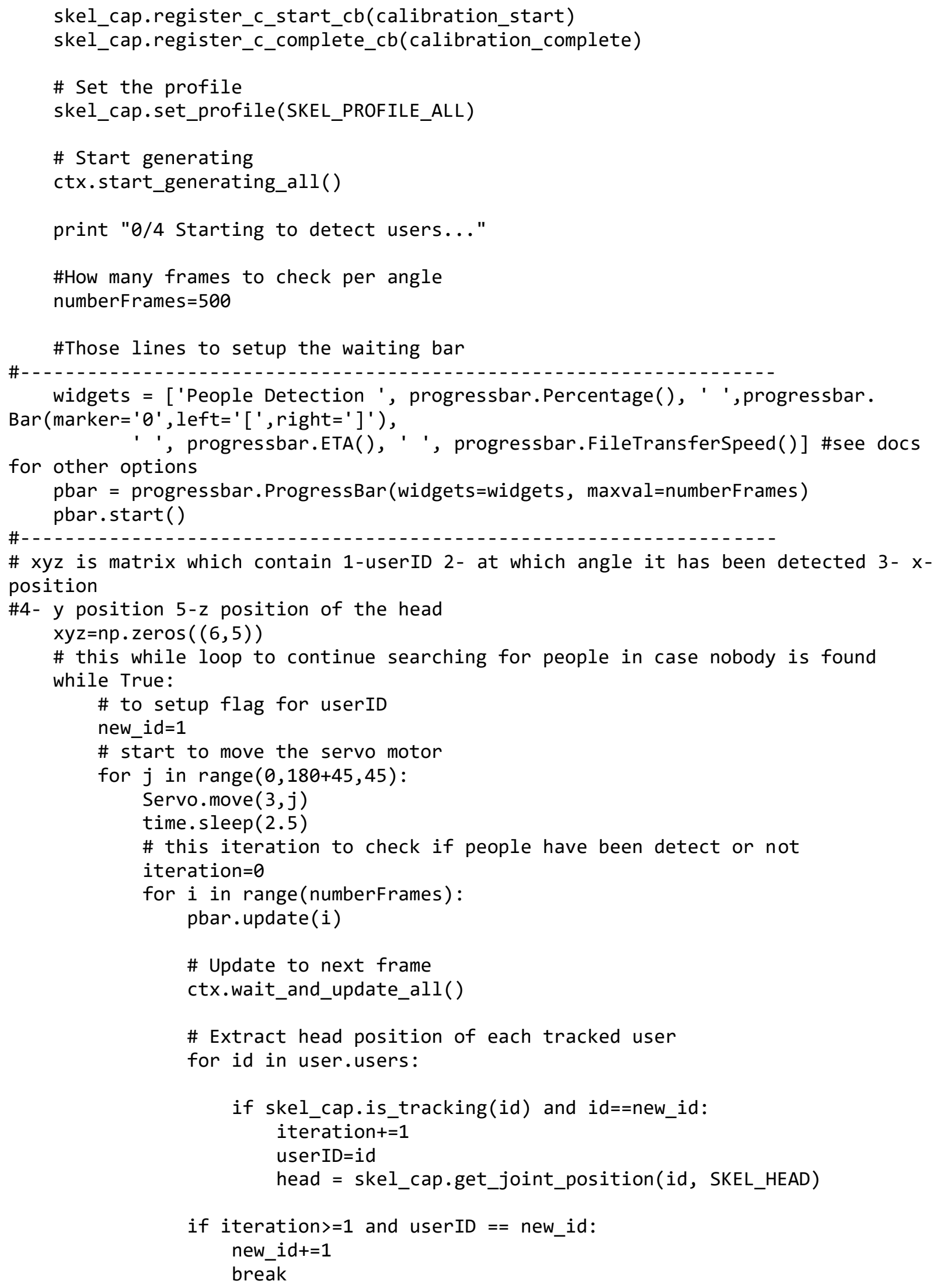


Appendix F. Python source code of the device

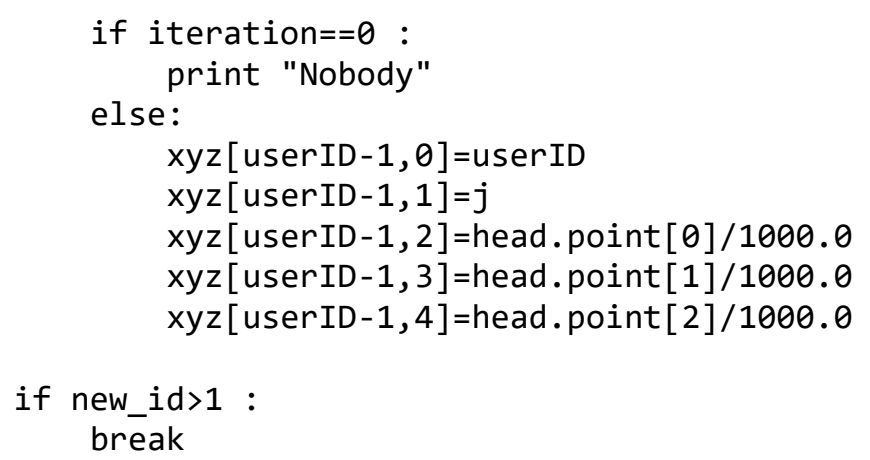

ON/OFF control Function

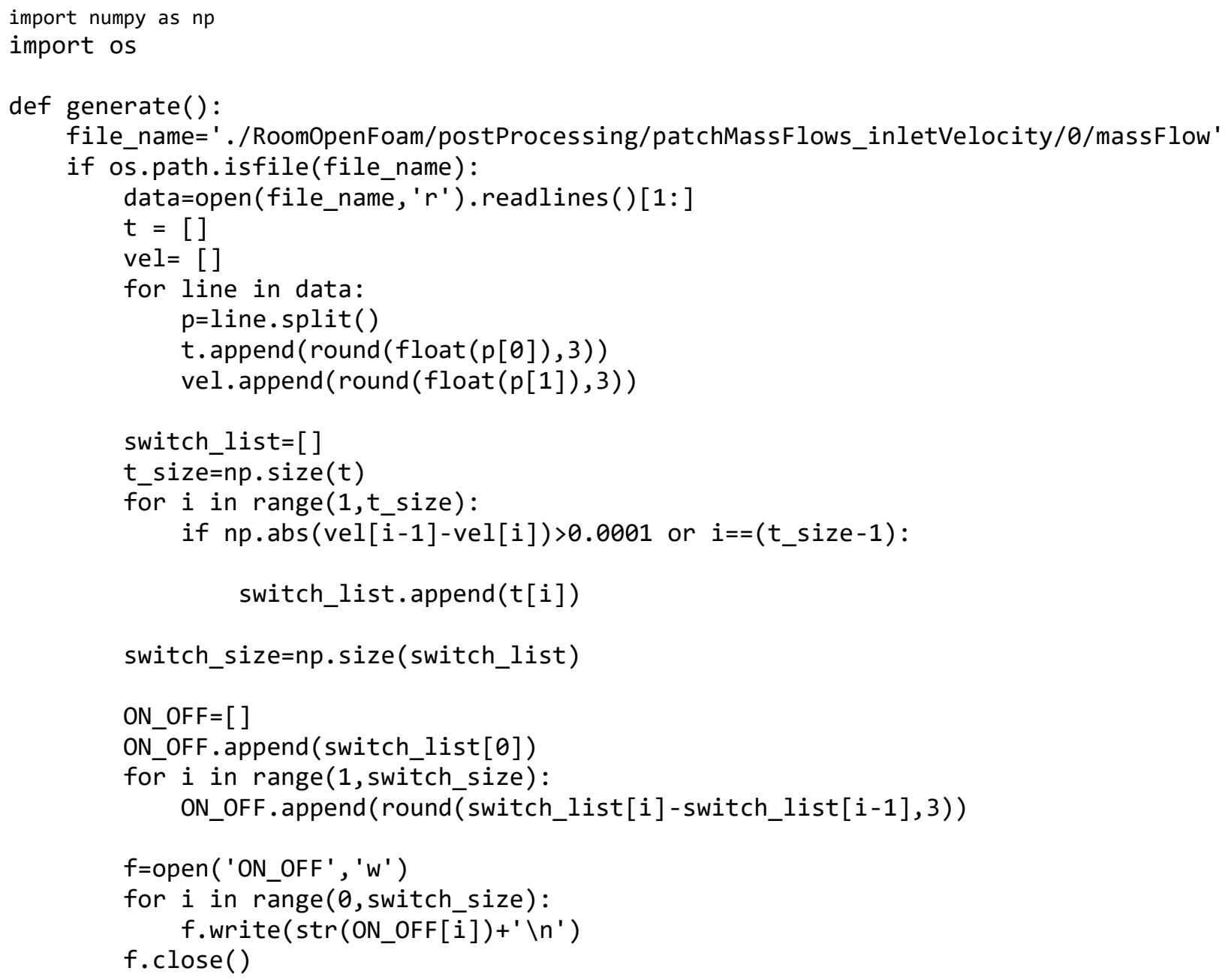


Appendix F. Python source code of the device

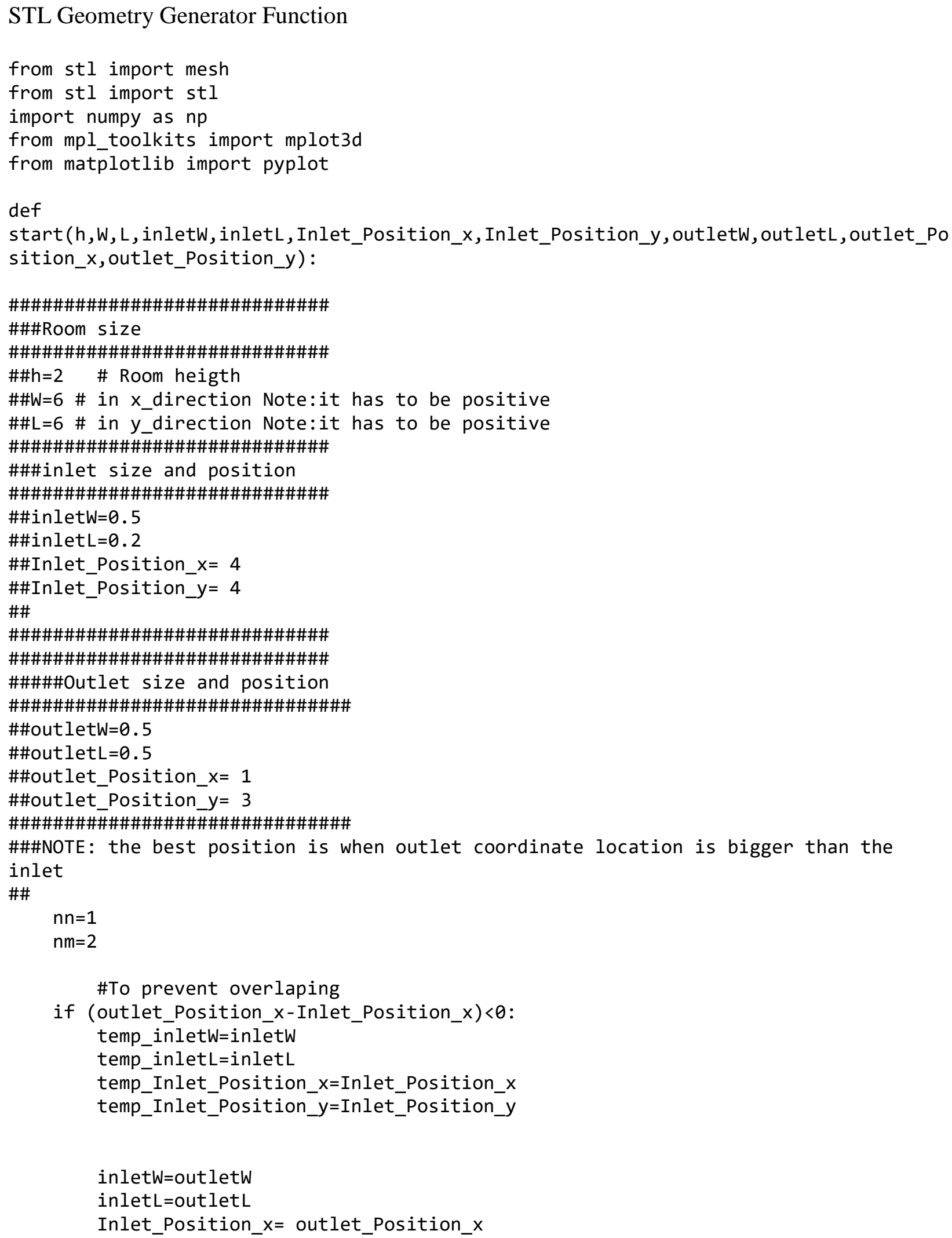


Appendix F. Python source code of the device

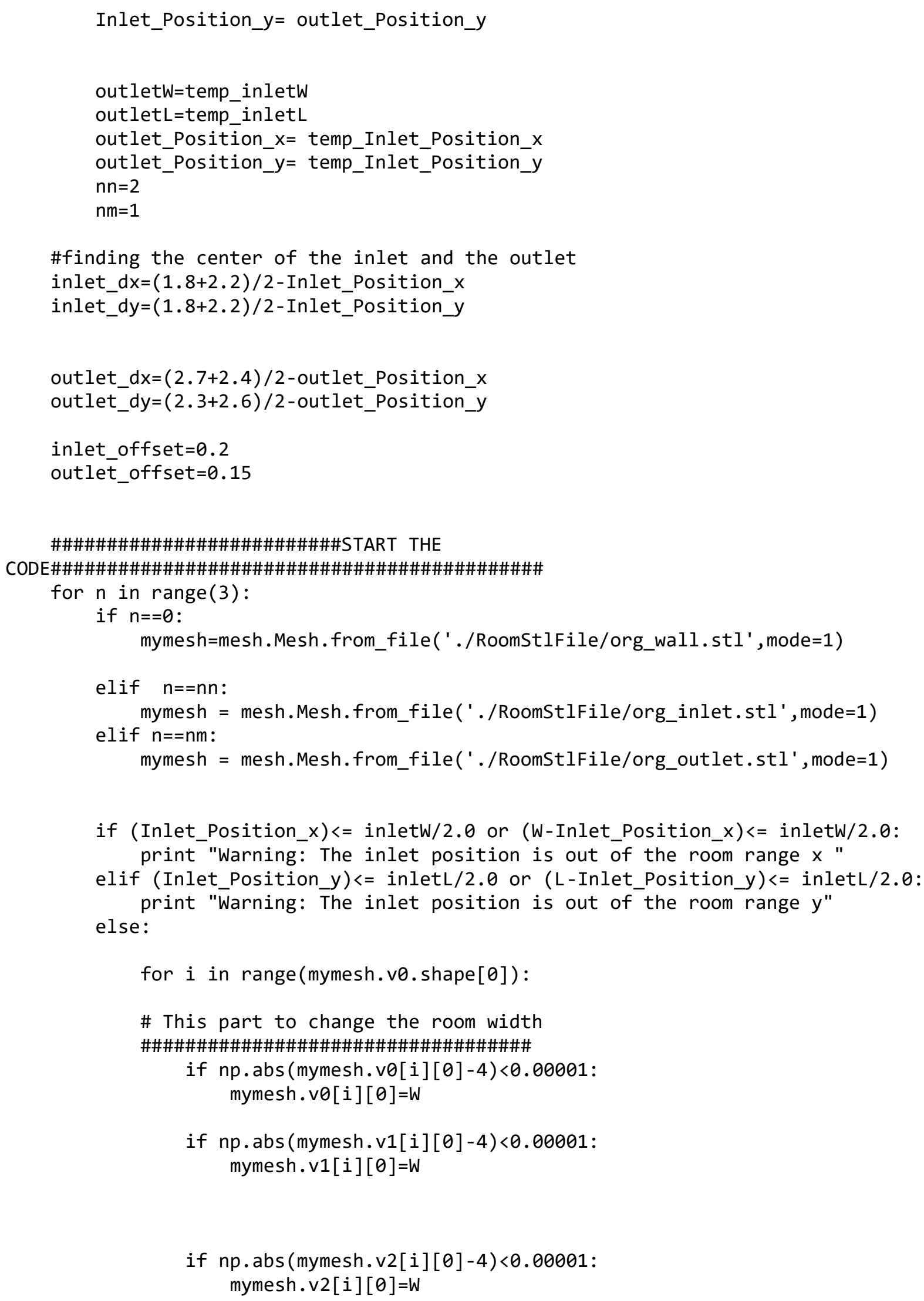


Appendix F. Python source code of the device

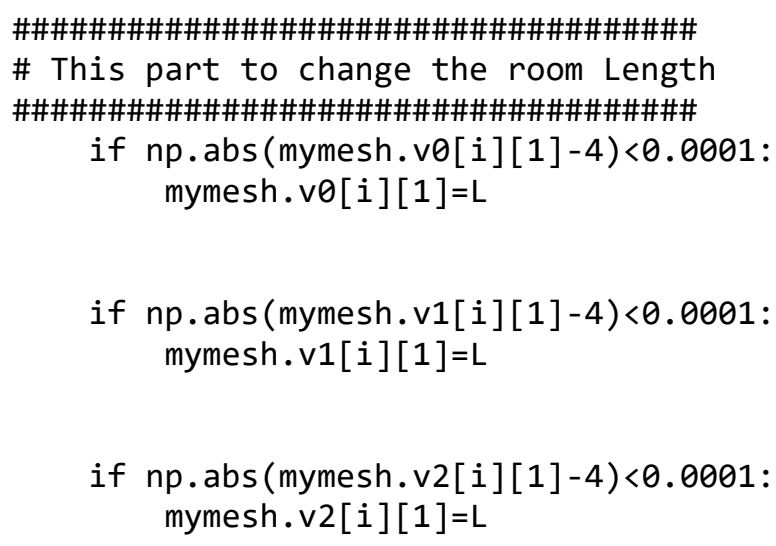


Appendix F. Python source code of the device

mymesh.v2[i][0]+=(inletW/2.0-inlet_offset)

mymesh.v2[i][0]-=inlet_dx

$2.2)<0.000001:$

if np.abs(mymesh.v0[i][1]-1.8)<0.000001 or np.abs(mymesh.v0[i][1]-

if np.abs(mymesh.v $\theta[i][1]-1.8)<0.000001$ : else:

mymesh.vo[i][1]-=(inletL/2.0-inlet_offset)

mymesh.v $\theta[i][1]+=($ inletL/2.0-inlet_offset)

mymesh.vӨ[i][1]-=inlet_dy

$2.2)<0.000001:$

if np.abs(mymesh.v1[i][1]-1.8)<0.000001 or np.abs(mymesh.v1[i][1]-

if np.abs(mymesh.v1[i][1]-1.8)< 0.000001 :

mymesh.v1[i][1]-=(inletL/2.0-inlet_offset)

else:

mymesh.v1[i][1]+=(inletL/2.0-inlet_offset)

mymesh.v1[i][1]-=inlet_dy

$2.2)<0.000001:$

if np.abs(mymesh.v2[i][1]-1.8)<0.000001 or np.abs(mymesh.v2[i][1]-

if np.abs (mymesh.v2[i][1]-1.8)<0.000001:

else:

mymesh.v2[i][1]-=(inletL/2.0-inlet_offset $)$

mymesh.v2[i][1]+=(inletL/2.0-inlet_offset)

mymesh.v2[i][1]-=inlet_dy

\#\#

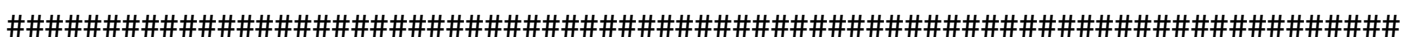

\#\# \# This part to change the outlet position

\#\#

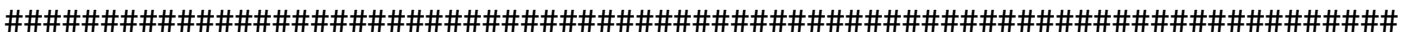

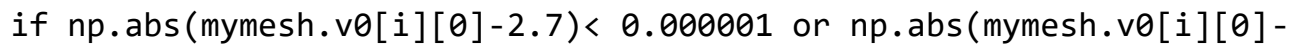

$2.4)<0.000001:$

if np.abs (mymesh.v0[i][0]-2.4)<0.000001:

mymesh.v $\theta[i][\theta]-=($ outletw/2.0-outlet_offset)

else:

mymesh.v0[i][0]+=(outletw/2.0-outlet_offset)

mymesh.vo[i][0]-=outlet_dx

$2.4)<0.000001:$

if np.abs(mymesh.v1[i][0]-2.7)<0.000001 or np.abs(mymesh.v1[i][0]-

if np.abs (mymesh.v1[i][0]-2.4)<0.000001:

mymesh.v1[i][0]-=(outletw/2.0-outlet_offset)

else:

mymesh.v1[i][0]+=(outletw/2.0-outlet_offset)

175 
Appendix F. Python source code of the device

mymesh.v1[i][0]-=outlet_dx

$2.4)<0.000001$ :

if np.abs(mymesh.v2[i][0]-2.7)<0.000001 or np.abs(mymesh.v2[i][0]-

if np.abs(mymesh.v2[i][0]-2.4)<0.000001:

else:

mymesh.v2[i][0]-=(outletw/2.0-outlet_offset)

mymesh.v2[i][0]+=(outletw/2.0-outlet_offset)

mymesh.v2[i][0]-=outlet_dx

$2.6)<0.000001:$

if $n p . a b s$ (mymesh.v $\theta[i][1]-2.3)<0.000001$ or np.abs (mymesh.v $\theta[i][1]-$

if np.abs(mymesh.v0[i][1]-2.3)< 0.000001 :

mymesh.v $\theta[i][1]-=($ outletL/2.0-outlet_offset) else:

mymesh.v $\theta[i][1]+=($ outletL/2.0-outlet_offset)

mymesh.v $\theta[i][1]-=o u t l e t \_d y$

$2.6)<0.000001:$

if np.abs(mymesh.v1[i][1]-2.3)< 0.000001 or np.abs (mymesh.v1[i][1]-

if np.abs (mymesh.v1[i][1]-2.3)<0.000001:

else:

mymesh.v1[i][1]-=(outletL/2.0-outlet_offset)

mymesh.v1[i][1]+=(outletL/2.0-outlet_offset)

mymesh.v1[i][1]-=outlet_dy

$2.6)<0.000001:$

if np.abs(mymesh.v2[i][1]-2.3)<0.000001 or np.abs(mymesh.v2[i][1]-

if np.abs(mymesh.v2[i][1]-2.3)<0.000001:

mymesh.v2[i][1]-=(outletL/2.0-outlet_offset)

else:

mymesh.v2[i][1]+=(outletL/2.0-outlet_offset)

if $n==0$ :

mymesh.v2[i][1]-=outlet_dy

mymesh. save( 'walls.stl' , mode=1)

elif $n==1$ :

mymesh. save('inlet. stl' , mode=1)

elif $n==2$ :

mymesh. save (' outlet. stl' , mode=1) 